\title{
Effect of Fuel Composition on the Response of an Acoustically Forced Flat Flame
}

\author{
by \\ Jan Gorski \\ A thesis submitted to The Faculty of Graduate Studies and Research \\ in partial fulfilment of the degree requirements of \\ Master of Applied Science in Mechanical Engineering \\ Ottawa-Carleton Institute for \\ Mechanical and Aerospace Engineering \\ Department of Mechanical and Aerospace Engineering \\ Carleton University \\ Ottawa, Ontario, Canada \\ November 2012
}

Copyright (C) 2012 - Jan Gorski 
The undersigned recommend to

the Faculty of Graduate Studies and Research

acceptance of the thesis

\title{
Effect of Fuel Composition on the Response of an Acoustically Forced Flat Flame
}

\author{
Submitted by Jan Gorski
}

in partial fulfilment of the requirements for the degree of

Master of Applied Science in Mechanical Engineering

Dr. Matthew Johnson, Thesis Supervisor

Dr. Wajid Chishty, Thesis Co-supervisor

Dr. Metin Yaras, Chair, Department of Mechanical and Aerospace Engineering

Carleton University

2012 


\section{Abstract}

Interest in alternative fuels for power generation is growing, yet these fuels bring new challenges to gas turbine design and operation. Among these challenges are combustor operability issues, highlighted by problems with combustion instabilities. For this thesis, a fundamental study of the effects of fuel composition on combustion dynamics was undertaken. An acoustically forced flat flame burner was constructed, allowing measurement of the flame transfer function (FTF) relating acoustic perturbations to heat release rate fluctuations in the flame. Tests were done using methane, along with simulated syngas and biogas fuel mixtures over a variety of operating conditions. Large variations in methane concentration had a significant impact on the FTF, while variations in the hydrogen to carbon monoxide ratio did not impact the FTF in fuel mixtures of equal parts methane and syngas. The Strouhal number was found to be an important parameter in predicting phase response independent of the fuel type. Flame liftoff distance and fuel composition were the key parameters determining the peak FTF magnitude. A hypothesis on the role of the non-adiabatic nature of the flat flame and thermal-diffusive effects on the trends in peak FTF magnitude is presented and discussed. 


\section{Acknowledgements}

I would like to thank my two supervisors, Professor Matthew Johnson and Dr. Wajid Chishty for their guidance throughout my Master's degree. Their technical advice as well as general life advice is truly appreciated.

There are many others who have helped along the way. Mike Player at NRC has provided invaluable assistance. I would also like to thank Dave Carey and Derek Winfield at the NRC machine shop, and Alex Proctor and Kevin Sangster at the Carleton machine shop for their patience and assistance. In addition, Dr. Hongsheng Guo provided technical assistance which is greatly appreciated and Dr. Prateep Chatterjee was kind enough to help me with understanding the intricacies of combustion dynamics.

Many thanks to my fellow graduate students for their camaraderie, there are too many to name but you know who you are. It's great to have friends with whom to share the excitement and challenge of research.

Lastly many thanks to my family for their support. 


\section{Table of Contents}

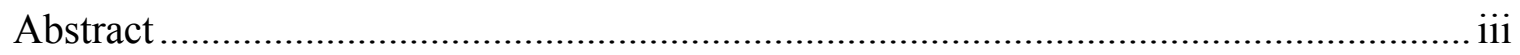

Acknowledgements ............................................................................................. iv

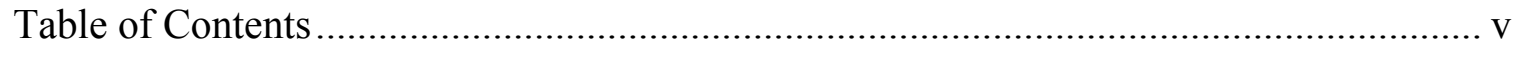

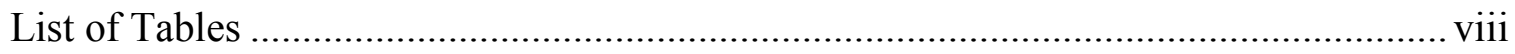

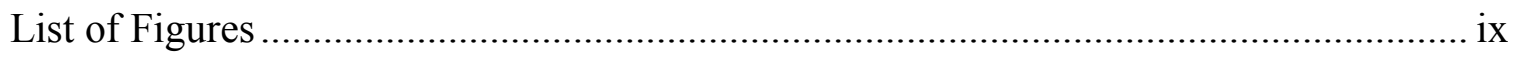

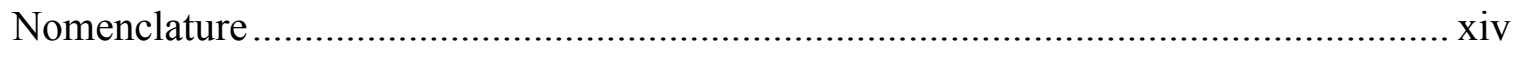

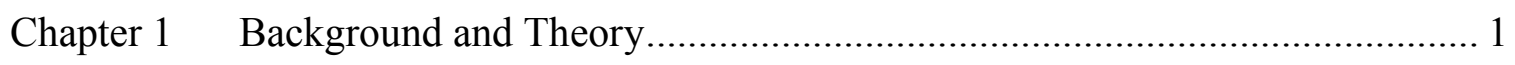

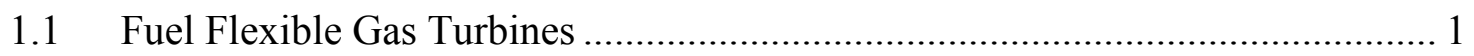

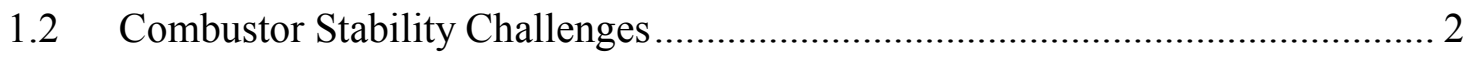

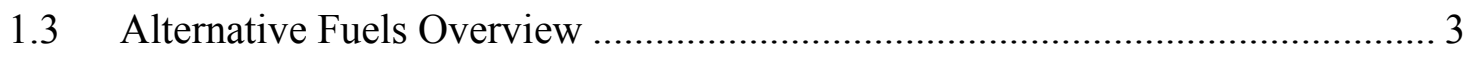

1.4 Properties of Constituent Gas Species ………….......................................... 4

1.5 Combustion Instabilities Overview .............................................................. 5

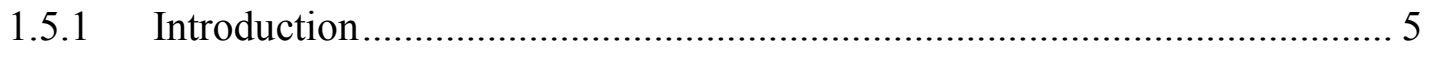

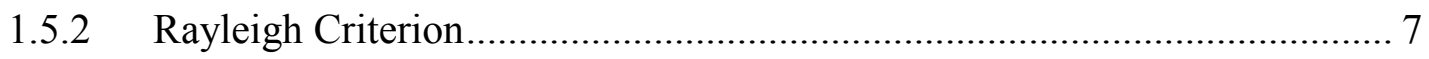

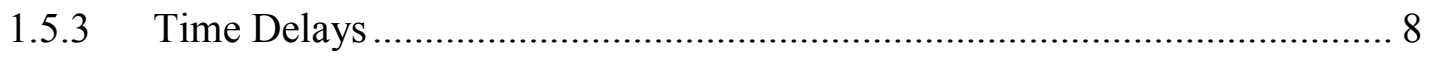

1.5.4 Instability Growth and Limit Cycle Behaviour ............................................ 9

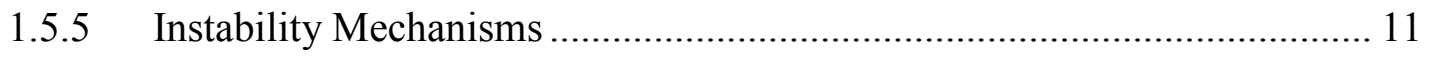

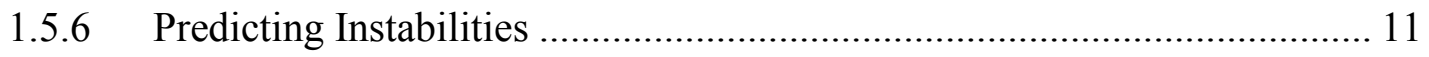

1.6 Flame Transfer Function Analysis ................................................................. 12

1.7 Motivation, Objectives and Outline of Thesis .................................................. 13

Chapter 2 Literature Review: Effect of Fuel Composition on Combustion Instabilities

2.1 Summary of Relevant Prior Investigations …………………....................... 15 
2.2 General Observations from Cited Literature ............................................. 26

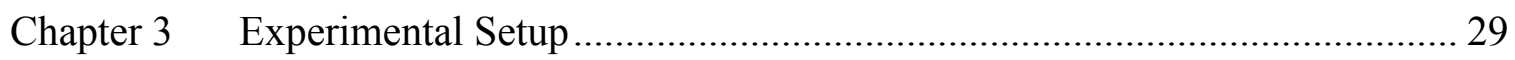

3.1 Overview of Experimental Setup ............................................................. 29

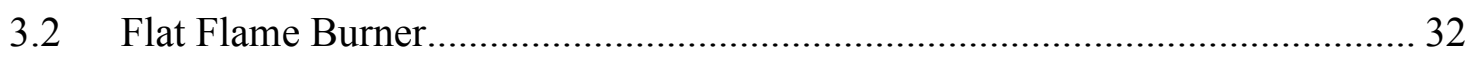

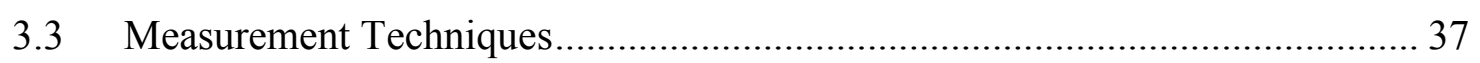

3.3.1 Overview of Measurements and Data Acquisition System ...................... 37

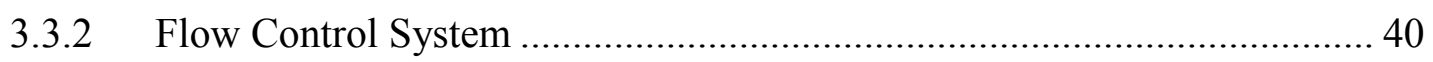

3.3.3 Fluctuating Velocity Measurement ........................................................ 41

3.3.4 Heat Release Rate Measurement ...................................................... 47

3.3.5 Flame Liftoff Distance Measurement .................................................. 49

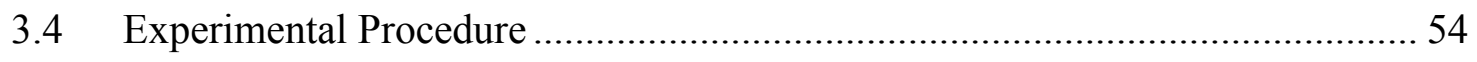

3.4.1 Acoustic Characterization ............................................................ 54

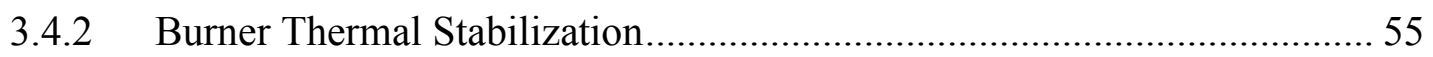

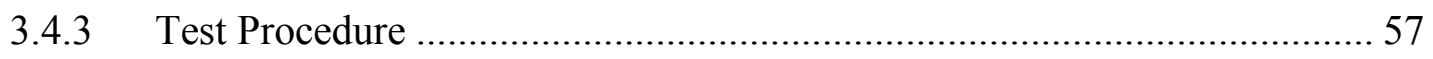

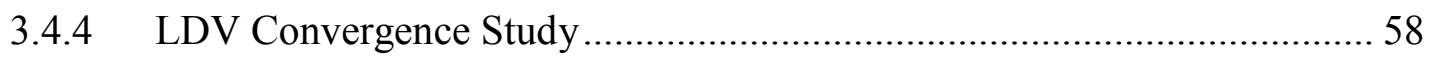

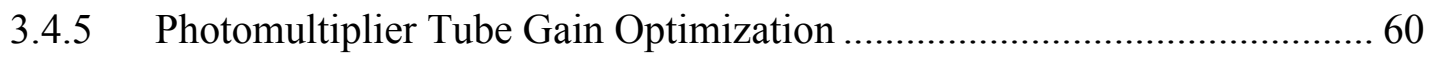

3.4.6 Photomultiplier Dark Current Correction Procedure ............................... 62

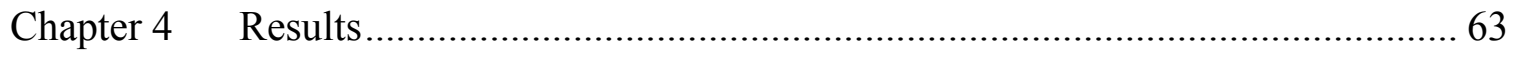

4.1 Fuel Test Matrix and Burner Operability Limits ...................................... 63

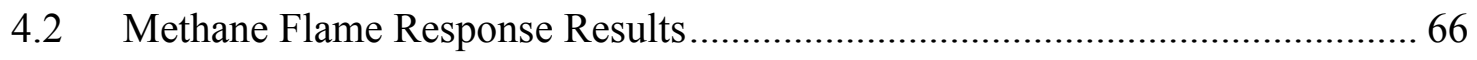

4.3 Results of Parametric Methane/Syngas Flame Response ............................. 70

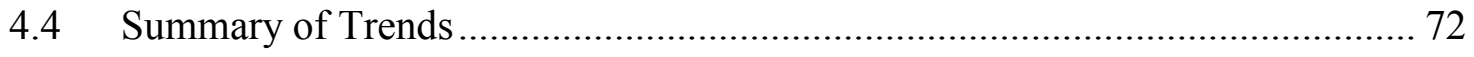

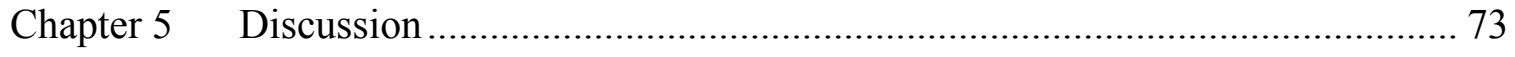

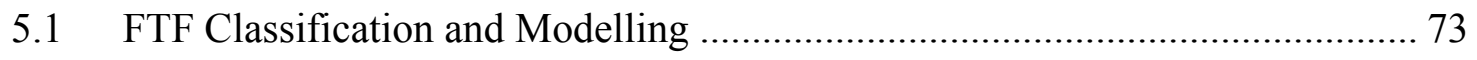

5.2 Static Stability of Non-adiabatic Flames................................................ 77 
5.3 Trends in Mean Heat Release Rate of Syngas-Methane Flames ..................... 82

5.4 Strouhal Number Correlation of Phase Response .......................................... 83

5.5 Trends in Flame Transfer Function Magnitude............................................. 88

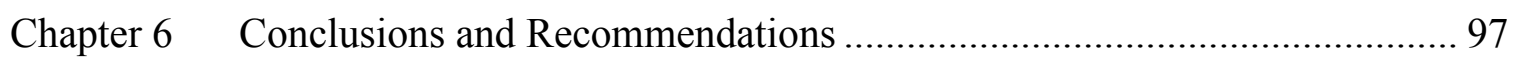

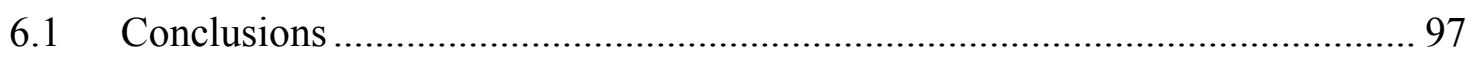

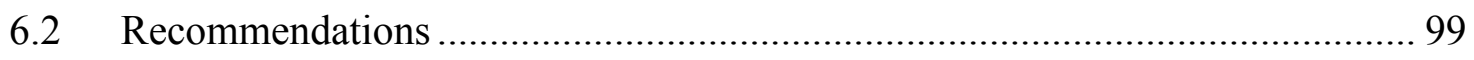

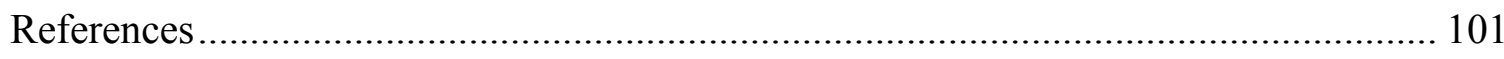

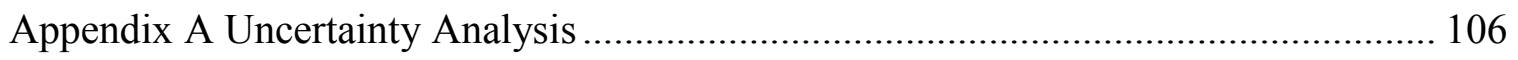

A.1 Flame Transfer Function Magnitude......................................................... 107

A.1.1 Bias Error of Mean Heat Release Rate .................................................. 108

A.1.2 Bias Error of Fluctuating Component of the Heat Release Rate .............. 111

A.1.3 Bias Error of Velocity Fluctuation.................................................... 112

A.1.4 Bias Error of Mean Velocity ........................................................... 112

A.1.5 Total Flame Transfer Function Bias Error ............................................ 114

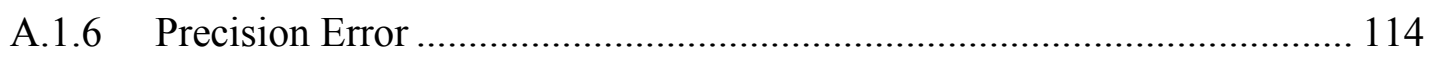

A.2 Flame Transfer Function Phase ................................................................ 116

A.3 Flame Transfer Function Peak Magnitude ................................................. 116

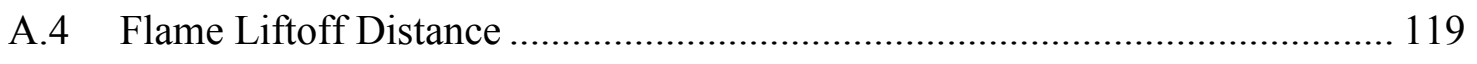

Appendix B Flame Transfer Function Models ..................................................... 121

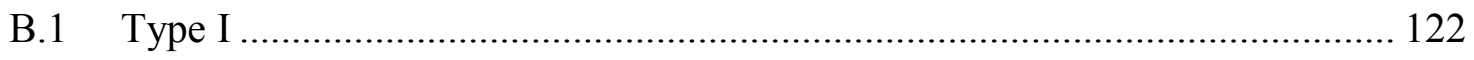

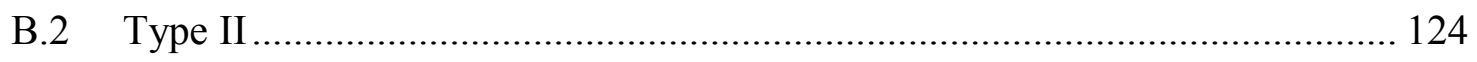

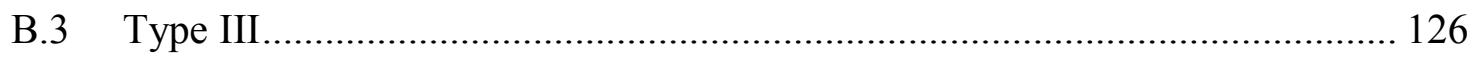

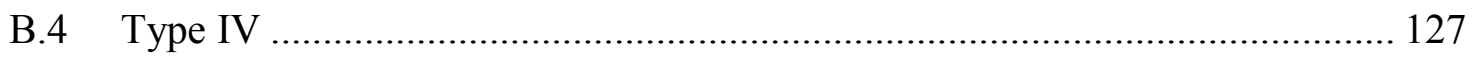

Appendix C Two Microphone Technique Theory and Calibration ............................. 128 


\section{List of Tables}

Table 1.1: Typical Syngas Compositions from Various Facilities (Todd, 2000) .............. 3

Table 1.2: Typical Biogas Compositions (Rasi et al., 2007) ........................................... 4

Table 1.3: Properties of Fuel Constituents.............................................................. 5

Table 2.1: Summary of Literature on the effect of fuel composition on combustion

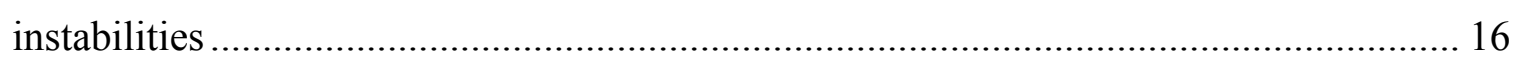

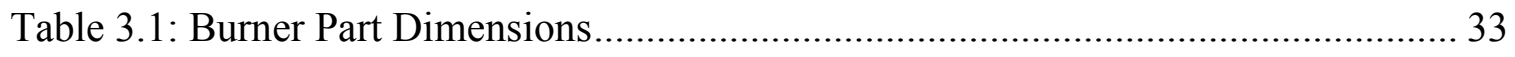

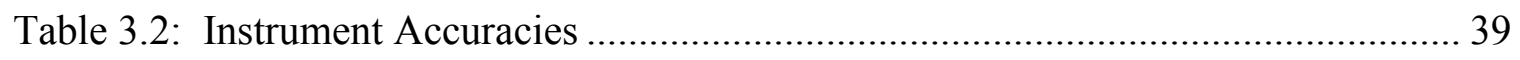

Table 3.3: National Instruments (NI) data acquisition modules ................................ 40

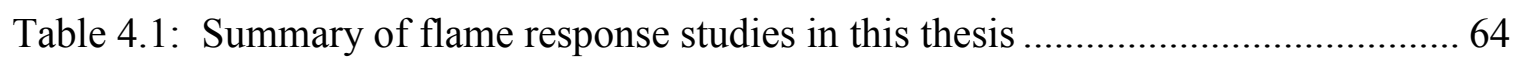

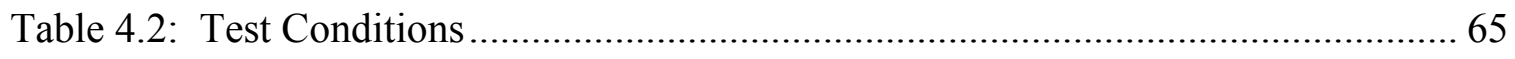

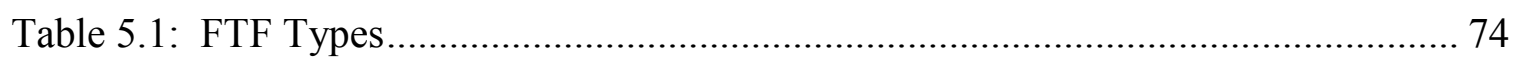

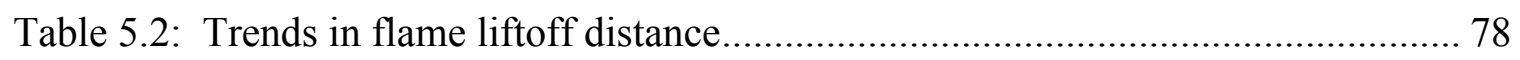

Table 5.3: Comparison of mean heat release rates, reactant temperature and flame liftoff

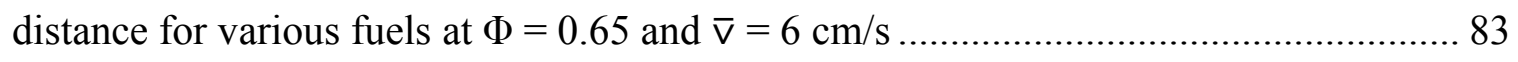

Table A.1: Sources of Error in Mean Heat Release Rate Measurement........................ 111

Table B.1: Model outputs for primary FTF peak ............................................... 121 


\section{List of Figures}

Figure 1.1: Schematic of feedback loop responsible for combustion instabilities (Candel, 2002) 7

Figure 1.2: Sample Time delays (Candel, 2002) 9

Figure 1.3: Schematic illustrating the how the instability amplitude, $A$, affects the energy added and removed by acoustic driving $\mathrm{E}_{\text {drive }}(A)$ and damping $\mathrm{E}_{\text {damp }}(A)$, processes (Lieuwen, 2006) 10

Figure 2.1: Stability characteristics along flame centre of heat release (Reproduced from Figura et al. 2007). 20

Figure 2.2 : Laminar flame speeds of $\mathrm{H} 2 / \mathrm{CO} / \mathrm{CH} 4$ mixtures at Tad of $1500 \mathrm{~K}, \mathrm{P}=4.4$ atm, and $460 \mathrm{~K}$ reactant temperature (Reproduced from Lieuwen et al., 2008). 22

Figure 2.3: (a) Dependence of turbulent flame speed upon turbulence intensity for various fuel blends with the same laminar flame speed (Reproduced from Kido et al., 2002); (b) Description of fuel mixtures

Figure 2.4: Overall sound pressure level as a function of heat release rate parameter, $S_{c}\left(\rho_{u} / \rho_{b}-1\right)$, at different hydrogen concentrations and inlet temperatures (Reproduced from Altay et al., 2009). 23

Figure 2.5: Stable flame images with increasing $\mathrm{H}_{2}$ concentration from (a) to (d) (Reproduced from Zhang et al. 2012) 26

Figure 3.1: Photographs of test chamber used in experiments. (a) open test chamber revealing burner and camera, and (b) closed test chamber as seen during experiments. . 30

Figure 3.2: Schematic of the acoustically forced, flat-flame experiment ........................ 31

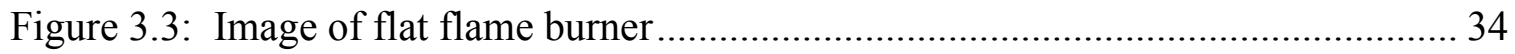

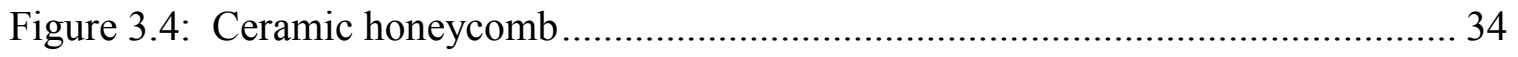

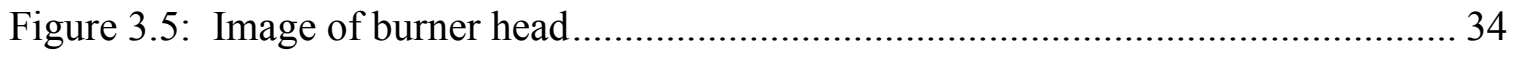


Figure 3.6: R-type thermocouple mounting for gas temperature measurement 37

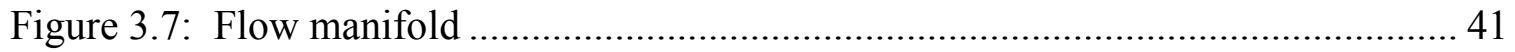

Figure 3.8: Original LDV velocity signal .......................................................... 44

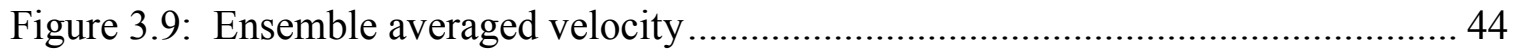

Figure 3.10: Comparison of Ensemble Average- and FFT-based LDV processing techniques used to calculate velocity fluctuations in the burner.................................. 46

Figure 3.11: Comparison of phase of velocity fluctuations from Ensemble Average- and

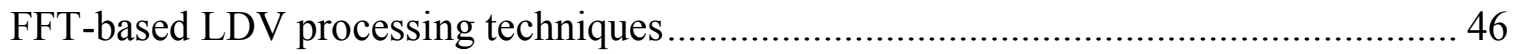

Figure 3.12: Emission spectrum in a lean premixed combustor (Lee \& Santavicca, 2003). Shaded green and blue rectangles correspond to the widths of the $\mathrm{OH}^{*}$ and $\mathrm{CH}^{*}$ filters

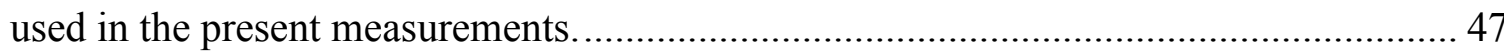

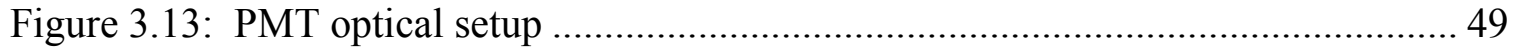

Figure 3.14: Image of $\mathrm{CH}_{4}$ flame at $\phi=0.65, \bar{v}=6 \mathrm{~cm} / \mathrm{s}$ with superimposed white lines showing the calculated burner edges and flame centre................................................. 52

Figure 3.15: Image of flame and burner showing image areas used for averaging during

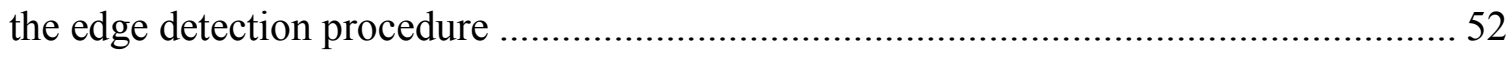

Figure 3.16: Horizontal slice across burner used to find burner side edges .................. 53

Figure 3.17: Vertical slice across burner to find burner top edge ............................... 53

Figure 3.18: Vertical slice across flame used to find flame centre ............................... 54

Figure 3.19: Variation of acoustic velocity with frequency at constant speaker voltage 55

Figure 3.20: Transfer function magnitude transient ................................................. 56

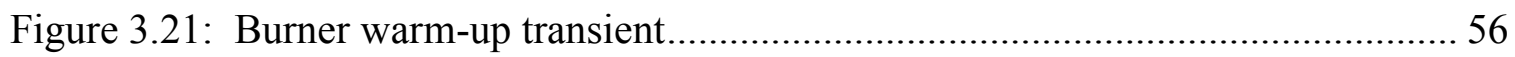

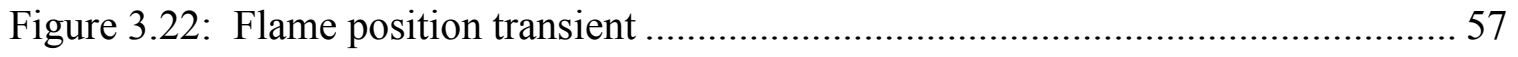

Figure 3.23: LDV acoustic velocity convergence .................................................... 59

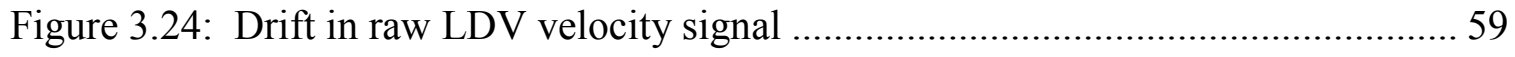


Figure 3.25: Effect of high voltage setting on PMT output. 61

Figure 3.26: Effect of PMT high voltage on heat release fluctuation and harmonics ..... 61

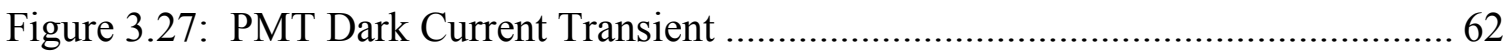

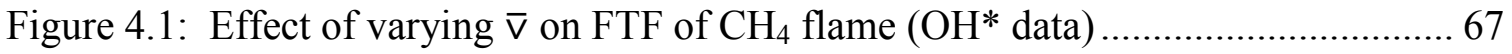

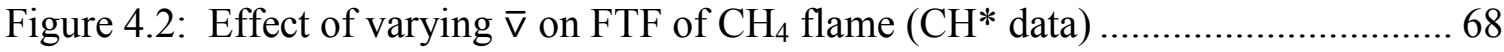

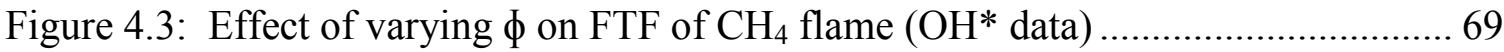

Figure 4.4: Effect of varying $\% \mathrm{CH}_{4}$ on $\mathrm{FTF}$ of $\mathrm{CH}_{4} /$ syngas flame $\left(\mathrm{OH}^{*}\right.$ data $)$............. 71

Figure 4.5: Effect of varying $\mathrm{H}_{2}$ : $\mathrm{CO}$ ratio on $\mathrm{FTF}$ of $\mathrm{CH}_{4} /$ syngas flame $\left(\mathrm{OH}^{*}\right.$ data $) \ldots . .71$

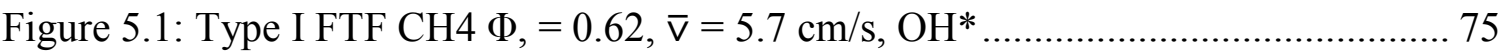

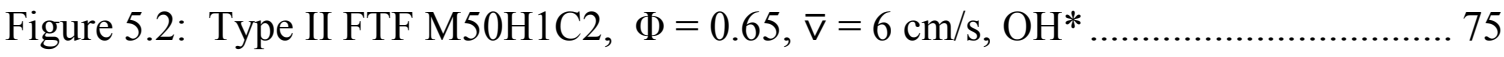

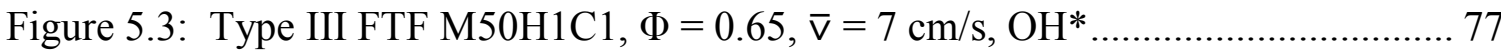

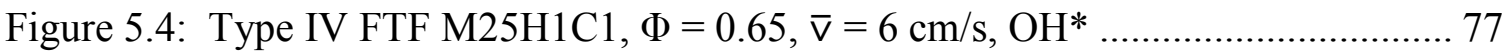

Figure 5.5: Trends in flame liftoff distance (Blue and red points are for methane, green

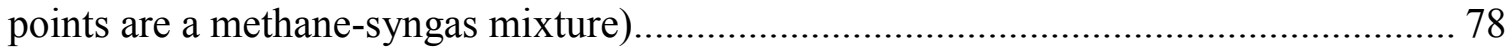

Figure 5.6: Trends in flame liftoff distance and flame temperature with a varying flow rate

Figure 5.7: Flame position, thickness, and reaction rate during one forcing cycle, velocity leads reaction rate by $150^{\circ}$ (Chatterjee 2004) 81

Figure 5.8: Flame transfer function magnitude and phase vs. frequency for all test conditions 85

Figure 5.9: Flame transfer function magnitude and phase vs. Strouhal number for all test conditions 86

Figure 5.10: Trends in Peak FTF Magnitude $\left(\mathrm{OH}^{*}\right.$ based) vs. $d_{f}$ for three fuels 89

Figure 5.11: Trends in Peak FTF Magnitude $\left(\mathrm{OH}^{*}\right.$ based) vs. reactant gas temperature for 3 fuels 89 
Figure 5.12: Reactant gas temperature vs. flame liftoff distance for all test conditions.. 90

Figure 5.13: Trends in Peak FTF Magnitude ( $\mathrm{OH}^{*}$ based) vs. $d_{f}$ by type 90

Figure 5.14: Dependence of damping factor on heat transfer potential for various fuel Khanna (2001)

Figure 5.15: Variation of flame speed with flame liftoff distance for three fuels at various operating conditions 93

Figure 5.16: Mass diffusivities of various fuel species as a function of temperature...... 96

Figure A.1: PMT output, sorted 109

Figure A.2: Difference between adjacent points in PMT Output 109

Figure A.3: Electron Tube PMT model 9125W gain curve (ET Enterprises, 2010) ...... 111

Figure A.4: Peak uncertainty for type I FTF $-\mathrm{M} 75 \mathrm{H} 1 \mathrm{C} 1, \phi=0.65, \overline{\mathrm{v}}=6 \mathrm{~cm} / \mathrm{s}, \mathrm{OH}^{*} 117$

Figure A.5: Peak uncertainty for type I FTF $-\mathrm{CH}_{4}, \phi=0.62, \bar{v}=5.7 \mathrm{~cm} / \mathrm{s}, \mathrm{OH}^{*} \ldots \ldots .118$

Figure A.6: Peak uncertainty for type II FTF $-\mathrm{M} 50 \mathrm{H} 1 \mathrm{C} 2, \phi=0.65, \bar{v}=6 \mathrm{~cm} / \mathrm{s}, \mathrm{OH}^{*} 118$

Figure A.7: Peak uncertainty for type II FTF $-\mathrm{CH}_{4}, \phi=0.7, \bar{v}=6 \mathrm{~cm} / \mathrm{s}, \mathrm{OH}^{*} \ldots \ldots \ldots .118$

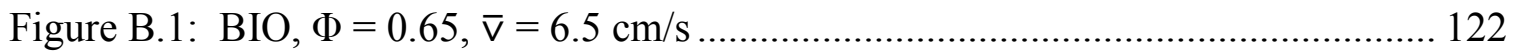

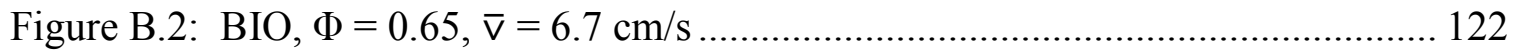

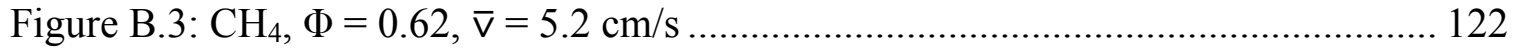

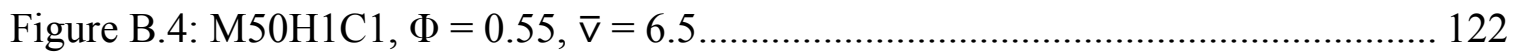

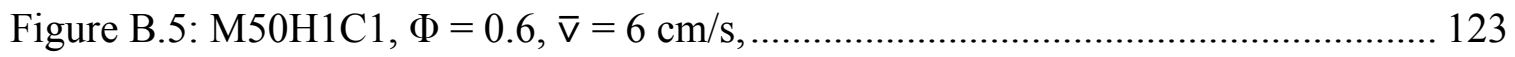

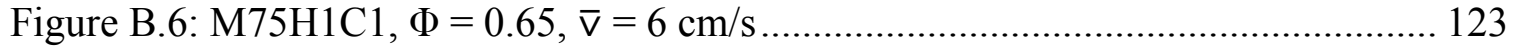

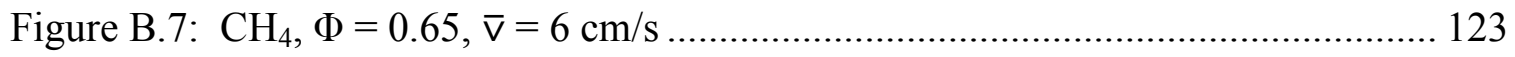

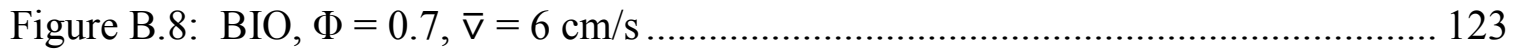

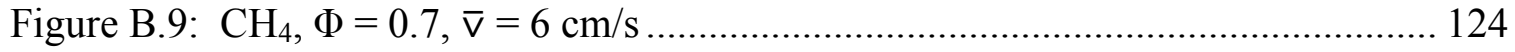




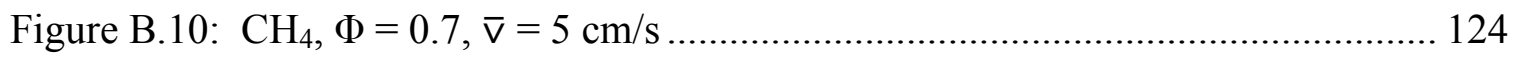

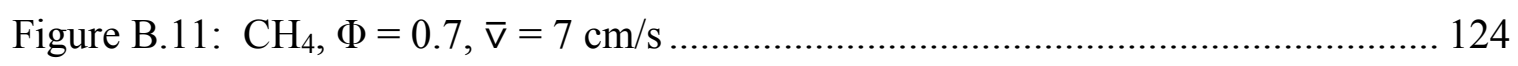

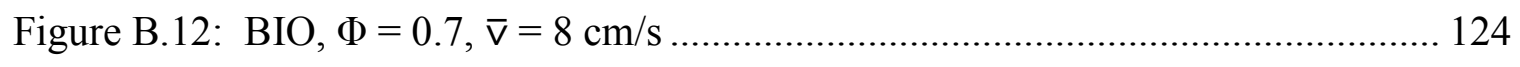

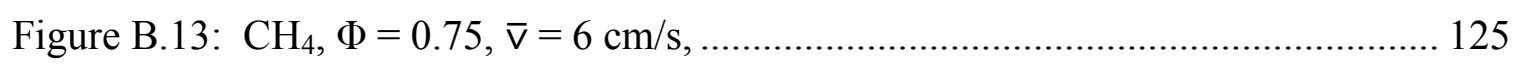

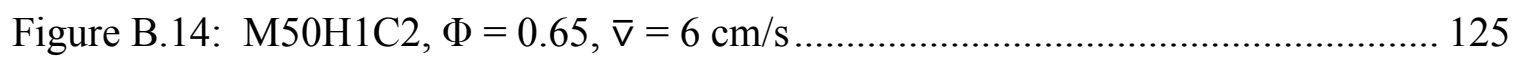

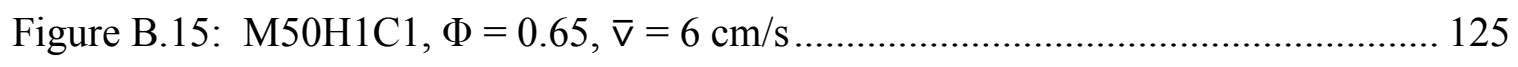

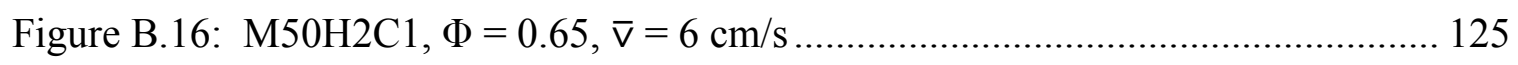

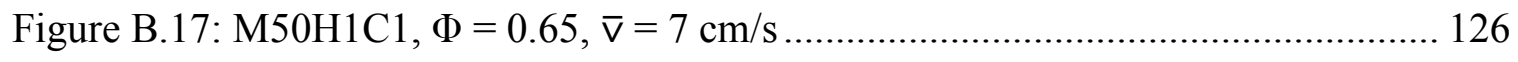

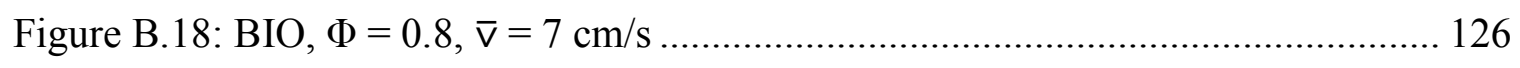

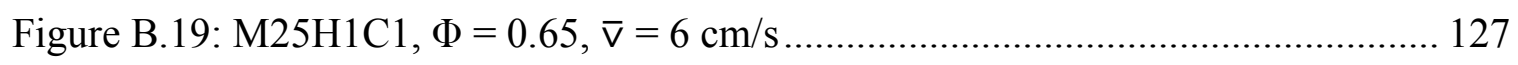

Figure C.1: Microphone phase mismatch measurement setup ................................. 130

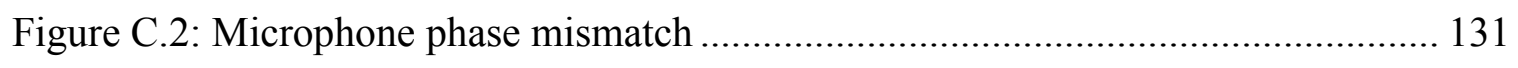

Figure C.3: Microphone amplitude ratio .......................................................... 131

Figure C.4: Microphone sensitivity variation with ambient pressure ......................... 133 


\section{Nomenclature}

\begin{tabular}{|c|c|c|}
\hline Symbol & Description & First Use \\
\hline$A$ & Forcing amplitude & Equation 1.2 \\
\hline$B$ & Bias error & Equation A.1 \\
\hline$d_{f}$ & Flame liftoff distance & Section 3.3.5 \\
\hline$d P / d x$ & Pressure gradient & Equation C.1 \\
\hline$d T / d x$ & Temperature gradient & Section 5.5 \\
\hline $\mathcal{D}$ & Mass diffusivity & Table 1.3 \\
\hline$E_{\text {damp }}$ & Energy associated with damping processes & Section 1.5.4 \\
\hline$E_{\text {drive }}$ & Energy associated with driving processes & Section 1.5.4 \\
\hline$f$ & Frequency & Equation 1.2 \\
\hline$H$ & Frequency response function gain & Equation 1.2 \\
\hline K & System gain & Equation 5.1 \\
\hline$P^{\prime}$ & Fluctuating component of pressure & Equation 1.1 \\
\hline$P$ & Pressure & Equation C.2 \\
\hline$q^{\prime}$ & Fluctuating component of heat release rate & Equation 1.1 \\
\hline $\bar{q}$ & Mean heat release rate & Equation 1.2 \\
\hline$L_{i}$ & Acoustic energy loss process & Equation 1.1 \\
\hline$L_{C H^{*} \max }$ & Flame length & Section 2.1 \\
\hline Le & Lewis number & Section 5.5 \\
\hline$N(s)$ & Polynomial of zeros & Equation 5.1 \\
\hline$R$ & Burner radius & Section 5.4 \\
\hline$S$ & Precision error & Equation A.3 \\
\hline$S_{c}$ & Strained flame consumption speed & Section 2.1 \\
\hline$S_{L}$ & Laminar flame speed & Section 5.4 \\
\hline
\end{tabular}




$\begin{array}{lll}S_{L}^{0} & \text { Unstrained laminar flame speed } & \text { Section } 1.4 \\ S t & \text { Strouhal number } & \text { Section } 2.1 \\ \mathrm{t}_{\text {adv }} & \text { Advection time } & \text { Equation } 5.4 \\ \mathrm{t}_{\text {acoustic }} & \text { Forcing time } & \text { Equation } 5.4 \\ T_{a d} & \text { Adiabatic flame temperature } & \text { Table } 1.3 \\ T_{f} & \text { Flame temperature } & \text { Figure } 5.6 \\ T_{f u e l} & \text { Fuel temperature } & \text { Equation } 2.1 \\ T_{s t d} & \text { Standard temperature } & \text { Equation } 2.1 \\ T_{R} & \text { Reactant temperature } & \text { Section } 3.2 \\ v^{\prime} & \text { Fluctuating component of velocity } & \text { Equation } 1.2 \\ \bar{v} & \text { Mean flow velocity } & \text { Equation } 1.2 \\ V & \text { Combustor volume } & \text { Equation } 1.1 \\ w_{b} & \text { Burner width } & \text { Equation A.23 } \\ \Delta x & \text { Microphone separation distance } & \text { Equation C.2 }\end{array}$

\section{Greek Symbols}

$\begin{array}{lll}\alpha & \text { Thermal diffusivity } & \text { Table } 1.3 \\ \beta & \text { Flame cone angle } & \text { Section } 5.4 \\ \delta & \begin{array}{l}\text { Laminar flame speed sensitivity to equivalence } \\ \text { ratio fluctuations }\end{array} & \text { Section } 2.1 \\ \zeta & \text { Damping ratio } & \text { Equation } 5.1 \\ \theta & \text { Phase angle } & \text { Equation A.22 } \\ \rho & \text { Density } & \text { Equation C.1 } \\ \rho_{u} & \text { Unburned gas density } & \text { Section } 2.1 \\ \rho_{b} & \text { Burned gas density } & \text { Section } 2.1 \\ \sigma & \text { Standard deviation } & \text { Equation A.3 } \\ \tau_{\text {osc }} & \text { Oscillation period } & \text { Equation } 1.1\end{array}$




$\begin{array}{lll}\tau & \text { Time delay } & \text { Equation 5.5 } \\ \Phi & \text { Equivalence ratio } & \text { Table } 1.3 \\ \omega & \text { Angular frequency } & \text { Section } 5.4 \\ \omega_{*} & \text { Reduced frequency } & \text { Section } 5.4 \\ \omega_{\mathrm{n}} & \text { Natural frequency } & \text { Equation 5.1 }\end{array}$

\section{Acronyms}

$\begin{array}{lll}\text { FFT } & \text { Fast Fourier transform } & \text { Section } 3.3 .3 \\ \text { FTF } & \text { Flame transfer function } & \text { Abstract } \\ \text { LC } & \text { Limit cycle } & \text { Section } 1.5 .4 \\ \text { LDV } & \text { Laser Doppler Velocimetry } & \text { Section } 3.1 \\ \text { LHV } & \text { Lower heating value } & \text { Equation } 2.1 \\ \text { PMT } & \text { Photomultiplier tube } & \text { Section } 3.3 .1 \\ \text { SG } & \text { Specific gravity } & \text { Equation } 2.1 \\ \text { SLPM } & \text { Standard litres per minute } & \text { Section 3.3.2 }\end{array}$




\section{Chapter 1}

\section{Background and Theory}

\subsection{Fuel Flexible Gas Turbines}

Concern over greenhouse gas emissions and future supplies of conventional fuels has increased interest in alternative fuels. For industrial gas turbines that typically run on natural gas, two potential alternatives are biogas and syngas. The use of syngas for gas turbine based power generation in Integrated Gasification Combined Cycle (IGCC) power plants is gaining popularity as a cleaner alternative to coal plants. The number of IGCC plants worldwide grew from eight to seventeen from 2000 to 2010 and is expected to double in the next five years (DOE National Energy Technology Laboratory, 2010). However, biogas and syngas have a lower energy content and greater variation in fuel composition than conventional fuels such as natural gas.

There are several key issues that complicate the use of syngas and biogas in gas turbines. Due to the low energy content and high diluent content of fuels such as syngas and biogas, higher mass flow rates are required to achieve the same power output, leading to the possibility of compressor stall problems (Lieuwen et al., 2008). Changes in reaction chemistry, temperatures, and aerodynamics have been shown to impact $\mathrm{NO}_{\mathrm{x}}$ and CO emissions in medium and low heating value fuels (Richards et al., 2001). Syngas has been found to contain corrosive alkali metals among other species that may cause damage to gas turbine components and have an impact on their lifetime (Richards et al., 2001). 
Changes in fuel composition will also have an impact on combustor stability issues (Lieuwen et al., 2008).

Lean premixed combustion systems are attractive due to their potential for lower $\mathrm{NO}_{\mathrm{x}}$ emissions resulting from lower flame temperatures at reduced equivalence ratios. However, lean premixed combustion systems are generally more susceptible to combustor operability issues than non-premixed (diffusion-flame) style combustors, and challenges posed by the use of alternative fuels further complicates this problem. The high hydrogen content of syngas may be especially problematic due to hydrogen's unique properties (McDonell, 2006). The effects of new fuels like syngas and biogas on combustion instabilities was the topic chosen for this thesis.

\subsection{Combustor Stability Challenges}

Combustor stability problems fall into two areas: static and dynamic. Static stability issues include blowoff, flashback, and autoignition, while dynamic stability issues are generally described as combustion instabilities. Blowoff occurs when the flow rate is too high for the flame to stabilize. By contrast, flashback occurs when the flame speed is much higher than the flow speed, resulting in flame propagation upstream into the premixing section which is not generally designed for high temperatures. Autoignition is the spontaneous ignition of the fuel-air mixture upstream of the combustor and can cause damage similar to flashback. Combustion instabilities - the focus of the present research - are unstable combustor oscillations that can cause thermal wear and damage to the combustor. They are typically caused by feedback between heat release rate and pressure oscillations. 


\subsection{Alternative Fuels Overview}

This thesis considers two classes of alternative fuels, syngas and biogas. These are studied in conjunction with baseline experiments using pure methane. Syngas or synthesis gas is produced through gasification. During gasification a solid or liquid feedstock is heated in a low oxygen environment such that partial oxidation occurs. Commonly used feedstock includes coal, petroleum, petcoke, and biomass/waste. The gasification process produces energy as well as a usable fuel and is cleaner than directly burning the feedstock to generate energy. In addition to a diverse range of feedstocks, there are also several options for gasifier design, including moving bed, fixed bed, and fluidized bed (Casleton et al., 2008). Syngas is typically composed of hydrogen, carbon monoxide, one or more diluents such as water vapour, carbon dioxide, and nitrogen, as well as small amounts of methane. Table 1.1 shows variations in syngas compositions from different production plants due to differences in feedstock and gasification technique (Todd, 2000).

Table 1.1: Typical Syngas Compositions from Various Facilities (Todd, 2000)

\begin{tabular}{|l|c|c|c|c|c|c|c|c|c|c|c|c|c|}
\hline Species & PSI & Tampa & $\begin{array}{c}\text { El } \\
\text { Dorado }\end{array}$ & Pernis & $\begin{array}{c}\text { Sierra } \\
\text { Pacific }\end{array}$ & ILVA & $\begin{array}{c}\text { Schwarze } \\
\text { Pumpe }\end{array}$ & Sarlux & Fife & $\begin{array}{c}\text { Exxon } \\
\text { Singapore }\end{array}$ & $\begin{array}{c}\text { Motiva } \\
\text { Delaware }\end{array}$ & PIEMSA & Tonghua \\
\hline $\mathrm{H}_{2}$ & 24.8 & 37.2 & 35.4 & 34.4 & 14.5 & 8.6 & 61.9 & 22.7 & 34.4 & 44.5 & 32 & 42.3 & 10.3 \\
\hline $\mathrm{CO}$ & 39.5 & 46.6 & 45 & 35.1 & 23.6 & 26.2 & 26.2 & 30.6 & 55.4 & 35.4 & 49.5 & 47.77 & 22.3 \\
\hline $\mathrm{CH}_{4}$ & 1.5 & 0.1 & 0 & 0.3 & 1.3 & 8.2 & 6.9 & 0.2 & 5.1 & 0.5 & 0.1 & 0.08 & 3.8 \\
\hline $\mathrm{CO}_{2}$ & 9.3 & 13.3 & 17.1 & 30 & 5.6 & 14 & 2.8 & 5.6 & 1.6 & 17.9 & 15.8 & 8.01 & 14.5 \\
\hline $\mathrm{N}_{2}+\mathrm{Ar}$ & 2.3 & 2.5 & 2.1 & 0.2 & 49.3 & 42.5 & 1.8 & 1.1 & 3.1 & 1.4 & 2.15 & 2.05 & 48.2 \\
\hline $\mathrm{H}_{2} \mathrm{O}$ & 22.7 & 0.3 & 0.4 & --- & 5.7 & --- & --- & 39.8 & --- & 0.1 & 0.44 & 0.15 & 0.9 \\
\hline
\end{tabular}

Biogas is produced from biomass or waste products through either anaerobic digestion or decomposition processes that involve the breakdown of the feedstock by 
bacteria into methane and carbon dioxide. As with syngas, biogas composition varies both with the feedstock and production process. Table 1.2 (Rasi et al., 2007) shows ranges of anticipated biogas compositions from various sources. The variability in syngas and biogas compositions poses a challenge for the design of gas turbines which are conventionally run on natural gas.

Table 1.2: Typical Biogas Compositions (Rasi et al., 2007)

\begin{tabular}{|l|llll|}
\hline Source & $\mathbf{C H}_{\mathbf{4}}(\mathbf{\%})$ & $\mathbf{C O}_{\mathbf{2}} \mathbf{( \% )}$ & $\mathbf{O}_{\mathbf{2}} \mathbf{( \% )}$ & $\mathbf{N}_{\mathbf{2}}(\mathbf{\%})$ \\
\hline Landfill & $47-57$ & $37-41$ & $<1$ & $<1-17$ \\
Sewage digester & $61-65$ & $36-38$ & $<1$ & $<2$ \\
Farm biogas plant & $55-58$ & $37-38$ & $<1$ & $<1-2$ \\
Landfill & $59.4-67.9$ & $29.9-38.6$ & n.a. & n.a. \\
Landfill & $37-62$ & $24-29$ & $<1$ & n.a. \\
Landfill & 55.6 & 37.14 & 0.99 & n.a. \\
Landfill & 44 & 40.1 & 2.6 & 13.2 \\
Sewage digester & 57.8 & 38.6 & 0 & 3.7 \\
Sewage digester & 62.6 & 37.4 & n.a. & n.a. \\
Sewage digester & 58 & 33.9 & 0 & 8.1 \\
\hline
\end{tabular}

\subsection{Properties of Constituent Gas Species}

Table 1.3 compares flame temperature, flammability limits, laminar flame speed, mass diffusivity, and thermal diffusivity of the three main fuel species in biogas and syngas: $\mathrm{CH}_{4}, \mathrm{CO}$, and $\mathrm{H}_{2}$. Mass diffusivity was calculated using the Chapman and Enskog Method as outlined in Kuo (2005).

Effects of fuel composition on combustion and combustion instabilities in particular are directly related to differences among the fuel components. Methane is the main constituent in natural gas, while hydrogen and carbon monoxide are the main 
species in syngas. Methane has a lower flame temperature than both hydrogen and carbon monoxide. Hydrogen is certainly an anomaly in terms of the lower flammability limits, laminar flame speed, mass diffusivity, and thermal diffusivity. Diluents such as nitrogen, carbon dioxide, and water will also play a role in syngas and biogas combustion. Nitrogen mainly influences the mixture specific heat capacity and adiabatic flame temperature while water and carbon dioxide also have an effect on the chemical kinetics and radiative heat transfer (Lieuwen et al., 2008).

Table 1.3: Properties of Fuel Constituents

\begin{tabular}{|c|c|c|c|c|c|}
\hline Species & $\begin{array}{c}\mathbf{T}_{\mathbf{a d}} \\
(\mathbf{K})^{\mathbf{a}}\end{array}$ & $\begin{array}{c}\text { Flammability } \\
\text { limit } \\
\left(\boldsymbol{\Phi}_{\min } / \boldsymbol{\phi}_{\mathbf{m a x}}\right)^{\mathbf{b}}\end{array}$ & $\begin{array}{c}\text { Laminar flame } \\
\mathbf{s p e e d}, \boldsymbol{S}_{\mathbf{L}}^{\mathbf{0}} \\
(\mathbf{c m} / \mathbf{s})\end{array}$ & $\begin{array}{c}\text { Mass } \\
\text { diffusivity, } \mathcal{D}, \\
\text { in air at 300 K } \\
\left(\mathbf{m}^{\mathbf{2}} / \mathbf{s}\right)^{\mathbf{e}}\end{array}$ & $\begin{array}{c}\text { Thermal } \\
\text { diffusivity, } \boldsymbol{\alpha}, \\
\text { in air at 300 K } \\
\left(\mathbf{m}^{\mathbf{2}} / \mathbf{s}\right)\end{array}$ \\
\hline $\mathrm{CH}_{4}$ & 2210 & $0.46 / 1.64$ & $40.5^{\mathrm{c}}$ & $2.22 \times 10^{-5}$ & $2.37 \times 10^{-5 \mathrm{f}}$ \\
\hline $\mathrm{CO}$ & 2400 & $0.34 / 6.76$ & $28.5^{\mathrm{d}}$ & $2.05 \times 10^{-5}$ & $2.13 \times 10^{-5 \mathrm{~g}}$ \\
\hline $\mathrm{H}_{2}$ & 2400 & $0.14 / 2.54$ & $210^{\mathrm{c}}$ & $7.58 \times 10^{-5}$ & $15.8 \times 10^{-5 \mathrm{~g}}$ \\
\hline
\end{tabular}

in air at $1 \mathrm{~atm}$ and stoichiometric conditions, from Glassman (1996)

$\mathrm{b}_{\text {in }}$ air at $1 \mathrm{~atm}$ and $25^{\circ} \mathrm{C}$, from Turns (2000)

${ }^{c}$ unstrained in air at $1 \mathrm{~atm}, 25^{\circ} \mathrm{C}$, and $\Phi=1$, from Glassman (1996)

d unstrained in air at $1 \mathrm{~atm}, 25^{\circ} \mathrm{C}$, and $\Phi=1.1$ (data unavailable at $\Phi=1$ ), from Glassman (1996)

ecalculated using the Chapman and Enskog method and Lennard-Jones potentials

f calculated using data from NIST database - Thermophysical Properties of Fluid Systems

(http://webbook.nist.gov/chemistry/fluid/)

${ }^{\mathrm{g}}$ from Incropera \& DeWitt (2002)

\subsection{Combustion Instabilities Overview}

\subsubsection{Introduction}

Combustion instability problems were first encountered in the 1950's and 1960's during the development of high performance rocket engines and jet propulsion systems (Candel, 2002). These problems resurfaced with the development of lean premixed 
combustion systems and recent interest in alternative fuels poses new challenges. A comprehensive overview of the general field of combustion dynamics can be found in Candel (2002) and more recently for lean premixed swirl stabilized systems in Huang and Yang (2009).

Premixed combustors are susceptible to instabilities because of their high energy density and low damping (Culick \& Yang, 1995). A large amount of energy is released during combustion, yet only a small fraction of that is required to drive oscillations. Thus even small fluctuations in the heat release rate may have enough energy to drive pressure oscillations. Scarinci \& Halpin (2000) concluded that in lean premixed combustors, the heat release is concentrated around the flame front, whereas in conventional combustors, it is more distributed. Another difference is that premixed combustors are weakly damped compared to diffusion combustors due to the lack of downstream combustion air holes which provide acoustic damping (Richards et al., 2001). As a result there is very little resistance to oscillations once they begin.

In lean premixed combustors, combustion instabilities often occur as a result of coupling between pressure and heat release rate oscillations, typically at one of the natural acoustic modes of the of the combustor. These oscillations can cause damage and thermal wear to the combustor, significantly reducing its lifespan. Oscillations can also trigger flashback, where the flame propagates upstream into the mixing chamber, which is not designed for the high temperatures produced by a flame.

Figure 1.1 shows a schematic of a feedback loop that causes combustion instabilities (Candel, 2002). An initial perturbation in the flow or mixture properties 
causes a fluctuation in the heat release. This in turn causes a fluctuation of the pressure inside the combustor, which again perturbs the flow or mixture, starting the process all over again. For these oscillations to grow and sustain themselves they must be in phase and the overall gain through the cycle must be higher than the damping present in the system.

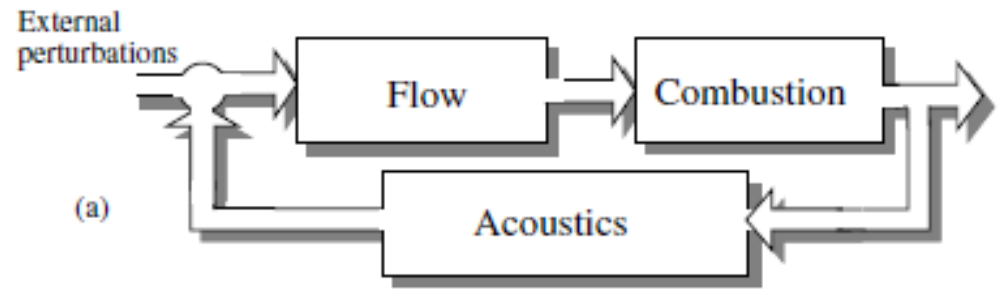

Figure 1.1: Schematic of feedback loop responsible for combustion instabilities (Candel, 2002)

\subsubsection{Rayleigh Criterion}

The coupling between pressure and heat release rate oscillations plays an integral role in the development of combustion instabilities. This coupling can be described by the Rayleigh criterion, which was first put forth by Lord Rayleigh (Rayleigh 1896). The Rayleigh criterion states that the pressure and heat release rate oscillations must be in phase for the system to become unstable. If this condition is satisfied, their interference will be constructive and there is a net energy addition to the system. Similarly, if they are out of phase there will be a net energy removal from the system. However, this does not ensure that the combustor will become unstable. A more complete criteria is presented in Equation 1.1 (Zinn \& Lieuwen, 2005). 


$$
\int_{V} \int_{\tau_{\text {osc }}} P^{\prime}(x, t) q^{\prime}(x, t) d t d V \geq \int_{V} \int_{\tau_{\text {osc }}} L_{i}(x, t) d t d V
$$

Here, $P^{\prime}$ and $q^{\prime}$ represent the fluctuating pressure and heat release rate respectively, $\tau_{o s c}$ and $V$ are the oscillation period and combustor volume respectively, and $L_{i}$ represents the individual acoustic energy loss processes.

Equation 1.1 implies that the presence of damping in the combustor must also be considered. The oscillations will only grow in amplitude if the energy addition due to the coupling of pressure and heat release in the combustor is larger than the damping forces present in the combustor. Sources of damping include viscous dissipation at the walls and radiation (Candel, 2002).

\subsubsection{Time Delays}

Rayleigh's criterion shows that time delays are an important part of combustion

dynamics as they determine the phase relationship between heat release rate and pressure oscillations. A change in the time delay can cause a transition to or away from an unstable mode. To further understand time delays, the mechanisms responsible for instabilities must be considered as further discussed in Section 1.5.5. As an example, two common mechanisms are equivalence ratio oscillations and flame-vortex interactions. In equivalence ratio oscillations, perturbations in the fuel and air feed lines create fluctuations in the equivalence ratio. These are carried by the flow from the mixing section to the flame where they cause fluctuations in the heat release rate. In the latter mechanism, vortices resulting from flow separation or other sources are carried by the flow and impinge on the flame, causing fluctuations in heat release rate. 
An example of the time delays present in a premixed combustor with instabilities resulting from equivalence ratio fluctuations is shown in Figure 1.2 (Candel, 2002). In this case, the total time delay from initiation of the perturbation until it is manifested as a fluctuation in the heat release rate is the sum of several components. Assuming that the initial perturbation stems from a pressure fluctuation at the flame, there is a time delay for this pressure fluctuation to reach the fuel injector. Once there, the pressure fluctuation interacts with the fuel injector, causing a fluctuation in the equivalence ratio. This equivalence ratio fluctuation is then advected by the flow to the centre of mass of the flame. Once at the flame, there is a chemical time delay due to a finite reaction rate before the fluctuation manifests itself in the heat release rate. There are three components to the time delay for this example: acoustic, bulk flow, and chemical.
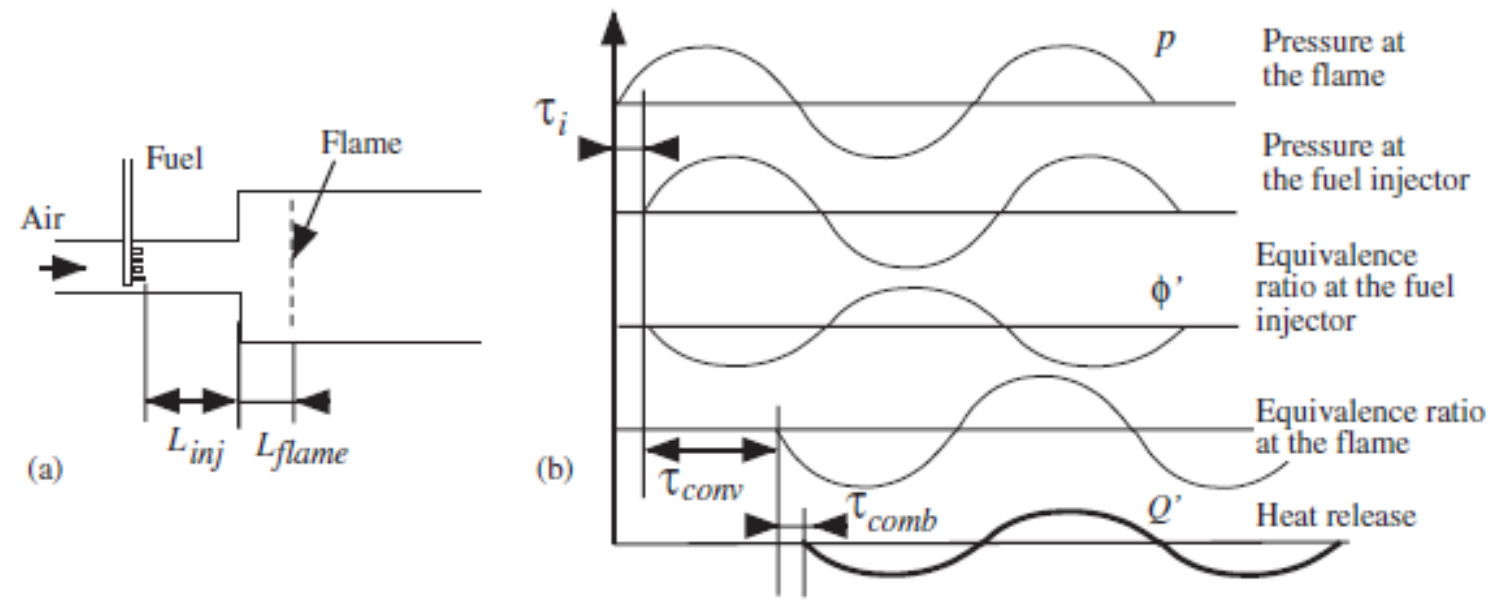

Figure 1.2: Sample Time delays (Candel, 2002)

\subsubsection{Instability Growth and Limit Cycle Behaviour}

If pressure and heat release rate oscillations are in phase and the overall gain exceeds the system damping, then the amplitude of oscillations will grow until they reach 
what is called the limit cycle amplitude, as illustrated in Figure 1.3 (Lieuwen, 2006). This is the point where the energy addition from the coupling of heat release rate and pressure oscillations, $E_{\text {drive }}$ matches the energy removal due to damping in the system, $E_{\text {damp }}$ (Lieuwen, 2006). Limit cycles and combustion instability growth are complex processes. Current theory based on experiments says that the amplitude grows linearly at first and then continues toward the limit cycle non-linearly. The complex non-linearities that lead to limit cycles are not well understood. The focus of this thesis is on the linear region of flame response typically found at low forcing amplitudes. Balachandran et al. (2005) found that a lean premixed turbulent bluff body stabilized flame had a linear response for forcing amplitudes below about 15\%. Ducruix et al. (2000) studied a laminar conical flame and found that the response was linear with forcing amplitudes as high as $20 \%$.

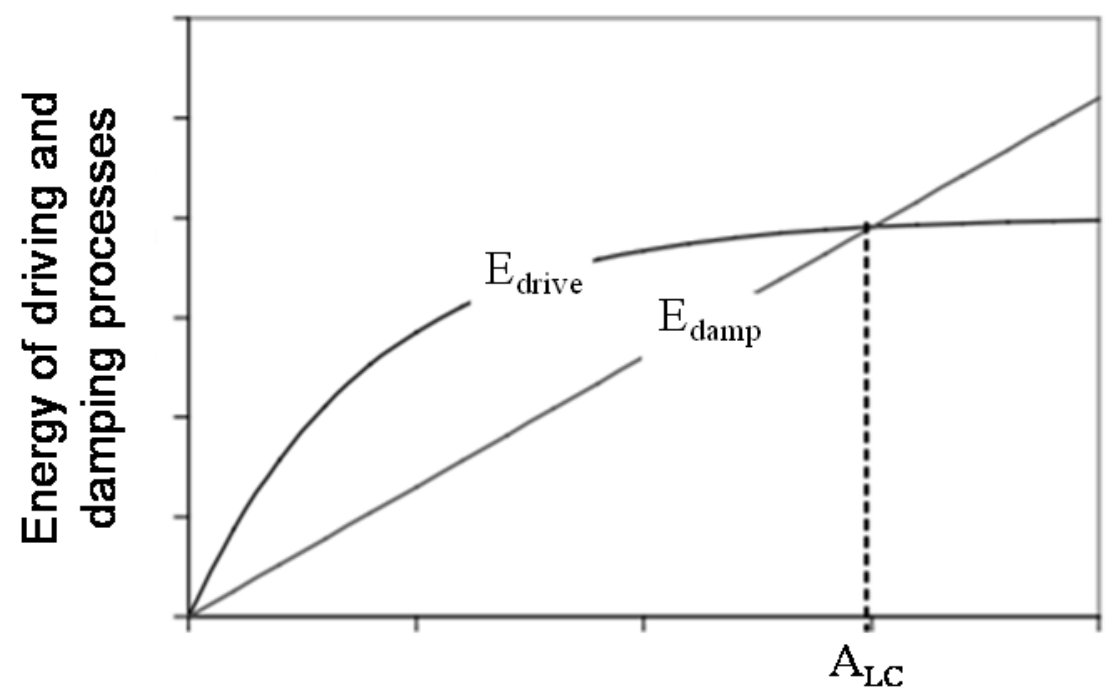

Forcing Amplitude, $\boldsymbol{A}$

Figure 1.3: Schematic illustrating the how the instability amplitude, $A$, affects the energy added and removed by acoustic driving $\mathbf{E}_{\mathrm{drive}}(A)$ and damping $\mathbf{E}_{\mathrm{damp}}(A)$, processes (Lieuwen, 2006) 


\subsubsection{Instability Mechanisms}

Further complexity to the problem of combustor oscillations is added by the presence of many different mechanisms responsible for oscillations. Heat release fluctuations can be caused by fluctuations in temperature, pressure, fuel composition, flame curvature, unsteady strain rate (Ducruix et al., 2003). In lean premixed gas turbines, common mechanisms driving heat release rate oscillations include fuel feed line coupling with pressure waves, equivalence ratio oscillations, flame area oscillations, and flame-vortex interactions (Zinn \& Lieuwen, 2005). Any perturbation that causes a change in flow rate, equivalence ratio, or flame area will affect the heat release rate. If this is coupled with pressure oscillations such that a feedback loop is established, combustion instabilities may arise.

A distinction should be made between the mechanisms described above that drive heat release rate oscillations and the coupling mechanism that creates a feedback loop leading to instabilities. The coupling mechanism is usually a pressure wave generated by the change in heat release rate (Ducruix et al., 2003). The various driving mechanisms all respond differently to changes in operating conditions or fuel composition (Allison \& Driscoll, 2012). Since these mechanisms are complex and may occur simultaneously in gas turbine combustors, it is important to gain understanding of their individual behaviour through controlled experiments.

\subsubsection{Predicting Instabilities}

The prediction of combustion instabilities requires an understanding of the underlying processes. Important characteristics of instabilities are the oscillation frequency, the conditions that result in instabilities, and the limit cycle amplitude (Zinn \& 
Lieuwen, 2005). Predicting the frequencies is done by studying the acoustics of a given combustor to determine its dynamic modes. Techniques for doing this are well developed as described by Dowling \& Stow (2005). Determining the conditions that cause instabilities requires an understanding of flame and flow interactions as well as the various instability mechanisms. Although this is more difficult, progress has been made with fundamental studies (Ducruix et al., 2003). Finally, the most challenging task is predicting the instability amplitudes (also referred to as limit cycle amplitudes), which would allow designers to determine if instabilities in a particular combustor can be tolerated.

Interest in new fuels introduces the variable of fuel composition. With fuels such as syngas and biogas, the variability in fuel composition highlights the importance of knowing the sensitivity of combustion instabilities to changes in fuel composition. Fuel composition will certainly affect the conditions that result in instabilities and as well as the limit cycle amplitudes. An understanding of how fuel composition affects important parameters such as flame position and structure, system time delays, as well as instability amplitudes is required. Current knowledge on this topic will be addressed in Chapter 2 .

\subsection{Flame Transfer Function Analysis}

Combustion instabilities are inherently a self-excited phenomenon. Two common methods of studying them are to either study self-excited flames or to examine the flame response to acoustic forcing. The first method is a more practically motivated, application driven approach used with more realistic combustors, whereas the acoustic forcing approach is typically used for fundamental studies on lab scale combustors. 
Acoustic forcing is typically applied using a loudspeaker or siren and allows the flame response to inlet velocity fluctuations to be studied quantitatively. To examine the flame response, the flame transfer function (FTF) is defined as the ratio of the normalized heat release rate fluctuation to the normalized velocity fluctuation

$$
H(f, A)=\frac{q^{\prime}(f, A) / \bar{q}}{v^{\prime}(f, A) / \bar{v}}
$$

where $\bar{q}$ and $\bar{v}$ are the mean heat release rate and flow velocity, and $q^{\prime}$ and $v^{\prime}$ are their respective fluctuating components at a given frequency. The transfer function, $H$ is a function of the forcing frequency $(f)$ and forcing amplitude $(A)$. It is typically a linear function of these variables at low forcing amplitudes, generally defined as less than 15$20 \%$ of the mean velocity (Balachandran et al., 2005; Ducruix et al., 2000).

\subsection{Motivation, Objectives and Outline of Thesis}

The problem of fuel composition for combustion instabilities is intensified due to emergence of alternative fuels such as syngas and biogas. As discussed with the literature review presented in Chapter 2, research in this area is scarce, especially in the context of syngas and biogas. The majority of experimental research has been on turbulent swirling flames. Consequently, a fundamental approach was chosen for this thesis to study the effect of flame composition on combustion instabilities using a simple acoustically forced laminar flat flame burner. A flat flame eliminates the complications of turbulence, flame curvature, and changes in flame area and allows a focus on how basic flame properties will affect the flame response. This thesis builds on the work done 
by Khanna (2001) on the flame response of methane, ethane, and propane, and considers syngas and biogas as fuels. Specific objectives were to:

- Build an experimental setup similar to the one used by Khanna (2001) to measure the FTF of a flat flame;

- Measure the FTF for a variety of methane, syngas, and biogas fuel mixtures and investigate the impact on the magnitude and phase of the FTF;

- Relate findings to physical processes; and

- Identify key parameters that control the dynamics of flat flames.

Chapter 2 provides a summary of the literature review conducted on the effect of fuel composition on combustion instabilities. A specific focus was placed on syngas and biogas fuels. Chapter 3 outlines the design of the flat flame burner, the implementation of various measurement techniques used, the testing procedure, as well as characterization and optimization of the system and measurement techniques. Chapter 4 presents the results of the flame response testing conducted in the form of trends in FTF magnitude and phase plots. Based on the results in Chapter 4, trends are explained and discussed in Chapter 5. An attempt is made to provide physical reasons for the trends observed. Chapter 6 draws conclusions, outlines lessons learned, and gives recommendations for future work. 


\section{Chapter 2}

\section{Literature Review: Effect of Fuel}

\section{Composition on Combustion Instabilities}

\subsection{Summary of Relevant Prior Investigations}

Table 2.1 summarizes several relevant studies that have considered the effects of fuel composition on combustion instabilities with a focus on premixed flames using gaseous fuels. Janus et al. (1997) studied self-excited combustion dynamics in a premixed swirl stabilized burner running on methane or propane with hydrogen addition. Stability maps were constructed showing the variation of the root mean square (RMS) of the pressure fluctuations with equivalence ratio and flow rate. Instabilities were found to stem from oscillations in the total flow rate. They concluded that the main influence of fuel composition on instabilities was its effect on the time delays in the system, i.e. advective, mixing, and reaction times. A change in fuel composition caused the instabilities to shift to different operating conditions. 
Table 2.1: Summary of Literature on the effect of fuel composition on combustion instabilities

\begin{tabular}{|c|c|c|c|c|c|c|}
\hline Author(s) & Flame & $\begin{array}{l}\text { Operating } \\
\text { Conditions }\end{array}$ & $\begin{array}{l}\text { Combustion } \\
\text { Instability } \\
\text { Mechanisms }\end{array}$ & Fuel & Forcing & Key Findings \\
\hline $\begin{array}{l}\text { Janus et al. } \\
(1997)\end{array}$ & Premixed swirl & $\begin{array}{l}\mathrm{v} \cong 16-35 \mathrm{~m} / \mathrm{s}^{\mathrm{a}} \\
\phi=0.65-1\end{array}$ & $\begin{array}{l}\text { Flow rate } \\
\text { fluctuations }\end{array}$ & $\begin{array}{l}\mathrm{NG}+\mathrm{H}_{2} \\
\mathrm{C}_{3} \mathrm{H}_{8}+\mathrm{H}_{2}\end{array}$ & Self-excited & $\begin{array}{l}\text { Presence of unstable oscillations is affected by temperature and fuel composition, } \\
\text { mainly through the time delays (advective, mixing, and reaction times) }\end{array}$ \\
\hline Khanna (2001) & $\begin{array}{l}\text { Premixed, } \\
\text { laminar flat } \\
\text { flame }\end{array}$ & $\begin{array}{l}\mathrm{v} \cong 0.042-0.06 \\
\mathrm{~m} / \mathrm{s}^{\mathrm{b}} \\
\phi=0.5-0.75\end{array}$ & $\begin{array}{l}\text { Heat transfer } \\
\text { oscillations }\end{array}$ & $\begin{array}{l}\mathrm{CH}_{4} \\
\mathrm{C}_{2} \mathrm{H}_{6} \\
\mathrm{C}_{3} \mathrm{H}_{8}\end{array}$ & Forced & $\begin{array}{l}\text { Flame response impacted by flow rate, equivalence ratio, and fuel. Fluctuating } \\
\text { heat transfer processes and reaction chemistry responsible for peak response. } \\
\text { Propane has lower damping than methane or ethane. }\end{array}$ \\
\hline $\begin{array}{l}\text { Wicksall and } \\
\text { Agrawal } \\
(2007)\end{array}$ & Premixed swirl & $\mathrm{v}=10 \mathrm{~m} / \mathrm{s}$ & Not specified & $\begin{array}{l}\mathrm{CH}_{4}+\mathrm{H}_{2} \\
\mathrm{C}_{3} \mathrm{H}_{8}+\mathrm{H}_{2}\end{array}$ & Self-excited & $\begin{array}{l}\text { Adding } \mathrm{H}_{2} \text { to } \mathrm{C}_{3} \mathrm{H}_{8} \text { and } \mathrm{CH}_{4} \text { increases sound power. Flame length decreases with } \\
\mathrm{H}_{2} \text { addition. Sound power proportional to } \mathrm{T}_{\mathrm{ad}}\end{array}$ \\
\hline $\begin{array}{l}\text { Ferguson et al. } \\
(2007)\end{array}$ & $\begin{array}{l}\text { Premixed, swirl } \\
\text { stabilized } \\
\text { AND } \\
\text { Ring stabilized }\end{array}$ & $\begin{array}{l}\mathrm{v}=1.5 \mathrm{~m} / \mathrm{s} \\
\phi=0.6-1.3 \\
\text { AND } \\
\mathrm{v}=20-30 \mathrm{~m} / \mathrm{s} \\
\phi=1 \text { iftoff- } 0.9\end{array}$ & Not specified & $\begin{array}{l}\mathrm{NG}+\mathrm{C}_{3} \mathrm{H}_{8}+ \\
\mathrm{N}_{2}\end{array}$ & Self-excited & $\begin{array}{l}\text { Heavy hydrocarbons impact dynamics, Wobbe index is not good indicator of } \\
\text { dynamics, small changes in composition do not significantly impact dynamics }\end{array}$ \\
\hline $\begin{array}{l}\text { Figura et al. } \\
(2007)\end{array}$ & $\begin{array}{l}\text { Premixed swirl } \\
\text { Variable length }\end{array}$ & $\begin{array}{l}\mathrm{v}=75-90 \mathrm{~m} / \mathrm{s} \\
\phi=0.5-0.75\end{array}$ & $\begin{array}{l}\text { Flame-vortex } \\
\text { interactions }\end{array}$ & $\mathrm{CH}_{4}+\mathrm{H}_{2}$ & Self-excited & $\begin{array}{l}\text { Adding } \mathrm{H}_{2} \text { shifts instability to lower equivalence ratios and weakens sound level. } \\
\text { Centre of heat release moves along fixed path characterized by stable and unstable } \\
\text { regions. }\end{array}$ \\
\hline $\begin{array}{l}\text { Lafay et al. } \\
(2007)\end{array}$ & Premixed swirl & $\begin{array}{l}\mathrm{v}=30 \mathrm{~m} / \mathrm{s} \\
\phi=0.66-0.84\end{array}$ & Not specified & $\begin{array}{l}\mathrm{CH}_{4} \\
\text { Biogas }\left(\mathrm{CH}_{4}\right. \\
\left.+\mathrm{CO}_{2}+\mathrm{N}_{2}\right) \\
\end{array}$ & Self-excited & $\begin{array}{l}\mathrm{CO}_{2} \text { addition to } \mathrm{CH}_{4} \text { affects flame structure. Dilution by } \mathrm{CO}_{2} \text { shifts instabilities to } \\
\text { higher equivalence ratios, laminar flame speed is a good predictor of transition } \\
\text { from stable to unstable modes }\end{array}$ \\
\hline $\begin{array}{l}\text { Lieuwen et al. } \\
(2008)\end{array}$ & $\begin{array}{l}\text { Review article } \\
\text { Various setups }\end{array}$ & N/A & $\begin{array}{l}\text { Equivalence ratio } \\
\text { oscillations, } \\
\text { Flame-vortex } \\
\text { interactions }\end{array}$ & $\begin{array}{l}\mathrm{CH}_{4}+\mathrm{H}_{2}+ \\
\mathrm{CO}\end{array}$ & - & $\begin{array}{l}\text { Mixture behaviour is different from individual constituent behaviour. Time delays } \\
\text { in unstable oscillations affected by combustion properties of fuel components. } \mathrm{H}_{2} \\
\text { properties differ significantly from other fuels }\end{array}$ \\
\hline $\begin{array}{l}\text { Altay et al. } \\
(2009)\end{array}$ & $\begin{array}{l}\text { Premixed step } \\
\text { combustor }\end{array}$ & $\begin{array}{l}\mathrm{v} \cong 5.1-6.7 \mathrm{~m} / \mathrm{s}^{\mathrm{c}} \\
\phi=0.4-0.95\end{array}$ & $\begin{array}{l}\text { Flame-vortex } \\
\text { interactions }\end{array}$ & $\mathrm{C}_{3} \mathrm{H}_{8}+\mathrm{H}_{2}$ & Self-excited & $\begin{array}{l}\text { Adding } \mathrm{H}_{2} \text { and increasing inlet temperature shifts transition from stable to } \\
\text { unstable modes, stability modes related to consumption speed and density change }\end{array}$ \\
\hline
\end{tabular}

Calculated from quoted air mass flow rate and burner diameter

${ }^{\mathrm{b}} \mathrm{Calculated}$ from quoted total volume flow rate and burner diameter

${ }^{\mathrm{c}}$ Calculated from quoted Reynolds number 
Table 2.1: Summary of Literature on the effect of fuel composition on combustion instabilities (continued)

\begin{tabular}{|c|c|c|c|c|c|c|}
\hline Author(s) & Flame & $\begin{array}{l}\text { Operating } \\
\text { Conditions }\end{array}$ & $\begin{array}{l}\text { Combustion } \\
\text { Instability } \\
\text { Mechanisms }\end{array}$ & Fuel & Forcing & Key Findings \\
\hline $\begin{array}{l}\text { Tuncer et al. } \\
(2009)\end{array}$ & Premixed swirl & $\begin{array}{l}\mathrm{v} \cong 6.3 \mathrm{~m} / \mathrm{s}^{\mathrm{d}} \\
\phi=0.6-1\end{array}$ & Flashback related & $\mathrm{CH}_{4}+\mathrm{H}_{2}$ & Self-excited & $\begin{array}{l}\mathrm{H}_{2} \text { addition shifts flame position closer to inlet plane and changes dominant } \\
\text { acoustic mode }\end{array}$ \\
\hline $\begin{array}{l}\text { Yilmaz et al. } \\
(2010)\end{array}$ & $\begin{array}{l}\text { Premixed low } \\
\text { swirl }\end{array}$ & $\begin{array}{l}\mathrm{v} \cong 3.5 \mathrm{~m} / \mathrm{s}^{\mathrm{e}} \\
\phi=0.5\end{array}$ & Flame-vortex interactions & $\mathrm{CH}_{4}+\mathrm{H}_{2}$ & Forced & $\begin{array}{l}\mathrm{H}_{2} \text { addition also results in a more compact flame. } \mathrm{H}_{2} \text { addition increases } \\
\text { coupling (in phase) at non-resonant frequencies but decreases coupling at } \\
\text { resonant frequency. }\end{array}$ \\
\hline $\begin{array}{l}\text { Kim and Park } \\
(2010)\end{array}$ & Premixed swirl & $\begin{array}{l}\mathrm{v}=25-38 \mathrm{~m} / \mathrm{s} \\
\phi=0.65-0.75\end{array}$ & Not specified & $\mathrm{NG}+\mathrm{H}_{2}$ & Forced & $\begin{array}{l}\mathrm{H}_{2} \text { addition affects flame geometry (flame centre moves towards burner) } \\
\text { which affects flame response. Flames with similar centre of mass have } \\
\text { similar response, regardless of fuel. }\end{array}$ \\
\hline $\begin{array}{l}\text { Kim et al. } \\
(2010)\end{array}$ & Premixed swirl & $\begin{array}{l}\mathrm{v}=60-100 \mathrm{~m} / \mathrm{s} \\
\phi=0.55-0.7\end{array}$ & Not specified & $\mathrm{NG}+\mathrm{H}_{2}$ & Forced & $\begin{array}{l}\mathrm{H}_{2} \text { addition causes change of flame shape from } \mathrm{V} \text { to } \mathrm{M} . \mathrm{M} \text { flames have } \\
\text { lower magnitude. Transfer function phase correlates well with Strouhal } \\
\text { number. }\end{array}$ \\
\hline $\begin{array}{l}\text { Hussain et al. } \\
\text { (2011) }\end{array}$ & $\begin{array}{l}\text { Premixed and } \\
\text { partially } \\
\text { premixed, } \\
\text { bluff body } \\
\text { stabilized }\end{array}$ & $\begin{array}{l}\mathrm{v}=9.9 \mathrm{~m} / \mathrm{s} \\
\phi=0.8\end{array}$ & Flame-vortex interactions & $\mathrm{CH}_{4}+\mathrm{H}_{2}$ & Forced & $\begin{array}{l}\text { Local } \mathrm{H}_{2} \text { addition decreased flame response at low frequencies, while adding } \\
\mathrm{H}_{2} \text { to a premixed } \mathrm{CH}_{4} \text { flame increases flame response at high frequencies }\end{array}$ \\
\hline $\begin{array}{l}\text { Zhang et al. } \\
(2012)\end{array}$ & Premixed swirl & $\begin{array}{l}\mathrm{v} \cong 22-45 \mathrm{~m} / \mathrm{s}^{\mathrm{f}} \\
\phi=0.1-0.9\end{array}$ & $\begin{array}{l}\text { Flame-vortex interactions } \\
\text { among others unspecified }\end{array}$ & $\begin{array}{l}\mathrm{CH}_{4}+\mathrm{H}_{2} \\
+\mathrm{CO}+ \\
\mathrm{N}_{2}\end{array}$ & Self-excited & $\begin{array}{l}\mathrm{H}_{2} \text { addition increases instability frequency, adding } \mathrm{H}_{2} \text { and } \mathrm{CO} \text { affect flame } \\
\text { shape significantly. Adding } \mathrm{N}_{2} \text { to } \mathrm{H}_{2} \text { decreases sound level and instability } \\
\text { frequency. }\end{array}$ \\
\hline $\begin{array}{l}\text { Allison et al. } \\
\text { (2012) }\end{array}$ & $\begin{array}{l}\text { Partially } \\
\text { premixed swirl }\end{array}$ & $\begin{array}{l}\mathrm{v} \cong 5-10 \mathrm{~m} / \mathrm{s}^{\mathrm{f}} \\
\phi=0.65-1.2\end{array}$ & $\begin{array}{l}\text { Flame-vortex interactions, } \\
\text { Helmholtz type } \\
\text { instabilities, } \\
\text { Organ tone resonances, } \\
\text { Fluid mechanical switching }\end{array}$ & $\begin{array}{l}\mathrm{C}_{3} \mathrm{H}_{8} \\
\text { Ethylene } \\
\text { Syngas } \\
\left(\mathrm{H}_{2}+\right. \\
\mathrm{CO})\end{array}$ & Self-excited & $\begin{array}{l}\text { Syngas flame dynamics differed from those of hydrocarbon fuels, even at } \\
\text { similar flame speeds. Several instability mechanisms thought to be present, } \\
\text { with flame speed, flame liftoff height, and flow speed all being important } \\
\text { parameters depending on the mechanism. High } \mathrm{H}_{2} \text { flames resulted attached } \\
\text { to the burner inlet and were quieter overall }\end{array}$ \\
\hline
\end{tabular}

Calculated from quoted total volume flow rate and burner diameter

${ }^{\mathrm{e}}$ Obtained from Huang \& Ratner (2009), an earlier paper from the same research group with details of the experimental setup and test conditions

${ }^{\mathrm{f}} \mathrm{Calculated}$ from quoted air mass flow rate and burner diameter 
Khanna (2001) studied the response of a laminar flat flame to acoustic forcing using pure methane, propane, and ethane as fuels. The flame transfer function was measured as a ratio of the fluctuating heat release rate measured via $\mathrm{OH}^{*}$ chemiluminescence and the fluctuating velocity measured via the two microphone technique. The two microphone technique is described in Appendix C. Fuel was found to have an impact on both the magnitude and phase of the flame response. Overall, propane exhibited higher flame transfer function magnitudes than methane for all conditions studied. The transfer function magnitudes of ethane flames compared to those of methane were lower at some equivalence ratios and forcing frequencies, but higher at others. Khanna (2001) observed two distinct instability mechanisms. A primary mechanism was found at lower frequencies, due to oscillations in the flame speed associated with unsteady conductive heat transfer from the flame to the honeycomb used to stabilize the flame. A secondary mechanism at higher frequencies resulting in lower transfer function magnitudes was attributed to oscillations in the reaction rate. Through modelling of the same burner, Chatterjee (2004) investigated the primary mechanism responsible for instabilities in more detail and showed that the most probable cause of heat release rate oscillations was actually fluctuations in the reactant gas temperature caused by unsteady convective heat transfer.

Wicksall \& Agrawal (2007) studied combustion dynamics with a self-excited premixed swirl stabilized flame using propane and methane as the base fuels. For methane and propane flames, it was found that the sound level increased proportionally with the adiabatic flame temperature and that hydrogen addition increased the sound level 
at a fixed adiabatic flame temperature. Hydrogen addition was also found to reduce the length of propane or methane flames.

Ferguson et al. (2007) studied self-excited combustion dynamics in a lab scale, atmospheric pressure combustor using a mixture of natural gas, propane, and nitrogen as fuel. They found that small variations in hydrocarbon concentration did not significantly affect the combustion dynamics. However, adding significant amounts of heavier hydrocarbons such as propane did affect the dynamics. The authors also compared different fuel mixtures in terms of the Wobbe index, a parameter often used as a measure of how easily fuels can be swapped for a given combustor configuration. As shown in Equation (2.1), Wobbe index is a function of the lower heating value (LHV), specific gravity $(\mathrm{SG})$, fuel temperature $\left(\mathrm{T}_{\text {fuel }}\right)$, and standard temperature $\left(\mathrm{T}_{\text {std }}\right)$. Fuel mixtures with a similar Wobbe index were found to exhibit different combustion dynamics. As a result it was concluded that the Wobbe index was not a good indicator of variation in combustion dynamics among fuels.

$$
\text { Wobbe Index }=\frac{L H V}{\sqrt{S G}} \sqrt{\frac{T_{\text {std }}}{T_{\text {fuel }}}}
$$

Figura et al. (2007) studied self-excited premixed swirl stabilized flames running on a mixture of methane and hydrogen in a variable length combustor. By varying the combustor length, stable combustion was always achievable, allowing stable flame images to be captured. As shown in Figure 2.1 the flame centre of heat release (COHR, measured with 2D CH* chemiluminescence flame imaging) was found to move along a fixed path as the operating conditions and fuel composition changed (Figura et al., 2007). 
Flames with a similar COHR exhibited the same flame structure and were associated with stable or unstable conditions, regardless of the operating conditions or fuel composition. The primary instability mechanism was found to be flame-vortex interactions. Hydrogen addition resulted in shorter flames and shifted the instabilities to lower equivalence ratios, causing the instabilities to weaken. The lower sound levels of hydrogen flames were attributed to a lower heat release per unit volume due to the presence of hydrogen and operation at low equivalence ratios.

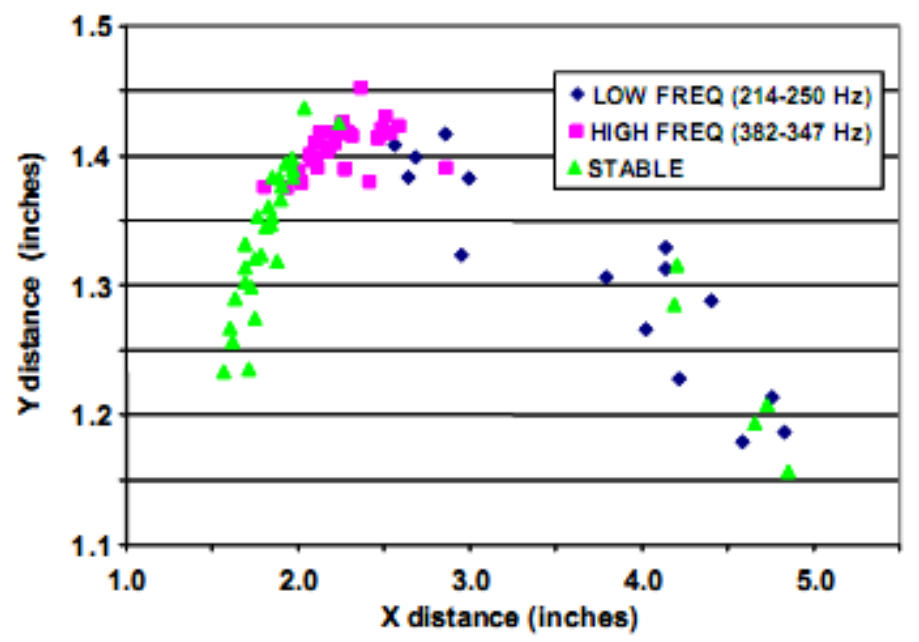

Figure 2.1: Stability characteristics along flame centre of heat release (Reproduced from Figura et al. 2007)

Lafay et al. (2007) studied self-excited methane and biogas (methane + carbon dioxide + nitrogen) flames in a premixed swirl stabilized combustor. The addition of carbon dioxide to methane flames was found to alter the flame structure and shift instabilities to higher equivalence ratios. Changes in laminar flame speed were observed to have a significant effect on the flame structure and dynamics. The sensitivity of the laminar flame speed to equivalence ratio, $\delta=\partial S_{L}^{0} / \partial \phi$ was also found to affect the 
amplitude of instabilities. An increase in carbon dioxide concentration caused a decrease in $\delta$, implying that carbon dioxide had a stabilizing effect on instabilities.

Lieuwen et al. (2008) conducted a review of the effect of fuel composition on combustor operation issues. They concluded that fuel composition has an effect on instabilities through time delays. These delays include the chemical time, which is directly affected by fuel composition through the reaction rate, and the advective time, which is mainly affected through the influence of flame speed on the location of the flame centre of mass (same as flame centre of heat release). They further observed that parameters influencing dynamics such as laminar flame speed, turbulent flame speed, and kinetic times vary non-linearly with fuel composition. Figure 2.2 shows laminar flame speeds of methane/hydrogen/carbon monoxide fuel mixtures at a fixed flame temperature of $1500 \mathrm{~K}$ (Lieuwen et al., 2008). The fuel composition is determined by the location of the point inside the triangle. This plot highlights the complex non-linear relationship between laminar flame speed and fuel composition. In addition, Figure 2.3a shows the variation in turbulent flame speed for various fuel mixtures as the turbulence intensity is increased (Kido et al., 2002). The legend for the fuel blends is shown in Figure 2.3b. The convergence of the curves to the same point at a turbulence intensity of 0 shows that the various mixtures have similar laminar flame speeds. However, they have different turbulence sensitivities, meaning that the turbulent flame speed of each mixture is affected differently by changes in the turbulence intensity. As an example, the fuels M07, $\mathrm{P} 07$, and $\mathrm{H} 07$ are methane, propane, and hydrogen diluted with varying amounts of nitrogen at the same equivalence ratio. The hydrogen mixture has a significantly higher turbulence sensitivity than methane or propane. 


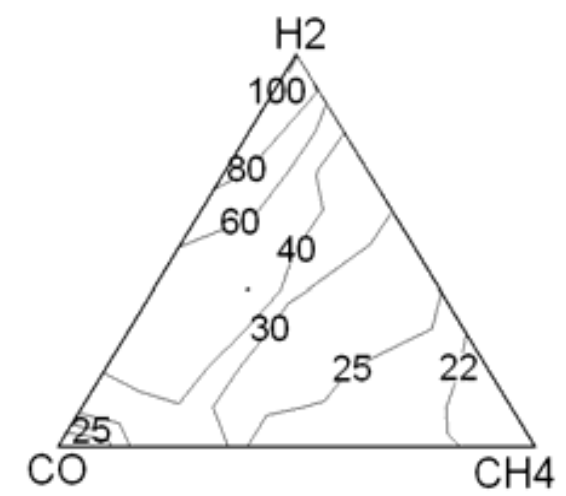

Figure 2.2 : Laminar flame speeds of $\mathrm{H2} / \mathrm{CO} / \mathrm{CH} 4$ mixtures at Tad of $1500 \mathrm{~K}, \mathrm{P}=$ $4.4 \mathrm{~atm}$, and $460 \mathrm{~K}$ reactant temperature (Reproduced from Lieuwen et al., 2008)

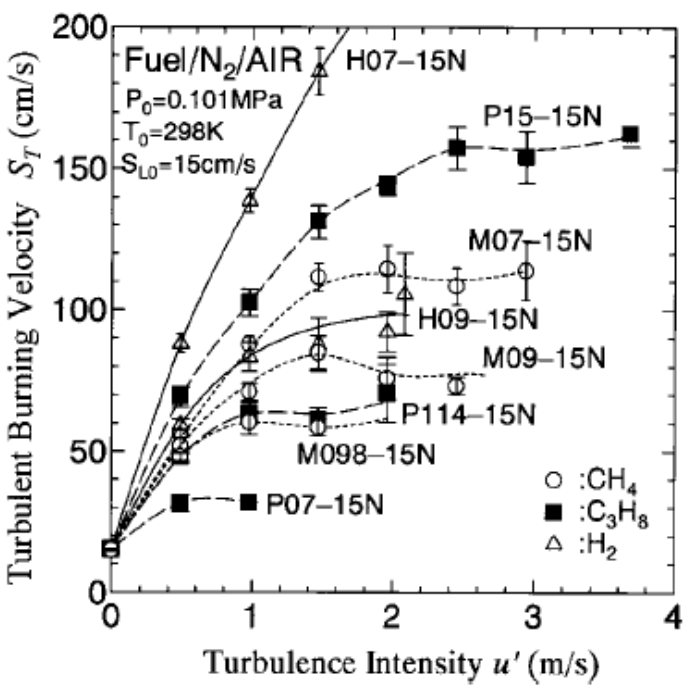

a)

\begin{tabular}{|c|c|c|c|c|c|}
\hline \multirow{2}{*}{ Mixture } & \multicolumn{3}{|c|}{ Molar Fraction } & \multirow{2}{*}{$\phi$} & \multirow{2}{*}{$\begin{array}{c}S_{L}^{0} \\
(\mathrm{~cm} / \mathrm{s})\end{array}$} \\
\hline & Fuel & $\mathrm{O}_{2}$ & $\mathbf{N}_{2}$ & & \\
\hline $\mathrm{H} 07-15 \mathrm{~N}$ & $\mathrm{H}_{2}$ & 0.71 & 7.14 & 0.7 & 15.26 \\
\hline $\mathrm{H} 09-15 \mathrm{~N}$ & $\mathrm{H}_{2}$ & 0.56 & 6.94 & 0.9 & 15.88 \\
\hline $\mathrm{M} 07-15 \mathrm{~N}$ & $\mathrm{CH}_{4}$ & 2.86 & 11.17 & 0.7 & 15.10 \\
\hline M09-15N & $\mathrm{CH}_{4}$ & 2.22 & 10.82 & 0.9 & 14.91 \\
\hline M098-15N & $\mathrm{CH}_{4}$ & 2.04 & 10.51 & 0.98 & 14.84 \\
\hline $\mathrm{P} 07-15 \mathrm{~N}$ & $\mathrm{C}_{3} \mathrm{H}_{8}$ & 7.14 & 29.05 & 0.7 & 14.94 \\
\hline P114-15N & $\mathrm{C}_{3} \mathrm{H}_{8}$ & 4.39 & 23.82 & 1.14 & 15.34 \\
\hline P15-15N & $\mathrm{C}_{3} \mathrm{H}_{8}$ & 3.33 & 13.70 & 1.5 & 14.99 \\
\hline
\end{tabular}

b)

Figure 2.3: (a) Dependence of turbulent flame speed upon turbulence intensity for various fuel blends with the same laminar flame speed (Reproduced from Kido et al., 2002); (b) Description of fuel mixtures

Altay et al. (2009) studied naturally excited instabilities in a step combustor using a propane-hydrogen mixture for fuel. Flame vortex interactions were found to be the main cause of instabilities. Increasing the inlet temperature or hydrogen concentration influenced the dynamic modes, shifting the transition from stable to unstable modes to 
lower equivalence ratios. A heat release rate parameter, $S_{c}\left(\frac{\rho_{u}}{\rho_{b}}-1\right)$, was found to be a good predictor of this transition. Here, $S_{c}$ is the consumption speed, which is a measure of the flame speed for a strained flame, while $\rho_{u}$ and $\rho_{b}$ are the densities of the unburned and burned gases respectively. This is shown in Figure 2.4 which plots the overall sound level curves against the heat release rate parameter (Altay et al., 2009).

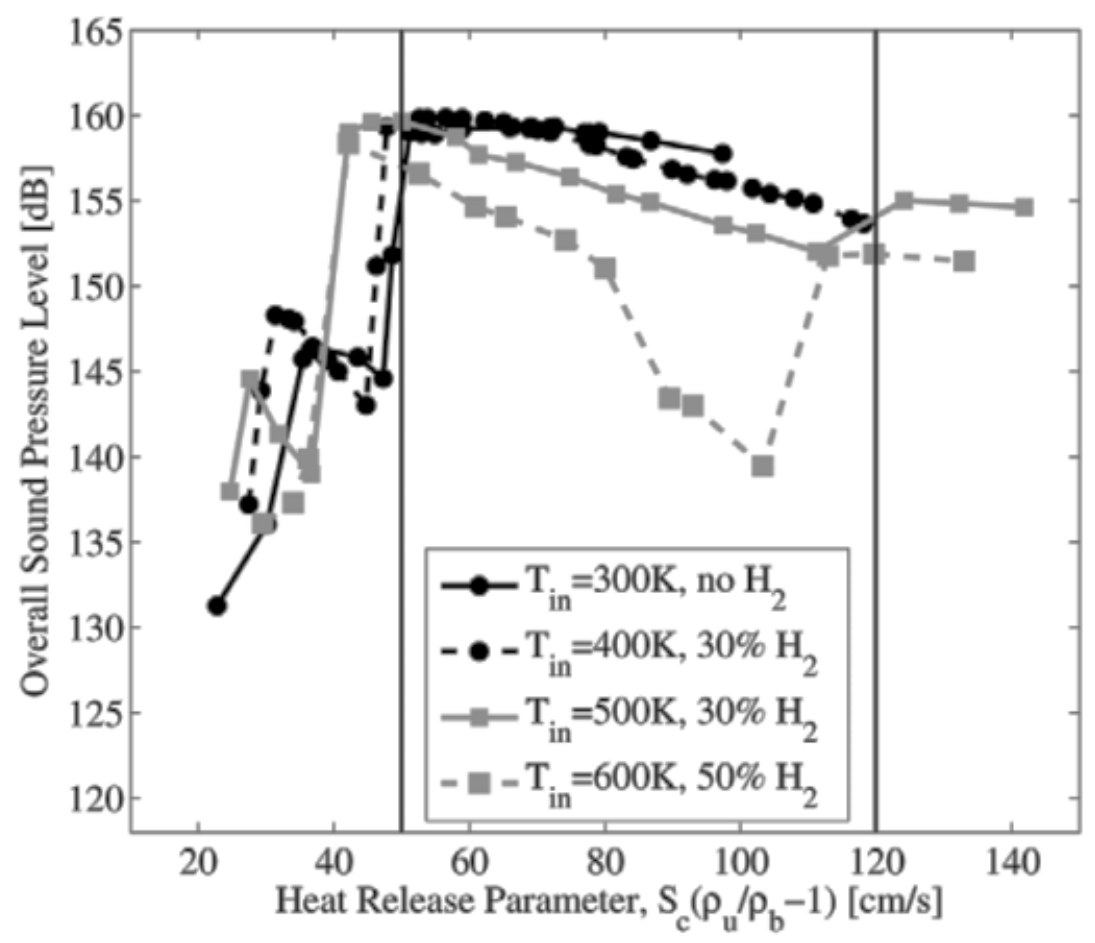

Figure 2.4: Overall sound pressure level as a function of heat release rate parameter, $S_{c}\left(\rho_{u} / \rho_{b}-1\right)$, at different hydrogen concentrations and inlet temperatures (Reproduced from Altay et al., 2009)

Tuncer et al. (2009) studied naturally excited instabilities in a premixed swirl stabilized combustor running on a mixture of methane and hydrogen. Hydrogen addition was found to shift the flame centre of mass closer to the combustor inlet. It also shifted 
the dominant acoustic mode to lower frequencies due to a coupling between an acoustic mode of the combustor and periodic flashback.

Yilmaz et al. (2010) performed acoustic forcing experiments on a low swirl burner using various mixtures of methane and hydrogen as fuel. They excited the flame at several frequencies in the range of 85 to $400 \mathrm{~Hz}$ and measured the variation of pressure and $\mathrm{OH}$ concentration in time. The flame response was calculated based on the Rayleigh index as a ratio of the $\mathrm{OH}^{*}$ chemiluminescence and pressure oscillations. They found that the addition of hydrogen increased flame response at non-resonant frequencies but reduced the response at the resonant frequency. Hydrogen addition also resulted in a more compact flame and shifted the coupling of pressure and heat release rate closer to the flame base. Coupling implies that the pressure and heat release rate oscillations are in phase. Flame-vortex interactions were found to be the main cause of instability.

Kim \& Park (2010) studied forced natural gas and hydrogen flames in a premixed swirl stabilized combustor. A flame transfer function was calculated using as a ratio of the normalized heat release rate to the normalized fluctuating velocity, as measured by a photomultiplier tube $\left(\mathrm{OH}^{*}\right.$ chemiluminescence) and hot wire anemometer respectively. The transfer function magnitude and phase were found to vary with fuel composition for fixed operating conditions. Similar to Figura et al. (2007), they also found that the flame centre of mass followed a fixed path as the conditions and fuel composition changed.

Kim et al. (2010) studied the effect of hydrogen addition on the flame response of acoustically forced methane flames in a premixed swirl stabilized burner. Hydrogen addition was found to change the flame shape from a V to an M. M-shaped flames were 
more stable and exhibited higher damping in the flame transfer function. A Strouhal number was defined as $S t=f L_{C H^{*} \max } / \bar{v}$, where $f$ is the frequency, $L_{C H^{*} \max }$ is the flame length, and $\bar{v}$ is the mean flow velocity. The Strouhal number represents the ratio of the advective period $\left(L_{C H^{*} \max } / \bar{v}\right)$ to the acoustic period $(1 / f)$ and characterized the phase of the flame transfer function well. The magnitude of the flame transfer function was determined by the Strouhal number along with the flame length and angle.

Hussain et al. (2011) studied the effect of local and global hydrogen addition on the response of a forced methane flame in a bluff body stabilized combustor. Local addition was done by injecting hydrogen directly into the flame through a pilot fuel injector, while global addition was done by premixing hydrogen with methane upstream of the flame. Local hydrogen addition decreased the flame response amplitude at low frequencies, while global hydrogen addition to a premixed methane flame increased the amplitude at high frequencies. Instabilities were found to be caused by flame-vortex interactions.

Zhang et al. (2012) studied naturally occurring instabilities in a premixed swirl stabilized combustor. Several fuel mixture combinations of methane, hydrogen, carbon monoxide and nitrogen were used. Varying the fuel composition affected the dominant acoustic mode and flame structure significantly. Flames running on hydrogen or a mixture of hydrogen and carbon monoxide closely resembled a jet flame. Increasing the hydrogen concentration in a methane flame increased the instability frequency and created a shorter flame, as shown in Figure 2.5 (Zhang et al., 2012). Adding nitrogen to a hydrogen flame decreased the sound level and instability frequency. Flame-vortex interactions were found to be involved in at least some of the cases studied. 


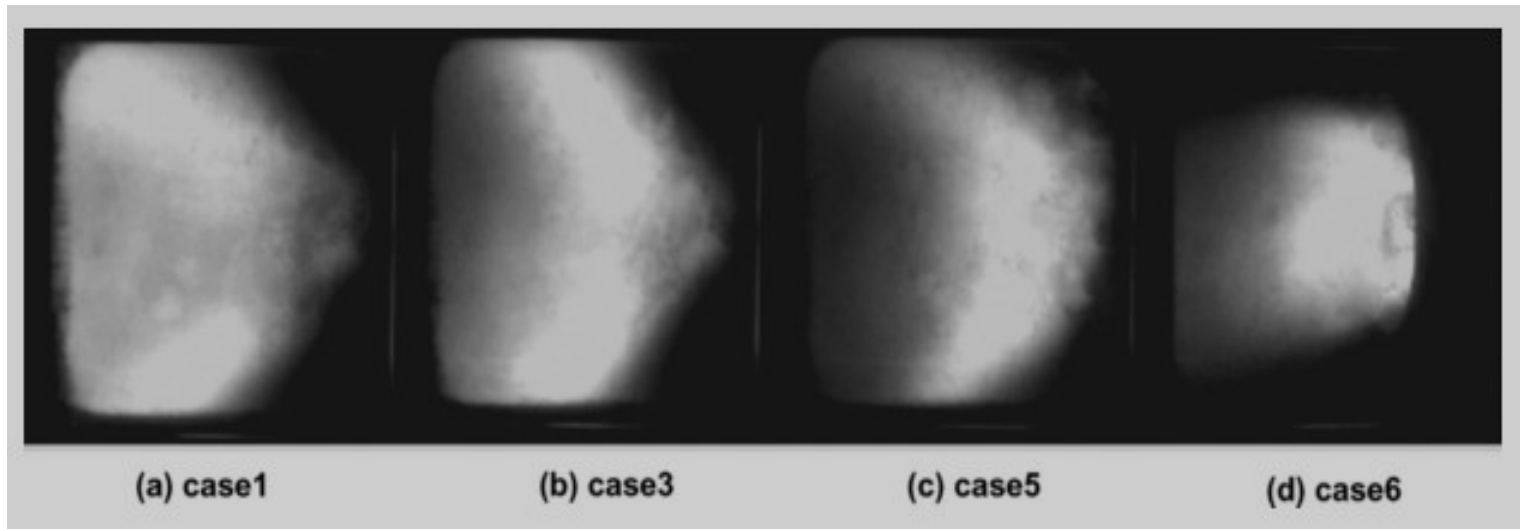

Figure 2.5: Stable flame images with increasing $\mathrm{H}_{2}$ concentration from (a) to (d) (Reproduced from Zhang et al. 2012)

Allison \& Driscoll (2012) studied naturally excited flames in a partially premixed model gas turbine combustor using propane, ethylene, and syngas (hydrogen and carbon monoxide). Equivalence ratio, flow rate, air temperature, fuel type, and burner geometry were varied. Syngas flame dynamics differed from those of hydrocarbon fuels, even at similar flame speeds. Several instability mechanisms were thought to be present (Helmholtz, convective-acoustic, fluid switching), with flame speed, flame liftoff height, and flow speed all being important parameters affecting instabilities depending on the mechanism. Flames with high hydrogen concentrations became anchored to the burner and were quieter overall.

\subsection{General Observations from Cited Literature}

Multiple authors have observed that adding hydrogen to premixed swirl stabilized flames fueled by methane, propane, or ethylene reduces flame length and causes the flame to move closer to the burner exit (Yilmaz et al., 2010; Zhang et al., 2012; Wicksall \& Agrawal, 2007; Tuncer et al., 2009; Kim et al., 2010; Kim \& Park, 2010; Figura et al., 
2007; Allison \& Driscoll, 2012). This is a direct result of the high mixture flame speed of fuels containing hydrogen, which itself has a very high flame speed. The effect of the flame movement on combustion instabilities is to alter the advective time delays present in the system. Kim et al. (2010) found that hydrogen addition caused the flame shape to change from a V to M. Meanwhile Zhang et al. (2012) found that hydrogen/carbon monoxide fuel mixtures created a jet flame, while natural gas and hydrogen flames were conical in shape.

Hydrogen addition to methane flames has been found to shift the dynamic mode (instability frequency), but there was disagreement on the direction of the shift. Altay et al. (2009) and Figura et al. (2007) found that hydrogen addition caused instabilities to occur at lower equivalence ratios for flame-vortex interaction driven instabilities. Allison \& Driscoll (2012) and Zhang et al. (2012) found that adding hydrogen to natural gas or propane flames increased the instability frequency. Meanwhile, Tuncer et al. (2009) observed the opposite effect due to the appearance of periodic flashback. Zhang et al. (2012) also found that nitrogen addition to hydrogen flames decreased the frequency of instabilities, and that hydrogen/carbon monoxide flames exhibited instabilities at low frequencies due to vortex shedding caused by the jet flame characteristic of this fuel combination. The effect of fuel composition on instability frequencies is dependent on the mechanisms involved.

The overall sound level is also affected by the fuel, but the specific trends are highly dependent on the fuel, burner, and operating conditions. Wicksall \& Agrawal (2007) found that hydrogen addition increased sound power, while Figura et al. (2007) saw lower sound power with hydrogen addition. Kim et al. (2010) found that hydrogen 
caused $\mathrm{V}$ flames to change shape to $\mathrm{M}$ flames, which resulted in lower transfer function amplitudes for a forced flame. Furthermore, the results of Allison \& Driscoll (2012) show that the effect of hydrogen addition varies depending on the equivalence ratio and flow rate. For instabilities involving advective time delays, such as flame-vortex interactions, the shift of instabilities to lower equivalence ratios means that less energy is available and thus the sound level will be lower.

The preceding review suggests that fuel composition affects combustion instabilities in a number of complex ways through changes in combustion parameters such as reaction rate and flame speed which affect the flame position and shape. The effect of these changes on the behavior of instabilities is dependent on the operating conditions and driving mechanisms. This has made it difficult to find trends and correlations that are widely applicable. Predicting instability amplitudes is particularly difficult due to the complexity of limit cycles and damping mechanisms present in gas turbine combustors. Studying the effect of fuel composition on time delays is simpler. Time delays play a key role in combustion dynamics and are influenced by fuel through changes in flame centre of mass and reaction rates. This is especially true of instabilities involving flame-vortex interactions and equivalence ratio oscillations that are advective in nature and thus affected by flame position. 


\section{Chapter 3}

\section{Experimental Setup}

\subsection{Overview of Experimental Setup}

The experimental setup for measuring the flame transfer function (FTF) with a flat flame burner is shown in photographs in Figure 3.1a,b and schematically in Figure 3.2. The burner used in this thesis was designed to produce a laminar flat flame thermally stabilized above a ceramic honeycomb and enclosed by a vertical quartz tube. Thermal mass flow controllers were used to set and read the fuel and air flow rates. Acoustic forcing was provided via a speaker attached to the bottom of the burner and powered by a function generator and amplifier. Various diagnostics were used to measure the velocity fluctuation, heat release rate fluctuation, flame liftoff distance, ambient pressure, and ambient temperature. Velocity fluctuations were initially measured using the two microphone technique as further detailed in Appendix C. A switch was made to using laser Doppler velocimetry (LDV) after errors were found with the two microphone technique attributed to heating of the microphones during experiments. A photomultiplier tube with optical filters was used to measure $\mathrm{OH}^{*}$ and $\mathrm{CH}^{*}$ chemiluminescence to obtain estimates of the heat release rate. The flame liftoff distance was measured using a digital camera and ambient pressure and temperature were measured with an Omega iBTX sensor. The burner and diagnostic equipment were situated in a darkened test chamber (as shown in Figure 3.1a,b) to reduce the amount of ambient light entering the 
photomultiplier tube. All peripheral electronics and flow controllers remained outside the darkened test chamber.

(a)

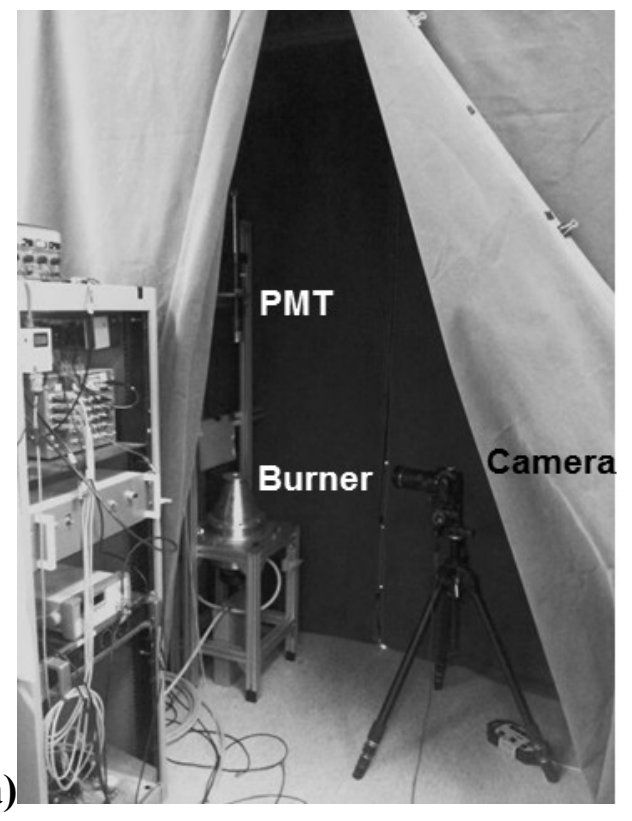

(b)

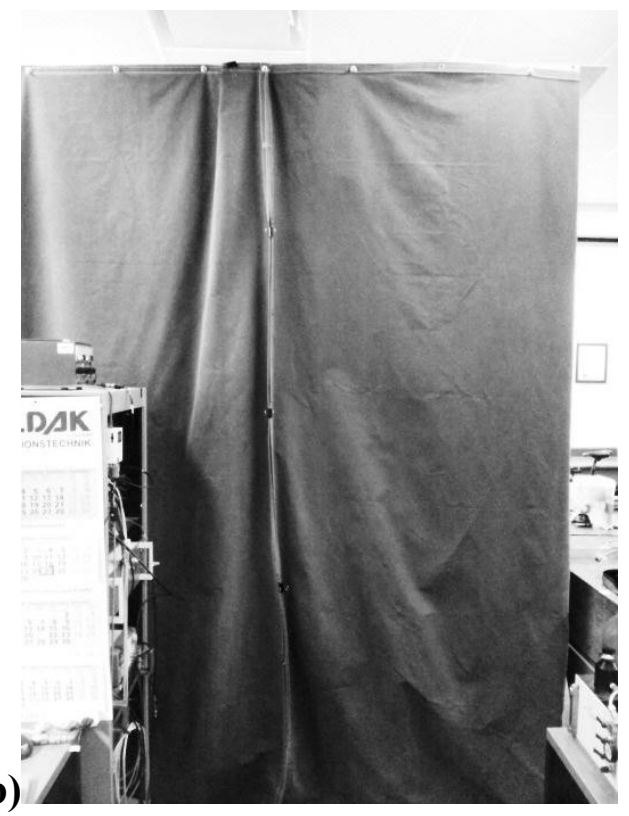

Figure 3.1: Photographs of test chamber used in experiments. (a) open test chamber revealing burner and camera, and (b) closed test chamber as seen during experiments. 


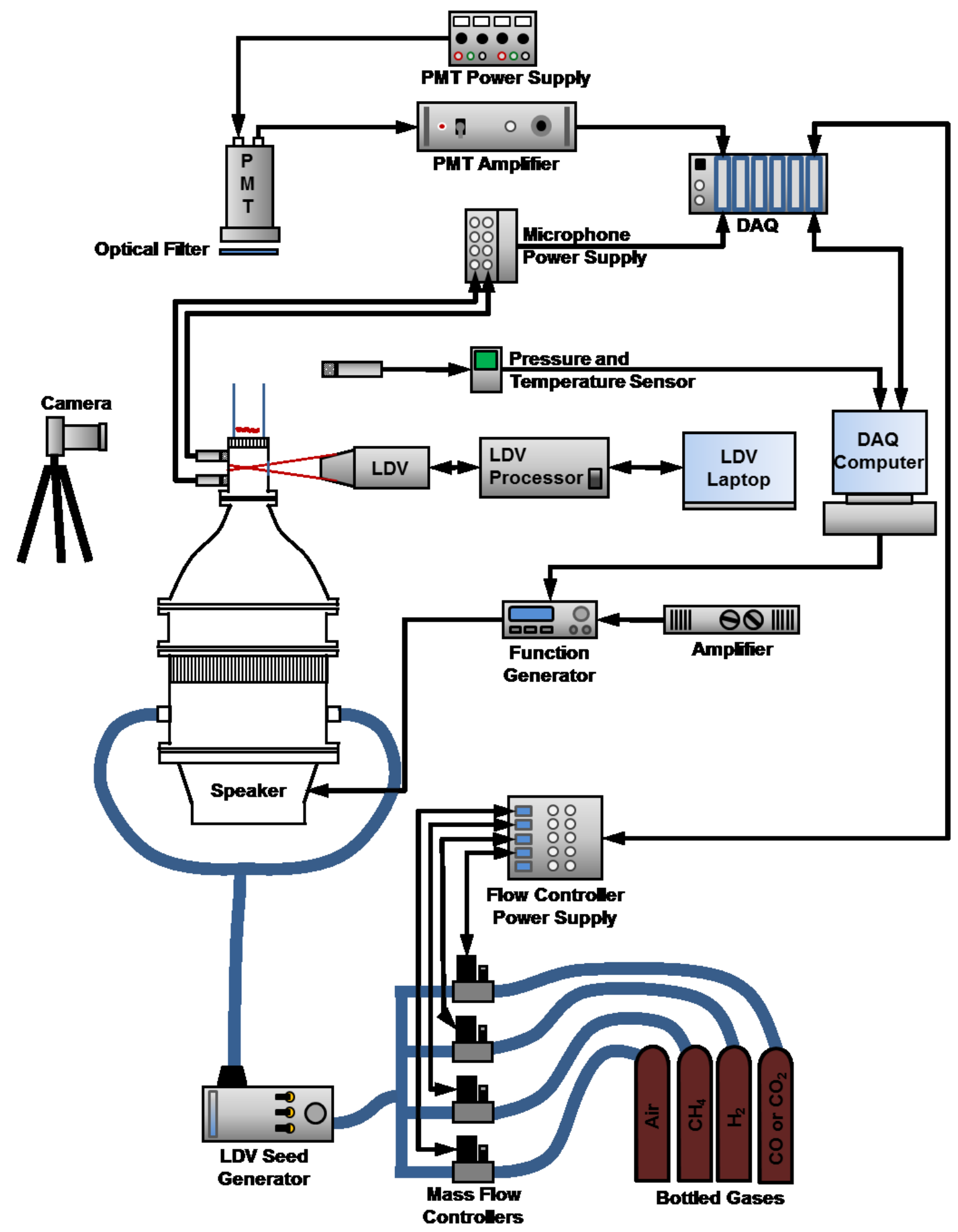

Figure 3.2: Schematic of the acoustically forced, flat-flame experiment 


\subsection{Flat Flame Burner}

Figure 3.3 shows an image of the flat flame burner. The burner consists of a speaker, injection section, flow conditioning section, contraction section, and a head. The head houses the ceramic honeycomb and allows mounting of the thermocouples and microphones. Premixed fuel and air are injected through two side ports located near the bottom of the burner. The fuel-air mixture then flows through an aluminum honeycomb and screen to reduce turbulence. The aluminum honeycomb has a diameter of $19.05 \mathrm{~cm}$ and thickness of $5.08 \mathrm{~cm}$. Its hexagonal cells have walls that are $0.1 \mathrm{~mm}$ thick and $1.85 \mathrm{~mm}$ long resulting in a porosity of approximately $90 \%$. The screen is a square mesh with a $0.14 \mathrm{~mm}$ wire diameter, $0.457 \mathrm{~mm}$ wide square, and a porosity of $59 \%$. The flow then enters a contraction section that reduces the diameter of the burner from $17.78 \mathrm{~cm}$ to $5.08 \mathrm{~cm}$. The contraction section was designed as per recommendations in Tavoularis (2005). It has a length of $18.42 \mathrm{~cm}$, an area ratio of 12.25 which exceeds the recommended minimum of 10 , and the inflection point of the curve defining the shape of the contraction is located $12.19 \mathrm{~cm}$ from the side with the larger opening. The length to maximum diameter ratio of 1 is lower than the recommended value of 1.5. This was chosen due to anticipated height constraints in the facility. Important burner dimensions are summarized in Table 3.1. 
Table 3.1: Burner Part Dimensions

\begin{tabular}{|c|c|}
\hline Part & Dimensions \\
\hline $\begin{array}{l}\text { Aluminum } \\
\text { honeycomb }\end{array}$ & $\begin{array}{l}\text { Diameter: } 19.05 \mathrm{~cm}, \\
\text { Thickness: } 5.08 \mathrm{~cm}, \\
\text { Hexagonal cells: } 1.85 \mathrm{~mm} \text { hexagon side length, } \\
\text { Cell wall thickness: } 0.1 \mathrm{~mm} \text {, } \\
\text { Porosity: } 90 \%\end{array}$ \\
\hline Wire screen & $\begin{array}{l}\text { Wire diameter: } 0.14 \mathrm{~mm} \text {, } \\
\text { Square cells: } 0.456 \mathrm{~mm} \text { wide, } \\
\text { Porosity: } 59 \%\end{array}$ \\
\hline $\begin{array}{l}\text { Contraction } \\
\text { section }\end{array}$ & $\begin{array}{l}\text { Length: } 18.42 \mathrm{~cm} \text {, } \\
\text { Area ratio: } 12.25 \text {, } \\
\text { Length: maximum diameter ratio }=1\end{array}$ \\
\hline $\begin{array}{l}\text { Ceramic } \\
\text { honeycomb }\end{array}$ & $\begin{array}{l}\text { Diameter: } 53.3 \mathrm{~mm} \text {, } \\
\text { Thickness: } 16.5 \mathrm{~mm} \text {, } \\
\text { Square channels: } 1.1 \mathrm{~mm} \text { wide, } \\
\text { Wall thickness: } 0.2 \mathrm{~mm} \text {, } \\
\text { Porosity: } 72 \%\end{array}$ \\
\hline Quartz tube & $\begin{array}{l}\text { Length: } 12.7 \mathrm{~cm} \text {, } \\
\text { Outer diameter: } 57 \mathrm{~mm} \text {, } \\
\text { Inner diameter: } 52.85 \mathrm{~mm}\end{array}$ \\
\hline
\end{tabular}

At the exit of the burner, the ceramic honeycomb shown in Figure 3.4 acts as a flame stabilizer. Due to the low flow velocity of the fuel air mixture $(5-7 \mathrm{~cm} / \mathrm{s})$ the flame would be unable to stabilize at the burner exit if a flame holder were not present. The honeycomb acts as a heat sink for the flame, reducing the flame speed so that it matches the oncoming flow velocity, allowing the flame to stabilize above the honeycomb. This flame liftoff distance depends on the fuel, flow velocity, and equivalence ratio for a given burner setup. The honeycomb is $53.3 \mathrm{~mm}$ in diameter, $16.5 \mathrm{~mm}$ thick with $1.1 \mathrm{~mm}$ square channels with $0.2 \mathrm{~mm}$ thick channel walls. This corresponds to an open area of approximately $72 \%$. The large porosity was chosen to minimize attenuation of the sound waves generated by the speaker. 


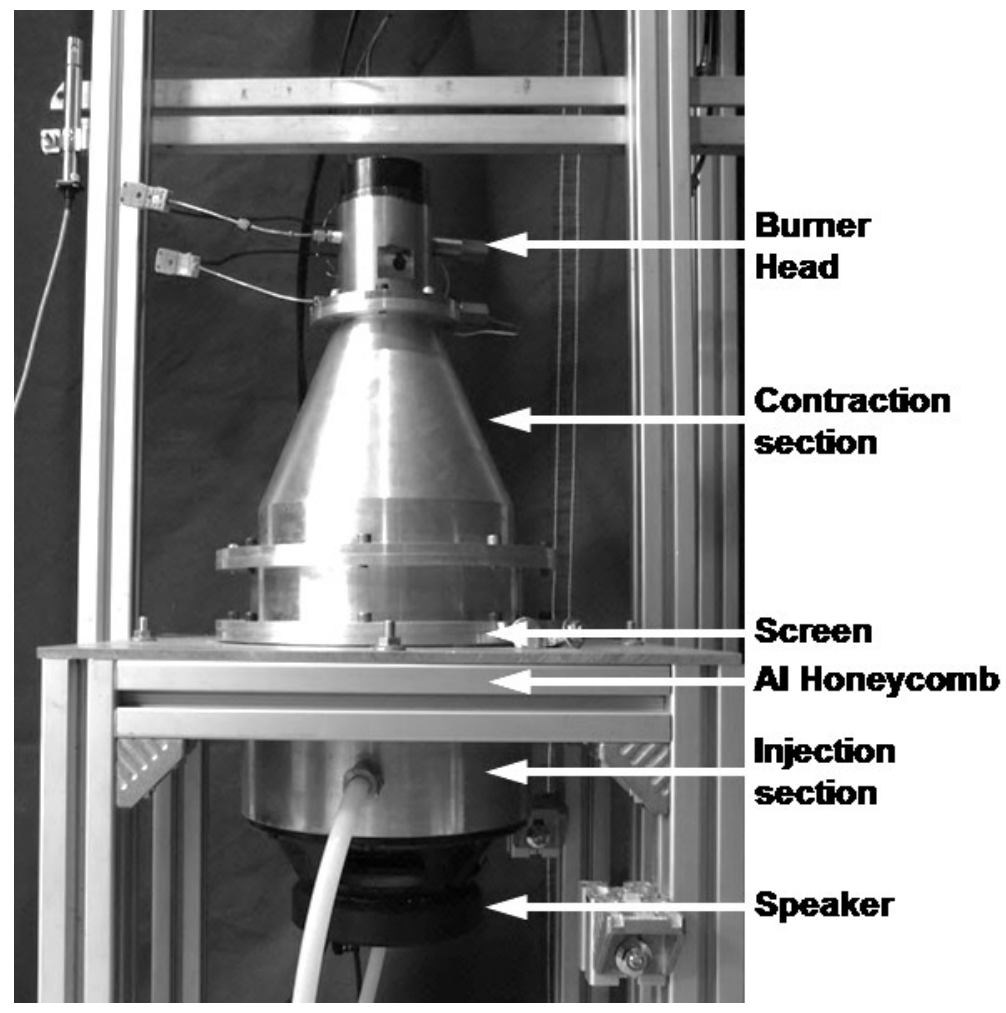

Figure 3.3: Image of flat flame burner

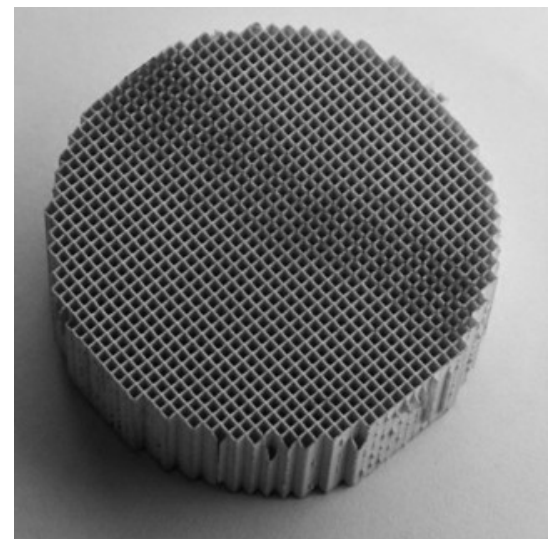

Figure 3.4: Ceramic honeycomb

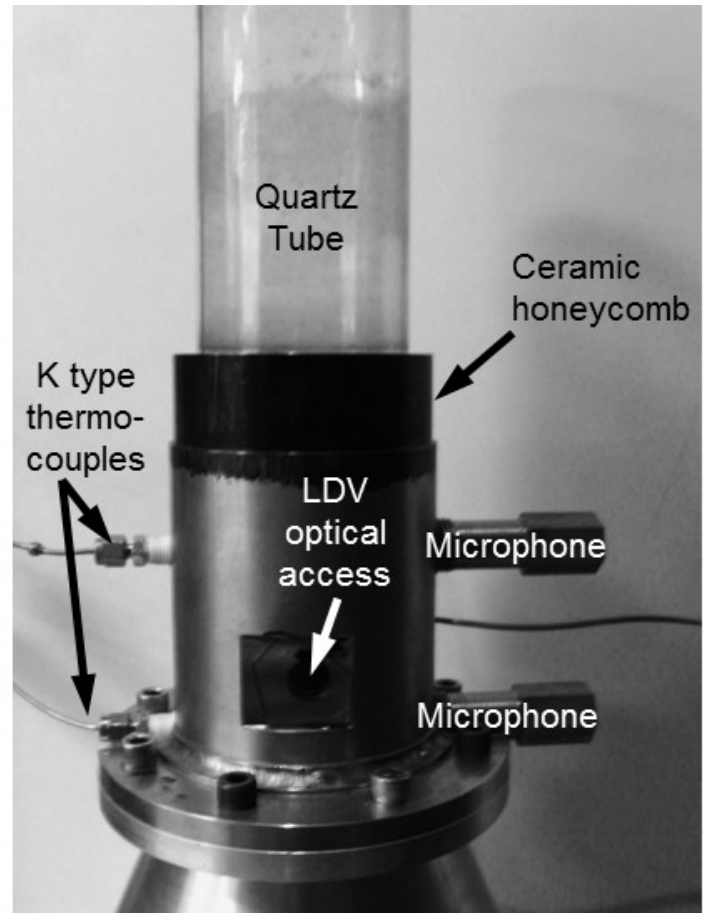

Figure 3.5: Image of burner head 
Acoustic forcing in the range of 20 to $400 \mathrm{~Hz}$ was applied using an Eminence Beta 8A speaker mounted to the bottom of the burner. The speaker was powered by a Yamaha P5000s amplifier. An Agilent 33220A function generator was used to provide the pure (sinusoidal) tones necessary for acoustic forcing. A quartz tube with an inner diameter of $52.85 \mathrm{~mm}$ and an outer diameter of $57 \mathrm{~mm}$ was placed atop the burner to prevent ambient flow from disturbing the flame. The quartz tube length was chosen to be $12.7 \mathrm{~cm}$ so that its resonance frequency was above the range of excitation frequencies. This was necessary to avoid self-excited oscillations between the flame and quartz tube. Assuming the speed of sound in ambient air is $343 \mathrm{~m} / \mathrm{s}$, the resonance frequency of the open quartz tube is around $1350 \mathrm{~Hz}$. During testing, the high temperature of the exhaust gas would increase the resonance frequency.

A close up of the burner head is shown in Figure 3.5. Two holes were drilled in the side to mount the microphones initially used for measurement of the fluctuating component of velocity via the two microphone technique. The top hole was $3.74 \mathrm{~cm}$ below the bottom surface of the honeycomb and the microphones were $5.08 \mathrm{~cm}$ apart. Two K type thermocouples were mounted to the inner surface of the burner head, directly across the microphones. These were initially meant for correction of the microphone signal due to increased gas temperature. However, they were instead used to determine when the burner temperature had stabilized at the start of an experiment.

A hole was drilled between the two microphones and covered with a piece of flat glass to allow measurement of the fluctuating component of velocity via laser Doppler velocimetry (LDV). The end of the hole was sanded so that the surface was not 
perpendicular to the laser beam, in order to avoid the laser reflecting directly back at the LDV collection optics.

An R type thermocouple with a wire diameter of $0.0762 \mathrm{~mm}$ and junction diameter of $0.17 \mathrm{~mm}$ was embedded in the honeycomb to measure the reactant gas temperature $\left(T_{R}\right)$, as shown in Figure 3.6. The thermocouple bead was mounted to be as close to the top surface of the honeycomb as possible. The thermocouple leads were positioned to avoid contact with the flame, and the area where the wires crossed the burner was covered in a ceramic coating so that the wires did not contact metal. A calculation of the heat transfer to the gas as it flows through the channels of the honeycomb reveals that the gas temperature very quickly matches the honeycomb temperature upon entering the small cross-section channels. The thermocouple used to indicate the gas temperature is in contact with the honeycomb, and it can be assumed that the gas temperature and honeycomb temperature are equal. While both the thermocouple and honeycomb would receive radiation heat transfer from the flame, so long as their emissivities were comparable, the readings from the thermocouple should accurately reflect the honeycomb temperature. Moreover, any discrepancies between the thermocouple and the honeycomb temperatures (and hence the gas temperature) are expected to be inconsequential since the thermocouple temperature readings were use solely for identifying trends, as outlined in Section 5.4. 


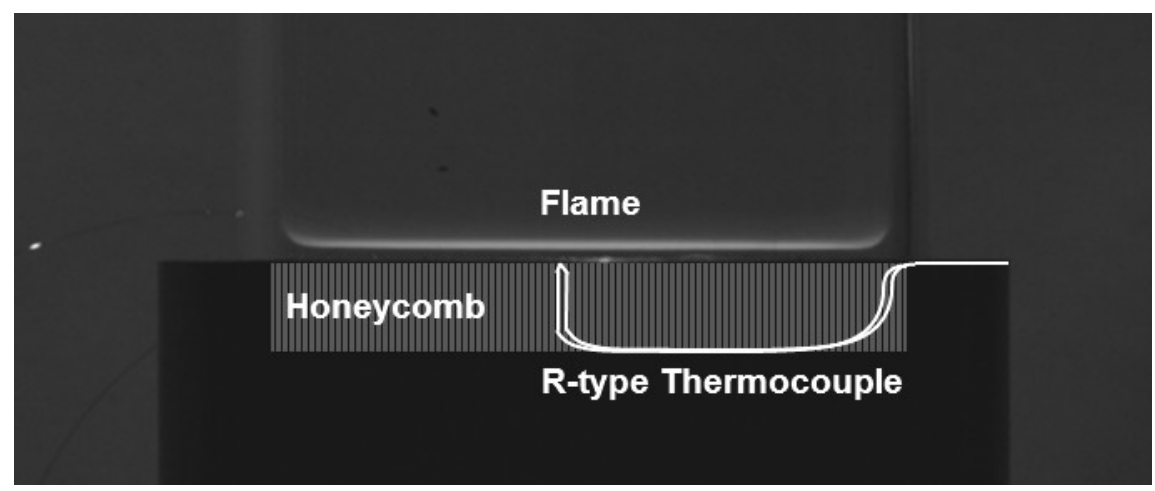

Figure 3.6: R-type thermocouple mounting for gas temperature measurement

\subsection{Measurement Techniques}

\subsubsection{Overview of Measurements and Data Acquisition System}

In addition to the temperature and flow rate measurements discussed above, the following measurements were also made:

- $\mathrm{OH}^{*}$ and $\mathrm{CH}^{*}$ chemiluminescence with a photomultiplier tube (PMT),

- Flow velocity via Laser Doppler Velocimetry (LDV),

- Fluctuating component of velocity via the two-microphone technique,

- Flame liftoff distance via imaging with a digital SLR camera.

Table 3.2 lists the instruments used for these measurements and their associated accuracies. Measurements of chemiluminescence, microphone pressure, temperature, and flow rates were acquired using a National Instruments (NI) cDAQ 9172 data acquisition system controlled by LabVIEW. Table 3.3 shows the breakdown of modules used in the cDAQ 9172 chassis for various measurements.

A single LabVIEW program was written to control the experiment. This program set and read the flow rates from the flow controllers, controlled the frequency generator settings, and read analog signals from the PMT, microphones, thermocouples, and the 
pressure and temperature sensor. $\mathrm{OH}^{*}$ and $\mathrm{CH}^{*}$ chemiluminescence signals and microphone measurement data were simultaneously sampled at a rate of $50 \mathrm{kHz}$ for $5 \mathrm{~s}$ at each forcing frequency using a 16 bit NI 9215 analog voltage input module. To synchronize this with the LDV measurements, a sync signal from the function generator was sent to the NI DAQ and to the LDV. A signal from the LDV stating its measurement status was sent to the NI DAQ to ensure that the NI DAQ and the LDV started taking data at the same time. Further details of the LDV system are presented in Section 3.3.3. The function generator was connected to the data acquisition computer via a universal serial bus (USB) cable. Flow rates were measured at $1000 \mathrm{~Hz}$ for $0.1 \mathrm{~s}$ and an average flow rate was recorded for each test point. Temperatures and the photomultiplier high voltage setting were measured once for each forcing frequency. An Omega iBTX sensor measured the ambient temperature and pressure and was connected to the data acquisition computer with an Ethernet cable. 
Table 3.2: Instrument Accuracies

\begin{tabular}{|c|c|c|c|c|}
\hline Category & Source & Part & Model & Accuracy \\
\hline \multirow{6}{*}{ DAQ } & $\begin{array}{l}\text { National } \\
\text { Instruments }\end{array}$ & DAQ chassis & $\begin{array}{l}\text { NI cDAQ } \\
9172\end{array}$ & Timing: $50 \mathrm{ppm}$ of sample rate \\
\hline & $\begin{array}{l}\text { National } \\
\text { Instruments }\end{array}$ & $\begin{array}{l}\text { DAQ module: } \\
\text { analog voltage input }\end{array}$ & $\begin{array}{l}\text { NI } 9215 \\
\text { with BNC }\end{array}$ & $\begin{array}{l}\text { Gain error: } 0.6 \% \text {, } \\
\text { Offset error: }-0.0001 \mathrm{~V}\end{array}$ \\
\hline & \begin{tabular}{|l|} 
National \\
Instruments
\end{tabular} & $\begin{array}{l}\text { DAQ module: } \\
\text { thermocouple input }\end{array}$ & NI 9211 & K-type: $1.3^{\circ} \mathrm{C}$, R-type: $2.5^{\circ} \mathrm{C}$ \\
\hline & \begin{tabular}{|l} 
National \\
Instruments
\end{tabular} & $\begin{array}{l}\text { DAQ module: } \\
\text { digital input/output }\end{array}$ & NI 9401 & Pulse width distortion: $10 \mathrm{~ns}$ \\
\hline & \begin{tabular}{|l|} 
National \\
Instruments
\end{tabular} & $\begin{array}{l}\text { DAQ module: } \\
\text { analog current output }\end{array}$ & NI 9265 & $\begin{array}{l}\text { Gain error: } 0.35 \% \text {, } \\
\text { Offset error: } 1.4 \%\end{array}$ \\
\hline & \begin{tabular}{|l} 
National \\
Instruments
\end{tabular} & $\begin{array}{l}\text { DAQ module: } \\
\text { analog voltage input }\end{array}$ & NI 9205 & $\begin{array}{l}\text { Gain error: } 0.012 \% \text {, } \\
\text { Offset error: } 0.96 \mathrm{mV}\end{array}$ \\
\hline \multirow{3}{*}{$\begin{array}{l}\text { Acoustic } \\
\text { Forcing }\end{array}$} & Eminence & Speaker & Beta-8A & $\mathrm{N} / \mathrm{A}$ \\
\hline & Yamaha & Power amplifier & P5000S & $\mathrm{N} / \mathrm{A}$ \\
\hline & Agilent & Function generator & $33220 \mathrm{~A}$ & $\begin{array}{l}\text { Frequency: } 1 \mu \mathrm{Hz}, \\
\text { Amplitude flatness: } 0.1 \mathrm{~dB}, \\
\text { Harmonic distortion: } 0.04 \% \mathrm{DC}\end{array}$ \\
\hline \multirow{6}{*}{ Velocity } & $\begin{array}{l}\text { Bruel and } \\
\text { Kjaer }\end{array}$ & Microphone & $\begin{array}{l}4188-\mathrm{A}- \\
021\end{array}$ & $\begin{array}{l}\text { Temperature coefficient: } 0.005 \mathrm{~dB} /{ }^{\circ} \mathrm{C} \text {, } \\
\text { Pressure coefficient: }-0.021 \mathrm{~dB} / \mathrm{kPa}\end{array}$ \\
\hline & G.R.A.S. & Pistonphone & $\begin{array}{l}\text { Type } \\
42 \mathrm{AC}\end{array}$ & Sound pressure level: $0.14 \mathrm{~dB}$ \\
\hline & \begin{tabular}{|l|} 
PCB \\
Piezotronics \\
\end{tabular} & $\begin{array}{l}\text { Microphone power } \\
\text { supply }\end{array}$ & 441A101 & N/A \\
\hline & $\begin{array}{l}\text { PCB } \\
\text { Piezotronics }\end{array}$ & $\begin{array}{l}\text { Microphone signal } \\
\text { conditioner }\end{array}$ & 442B104 & $8.5 \mu \mathrm{V}$ \\
\hline & Dantec & $\begin{array}{l}\text { Laser Doppler } \\
\text { Velocimetry }\end{array}$ & BSA P30 & $\begin{array}{l}\text { Fringe spacing: } 0.07 \% \text {, } \\
\text { Signal processor: } 0.1 \%\end{array}$ \\
\hline & TSI & 6 jet atomizer & 9306 & $\mathrm{~N} / \mathrm{A}$ \\
\hline \multirow{2}{*}{$\begin{array}{l}\text { Heat } \\
\text { Release } \\
\text { Rate }\end{array}$} & $\begin{array}{l}\text { ET } \\
\text { Enterprises }\end{array}$ & Photomultiplier tube & $9125 \mathrm{~B}$ & $\begin{array}{l}\text { Maximum cark current: } 2 \mathrm{nA}, \\
\text { Pulsed linearity: } 100 \mathrm{~mA}, \\
\text { Temperature coefficient: } 0.5 \% /{ }^{\circ} \mathrm{C}\end{array}$ \\
\hline & \begin{tabular}{|l|} 
Anatek \\
Electronics
\end{tabular} & Power supply & $50-1.0 \mathrm{D}$ & $\begin{array}{l}\text { Stability: } 0.02 \% \text {, } \\
\text { Temperature coefficient: } 0.015 \% /{ }^{\circ} \mathrm{C}\end{array}$ \\
\hline \multirow{4}{*}{ General } & Brooks & $\begin{array}{l}\text { Thermal mass flow } \\
\text { controller }\end{array}$ & $5850 \mathrm{~S}$ & $1 \%$ or $0.2 \%$ of Full Scale \\
\hline & Omega & $\begin{array}{l}\text { Pressure and } \\
\text { temperature sensor }\end{array}$ & $\begin{array}{l}\text { iBTX- } \\
\text { SD-5 }\end{array}$ & $\begin{array}{l}\text { Temperature: } 2{ }^{\circ} \mathrm{C} \text {, } \\
\text { Pressure: } 200 \mathrm{~Pa}\end{array}$ \\
\hline & Omega & \begin{tabular}{|l} 
K-type \\
Thermocouple
\end{tabular} & $\begin{array}{l}\text { KMQSS- } \\
062 \mathrm{G}-6 \\
\end{array}$ & $2.2^{\circ} \mathrm{C}$ or $2.0 \%$ \\
\hline & Omega & R-type Thermocouple & P13R-003 & $1.5^{\circ} \mathrm{C}$ or $0.25 \%$ \\
\hline
\end{tabular}


Table 3.3: National Instruments (NI) data acquisition modules

\begin{tabular}{|l|l|l|}
\hline NI DAQ Module & Data Acquired & $\begin{array}{l}\text { Data Rate and } \\
\text { Time }\end{array}$ \\
\hline $\begin{array}{l}\text { NI 9215 } \\
\text { (analog BNC input) }\end{array}$ & $\begin{array}{l}\text { Read microphone signal } \\
\text { Read photomultiplier signal } \\
\text { Read function generator sync signal } \\
\text { Read photomultiplier high voltage setting }\end{array}$ & $\begin{array}{l}50,000 \mathrm{~Hz} \text { for 5 s } \\
50,000 \mathrm{~Hz} \text { for 5 } 5 \mathrm{~s} \\
1 \text { sample }\end{array}$ \\
\hline $\begin{array}{l}\text { NI 9211 (analog } \\
\text { thermocouple input) }\end{array}$ & $\begin{array}{l}\text { Read K type thermocouples } \\
\text { Read R type thermocouple }\end{array}$ & $\begin{array}{l}1 \text { sample } \\
1 \text { sample }\end{array}$ \\
\hline $\begin{array}{l}\text { NI 9401 (digital } \\
\text { input/output) }\end{array}$ & $\begin{array}{l}\text { Read function generator sync signal } \\
\text { Read LDV measurement status signal }\end{array}$ & $\begin{array}{l}\text { Trigger } \\
1 \text { sample }\end{array}$ \\
\hline $\begin{array}{l}\text { NI 9205 } \\
\text { (analog input) }\end{array}$ & Read flow rates & $1000 \mathrm{~Hz}$ for $0.1 \mathrm{~s}$ \\
\hline $\begin{array}{l}\text { NI 9265 } \\
\text { (analog output) }\end{array}$ & Set flow rates & 1 sample \\
\hline
\end{tabular}

\subsubsection{Flow Control System}

Accurate control and measurement of the gas flows was done using four Brooks SLA5850S thermal mass flow controllers. A 10 SLPM flow controller was calibrated for air, two 1 SLPM flow controllers were calibrated for methane and hydrogen, and a 1 SLPM flow controller was calibrated with both carbon dioxide and carbon monoxide. The measured flows were reported in standard litres per minute calculated using a standard temperature and pressure of $21.11^{\circ} \mathrm{C}$ and $101.325 \mathrm{kPa}$. A $0-5 \mathrm{~V}$ signal was sent from LabVIEW controlled DAQ to the flow controllers to set the flow rate, and a 0 $5 \mathrm{~V}$ signal was read back from the flow controllers to measure the actual flow rate. The gases were mixed using a manifold as shown in Figure 3.7. The nominal mean flow velocity was calculated based the total flow rate, using the quartz tube diameter of $52.85 \mathrm{~mm}$, and the density calculated based on the incoming flow mixture along with the ambient temperature and pressure measured by the Omega iBTX sensor. 


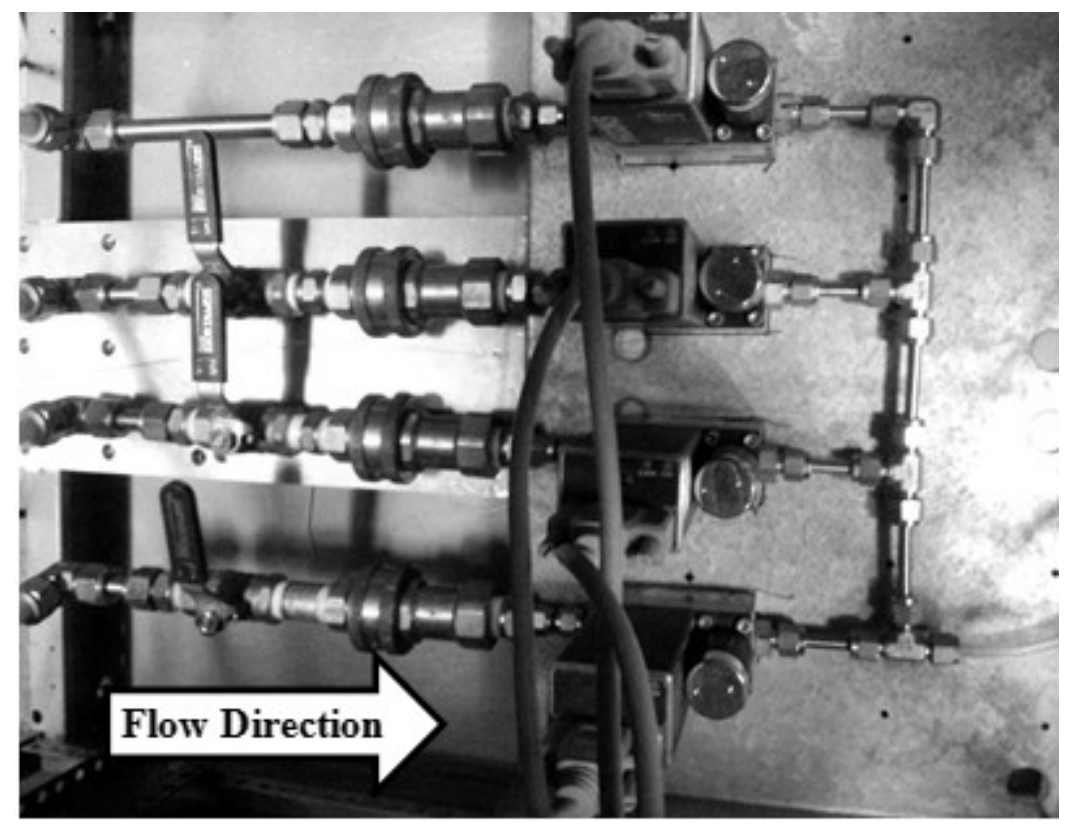

Figure 3.7: Flow manifold

\subsubsection{Fluctuating Velocity Measurement}

Measurement of the fluctuating component of velocity was initially performed using the two- microphone technique due to its simplicity. The two microphone technique is commonly used for this purpose in flame response studies, as outlined in Khanna (2001), Seybert \& Ross (1977), and Waser \& Crocker (1984). Details on the implementation of the two microphone technique can be found in Appendix C.

After concluding that the two microphone technique suffered from errors in the current apparatus attributed to heating of the microphones during experiments, a decision was made to instead measure the velocity fluctuations using LDV. A Dantec backscatter LDV system with a BSA P30 signal processor was used. While this approach had the disadvantage of requiring the flow to be seeded with aerosolized water droplets, the added 
complexity was justified given the problems encountered with the two-microphone technique.

The LDV was aligned to measure the velocity through a $9.53 \mathrm{~mm}$ diameter hole $6.3 \mathrm{~cm}$ below the bottom (upstream surface) of the honeycomb and half way between the mounting locations of the two microphones, as shown previously in Figure 3.5. Ideally, the velocity fluctuations would be measured directly below the flame; however, this area was inaccessible due to the small stand-off distance of the flame above the honeycomb (between 0.5 and $1.5 \mathrm{~mm}$ ). The port hole could also have been drilled closer to the honeycomb, but the position was chosen so that measurements done with the LDV and two microphone technique could be compared.

A TSI model 9306 atomizer with water soluble SAFEX fog fluid was used to seed the flow for LDV measurements. The flow rate of seeding fluid was estimated to be $0.000061 \mathrm{lpm}$ by running the system for 32 hours at an air flow of 8 SLPM and measuring the change in the seeding fluid level in the TSI atomizer. The maximum droplet fraction at the lowest flow rate of 6 slpm was then $9.3 \times 10^{-6}$ by volume. Any volume fraction between $10^{-6}$ and $10^{-3}$ results in two-way coupling between the particles and turbulence (Elghobashi 1994). In this regime of particle-turbulence interaction, the particles have an effect on the turbulence structure of the flow. This should not be a concern here due to the laminar nature of the flow. A more pertinent issue is that the particles must be able to track the flow accurately at frequencies up to $400 \mathrm{~Hz}$. The analysis of Melling (1997) shows that for a high particle:fluid density ratio, particles up to $3 \mu \mathrm{m}$ in diameter track the fluid well below frequencies of $1000 \mathrm{~Hz}$. The mean droplet diameter quoted in the atomizer manual TSI Incorporated (2003) is $0.3 \mu \mathrm{m}$. For a 
conservative estimate, a droplet diameter of $2 \mu \mathrm{m}$ can be assumed, as quoted for liquid droplets in Adrian \& Westerweel (2011). Assuming the particles had the density of water at a temperature of $323 \mathrm{~K}$ (the average burner temperature at the point where the LDV measurement takes place), then based on the results of Melling (1997), the droplets should have easily tracked fluctuations in the flow above $1000 \mathrm{~Hz}$, whereas the maximum forcing frequency in this study was $360 \mathrm{~Hz}$. Another consideration is the effect of seeding on the flame heat loss. Tests showed that the decrease in the heat release rate due to seeding was minimal, implying that the reaction chemistry was negligibly affected.

Since particles pass through the LDV measurement volume at random, the measured data were randomly spaced in time. Hence the quoted data rates were an average, and the actual data rate varied significantly. Optimization of the LDV settings was required to obtain a reasonable data rate. The data rate was strongly affected by the flow rate and gain setting of the LDV receiving optics (photomultiplier tubes), and weakly affected by the amount of seeding. The LDV optics gain was set as high as possible without damaging the photomultiplier tubes or losing signal quality. This resulted in data rates in the range of 60 to $120 \mathrm{~Hz}$. 10,000 points were sampled at each test frequency.

With these low data rates, it was not possible to resolve the velocity fluctuations from the raw data. However, the uneven spacing in LDV data allowed ensemble averaging to be done. The time values of the raw data shown in Figure 3.8 were sorted using a reference sync signal from the frequency generator to allow the velocity signal of one full forcing cycle to be reconstructed, as shown in Figure 3.9. 


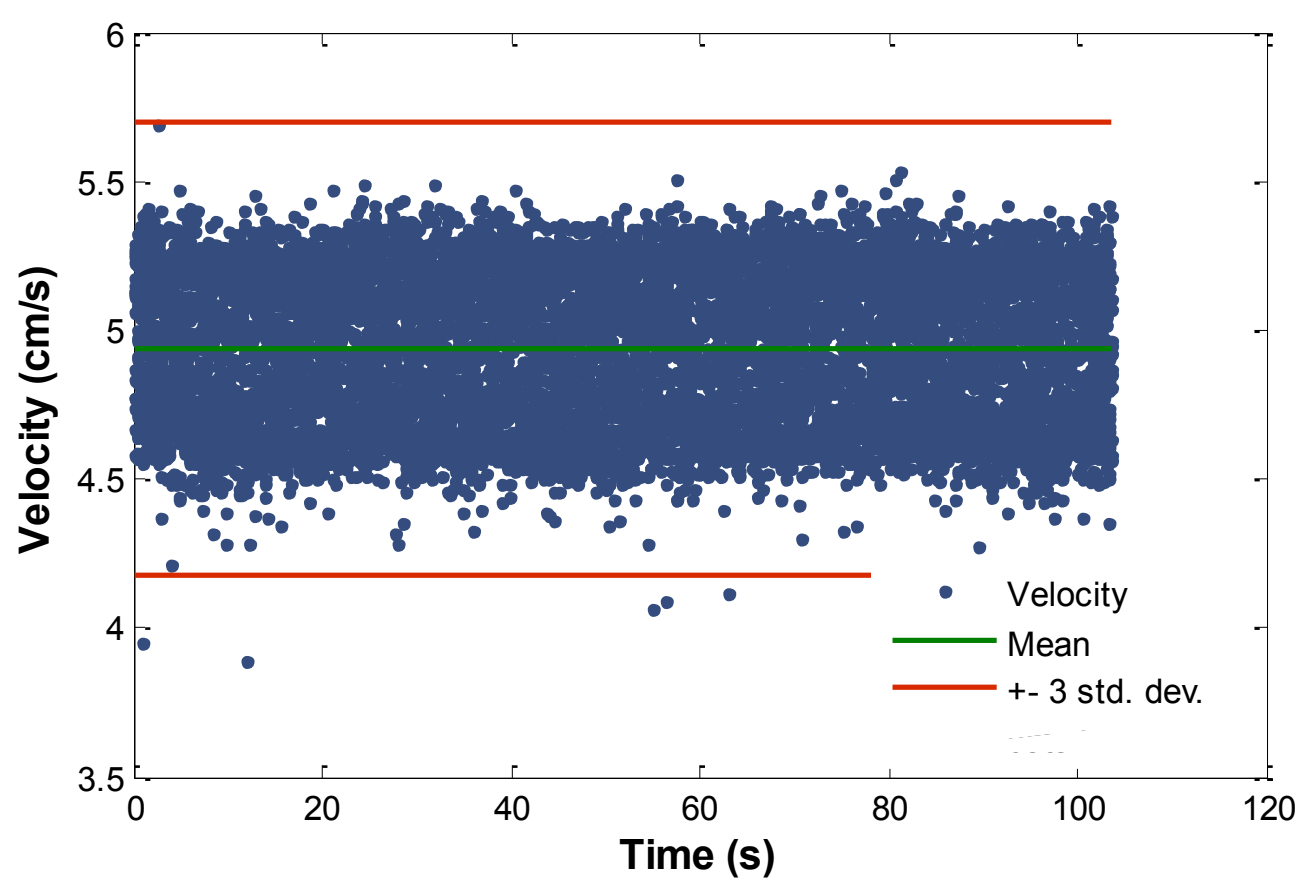

Figure 3.8: Original LDV velocity signal

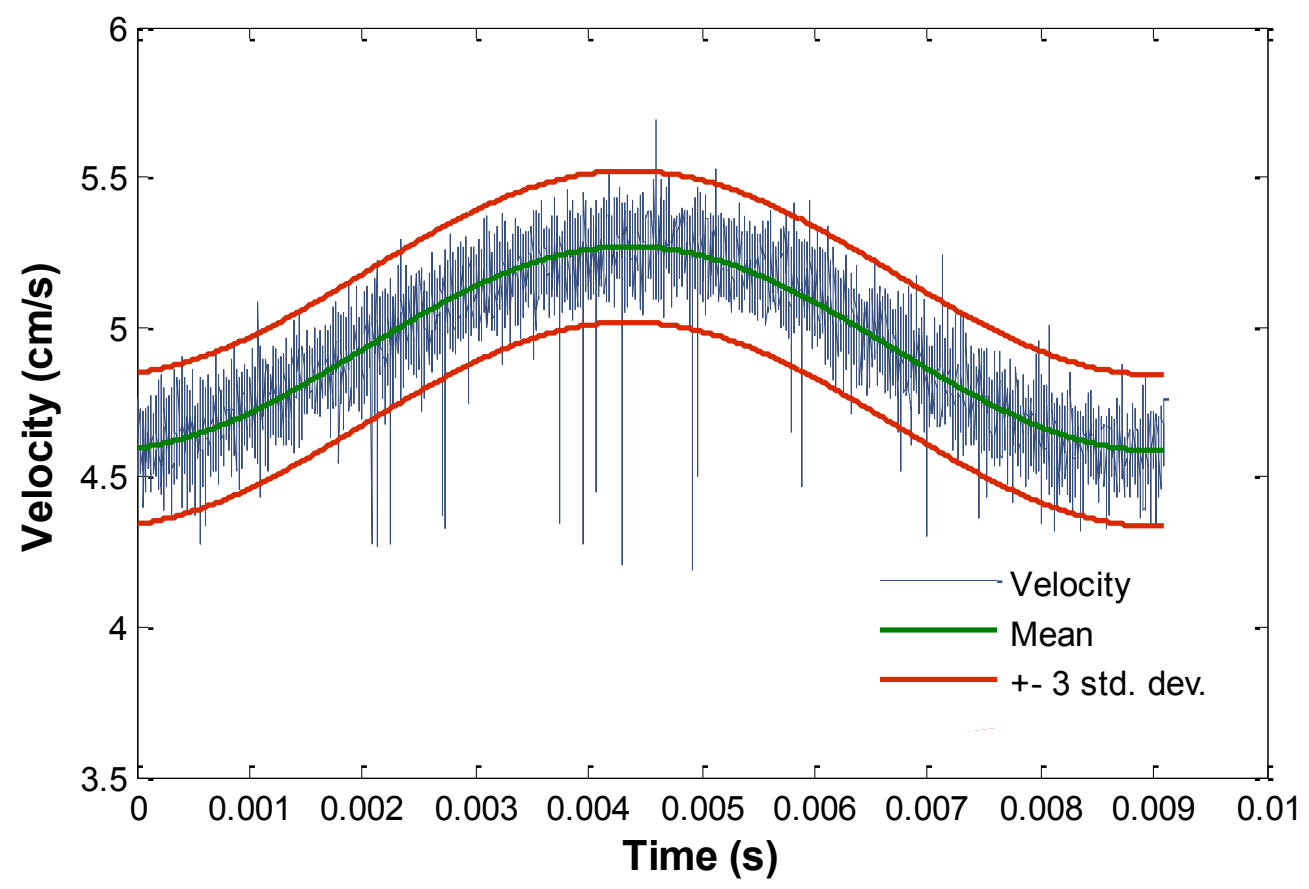

Figure 3.9: Ensemble averaged velocity 
First, any data points more than three standard deviations from the original velocity signal were discarded to eliminate low frequency noise that was sometimes present in the data. A sample raw data signal with the mean and outlier limits is shown in Figure 3.8. The data was then ensemble averaged and fitted with a sine curve using Matlab's fminsearch function. To ensure an accurate sine fit, any outliers more than three standard deviations from the sine fit were removed, as shown in Figure 3.9. The final velocity signal was then fitted with a sine curve again to obtain the amplitude and phase of the fluctuating velocity signal.

For comparison, FFT analysis was also used to obtain the amplitude and phase of the velocity fluctuation from the LDV velocity signal. To perform FFT analysis, ensemble averaging was done to show 100 cycles instead of one to avoid aliasing due to Nyquist frequency restrictions. Since the data were randomly spaced in time, the data were re-sampled using linear interpolation to obtain evenly spaced data. FFT analysis was then done in LabVIEW to obtain the amplitude and phase of the velocity fluctuation. Figure 3.10 shows the velocity fluctuation amplitudes at various frequencies for the methane flame at $\Phi=0.65$ and a mean velocity of $6 \mathrm{~cm} / \mathrm{s}$. The results show that the velocity fluctuation amplitudes calculated via FFT analysis were in good agreement with the ensemble average results. As shown in Figure 3.11, the phase data was not in good agreement due to the poor temporal resolution of the interpolated raw data used for FFT analysis. 


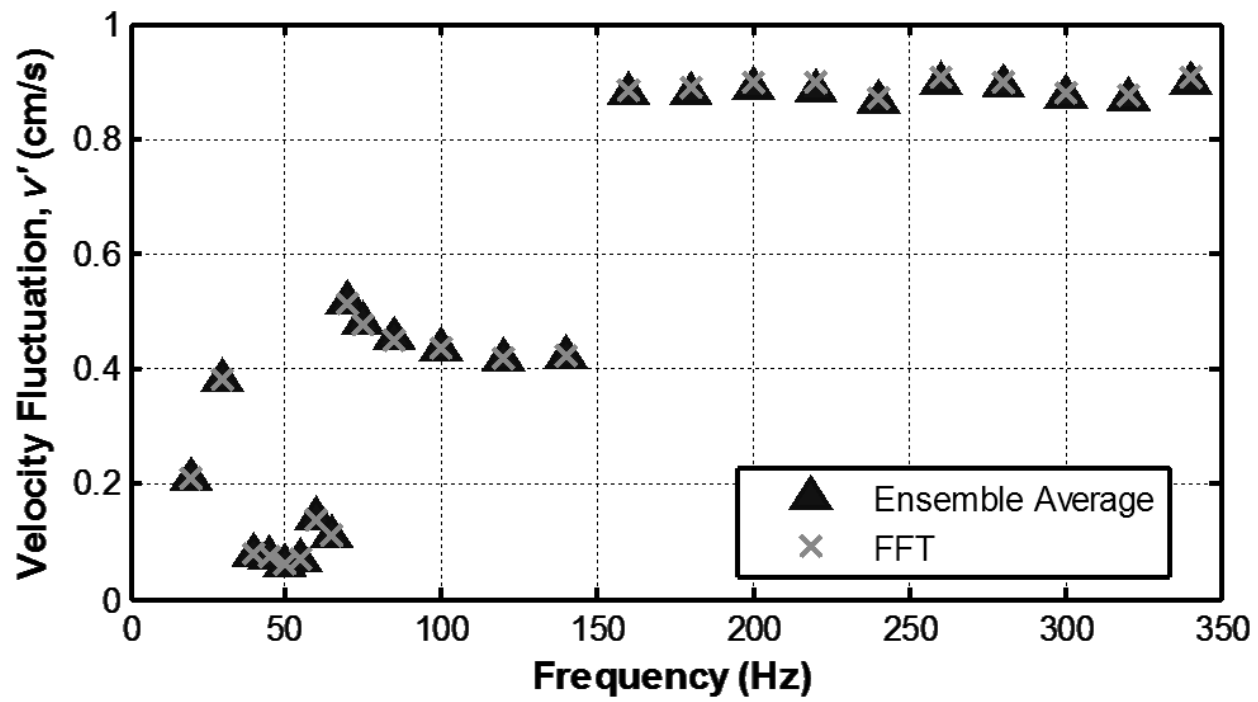

Figure 3.10: Comparison of Ensemble Average- and FFT-based LDV processing techniques used to calculate velocity fluctuations in the burner

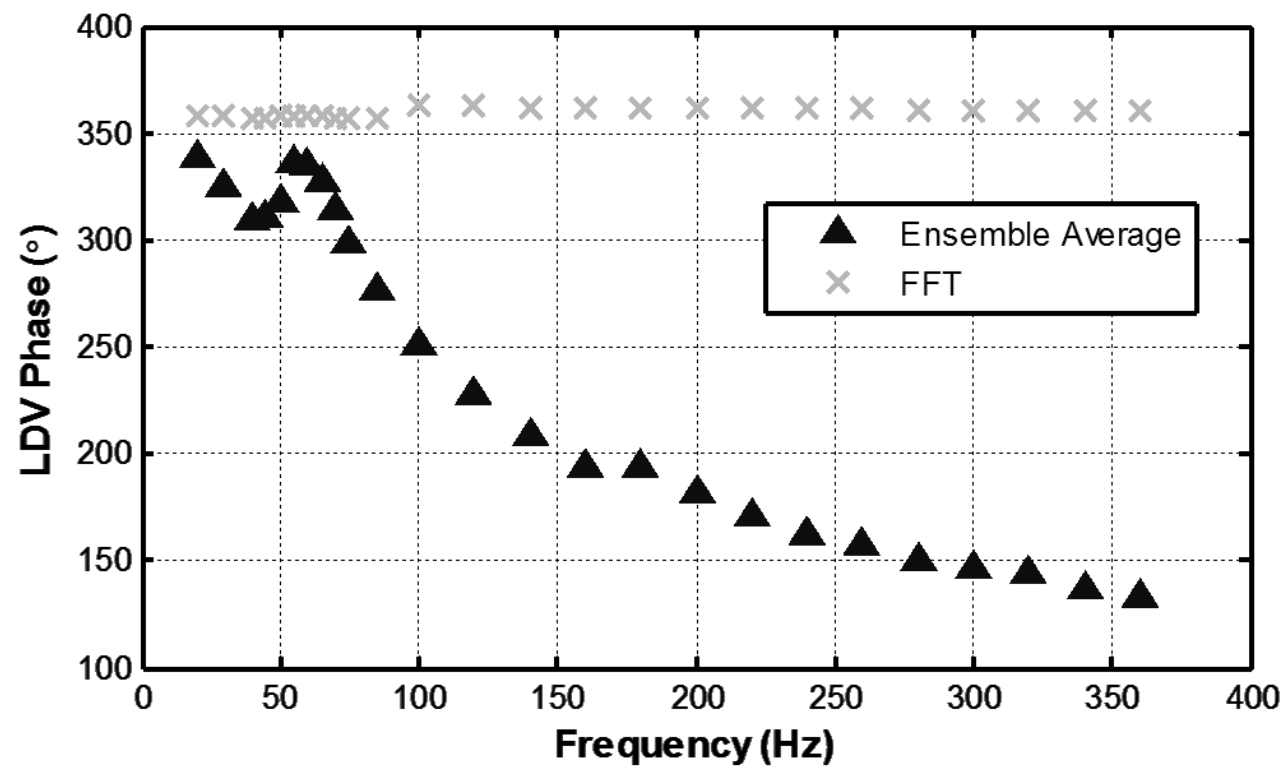

Figure 3.11: Comparison of phase of velocity fluctuations from Ensemble Averageand FFT-based LDV processing techniques 


\subsubsection{Heat Release Rate Measurement}

The most common method of estimating the heat release rate in studies of combustion dynamics is through measurements of flame chemiluminescence, which is the radiation from excited intermediate species formed by chemical reactions (Lee \& Santavicca, 2003). $\mathrm{OH}^{*}, \mathrm{CH}^{*}$, and $\mathrm{CO}_{2} *$ are species commonly used in lean combustion due to their high signal strength. An example of an emission spectrum in a lean premixed combustor is shown in Figure 3.12. $\mathrm{OH}^{*}$ and $\mathrm{CH}^{*}$ have narrow emission bands, while $\mathrm{CO}_{2}$ * covers a broad range of wavelengths. Consequently, any measurement of the $\mathrm{OH}^{*}$ and $\mathrm{CH}^{*}$ signals will also contain some $\mathrm{CO}_{2} *$ signal.

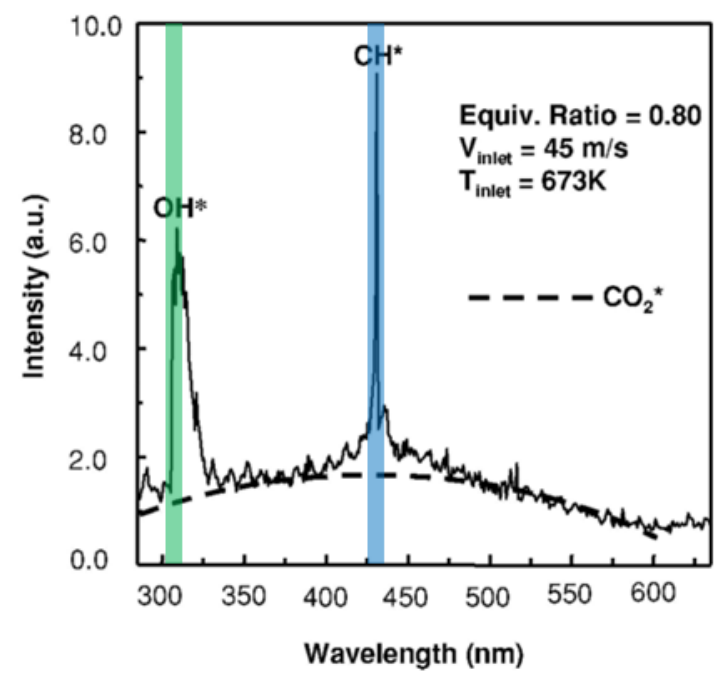

Figure 3.12: Emission spectrum in a lean premixed combustor (Lee \& Santavicca, 2003). Shaded green and blue rectangles correspond to the widths of the $\mathrm{OH}^{*}$ and $\mathrm{CH}^{*}$ filters used in the present measurements.

In the present work, both $\mathrm{OH}^{*}$ and $\mathrm{CH}^{*}$ chemiluminescence were separately measured using different optical filters fitted to an Electron Tubes $9125 \mathrm{~W}$ photomultiplier tube. Andover optical filters with wavelengths of $430.0 \mathrm{~nm} \pm 5 \mathrm{~nm}$ and $307.1 \mathrm{~nm} \pm 5 \mathrm{~nm}$ were used to measure $\mathrm{CH}^{*}$ and $\mathrm{OH}^{*}$ chemiluminescence respectively. The wavelength 
ranges of these $\mathrm{OH}^{*}$ and $\mathrm{CH}^{*}$ filters are superimposed on the sample emission spectrum shown in Figure 3.12 as shaded green and blue rectangles respectively. The photomultiplier tube was powered by an Anatek Electronics 50-1D DC power supply and connected in line with an Electron Tubes A1 amplifier module. Figure 3.13 shows the optical setup designed to focus the PMT onto a $35 \mathrm{~mm}$ diameter area of the flame. The imaged area was restricted to the center region of the flame to avoid the non-flat flame edges as apparent in Figure 3.14. A $50.8 \mathrm{~mm}$ diameter fused silica lens with a UV AR coating (Thorlabs, model LB4842) was used for this purpose. This lens was used with both the $\mathrm{OH}^{*}$ and $\mathrm{CH}^{*}$ filters, and despite the UV coating, the $\mathrm{CH}^{*}$ signal was still strong. An optical tube was designed and manufactured to hold the PMT and lens aligned at a fixed distance. The end of the tube was adjustable within a range of $3.4 \mathrm{~mm}$, allowing some freedom in setting the distance between the PMT and lens. A slot was cut in the side of this tube to allow the optical filter to be easily changed.

The burner assembly was placed in a 2.13 by $1.22 \mathrm{~m}$ darkened enclosure (shown in Figure 3.1) to shield the PMT from ambient light and minimize the background PMT signal (i.e. the effective dark current). The PMT dark current was corrected for during testing as outlined in Section 3.4. 


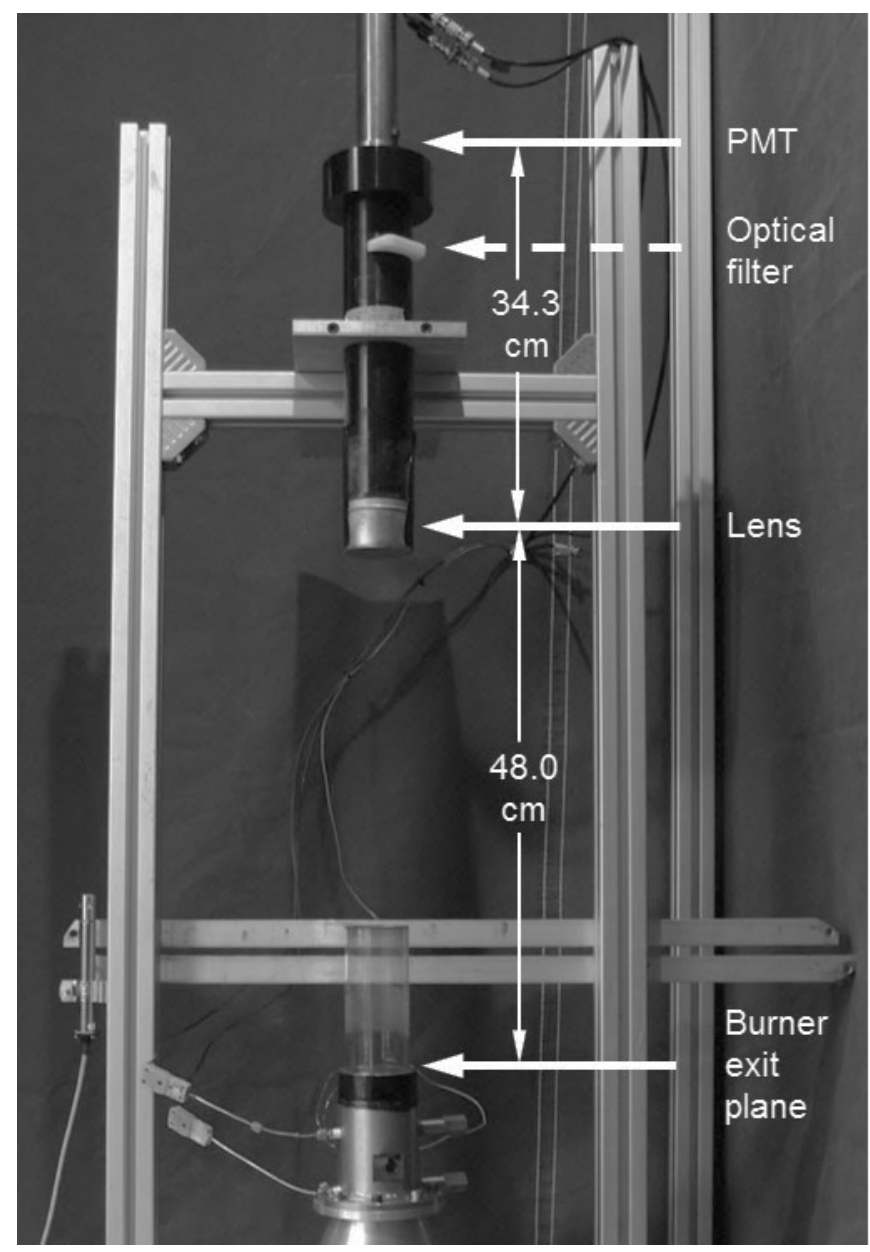

Figure 3.13: PMT optical setup

\subsubsection{Flame Liftoff Distance Measurement}

A Nikon D70s digital SLR camera was used to record flame images for measurement of the liftoff distance $\left(d_{f}\right)$ of the flame above the honeycomb. This was done without acoustic forcing. The camera was carefully aligned with the top plane of the burner to ensure an accurate measurement of the flame liftoff distance. The top of the burner was painted black and a red background was placed behind the burner to improve contrast. A sample flame image is shown in Figure 3.14. 
A three step process was used to determine the flame liftoff distance from the images:

1. Find burner side edges;

2. Find burner top edge; and

3. Find flame centre.

To find the burner side edges, the bottom $25 \%$ of the image was used as indicated by the shaded area labelled as "1" in Figure 3.15. Column averaging of the red light intensity values was done to obtain an average horizontal profile of red intensity across the bottom of the burner as shown in Figure 3.16. The average of the maximum and minimum values of the average horizontal red light intensity profile (red curve in Figure 3.16) was used as the threshold for finding the burner side edges, as indicated by the two triangles in Figure 3.16.

A similar procedure was used to find the burner top edge. In this case, row averaging of red light intensity data was done in the areas between the burner side edge and the edge of the quartz tube as indicated by the shaded regions labelled " 2 " in Figure 3.15. The edges of the quartz tube were obtained knowing the dimensions of the burner and the previously calculated burner side edges. An average vertical red light intensity profile was obtained across the top edge of the burner in the areas unobstructed by the flame, as shown in Figure 3.17.

The threshold was first calculated as the average of the maximum and minimum of the averaged vertical red light intensity profile, and this was used to find the burner top edge. Using this burner top edge value, the average maximum red light intensity was 
calculated by averaging all the values of the average vertical red light intensity profile left of the top edge (triangle) in Figure 3.17. Similarly, an average minimum red light intensity was calculated from the values on the right side of the top edge. The threshold was then redefined as the average of these two max and min values, and used to find the burner top edge. This was done to ensure that any large spikes in the red light intensity did not influence the results.

Finally, the flame centre was found by row averaging the blue light intensity in the flat portion of the flame indicated by the shaded red area labelled "3" in Figure 3.15. This area represents a $35 \mathrm{~mm}$ diameter centre section of the flame, where the flame was flat for all test cases. An averaged vertical blue light intensity profile across the flame is shown in Figure 3.18 with the flame centre indicated by a triangle. To find the flame centre, a $5^{\text {th }}$ order polynomial was fitted to the 17 points adjacent to the peak in the average vertical blue light intensity profile. The root of the polynomial closest to the peak blue light intensity was used as the flame centre.

The flame liftoff distance was calculated in pixels as the difference between the pixel locations of the flame centre and burner top edge. The burner width in pixels was calculated from the locations of the side edges. Knowing the actual width of the burner, the scale of image was calculated and used to find the flame liftoff distance in metres. A sample photograph of the flame, with superimposed lines indicating the locations of the burner edges and flame centre obtained via the procedures described above is shown in Figure 3.14. 
Figure 3.14: Image of $\mathrm{CH}_{4}$ flame at $\phi=0.65, \bar{v}=6 \mathrm{~cm} / \mathrm{s}$ with superimposed white lines showing the calculated burner edges and flame centre

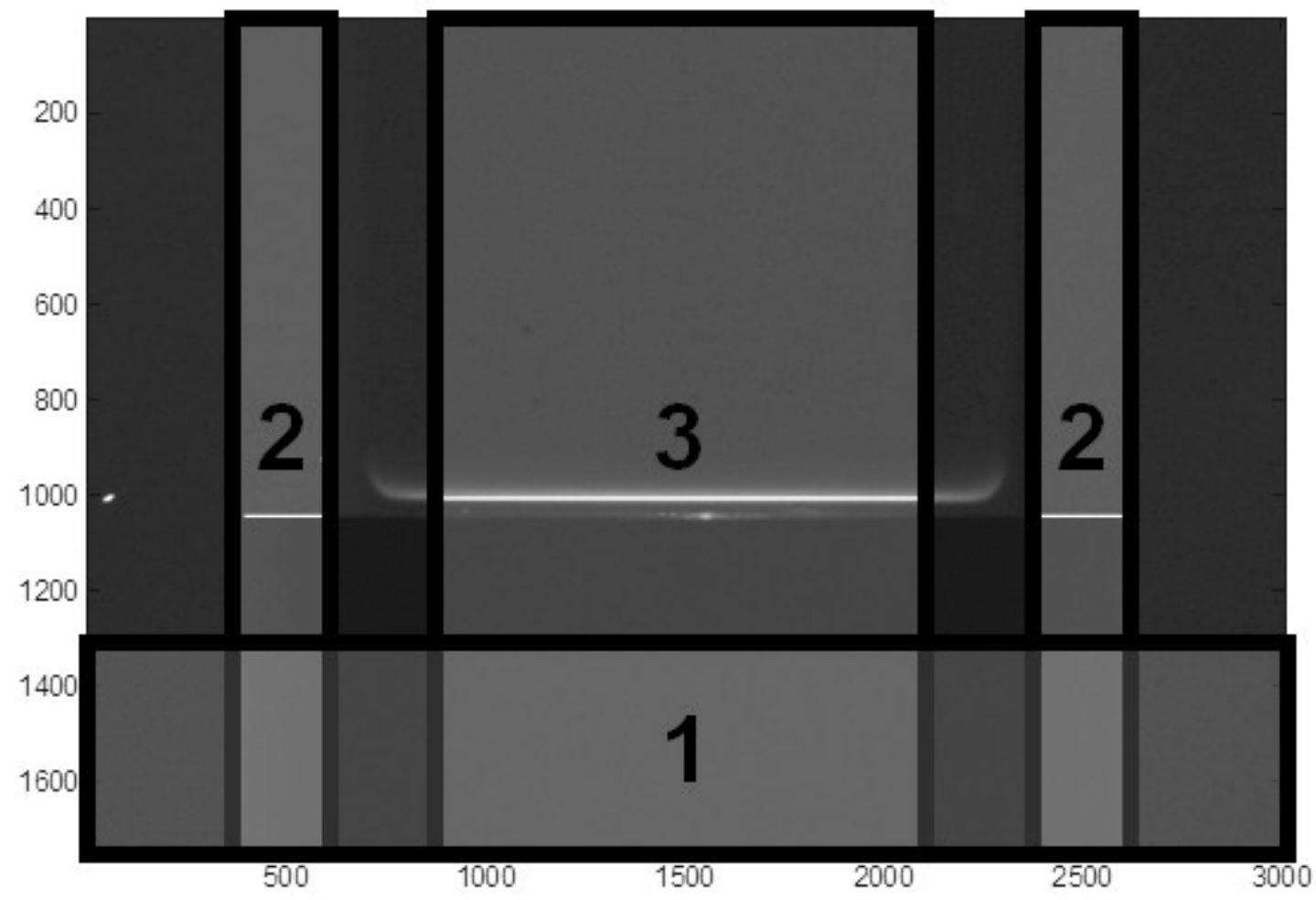

Figure 3.15: Image of flame and burner showing image areas used for averaging during the edge detection procedure 


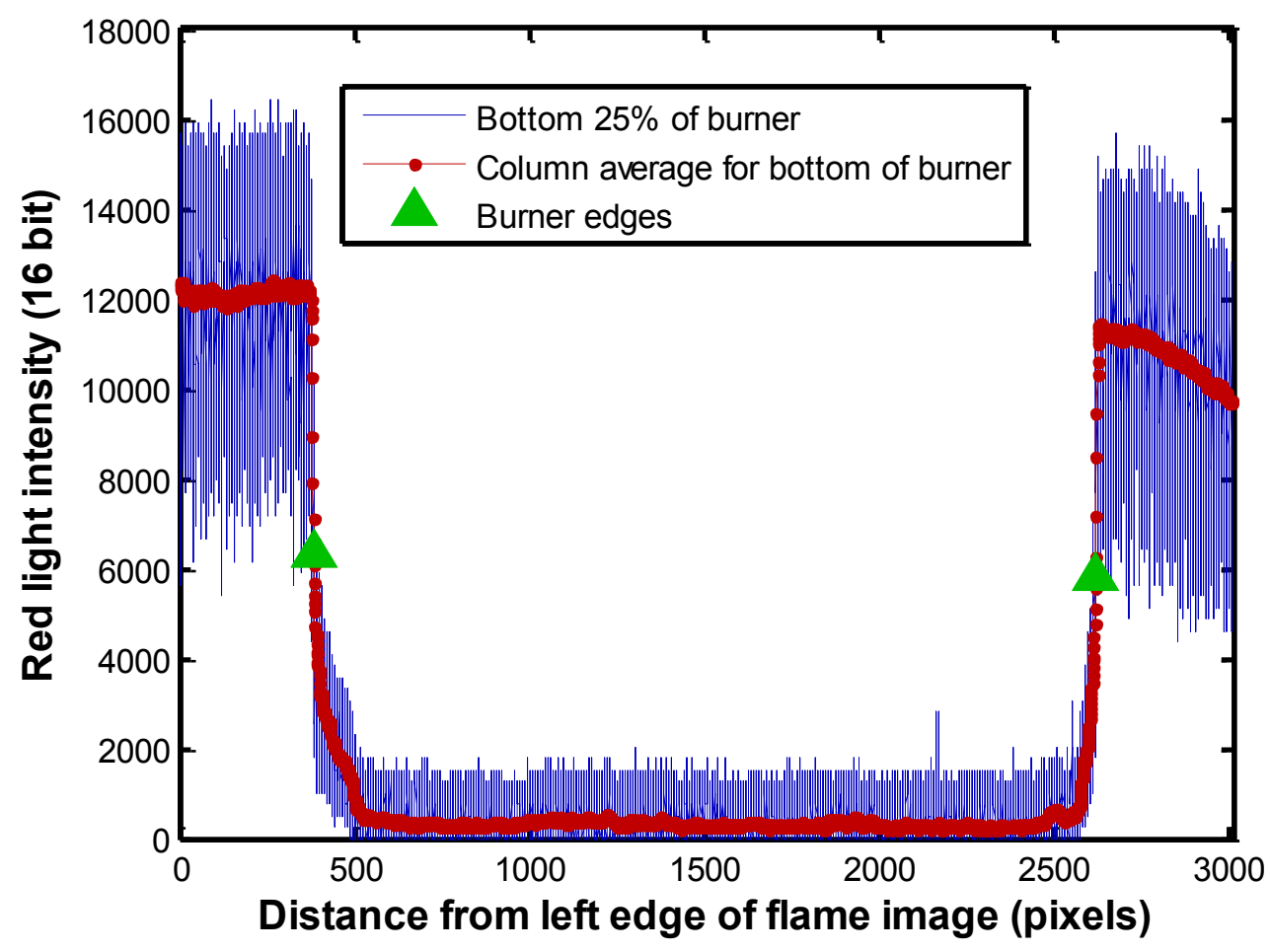

Figure 3.16: Horizontal slice across burner used to find burner side edges

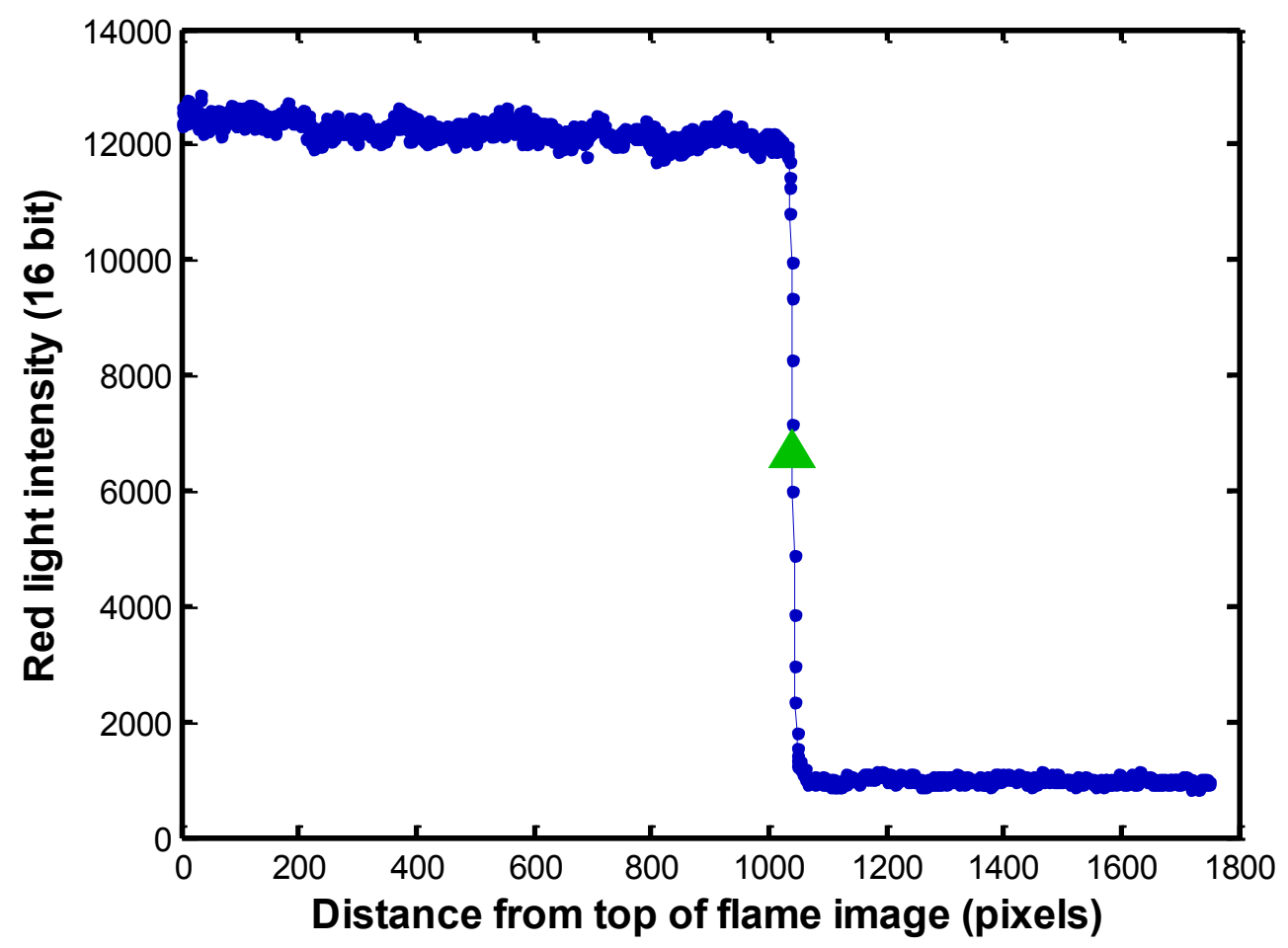

Figure 3.17: Vertical slice across burner to find burner top edge 


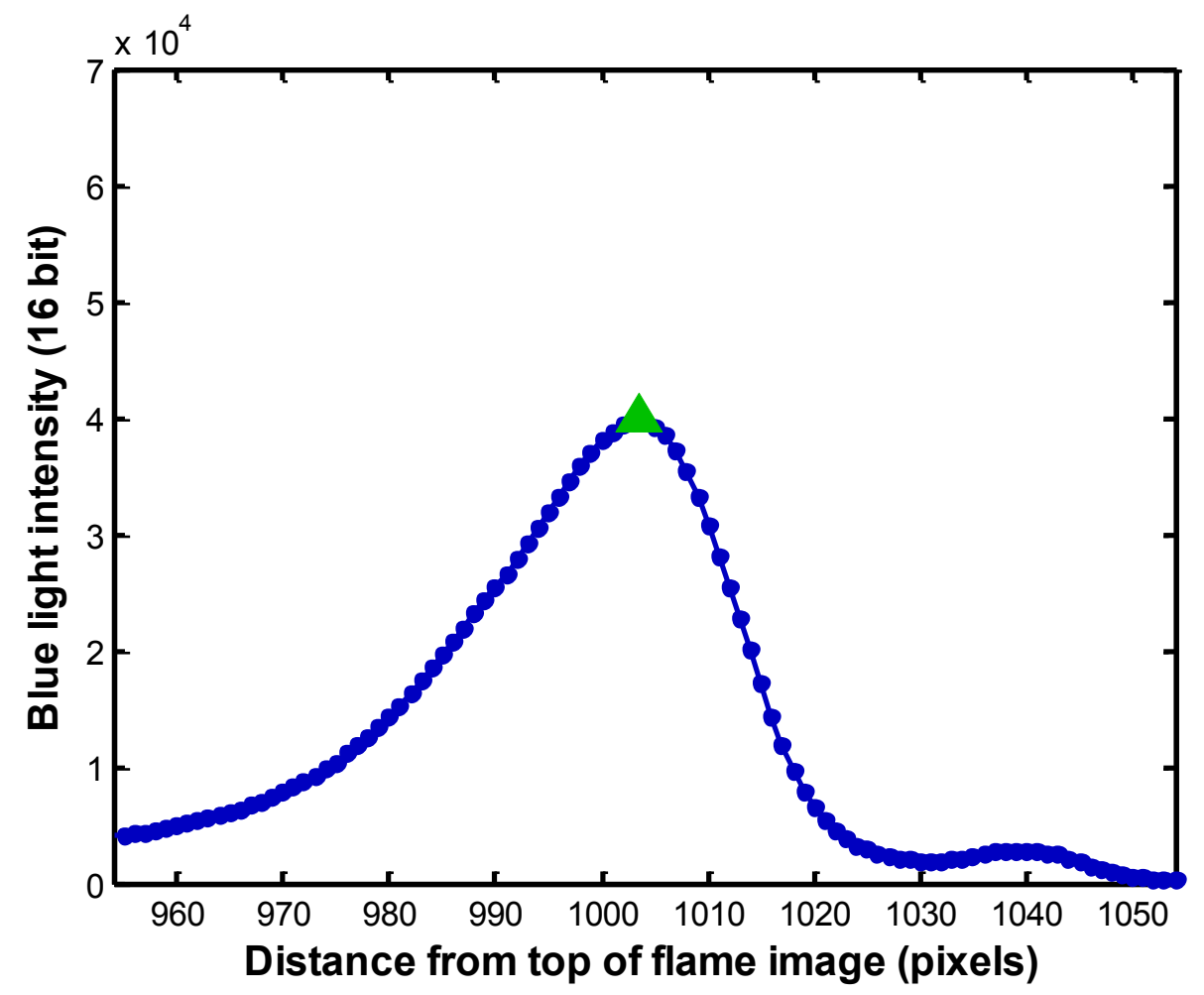

Figure 3.18: Vertical slice across flame used to find flame centre

\subsection{Experimental Procedure}

\subsubsection{Acoustic Characterization}

Figure 3.19 shows the variation in the acoustic velocity (the fluctuating component of velocity) with frequency for a fixed speaker voltage. There is a jump in the acoustic velocity at $200 \mathrm{~Hz}$ which corresponds to the point where the speaker amplification was increased to ensure that the higher frequency signals could be resolved. The lack of peaks demonstrates that the burner has no acoustic modes within this frequency range. 


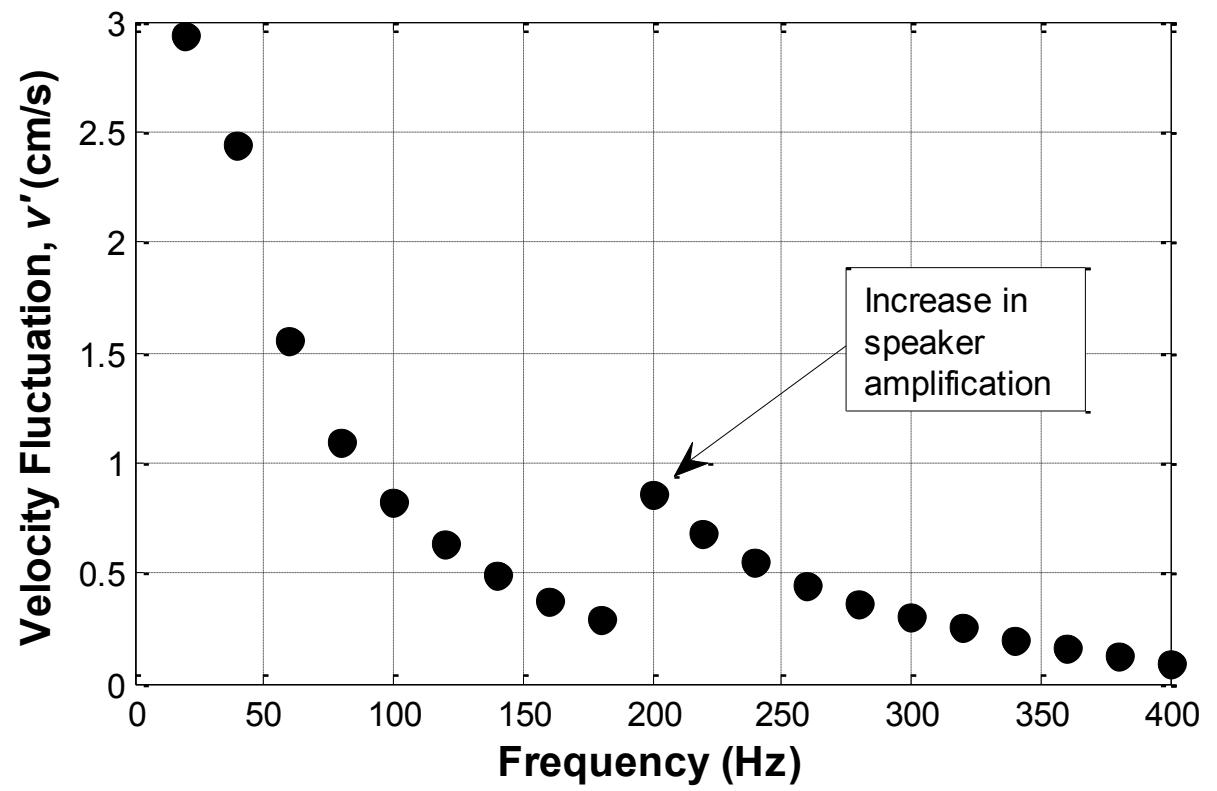

Figure 3.19: Variation of acoustic velocity with frequency at constant speaker voltage

\subsubsection{Burner Thermal Stabilization}

Studies were done to characterize system transients that would affect the flame response measurements. The flame was forced at a constant frequency and amplitude and data were collected for a duration of two hours after the flame was lit. Figure 3.20 shows the start-up transients in the transfer function magnitude and the reactant gas temperature. Both stabilized after 60 min. Figure 3.21 shows the transients in the mean velocity measured by the LDV at the central axis of the burner and the burner temperature measured by the K-type thermocouple closer to the top of the burner. As the burner heats up, the mean velocity drops, most likely caused by the development of a thermal boundary layer within the burner which causes a local convection cell. The ceramic honeycomb re-establishes a uniform velocity profile, as evidenced by the flat nature of 
the flame. The velocity profile upstream of the honeycomb did not influence the fluctuating component of velocity.

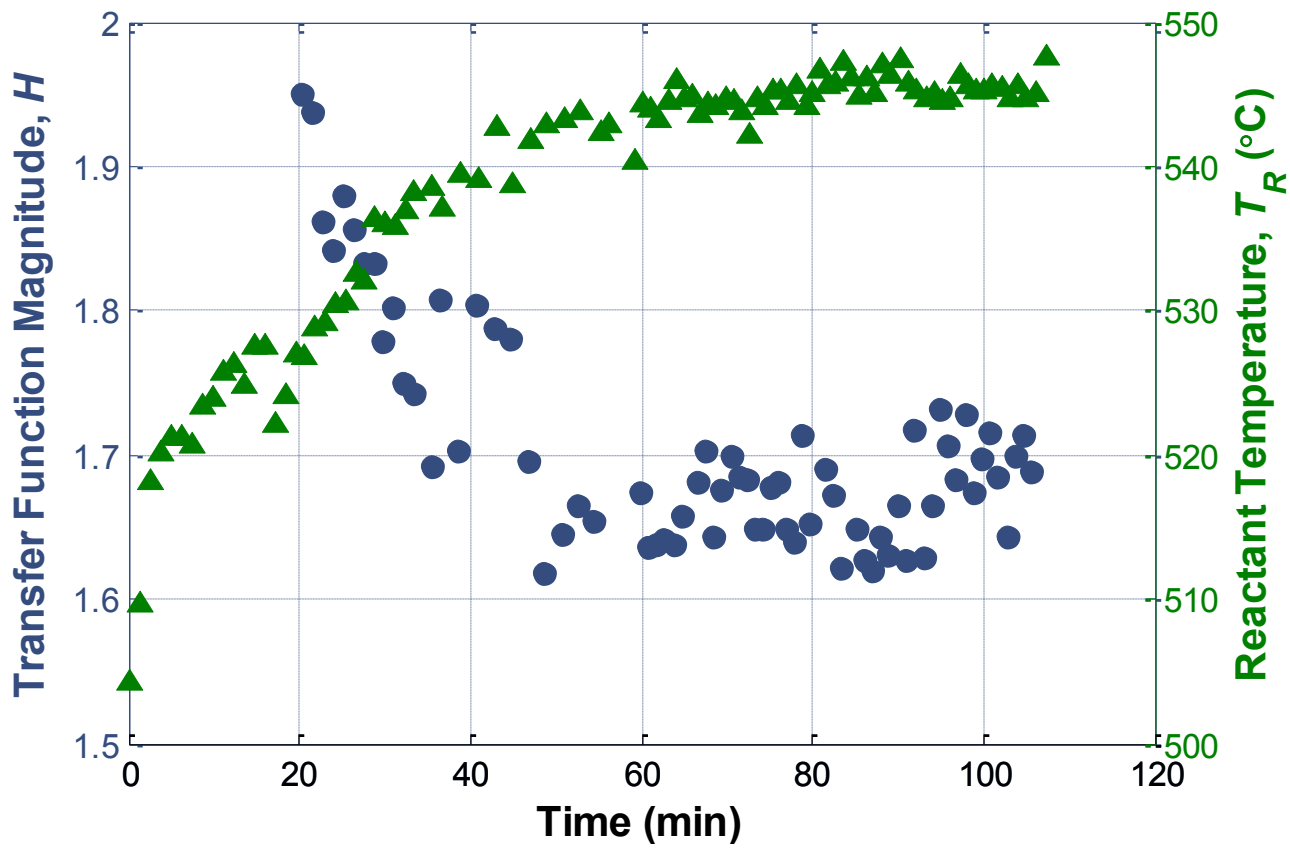

Figure 3.20: Transfer function magnitude transient

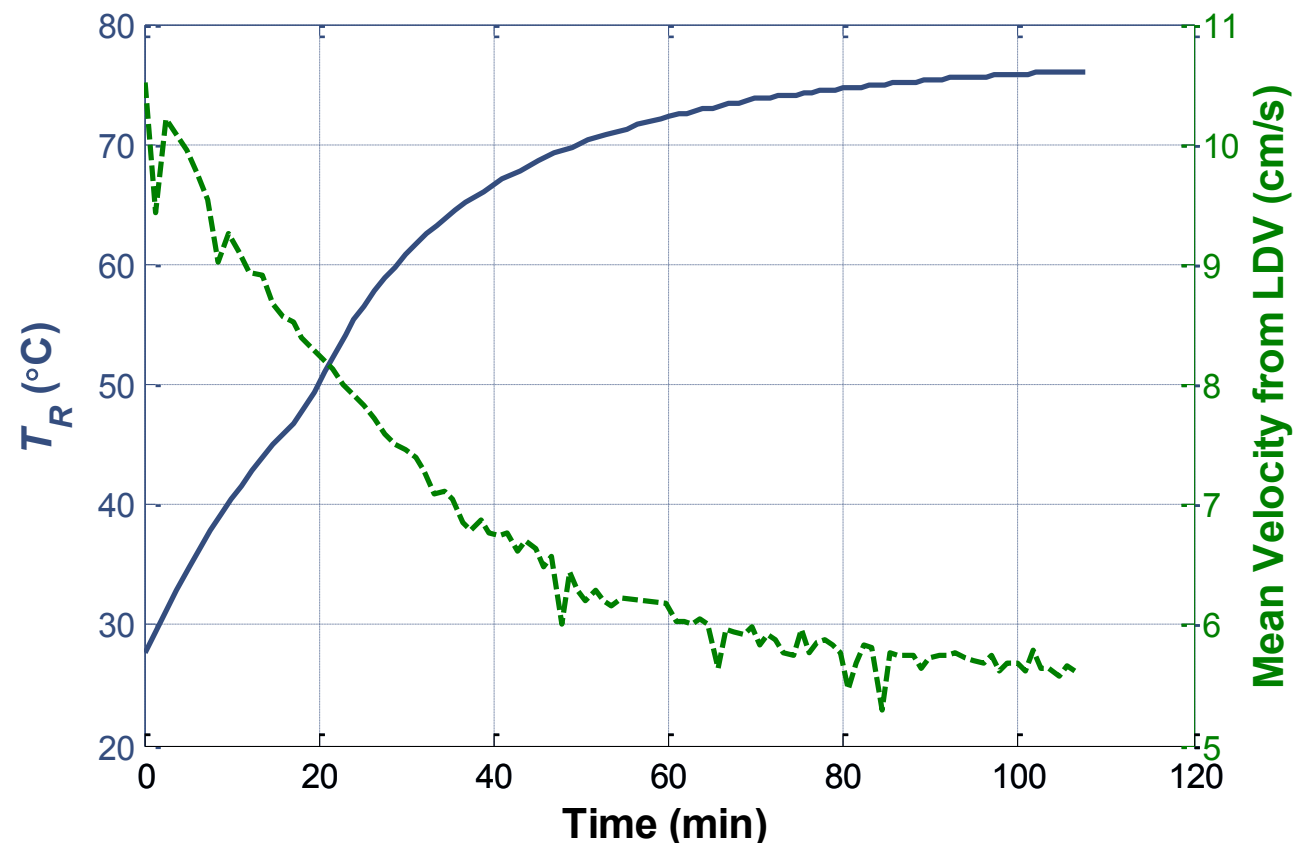

Figure 3.21: Burner warm-up transient 
Figure 3.22 shows the transient in the flame liftoff distance. The variation in the flame liftoff distance after 90 min was assumed to be part of the measurement uncertainty and taken as the precision error of the liftoff distance measurement, as outlined in the uncertainty analysis in Appendix A.4. From these results, it was decided that a $90 \mathrm{~min}$ warm-up time was sufficient to allow the transients in the system to stabilize.

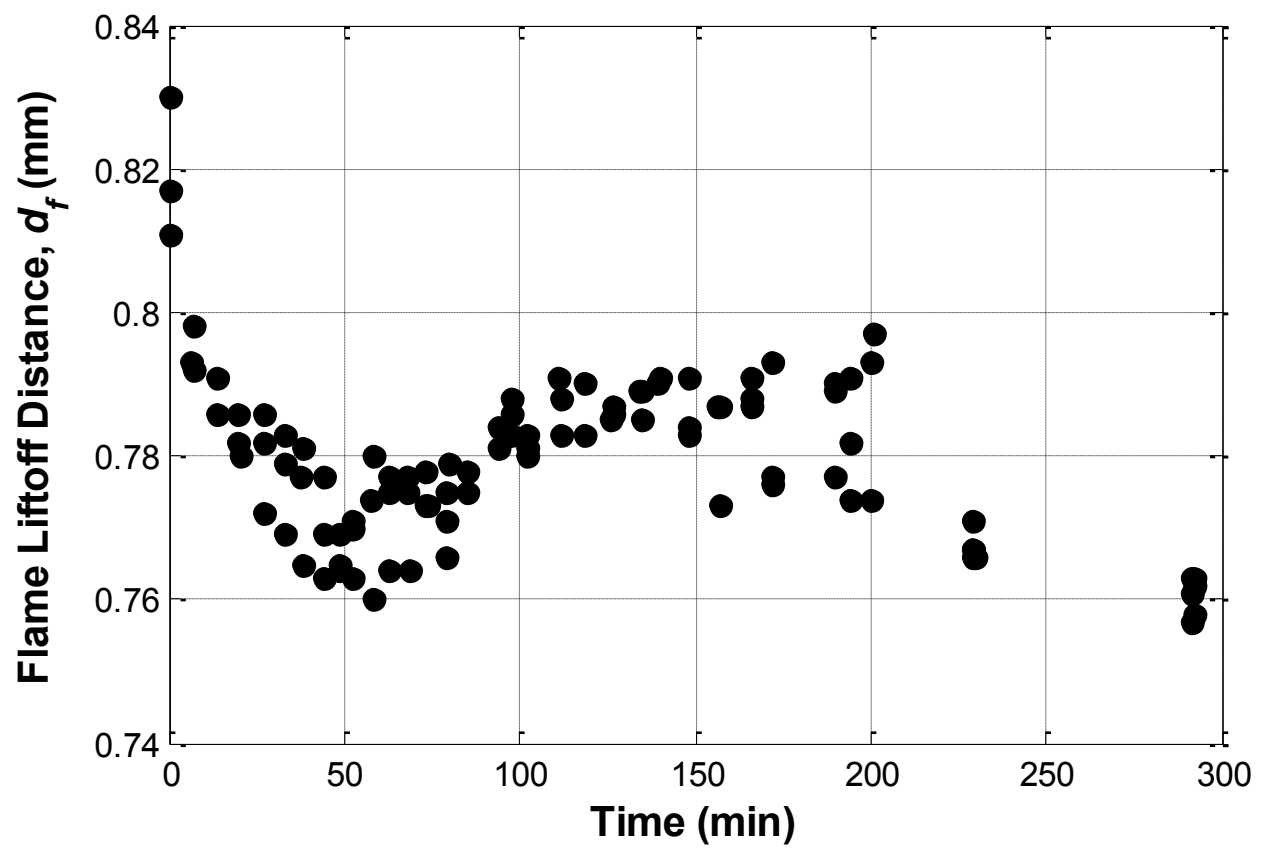

Figure 3.22: Flame position transient

\subsubsection{Test Procedure}

At the start of testing, the equipment was first turned on to allow warm up. Next the LabVIEW control and data acquisition program was started and the bottled gas tanks were opened, pressurizing the lines. A methane flame was always used to start the burner. The system was allowed to stabilize for $30 \mathrm{~min}$. The gas flows were then set for 
the required test condition, the flow of LDV seeding fluid was turned on, and the burner was given at least another 60 min to thermally stabilize.

Once the burner was thermally stable and the system was ready for testing, the dark current was measured and a set of flame images were taken. The flame transfer function measurements were then conducted by stepping through the chosen forcing frequencies. The dark current was then measured again and another set of flame images were taken to see if the flame position changed during testing. The flow rates and operating conditions were then changed as required for the next test points and the burner was given another $30 \mathrm{~min}$ to thermally stabilize.

\subsubsection{LDV Convergence Study}

A convergence study was done to determine the number of data points required to accurately measure the acoustic velocity via LDV. Figure 3.23 shows the variation in the acoustic velocity measured with the LDV as the number of data points used in the calculation increases. The acoustic velocity reaches a steady level at around 10000 data points and then slowly decreases. This decrease may be due to the influence of drift in the LDV mean velocity shown in Figure 3.24. Once the signal is ensemble averaged, the drift adds extra noise, and for longer sampling times there will be proportionally more noise added to the fluctuating component of velocity by drift. The phase of the acoustic velocity was within the range of 310 to $314^{\circ}$ relative the reference signal for all cases.

From these results, it was decided that 10000 points was sufficient to accurately calculate the acoustic velocity, without incurring additional error due to drift associated with longer sampling times. 


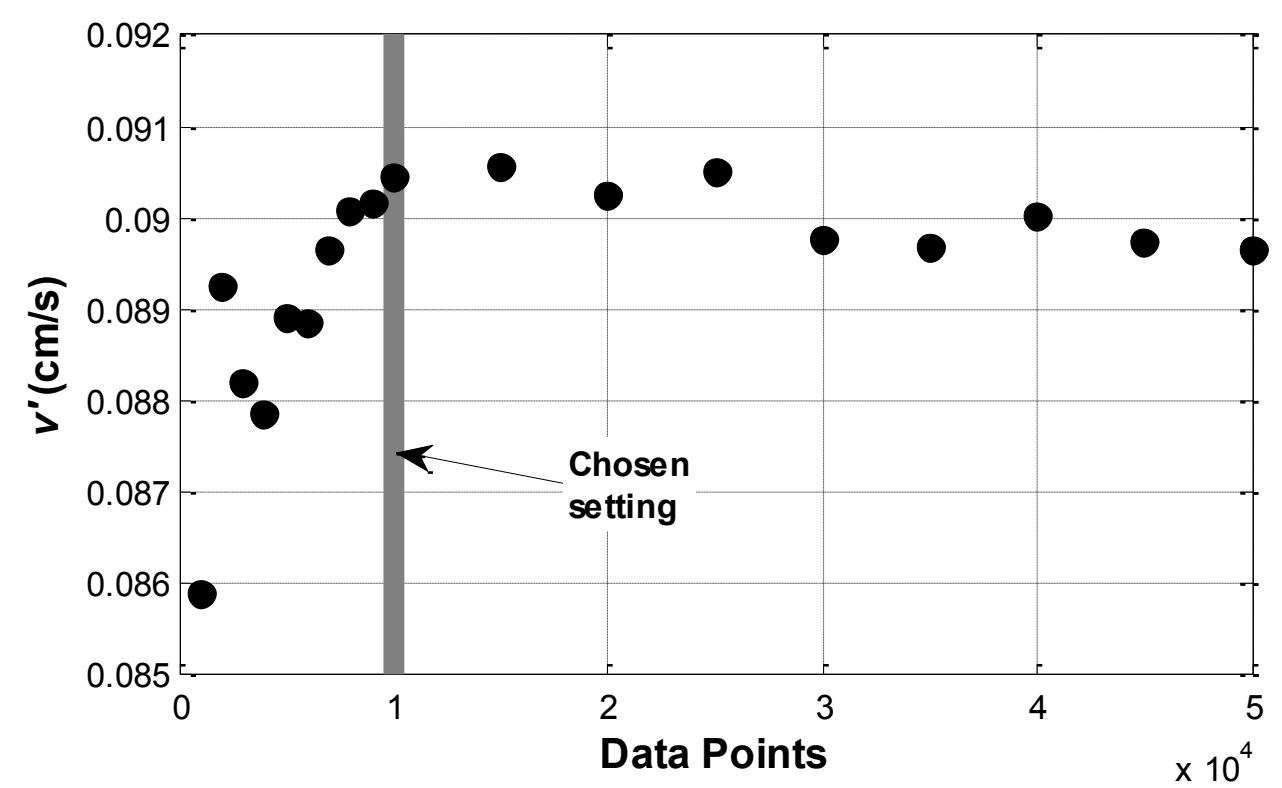

Figure 3.23: LDV acoustic velocity convergence

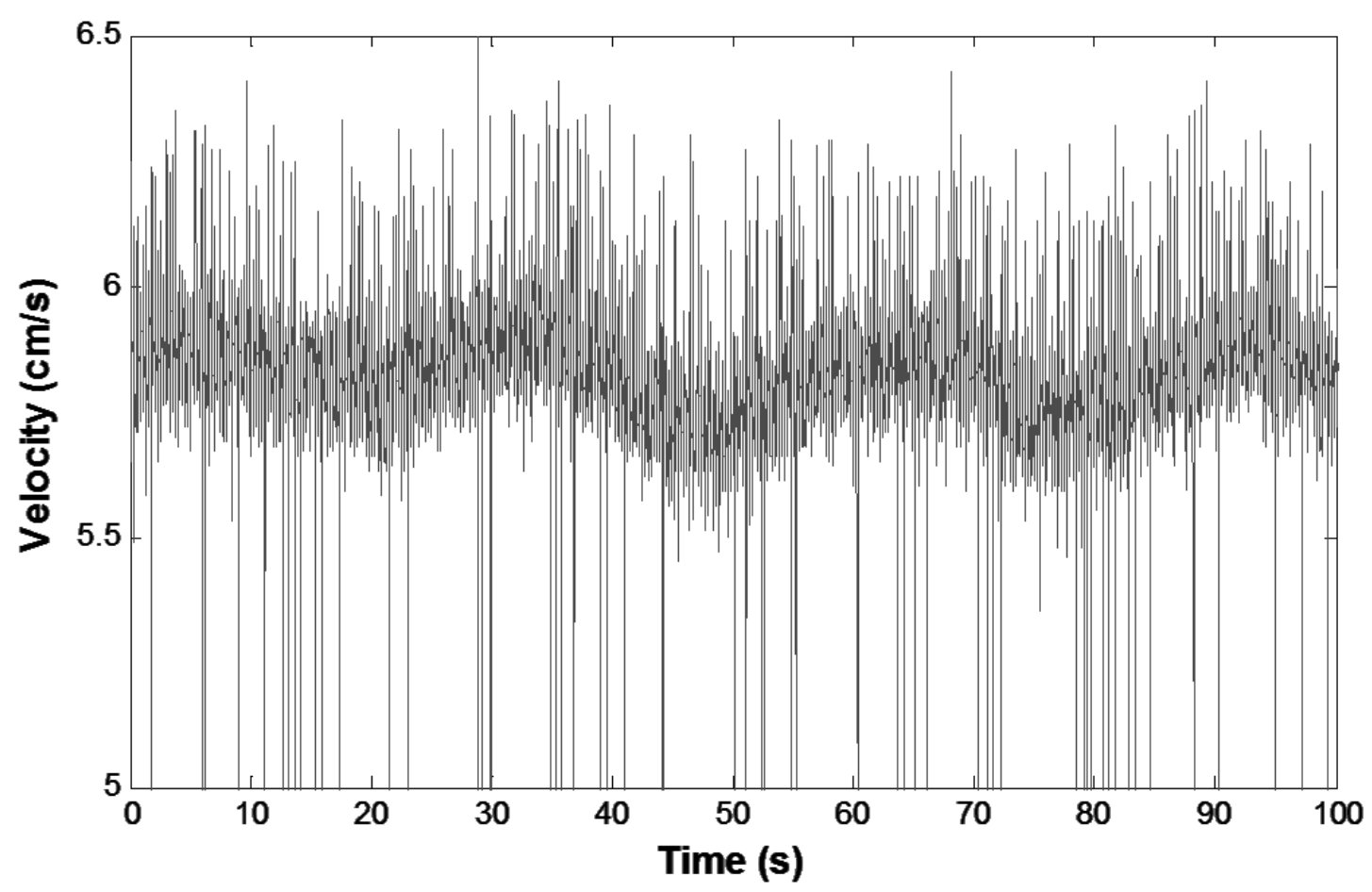

Figure 3.24: Drift in raw LDV velocity signal 


\subsubsection{Photomultiplier Tube Gain Optimization}

Prior to commencing full experiments, studies were done to characterize the linearity of the photomultiplier tube (PMT) so that a suitable high voltage setting could be chosen. The gain curve of the PMT supplied by the manufacturer states that the gain varies exponentially from $10^{4}$ to $10^{7}$ as the high voltage is varied from 0.6 to $1.6 \mathrm{kV}$. Due to the low light levels of the flame chemiluminescence signal, it was desirable to have a high gain while staying within the linear operating region of the PMT. Tests were done on a methane flame operating at an equivalence ratio of 0.8 and mean velocity of $5.8 \mathrm{~cm} / \mathrm{s}$ as this flame was expected to have a high heat release rate relative to the range of operating conditions to be studied. Forcing was applied at $100 \mathrm{~Hz}$ at with an amplitude similar to what would be used during testing.

Figure 3.25 shows the mean of the PMT output signal (an indicator of the heat release rate) as the high voltage setting of the PMT is increased. After $1.6 \mathrm{kV}$, the PMT saturates and the output plateaus. This level was therefore avoided.

Figure 3.26 shows the variations of the heat release rate fluctuation (normalized by the mean heat release rate) and its first harmonic (normalized by the heat release rate fluctuation) as the high voltage setting of the PMT (which determines the PMT gain) is increased. The fluctuating component of heat release rate is constant for high voltage settings above $1.2 \mathrm{kV}$ while the $1^{\text {st }}$ harmonic exhibits some variation. This is most likely due to a low signal to noise ratio in the FFT since the harmonic signal is much weaker than the signal at the forcing frequency. The signal to noise ratio of the fluctuating component of heat release rate compared to the background levels of the FFT was in the range of 65 to 70 throughout the optimization tests. A high voltage setting of $1.4 \mathrm{kV}$ was 
chosen to achieve high gain, while ensuring that the heat release rate would not reach the saturation point.

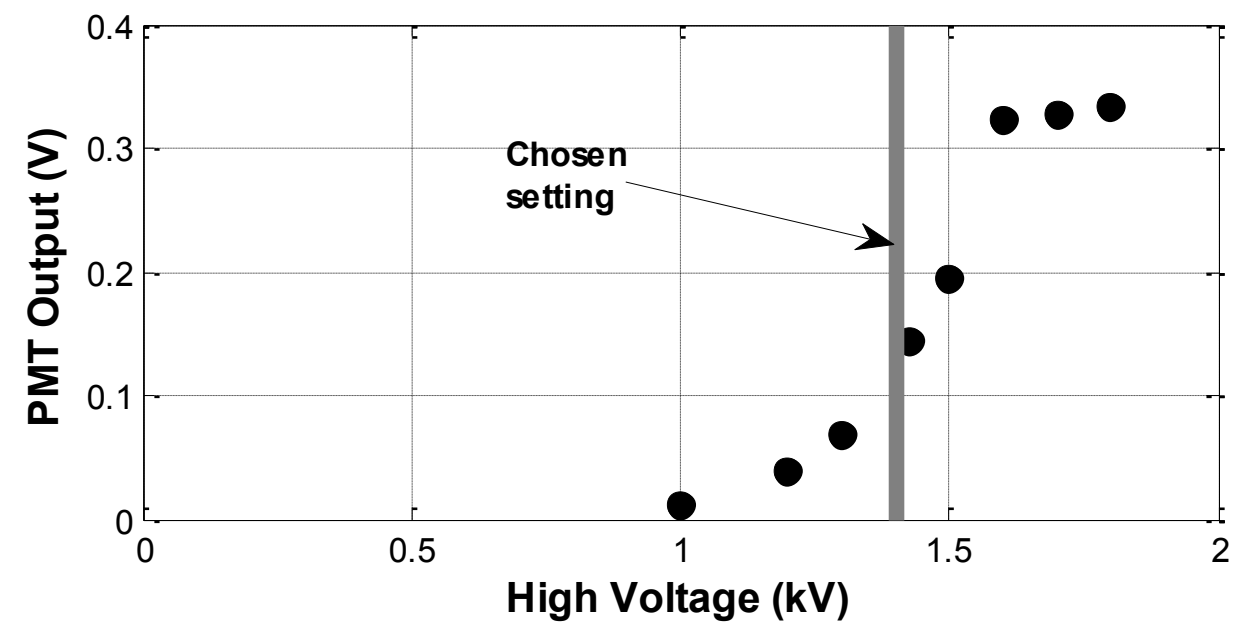

Figure 3.25: Effect of high voltage setting on PMT output

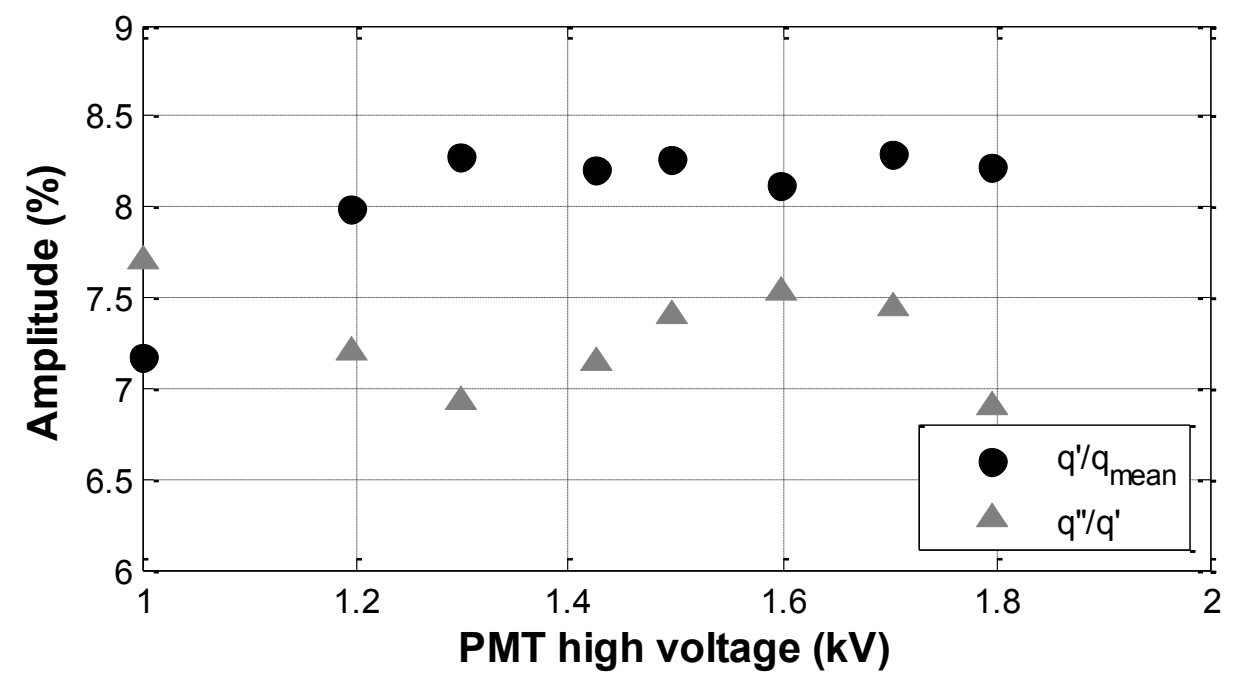

Figure 3.26: Effect of PMT high voltage on heat release fluctuation and harmonics 


\subsubsection{Photomultiplier Dark Current Correction Procedure}

The PMT dark current was measured before and after every flame condition (fuel mixture). At the beginning, the dark current was measured by turning off the flame in the darkened enclosure and allowing the PMT signal to stabilize. The flame was then lit again, and given 15 min to stabilize. Later on it was determined that covering the PMT yielded the same measurement of dark current as turning off the flame. This implies that the darkened test enclosure was well sealed and most of the dark current is internal. The second method of covering up the PMT to measure the dark current was used afterwards. This was done to reduce the total testing time and remove an extra stabilization period. Figure 3.27 shows the dark current transient over a typical 7 hour test day. The dark current stabilizes after about 2 hours. Data taking was normally started after 1.5 hours.

To obtain an accurate estimate of the dark current for a given forcing frequency, a linear interpolation was done using the dark current measured before and after the flame response data were collected.

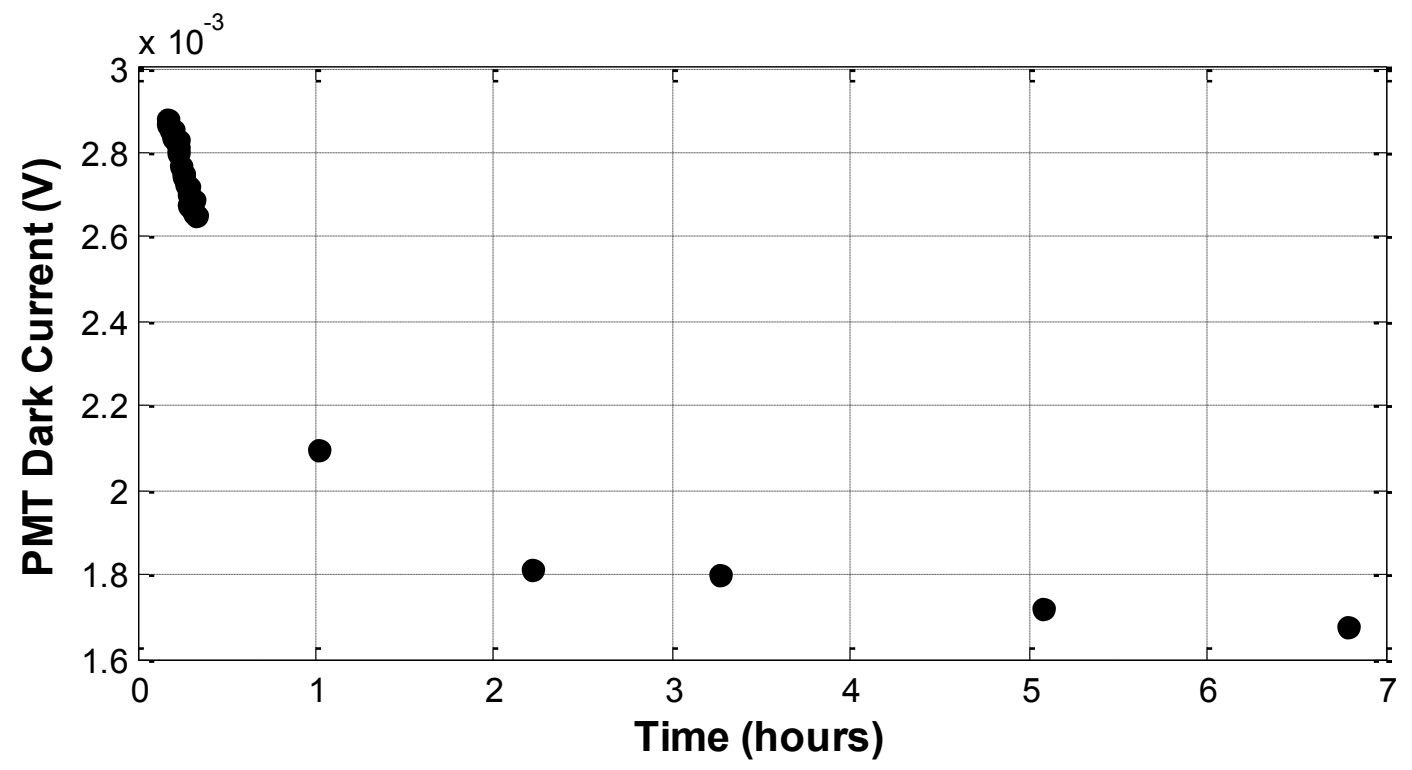

Figure 3.27: PMT Dark Current Transient 


\section{Chapter 4}

\section{Results}

\subsection{Fuel Test Matrix and Burner Operability Limits}

This research is motivated by the limits of current understanding of the effects of fuel composition on combustion instabilities, especially in the context of syngas and biogas. The primary goal of this thesis was to examine the effect of fuel composition on flame response. Methane was chosen as the base fuel for experiments since it is the major constituent in natural gas - a common fuel for industrial gas turbines. Fundamental studies of methane flames investigating the effect of flow velocity and equivalence ratio were also conducted to allow a comparison with previous work by Khanna (2001). Biogas was simulated as a mixture of $60 \% \mathrm{CH}_{4}$ and $40 \% \mathrm{CO}_{2}$, while syngas was simulated as a mixture of $\mathrm{H}_{2}$ and $\mathrm{CO}$ in varying concentrations which were blended with $\mathrm{CH}_{4}$. Due to the high flame speeds, flames of pure syngas mixtures could not be stabilized in the current apparatus. All flame response studies were done independently using both $\mathrm{OH}^{*}$ and $\mathrm{CH}^{*}$ chemiluminescence as an estimate of the flame heat release rate.

Table 4.1 summarizes the different experimental studies that were undertaken in this thesis. Studies 1 and 2 were conducted with a methane flame to examine how flame response was affected by independently varying the equivalence ratio and mean velocity while holding other operating conditions constant. Fuel composition effects were 
considered in studies 3 and 4, for which various methane/syngas flames were used with a constant mean velocity of $6 \mathrm{~cm} / \mathrm{s}$ and an equivalence ratio of 0.65 . Study 3 examined the effect of varying the $\mathrm{CH}_{4}$ concentration while keeping the $\mathrm{H}_{2}$ :CO ratio constant. Study 4 considered the effect of varying the $\mathrm{H}_{2}$ : $\mathrm{CO}$ ratio while keeping the $\mathrm{CH}_{4}$ concentration constant. For Study 5, the flame responses of methane, biogas, and methane/syngas flames were compared over a wide range of operating conditions.

Table 4.1: Summary of flame response studies in this thesis

\begin{tabular}{|c|l|c|c|}
\hline Study \# & Fuel Mixtures & Constants & Variables \\
\hline 1 & $\mathrm{CH}_{4}$ & Fuel, $\bar{v}$ & $\phi$ \\
\hline 2 & $\mathrm{CH}_{4}$ & Fuel, $\phi$ & $\bar{v}$ \\
\hline 3 & $\mathrm{CH}_{4}+\mathrm{H}_{2}+\mathrm{CO}$ & $\begin{array}{c}\bar{v}, \phi, \\
\mathrm{H}_{2}: \mathrm{CO} \text { ratio }\end{array}$ & $\% \mathrm{CH}_{4}$ \\
\hline 4 & $\mathrm{CH}_{4}+\mathrm{H}_{2}+\mathrm{CO}$ & $\begin{array}{c}\bar{v}, \phi, \\
\% \mathrm{CH}_{4}\end{array}$ & $\mathrm{H}_{2}: \mathrm{CO}$ ratio \\
\hline 5 & $\begin{array}{l}1 . \mathrm{CH}_{4} \\
2 . \mathrm{Biogas}\left(60 \% \mathrm{CH}_{4}, 40 \% \mathrm{CO}_{2}\right) \\
3.50 \% \mathrm{CH}_{4}+25 \% \mathrm{H}_{2}+25 \% \mathrm{CO}\end{array}$ & - & Fuel, $\bar{v}, \phi$ \\
\hline
\end{tabular}

Table 4.2 shows all the individual test conditions for which flame response was measured as part of the five studies listed in Table 4.1. In calculating the equivalence ratio for biogas, carbon dioxide was considered as part of the fuel. The mean flow velocity was calculated based on the total flow rate using the quartz tube diameter of $52.85 \mathrm{~mm}$, and the density was calculated for the incoming flow mixture at ambient temperature and pressure as measured by the Omega iBTX sensor.

Viable operating conditions were limited by flame stability as well as the thermal stresses on the honeycomb. The lowest equivalence ratio that generated a stable flame 
varied depending on the fuel. For example, biogas tended to blow off below an equivalence ratio of 0.65 . Flames at flow velocities below $5 \mathrm{~cm} / \mathrm{s}$ were avoided as they were prone to disturbances from air circulation. At high equivalence ratios (or high hydrogen concentration) the thermal stresses on the ceramic honeycomb were high enough to cause pitting to occur, so they were avoided. A frequency range of 20 to $400 \mathrm{~Hz}$ was chosen for forcing. It was not possible to resolve fluctuations in the heat release rate past $400 \mathrm{~Hz}$.

Table 4.2: Test Conditions

\begin{tabular}{|c|c|c|c|c|c|c|c|c|c|}
\hline \multirow{2}{*}{$\begin{array}{l}\text { Fuel } \\
\text { Type }\end{array}$} & \multirow{2}{*}{$\begin{array}{c}\text { Mixture } \\
\text { Designation }\end{array}$} & \multirow[b]{2}{*}{$\phi$} & \multirow{2}{*}{$\begin{array}{c}\bar{v}^{\mathrm{a}} \\
(\mathbf{c m} / \mathbf{s})\end{array}$} & \multicolumn{4}{|c|}{ Fuel Fractions } & \multirow{2}{*}{$\begin{array}{c}\mathbf{d}_{\mathbf{f}}^{\mathbf{b}, \mathbf{c}} \\
(\mathbf{m m})\end{array}$} & \multirow{2}{*}{$\begin{array}{c}\mathbf{T}_{\mathbf{R}}^{\mathbf{b}, \mathbf{d}} \\
(\mathbf{K})\end{array}$} \\
\hline & & & & $\mathrm{CH}_{4}$ & $\mathbf{H}_{2}$ & CO & $\mathrm{CO}_{2}$ & & \\
\hline \multirow{6}{*}{ Methane } & M & 0.62 & 5.7 & 1 & 0 & 0 & 0 & 1.508 & 598 \\
\hline & M & 0.65 & 6 & 1 & 0 & 0 & 0 & 1.226 & 675 \\
\hline & M & 0.7 & 5 & 1 & 0 & 0 & 0 & 1.087 & 753 \\
\hline & M & 0.7 & 6 & 1 & 0 & 0 & 0 & 0.884 & 794 \\
\hline & M & 0.7 & 7 & 1 & 0 & 0 & 0 & 0.684 & 835 \\
\hline & M & 0.75 & 6 & 1 & 0 & 0 & 0 & 0.693 & 867 \\
\hline \multirow{5}{*}{ Biogas } & B & 0.65 & 6.5 & 0.6 & 0 & 0 & 0.4 & 1.470 & 590 \\
\hline & B & 0.65 & 6.7 & 0.6 & 0 & 0 & 0.4 & 1.386 & 597 \\
\hline & B & 0.7 & 6 & 0.6 & 0 & 0 & 0.4 & 1.110 & 710 \\
\hline & B & 0.8 & 8 & 0.6 & 0 & 0 & 0.4 & 0.781 & 763 \\
\hline & B & 0.8 & 7 & 0.6 & 0 & 0 & 0.4 & 0.602 & 886 \\
\hline \multirow{8}{*}{$\begin{array}{l}\text { Syngas/ } \\
\text { Methane }\end{array}$} & M50H1C1 & 0.55 & 6.5 & 0.5 & 0.25 & 0.25 & 0 & 1.485 & 555 \\
\hline & M50H1C1 & 0.6 & 6 & 0.5 & 0.25 & 0.25 & 0 & 0.937 & 733 \\
\hline & $\mathrm{M} 25 \mathrm{H} 1 \mathrm{C} 1$ & 0.65 & 6 & 0.25 & 0.375 & 0.375 & 0 & 0.553 & 883 \\
\hline & M50H1C1 & 0.65 & 6 & 0.5 & 0.25 & 0.25 & 0 & 0.901 & 785 \\
\hline & M75H1C1 & 0.65 & 6 & 0.75 & 0.125 & 0.125 & 0 & 1.146 & 705 \\
\hline & $\mathrm{M} 50 \mathrm{H} 2 \mathrm{C} 1$ & 0.65 & 6 & 0.5 & 0.333 & 0.167 & 0 & 0.865 & 781 \\
\hline & M50H1C2 & 0.65 & 6 & 0.5 & 0.167 & 0.333 & 0 & 0.827 & 800 \\
\hline & M50H1C1 & 0.65 & 7 & 0.5 & 0.25 & 0.25 & 0 & 0.631 & 839 \\
\hline
\end{tabular}

${ }^{\mathrm{a}} \overline{\boldsymbol{v}}=$ mean flow velocity; ${ }^{\mathrm{b}}$ typical results for this test condition; ${ }^{\mathrm{c}} \mathrm{d}_{\mathrm{f}}=$ flame liftoff distance; ${ }^{\mathrm{d}} \mathrm{T}_{\mathrm{R}}=$ reactant temperature, measured with an R-type thermocouple 


\subsection{Methane Flame Response Results}

Figure 4.1 compares the flame transfer function (FTF) magnitude and phase curves for methane flames with mean velocities of 5,6 , and $7 \mathrm{~cm} / \mathrm{s}$ at a constant equivalence ratio of 0.7 . The magnitude plots resemble those of a low pass filter, where low frequency oscillations are amplified until a cutoff frequency is reached, after which oscillations are attenuated. The error bars represent the measurement uncertainty of the transfer function magnitude. Details of the uncertainty calculations are provided in Appendix A.

Several trends in the magnitude plots are visible in Figure 4.1. Two peaks are visible in all the magnitude plots, a primary peak at higher frequencies and a secondary peak with a lower magnitude at slightly less than half the frequency of primary peak. This bimodal behaviour is considered further in the discussion. As the mean velocity is increased, the peak magnitude decreases and the frequency at which the peak magnitude occurs increases. This is true for both the primary and secondary peaks. At higher mean velocities, the magnitude of the primary peak approaches the magnitude of the secondary peak. 


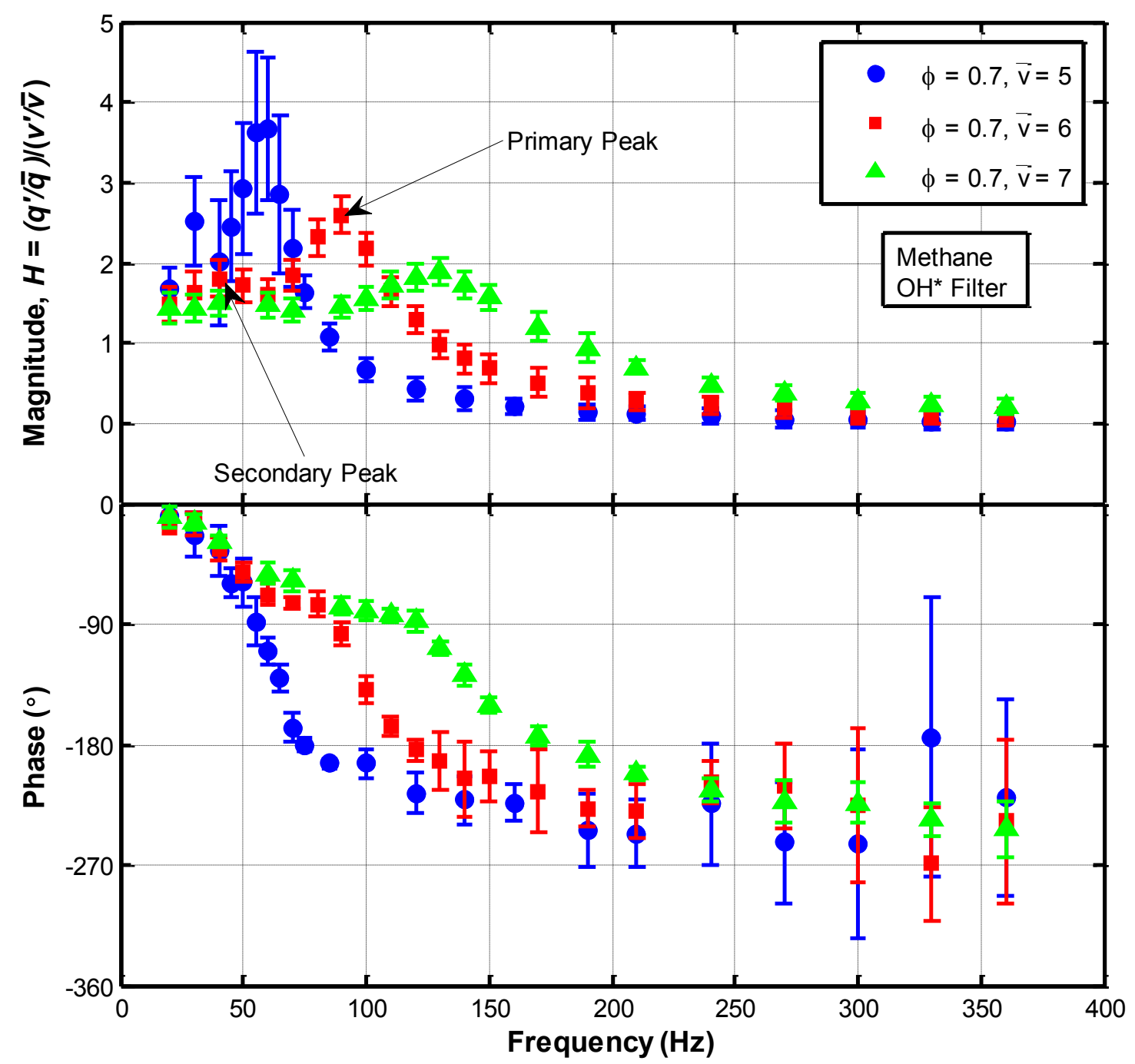

Figure 4.1: Effect of varying $\bar{v}$ on $\mathrm{FTF}$ of $\mathrm{CH}_{4}$ flame $\left(\mathrm{OH}^{*}\right.$ data)

Figure 4.2 shows the magnitude and phase curves for the same test conditions as Figure 4.1, except measured using $\mathrm{CH}^{*}$ chemiluminescence. Although the $\mathrm{CH}^{*}$ filter based plot have higher absolute values of FTF magnitude than the $\mathrm{OH}^{*}$ based plots, the trends are comparable. Flame response magnitudes from $\mathrm{OH}^{*}$ measurements were always higher than those based on $\mathrm{CH}^{*}$ measurements. This was independent of the mean values of the heat release rate measured by using $\mathrm{OH}^{*}$ and $\mathrm{CH}^{*}$ 
chemiluminescence, which varied significantly and showed inconsistent trends. These are discussed further in Section 5.3. Although all flame response measurements were repeated using both $\mathrm{OH}^{*}$ and $\mathrm{CH}^{*}$ filters, only results from $\mathrm{OH}^{*}$ chemiluminescence are shown from this point forward since the $\mathrm{OH}^{*}$ and $\mathrm{CH}^{*} \mathrm{FTF}$ plots always show the same trends.

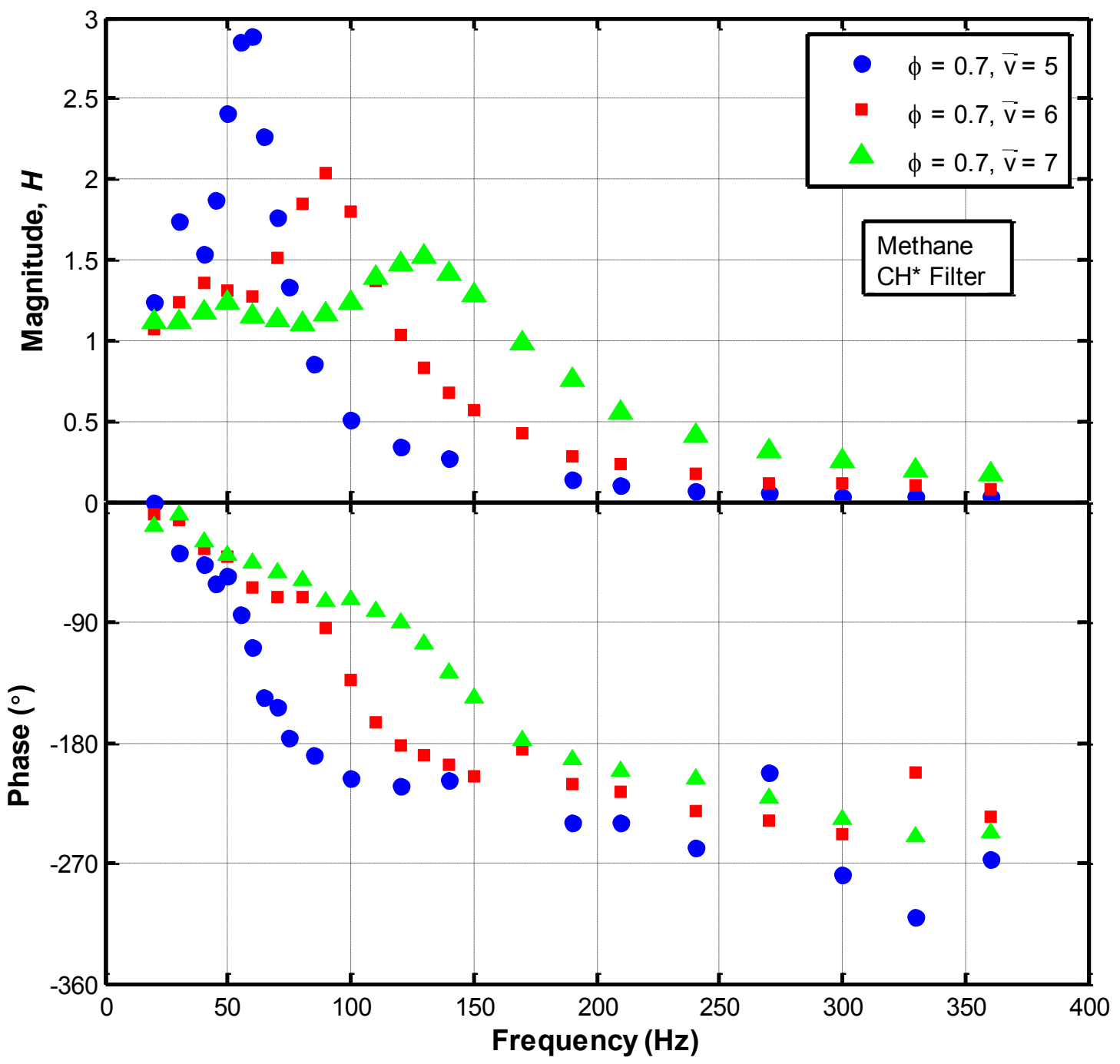

Figure 4.2: Effect of varying $\bar{v}$ on $\mathrm{FTF}$ of $\mathrm{CH}_{4}$ flame $\left(\mathrm{CH}^{*}\right.$ data) 
Figure 4.3 shows the flame transfer function magnitude and phase for methane flames with equivalence ratios of $0.65,0.7$ and 0.75 at a constant mean velocity of $6 \mathrm{~cm} / \mathrm{s}$. Trends are similar to those observed previously for methane flames with varying mean velocity. As the equivalence ratio is increased, the peak magnitude decreases while the forcing frequency corresponding to the peak magnitude increases. All of the magnitude curves exhibit the dual peak phenomenon except for the lowest equivalence ratio. This difference may simply be due to the lack of data points at low frequencies.

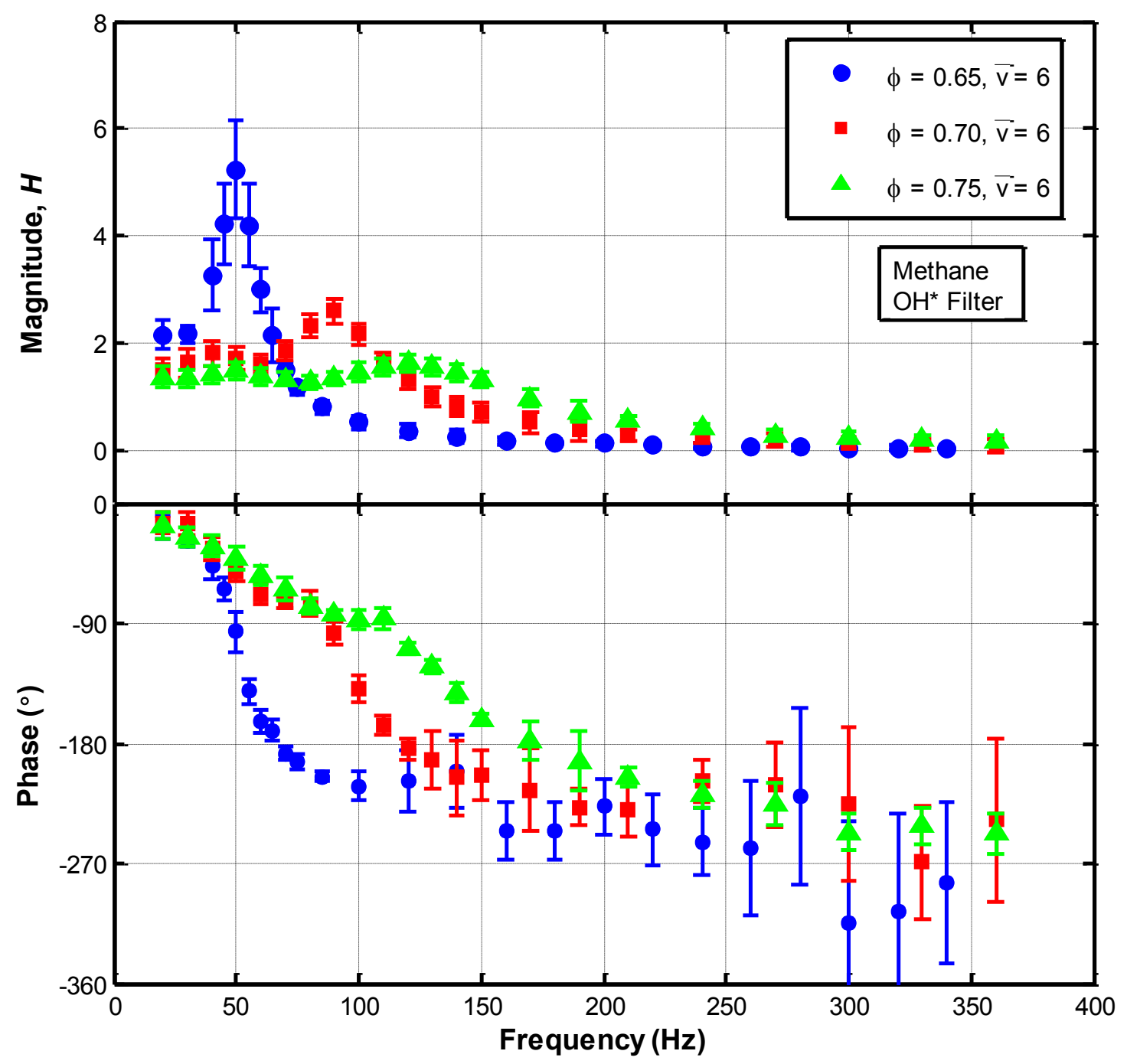

Figure 4.3: Effect of varying $\phi$ on $\mathrm{FTF}$ of $\mathrm{CH}_{4}$ flame $\left(\mathrm{OH}^{*}\right.$ data) 


\subsection{Results of Parametric Methane/Syngas Flame Response}

Figure 4.4 shows how varying the methane concentration from $25 \%$ to $100 \%$ in a methane/syngas flame affects the magnitude of the flame transfer function. Syngas is simulated as an equal volumetric mix of hydrogen and carbon monoxide. The mean velocity and equivalence ratio were kept constant at $6 \mathrm{~cm} / \mathrm{s}$ and 0.65 respectively. These operating conditions were chosen due to the ability to obtain a stable flame at all fuel compositions. None of the FTF magnitude curves show the secondary peak seen in previous methane magnitude plots. This may be due to inadequate resolution in the data, and could be confirmed by measuring the transfer functions at more frequencies in this area. Here we see that as the syngas concentration increases, the peak magnitude decreases and the forcing frequency at which the peak occurs increases. For the $25 \% \mathrm{CH}_{4}$ mixture, the FTF magnitude plot has no peak and instead decreases monotonically. This implies that the flame is highly damped. Attempts were made to obtain flame response data for $\mathrm{H}_{2} / \mathrm{CO}$ syngas without $\mathrm{CH}_{4}$, but it was difficult to stabilize these flames due to the high flame speed of the mixture. Mixtures with high concentrations of hydrogen were prone to flashback which ignited the gas inside the main chamber of the burner. This created a pressure wave strong enough to influence the calibration of the microphones and occasionally even break the quartz tube.

Figure 4.5 shows the flame transfer function magnitude plots for methane/syngas flames with a constant methane concentration of $50 \%$ and varying $\mathrm{H}_{2}: \mathrm{CO}$ ratios from 0.5 to 2. The magnitude plots are similar for all three cases and a secondary peak is again visible. While it would have been interesting to see how the $\mathrm{H}_{2}$ : $\mathrm{CO}$ ratio affects the flame 
response in the absence of $\mathrm{CH}_{4}$, this was not possible due to flame stability issues mentioned previously.

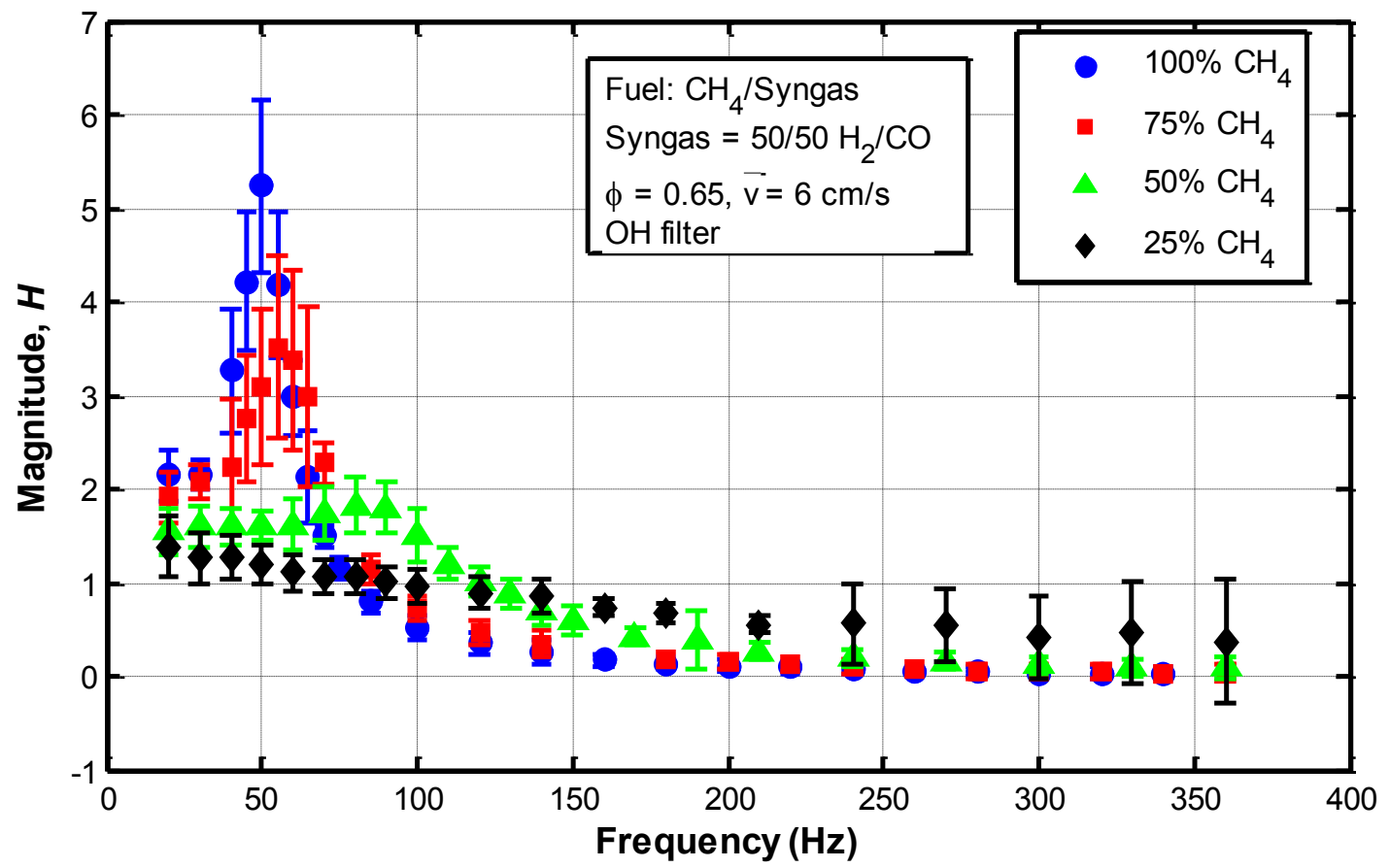

Figure 4.4: Effect of varying \% $\mathrm{CH}_{4}$ on $\mathrm{FTF}$ of $\mathrm{CH}_{4} /$ syngas flame ( $\mathrm{OH}^{*}$ data)

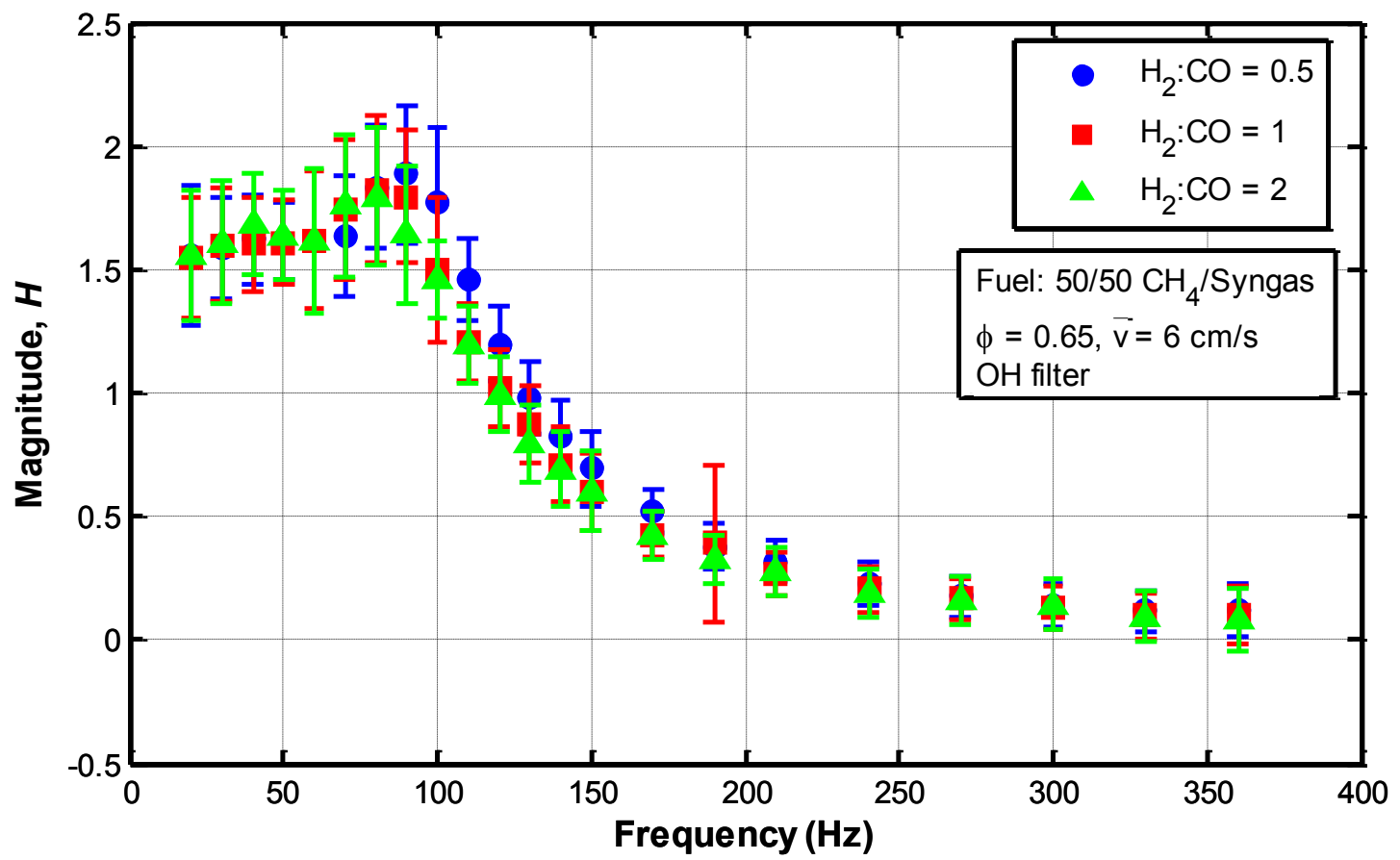

Figure 4.5: Effect of varying $\mathrm{H}_{2}$ : $\mathrm{CO}$ ratio on $\mathrm{FTF}$ of $\mathrm{CH}_{4} / \mathrm{syngas}$ flame (OH* data) 


\subsection{Summary of Trends}

From the above data it is clear that the operating conditions and fuel composition have a significant impact on the flame transfer magnitude and phase. Increasing the equivalence ratio, mean velocity, and syngas concentration all had the same effect on the FTF - to increase the frequency of the primary and secondary peaks while reducing the magnitude of the peak. A change in the hydrogen to carbon monoxide ratio had little effect on the FTF for a syngas-methane mixture.

Two distinct trends to be investigated further are the shift in the frequency of the

peak, (also visible as a change in the phase of the FTF), and the accompanying change in the magnitude of the peak. 


\section{Chapter 5}

\section{Discussion}

\subsection{FTF Classification and Modelling}

Flame transfer functions were modelled using the System Identification Toolbox in Matlab. The main goal of the modelling was to estimate the magnitude of the primary peak. Trends in peak magnitudes are analyzed and discussed in Section 5.5. A built-in Matlab function based on the iterative prediction-error minimization method was used to generate state space models that matched the experimental FTF magnitude and phase curves. Given frequency domain data as the input, the output of the Matlab function was a transfer function model. Damping ratios and natural frequencies of the primary peak along with the resulting transfer function models for all the test conditions are shown in Appendix B. The flame transfer functions were classified into one of four types based on their magnitude plots. Table 5.1 shows which test conditions fall under each classification. 
Table 5.1: FTF Types

\begin{tabular}{|c|c|c|c|c|c|}
\hline Type & Fuel & $\phi$ & $\begin{array}{c}\bar{v} \\
(\mathbf{c m} / \mathbf{s})\end{array}$ & $\begin{array}{c}\mathbf{d}_{\mathrm{f}} \\
(\mathbf{m m})\end{array}$ & $T_{R}(K)$ \\
\hline \multirow{8}{*}{$\begin{array}{c}\text { I } \\
\text { (Single Dominant } \\
\text { peak) }\end{array}$} & $\mathrm{M}$ & 0.62 & 5.7 & 1.508 & 598 \\
\hline & B & 0.65 & 6.5 & 1.47 & 590 \\
\hline & $\mathrm{M} 50 \mathrm{H} 1 \mathrm{Cl}$ & 0.55 & 6.5 & 1.485 & 555 \\
\hline & B & 0.65 & 6.7 & 1.386 & 597 \\
\hline & M & 0.65 & 6 & 1.226 & 675 \\
\hline & $\mathrm{M} 75 \mathrm{H} 1 \mathrm{Cl}$ & 0.65 & 6 & 1.146 & 705 \\
\hline & B & 0.7 & 6 & 1.11 & 710 \\
\hline & $\mathrm{M} 50 \mathrm{H} 1 \mathrm{Cl}$ & 0.6 & 6 & 0.937 & 733 \\
\hline \multirow{8}{*}{$\begin{array}{c}\text { II } \\
\text { (Two distinct peaks: } \\
1 \text { dominant, } \\
1 \text { secondary) }\end{array}$} & $\mathrm{M}$ & 0.7 & 5 & 1.087 & 753 \\
\hline & $\mathrm{M} 50 \mathrm{H} 1 \mathrm{Cl}$ & 0.65 & 6 & 0.901 & 785 \\
\hline & M & 0.7 & 6 & 0.884 & 794 \\
\hline & $\mathrm{M} 50 \mathrm{H} 2 \mathrm{C} 1$ & 0.65 & 6 & 0.865 & 781 \\
\hline & $\mathrm{M} 50 \mathrm{H} 1 \mathrm{C} 2$ & 0.65 & 6 & 0.827 & 800 \\
\hline & B & 0.7 & 8 & 0.781 & 763 \\
\hline & M & 0.75 & 6 & 0.693 & 867 \\
\hline & M & 0.7 & 7 & 0.684 & 835 \\
\hline \multirow{2}{*}{$\begin{array}{c}\text { III } \\
\text { (Two distinct, equal } \\
\text { magnitude peaks) }\end{array}$} & $\mathrm{M} 50 \mathrm{H} 1 \mathrm{C} 1$ & 0.65 & 7 & 0.631 & 839 \\
\hline & B & 0.8 & 7 & 0.602 & 886 \\
\hline $\begin{array}{c}\text { IV } \\
\text { (No visible peak) }\end{array}$ & $\mathrm{M} 25 \mathrm{H} 1 \mathrm{C} 1$ & 0.65 & 6 & 0.553 & 883 \\
\hline
\end{tabular}

Type I FTFs were characterized by one dominant peak with no visible secondary peak. They were adequately described by a second order transfer function model in Matlab of the form:

$$
H(s)_{I}=\frac{K N(s)}{\left(s^{2}+2 \zeta \omega_{n} s+\omega_{n}^{2}\right)}
$$

where $K$ is the system gain, $N(s)$ is the polynomial of zeros, $\zeta$ is the damping ratio, and $\omega_{n}$ is the natural frequency of the system. Figure 5.1 shows the magnitude and phase curves of a type I FTF for $\mathrm{CH}_{4}$ at $\Phi=0.62$ and $\bar{v}=5.7 \mathrm{~cm} / \mathrm{s}$, along with the second order 
Matlab model. Error bars showing the experimental measurement uncertainty in this and subsequent figures were calculated using the procedures outlined in Appendix A.

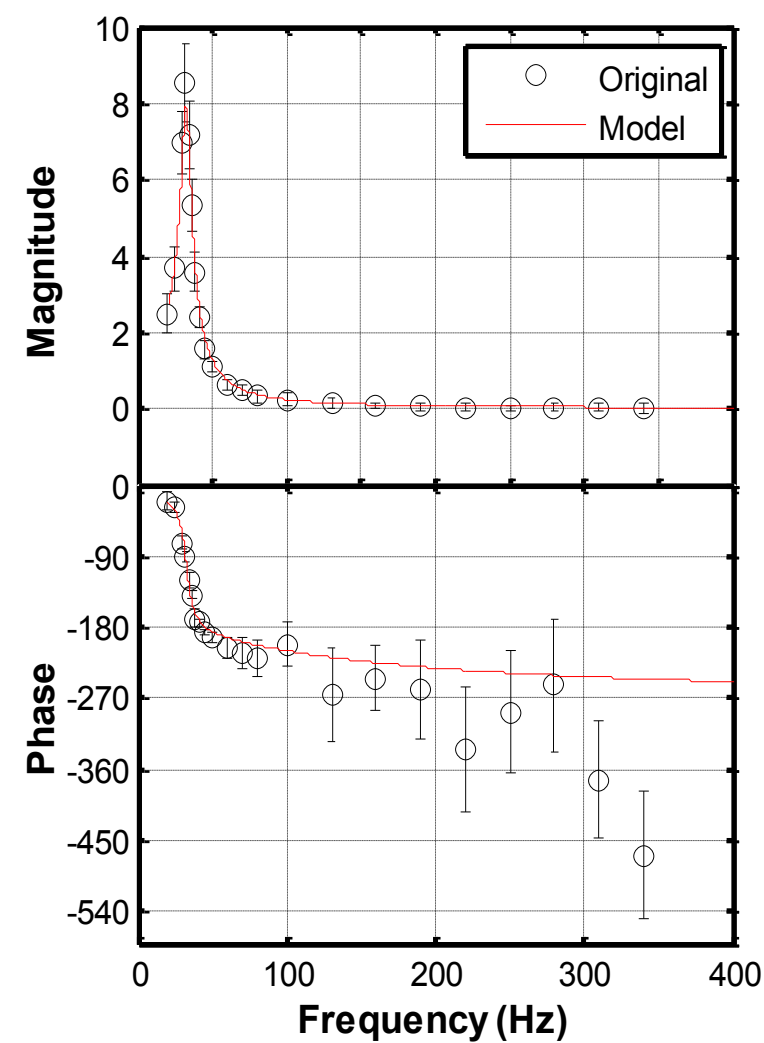

Figure 5.1: Type I FTF $\mathrm{CH} 4 \Phi,=0.62, \bar{v}=5.7 \mathrm{~cm} / \mathrm{s}, \mathrm{OH}^{*}$

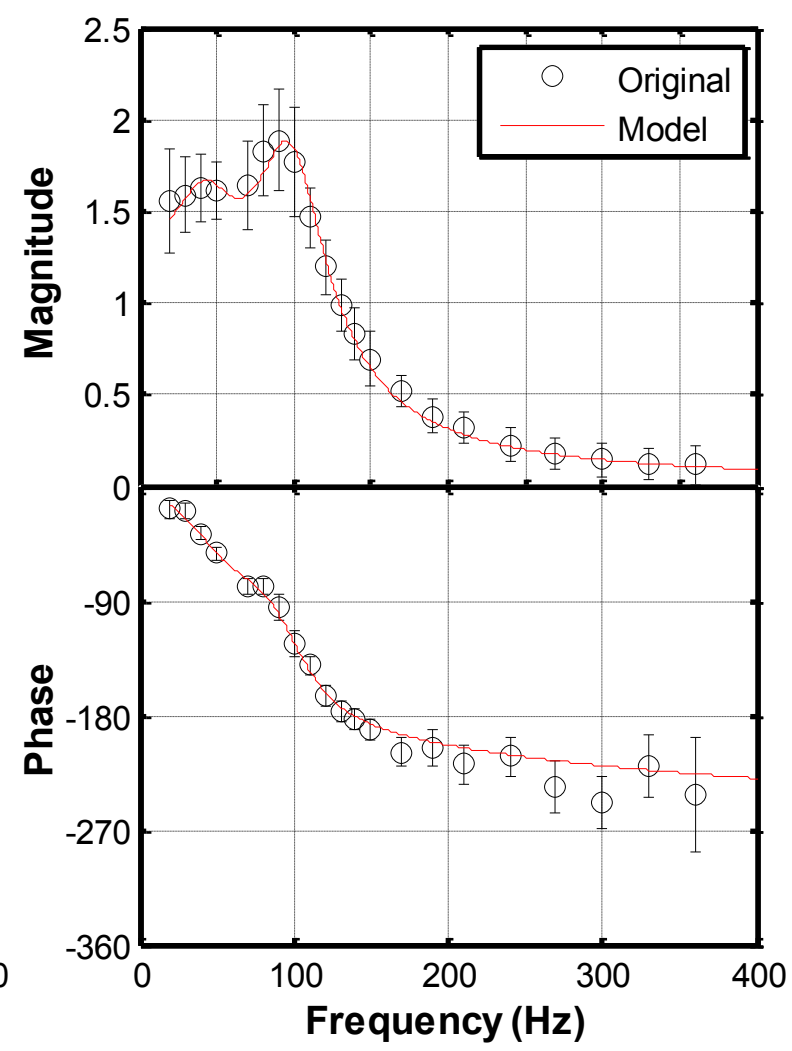

Figure 5.2: Type II FTF M50H1C2, $\Phi=0.65, \bar{v}=6 \mathrm{~cm} / \mathrm{s}, \mathrm{OH}^{*}$

Type II FTFs exhibited two distinct peaks: a dominant primary peak at a higher frequency, and a secondary peak at a lower frequency with lower magnitude. A fourth order model of the form shown in Eq. (5.2) was found to fit the magnitude and phase curves well. Figure 5.2 shows the magnitude and phase curves of a type II FTF obtained for the M50H1C2 fuel mixture at $\Phi=0.65$ and $\bar{v}=6 \mathrm{~cm} / \mathrm{s}$, along with the fourth order model used for fitting. 


$$
H(s)_{I I}=\frac{K N(s)}{\left(s^{2}+2 \zeta_{1} \omega_{n 1} s+\omega_{n 1}^{2}\right)\left(s^{2}+2 \zeta_{2} \omega_{n 2} s+\omega_{n 2}^{2}\right)}
$$

Type III FTFs also exhibited two distinct peaks, but of a similar magnitude. Type III FTFs required a fifth order model (Eq. (5.3)) to accurately capture the magnitude and phase. Figure 5.3 shows the magnitude and phase curves of a type III FTF obtained for M50H1C1 fuel at $\Phi=0.65$ and $\bar{v}=7 \mathrm{~cm} / \mathrm{s}$, along with the fifth order Matlab model.

$$
H(s)_{I I I}=\frac{K N(s)}{\left(s+\zeta_{1} \omega_{n 1}\right)\left(s^{2}+2 \zeta_{2} \omega_{n 2} s+{\omega_{n 2}}^{2}\right)\left(s^{2}+2 \zeta_{3} \omega_{n 3} s+\omega_{n 3}{ }^{2}\right)}
$$

Only one type IV FTF was found, occurring with the M25H1C1 fuel mixture at $\Phi=0.65$ and $\bar{v}=6 \mathrm{~cm} / \mathrm{s}$. The monotonically decreasing trend with no visible peak is indicative of a highly damped system. The system order was more difficult to determine in this case. Both second and third order models fit the curve well, so the second order model was chosen for simplicity. Figure 5.4 shows the magnitude and phase curves of the type IV FTF along with the Matlab model. 


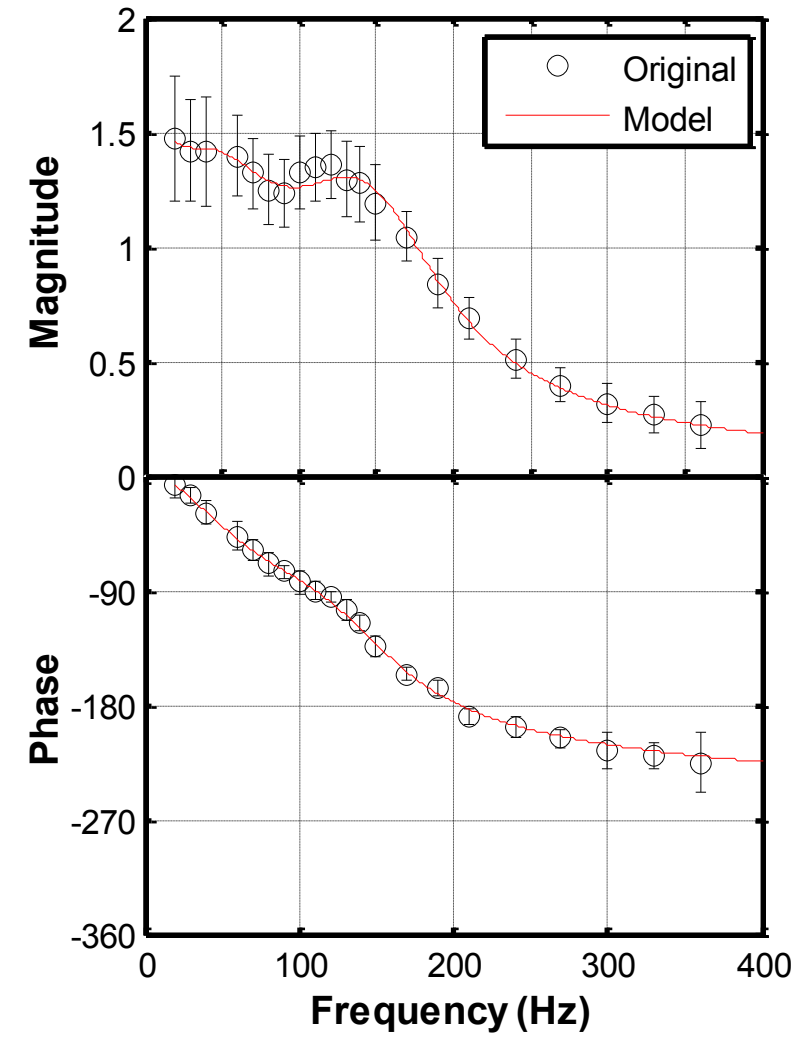

Figure 5.3: Type III FTF M50H1C1, $\Phi=0.65, \bar{v}=7 \mathrm{~cm} / \mathrm{s}, \mathrm{OH}^{*}$

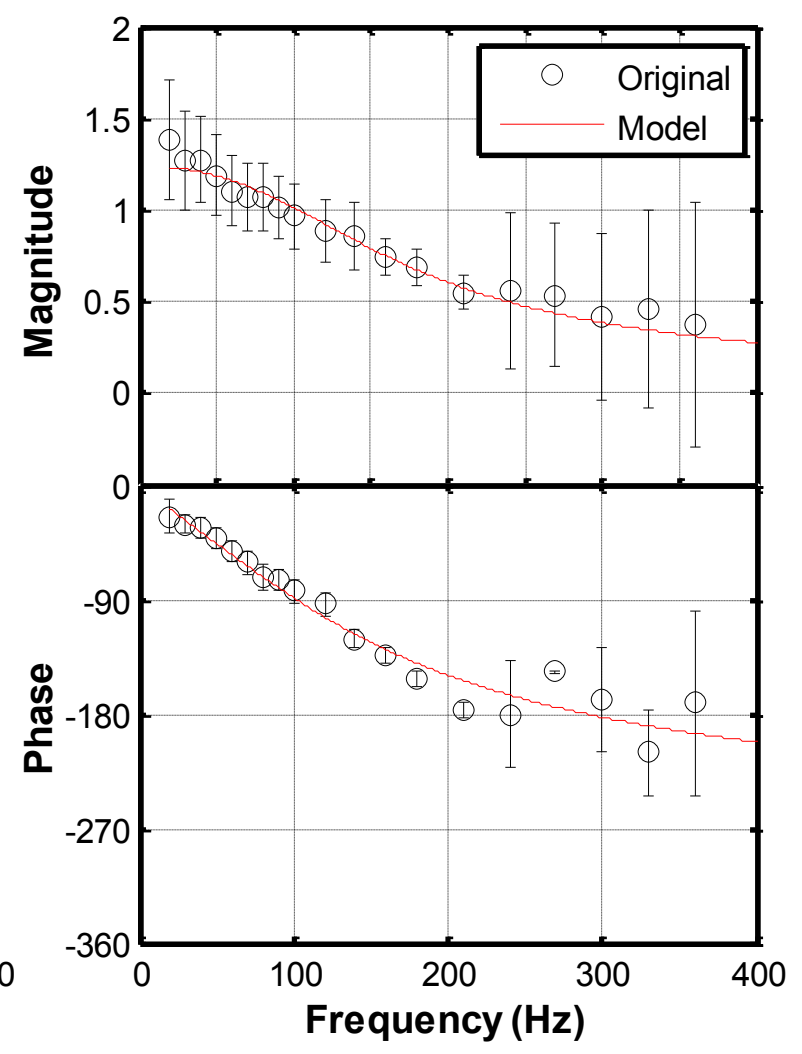

Figure 5.4: Type IV FTF M25H1C1, $\Phi=0.65, \bar{v}=6 \mathrm{~cm} / \mathrm{s}, \mathrm{OH}^{*}$

\subsection{Static Stability of Non-adiabatic Flames}

The liftoff distance of a flame stabilized by heat loss is determined by the geometry of the burner and the operating conditions, including the flow velocity, equivalence ratio, and fuel composition. Table 5.2 is a subset of the full data set and shows trends in flame liftoff distance for changes in equivalence ratios, flow velocity, and fuel composition. Figure 5.5 shows the same trends in graphical form. 
Table 5.2: Trends in flame liftoff distance

\begin{tabular}{|c|c|c|c|c|}
\hline $\begin{array}{c}\text { Independent } \\
\text { Variable }\end{array}$ & $\begin{array}{c}\text { Fuel } \\
\text { Mixture }\end{array}$ & $\begin{array}{c}\overline{\boldsymbol{v}} \\
(\mathbf{c m} / \mathbf{s})\end{array}$ & $\boldsymbol{\Phi}$ & $\boldsymbol{d}_{\boldsymbol{f}}(\mathbf{m m})$ \\
\hline Flow & $\mathrm{M}$ & 5 & 0.7 & 1.09 \\
velocity & $\mathrm{M}$ & 6 & 0.7 & 0.884 \\
& $\mathrm{M}$ & 7 & 0.7 & 0.682 \\
\hline Equivalence & $\mathrm{M}$ & 6 & 0.65 & 1.224 \\
Ratio & $\mathrm{M}$ & 6 & 0.70 & 0.884 \\
& $\mathrm{M}$ & 6 & 0.75 & 0.693 \\
\hline \multirow{2}{*}{ Fuel } & $\mathrm{M} 25 \mathrm{H} 1 \mathrm{C} 1$ & 6 & 0.65 & 0.553 \\
Composition & $\mathrm{M} 50 \mathrm{H} 1 \mathrm{C} 1$ & 6 & 0.65 & 0.901 \\
& $\mathrm{M} 75 \mathrm{H} 1 \mathrm{C} 1$ & 6 & 0.65 & 1.146 \\
& $\mathrm{M}$ & 6 & 0.65 & 1.224 \\
\hline \multicolumn{4}{|r}{}
\end{tabular}

For a constant flow velocity and fuel composition, an increase in the equivalence ratio causes the flame to move closer to the burner. This is expected since an increase in the equivalence ratio causes the reaction rate and flame speed to increase. Subsequently the flame moves closer and the heat loss increases, reducing the flame speed and allowing the flame to stabilize.

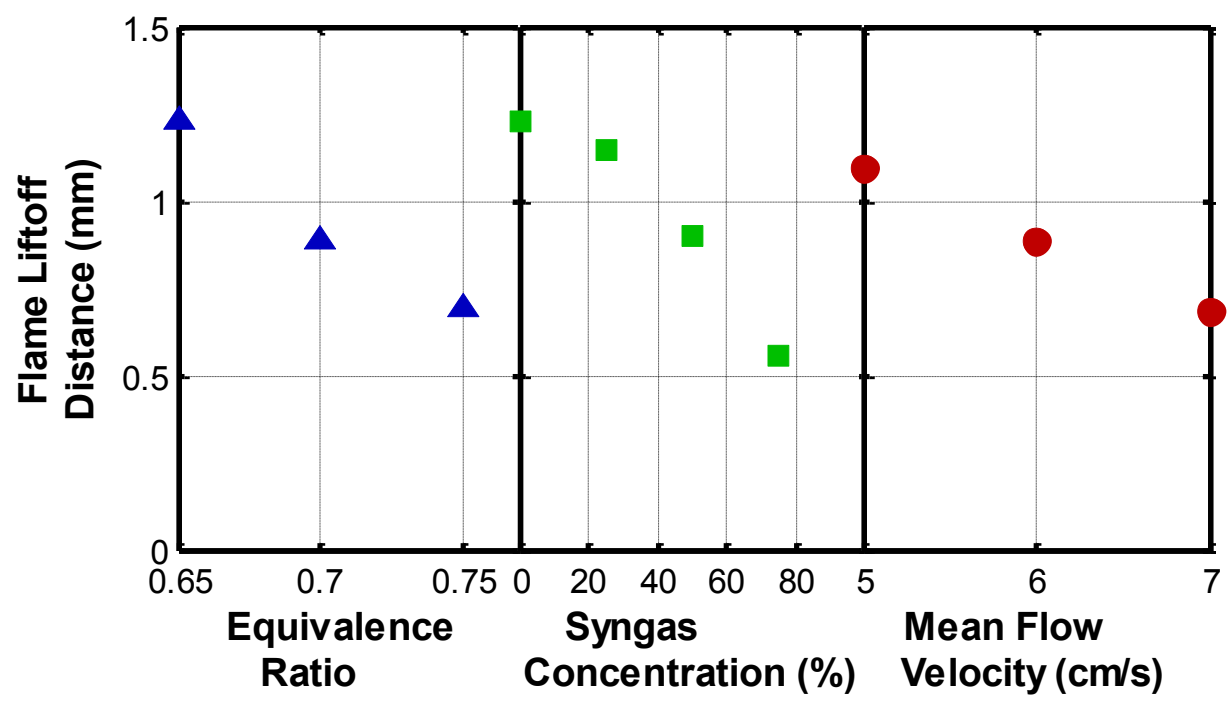

Figure 5.5: Trends in flame liftoff distance (Blue and red points are for methane, green points are a methane-syngas mixture) 
Similarly, for a constant flow velocity and equivalence ratio, as the methane concentration decreases and the syngas concentration increases, the flame moves towards the burner. This is due to an increase in the hydrogen concentration (in the syngas) which again causes the mixture flame speed to increase. Consequently, the flame moves closer to the burner resulting in an increased heat loss and reduction in the flame speed.

A less obvious trend is that an increase in mean flow velocity causes the flame to move closer to the burner. Eng et al. (1995) observed similar trends in experiments conducted using flat flame thermally stabilized with a porous plug. In contrast to the present work, Eng et al. (1995) kept the burner surface temperature at a constant $332 \mathrm{~K}$ through water cooling. They burned methane at an equivalence ratio of 0.7 and observed that the flame moved closer to the burner as the flow was increased. A comparison of data from Eng et al. (1995) and the present work at the same conditions is shown in Figure 5.6. Eng et al. (1995) also found that as the flame moved closer to the burner, the flame temperature approached the adiabatic flame temperature. 


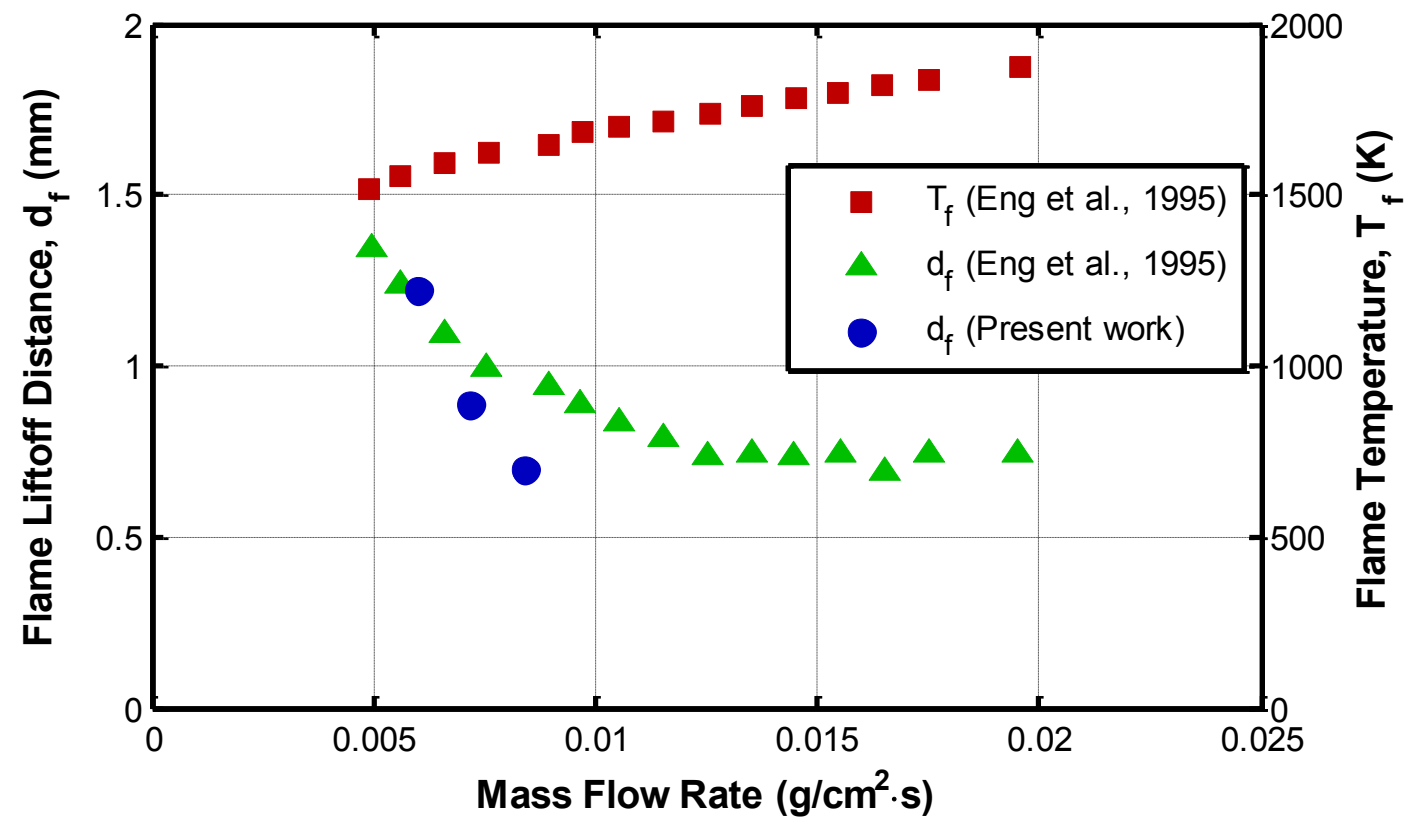

Figure 5.6: Trends in flame liftoff distance and flame temperature with a varying flow rate

This behaviour is attributable to the non-adiabatic nature of the flame. As the flow velocity is increased, more reactants are available for combustion and so the flame generates more heat. The extra heat generated increases the (non-adiabatic) flame temperature and consequently the reaction rate and flame speed. This causes the flame to move closer to the burner. By contrast, for a flame with minimal heat loss, the flame temperature is close to the adiabatic flame temperature and an increase in flame temperature and flame speed associated with an increase in reactant flow rate is not enough to match the increase in flow speed. As a result, the flame is pushed away from the burner where the heat loss is reduced and the flame speed can increase to match the new flow speed. 
Chatterjee (2004) describes similar behaviour during the forcing cycle of an acoustically forced flat flame studied through simulations. A simulation of a single channel of the honeycomb stabilizer used in the flat flame burner was able to capture the experimental flame response results obtained by Khanna (2001). Chatterjee (2004) found that during the forcing cycle, the reaction rate increased after the velocity peaked and the flame moved closer to the burner. The time varying reaction rates and flame positions of Chatterjee (2004) are shown in Figure 5.7. The opposite occurred when the velocity reached a minimum. For the flame condition studied, there was a $150^{\circ}$ lag between the peak velocity and reaction rates.

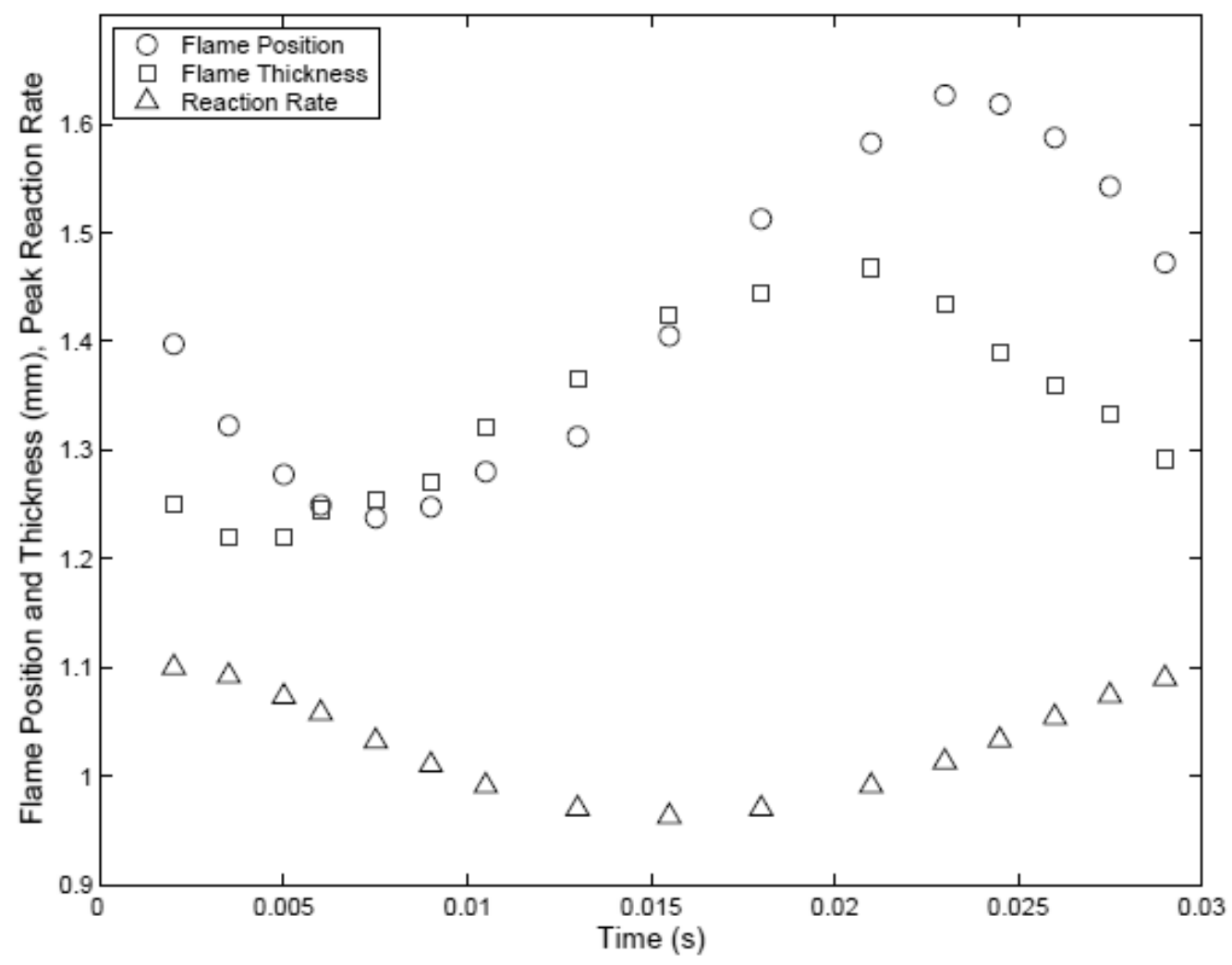

Figure 5.7: Flame position, thickness, and reaction rate during one forcing cycle, velocity leads reaction rate by $150^{\circ}$ (Chatterjee 2004) 
Although the simulations of Chatterjee (2004) were of a cyclic process, they support the hypothesis that increasing the flow velocity causes the temperature of the nonadiabatic flame to increase, which increases the flame speed and results in the movement of the flame toward the burner. The results of Eng et al. (1995) shown in Figure 5.6 further support this explanation, where it is apparent that the flame stops moving towards the burner as the flame temperature approaches the adiabatic limit. It can be concluded that the reaction rate and flame speed for a non-adiabatic flame are more sensitive to changes in the flow velocity (and probably other operating conditions) than for a flame operating close to the adiabatic limit.

\subsection{Trends in Mean Heat Release Rate of Syngas-Methane Flames}

Table 5.3 shows the trends in measured $\mathrm{OH}^{*}$ and $\mathrm{CH}^{*}$ chemiluminescence for syngas-methane flames, where $\mathrm{OH}^{*}$ and $\mathrm{CH}^{*}$ chemiluminescence are useful qualitative indicators of the heat release rate. As the methane concentration in the mixture drops, the $\mathrm{OH}^{*}$ signal intensity decreases, while the $\mathrm{CH}^{*}$ signal intensity increases. For a constant methane concentration, as hydrogen is replaced by carbon monoxide both the $\mathrm{OH}^{*}$ and $\mathrm{CH}^{*}$ signals increase. The $\mathrm{CH}^{*}$ signal increases significantly more than the $\mathrm{OH}^{*}$ signal in this case. One possible explanation is the presence of $\mathrm{CO}_{2}{ }^{*}$ chemiluminescence in both the $\mathrm{OH}^{*}$ and $\mathrm{CH}^{*}$ signals, as discussed in Chapter 3. This is especially true for syngas mixtures where the contribution of $\mathrm{CO}_{2} *$ and $\mathrm{OH}^{*} / \mathrm{CH}^{*}$ to the chemiluminescence signal is unknown. Most importantly, despite the inconsistency between the absolute intensities of the $\mathrm{OH}^{*}$ and $\mathrm{CH}^{*}$ chemiluminescence, the measured trends in flame transfer functions were the same whether $\mathrm{OH}^{*}$ and $\mathrm{CH}^{*}$ data were used in the calculations. This is because the fluctuating component of chemiluminescence signal (i.e. the experimental 
measure of the heat release rate) was normalized by the mean value of the chemiluminescence signal during calculation of the FTF.

Table 5.3: Comparison of mean heat release rates, reactant temperature and flame liftoff distance for various fuels at $\Phi=0.65$ and $\bar{v}=6 \mathrm{~cm} / \mathrm{s}$

\begin{tabular}{|c|c|c|c|c|c|}
\hline $\begin{array}{c}\text { Independent } \\
\text { Variable }\end{array}$ & $\begin{array}{c}\text { Fuel } \\
\text { Mixture }\end{array}$ & $\begin{array}{c}\overline{\boldsymbol{q}} \\
\mathbf{O H}(\mathbf{V})\end{array}$ & $\begin{array}{c}\overline{\boldsymbol{q}} \\
\mathbf{C H}(\mathbf{V})\end{array}$ & $\boldsymbol{T}_{\boldsymbol{R}}(\mathbf{K})$ & $\begin{array}{c}\boldsymbol{d}_{\boldsymbol{f}} \\
(\mathbf{m m})\end{array}$ \\
\hline \multirow{3}{*}{$\mathrm{CH}_{4}$} & $\mathrm{M}$ & 0.038 & 0.057 & 674 & 1.22 \\
& $\mathrm{M} 75 \mathrm{H} 1 \mathrm{C} 1$ & 0.034 & 0.057 & 706 & 1.15 \\
& $\mathrm{M} 50 \mathrm{H} 1 \mathrm{C} 1$ & 0.030 & 0.062 & 785 & 0.90 \\
& $\mathrm{M} 25 \mathrm{H} 1 \mathrm{C} 1$ & 0.024 & 0.074 & 882 & 0.55 \\
\hline \multirow{3}{*}{$: \mathrm{CO}$ ratio } & $\mathrm{M} 50 \mathrm{H} 2 \mathrm{C} 1$ & 0.028 & 0.053 & 781 & 0.87 \\
& $\mathrm{M} 50 \mathrm{H} 1 \mathrm{C} 1$ & 0.030 & 0.062 & 785 & 0.90 \\
& $\mathrm{M} 50 \mathrm{H} 1 \mathrm{C} 2$ & 0.032 & 0.070 & 800 & 0.83 \\
\hline
\end{tabular}

\subsection{Strouhal Number Correlation of Phase Response}

Previous experimental studies have used non-dimensional parameters to predict flame dynamics in both laminar and turbulent premixed flames. Ducruix et al. (2000) studied acoustically forced laminar premixed conical flames and found that a reduced frequency, $\omega_{*}=(\omega R) /\left(S_{L} \cos \beta\right)$ predicted the phase of the flame response well. Here $\omega$ is the angular frequency, $R$ is the burner radius, $S_{L}$ is the laminar flame speed, and $\beta$ is the flame cone angle. Kim et al. (2010) examined turbulent premixed flames in a swirl stabilized combustor and found that a Strouhal number, $S t=f L_{C H^{*} \max } / \bar{v}$ predicted the phase of flame response plots for both $\mathrm{V}$ and $\mathrm{M}$ shaped flames. In this case, $f$ is the frequency, $L_{C H^{*} \max }$ is the flame length, and $\bar{v}$ is the mean flow velocity. For the current study, Strouhal number is redefined as 


$$
S t=\frac{f d_{f}}{\bar{v}}=\frac{t_{a d v}}{t_{\text {acoustic }}}
$$

where $f$ is the forcing frequency, $d_{f}$ is the flame liftoff distance relative to the top surface of the honeycomb, and $\bar{v}$ is the bulk reactant flow velocity corrected for the reactant temperature measured at the honeycomb exit using an R-type thermocouple. This definition of Strouhal number replacing $L_{C H^{*} \max }$ with $d_{f}$ reflects the differences in current flame geometry relative to the work of Kim et al. (2010). Both of these terms are a measure of the distance that a perturbation travels from the burner exit until it reaches the flame.

Figure 5.8 shows flame transfer function phase plots for all test conditions as a function of frequency, while Figure 5.9 shows the phase as a function of St. The flame transfer function phase curves correlate well with St. The primary peak frequency falls in the range of 32 to $165 \mathrm{~Hz}$ for the test conditions, while the Strouhal number of the primary peak falls between 0.39 and 0.56 .

The Strouhal number represents the ratio of the advection time $\left(t_{a d v}\right)$ to the forcing time $\left(t_{\text {acoustic }}\right)$, where the advection time is the time required for a perturbation at the honeycomb exit to reach the flame. The Strouhal number correlation shown in Figure 5.9 implies that the mechanism responsible for primary peak is advective in nature. It is interesting to note that the peak magnitude of the FTF occurs around a Strouhal number of 0.5 , when the acoustic period is twice as large as the advection period. 


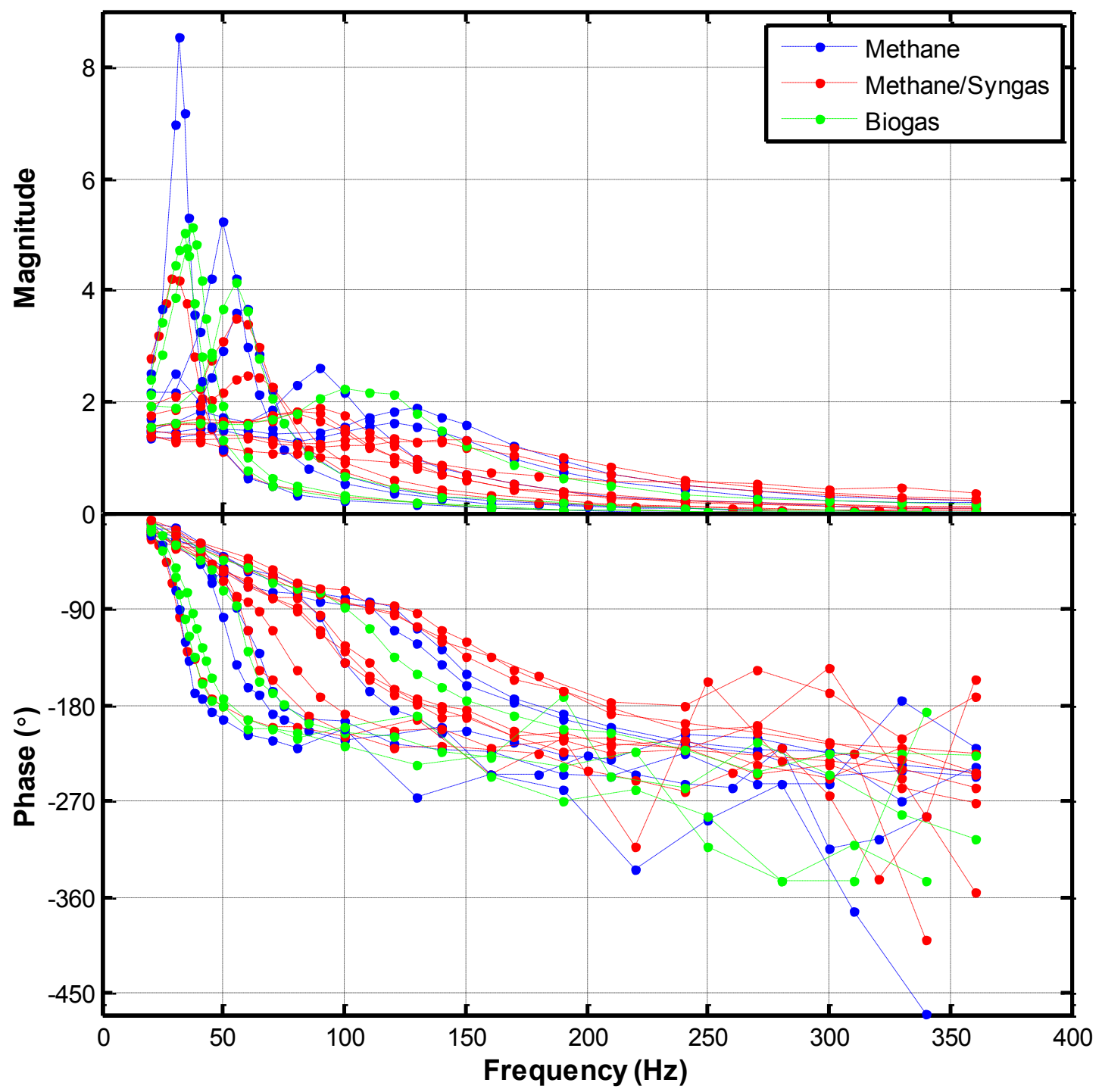

Figure 5.8: Flame transfer function magnitude and phase vs. frequency for all test conditions 


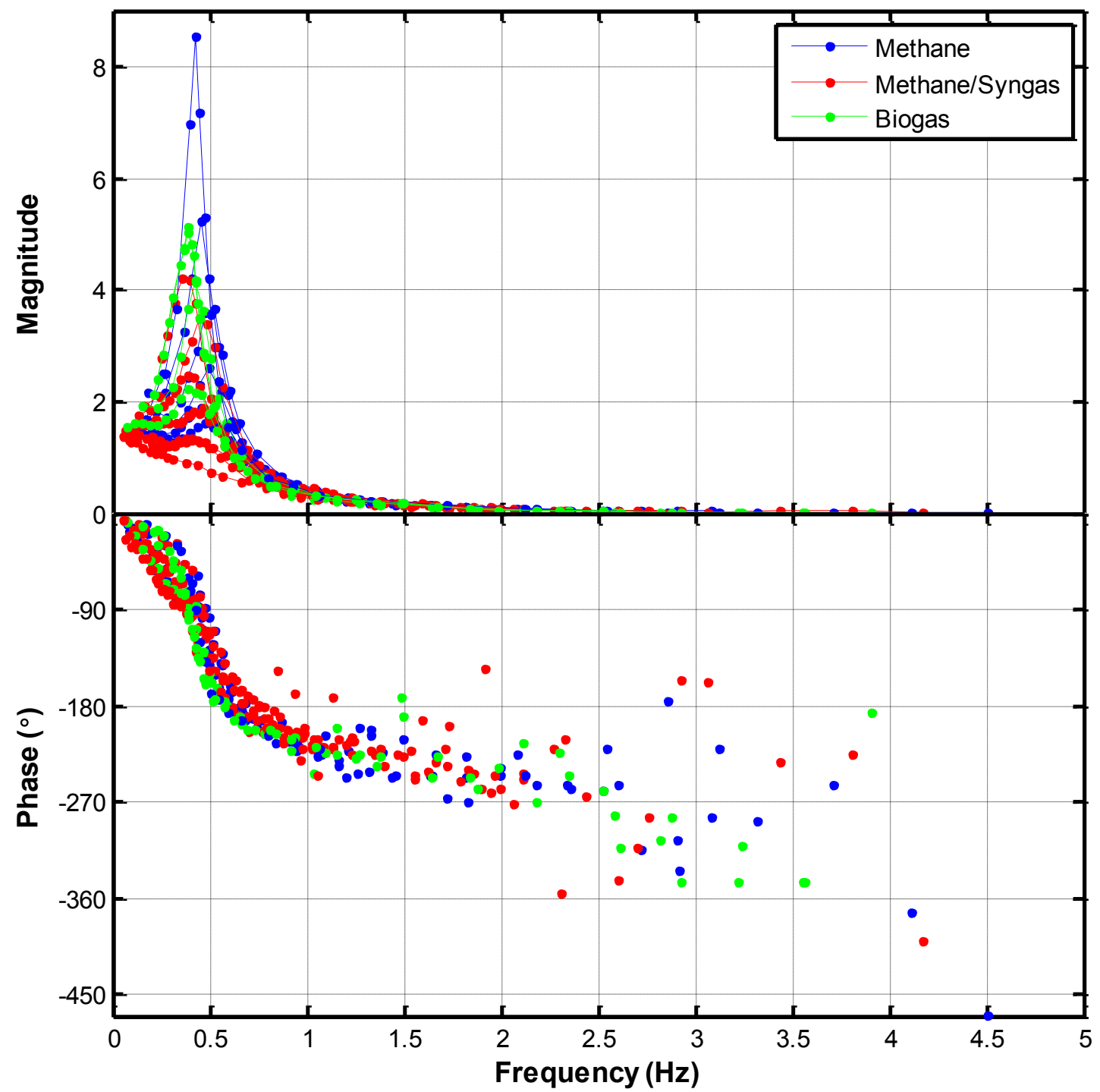

Figure 5.9: Flame transfer function magnitude and phase vs. Strouhal number for all test conditions

Khanna (2001) conducted flame response studies using a similar flat flame burner running on methane, propane, and ethane. The primary peak in the magnitude plots was found to be caused by an oscillation in the conductive heat transfer between the flame and the honeycomb. He also suggested that oscillations in the convective heat transfer 
between the honeycomb and oncoming flow of reactants were not the mechanism responsible for the primary peak. His reasoning was that the convective heat transfer coefficient inside the honeycomb is not affected significantly by acoustic forcing.

Chatterjee (2004) came to a different conclusion through simulations of a flat flame. A simulation of a single channel of the honeycomb stabilizer used in the flat flame burner was able to capture the flame response measured by Khanna (2001). To further study the role of unsteady heat transfer on the flame response, a simulation of the flat flame burner was conducted where the flame was replaced by a time-varying heat source. Through this simulation, Chatterjee (2004) found that the both the honeycomb temperature and gas temperature within the honeycomb were affected by the fluctuating heat source. The fluctuation in honeycomb temperature was small due to the honeycomb's thermal mass, but the fluctuation in gas temperature was much larger. The author concluded that the fluctuation in honeycomb temperature influenced the convective heat transfer coefficient within the channel walls. This caused a much larger fluctuation in the gas temperature, which was deemed responsible for the change in heat release rate of the flame. The success of the Strouhal number correlation in Figure 5.9 supports the results of Chatterjee (2004), which show that the mechanism responsible for primary peak resonance is of an advective nature. In accordance with this hypothesis, an oscillation in the reactant gas temperature is carried by the flow to the flame. This causes an oscillation in the heat release rate and a feedback loop is created between the driving mechanism (velocity fluctuation) and feedback mechanism (reactant temperature oscillation). Since both of these processes affect the heat release rate, the oscillation in the heat release rate will be amplified when they are in phase. 
The secondary peak seems to exhibit similar trends to the primary peak, but has lower magnitudes. This implies that it may be a sub-harmonic of the primary peak that is also a consequence of an advective mechanism similar to the one described above.

\subsection{Trends in Flame Transfer Function Magnitude}

To investigate the trends in flame transfer function magnitude, flame response was measured for three fuels (methane, biogas, and a 50:50 mixture of methane and syngas) at a variety of operating conditions. This corresponds to study 5 in Table 4.1. Transfer function modelling described earlier was used to find the peak magnitudes for each transfer function. The peak magnitude was found to correlate well with flame liftoff distance and the temperature of the reactants measured at the honeycomb exit. This is shown in Figure 5.10 and Figure 5.11 respectively. At high flame liftoff distances (and low reactant temperatures), it becomes apparent that methane flames have the highest FTF magnitude, followed by biogas and subsequently the methane/syngas mixture. By contrast, the peak magnitudes of these three fuels converge at low flame standoff distances (and high reactant temperature respectively). However, the degree of convergence is difficult to quantify given the measurement uncertainties as shown on the Figure 5.10. An interesting trend identified in Figure 5.12 is that the reactant temperature correlates well with the flame standoff distance, regardless of the fuel. Furthermore, if the data points in Figure 5.10 are classified by FTF type as shown in Figure 5.13, it is apparent that the FTF type correlates with the flame liftoff distance such that as the flame liftoff distance increases, so does the FTF type number. 


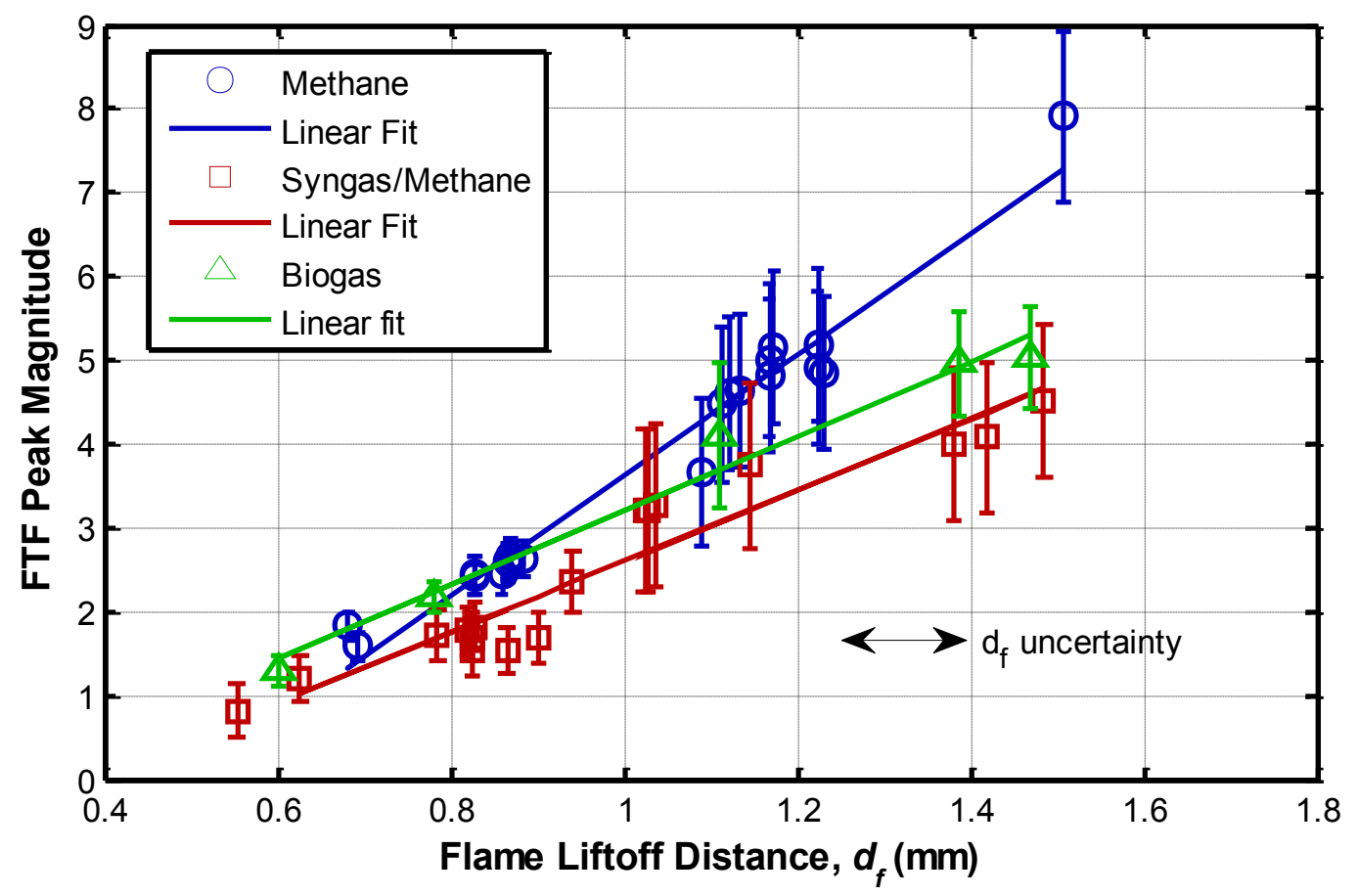

Figure 5.10: Trends in Peak FTF Magnitude $\left(\mathrm{OH}^{*}\right.$ based) vs. $d_{f}$ for three fuels

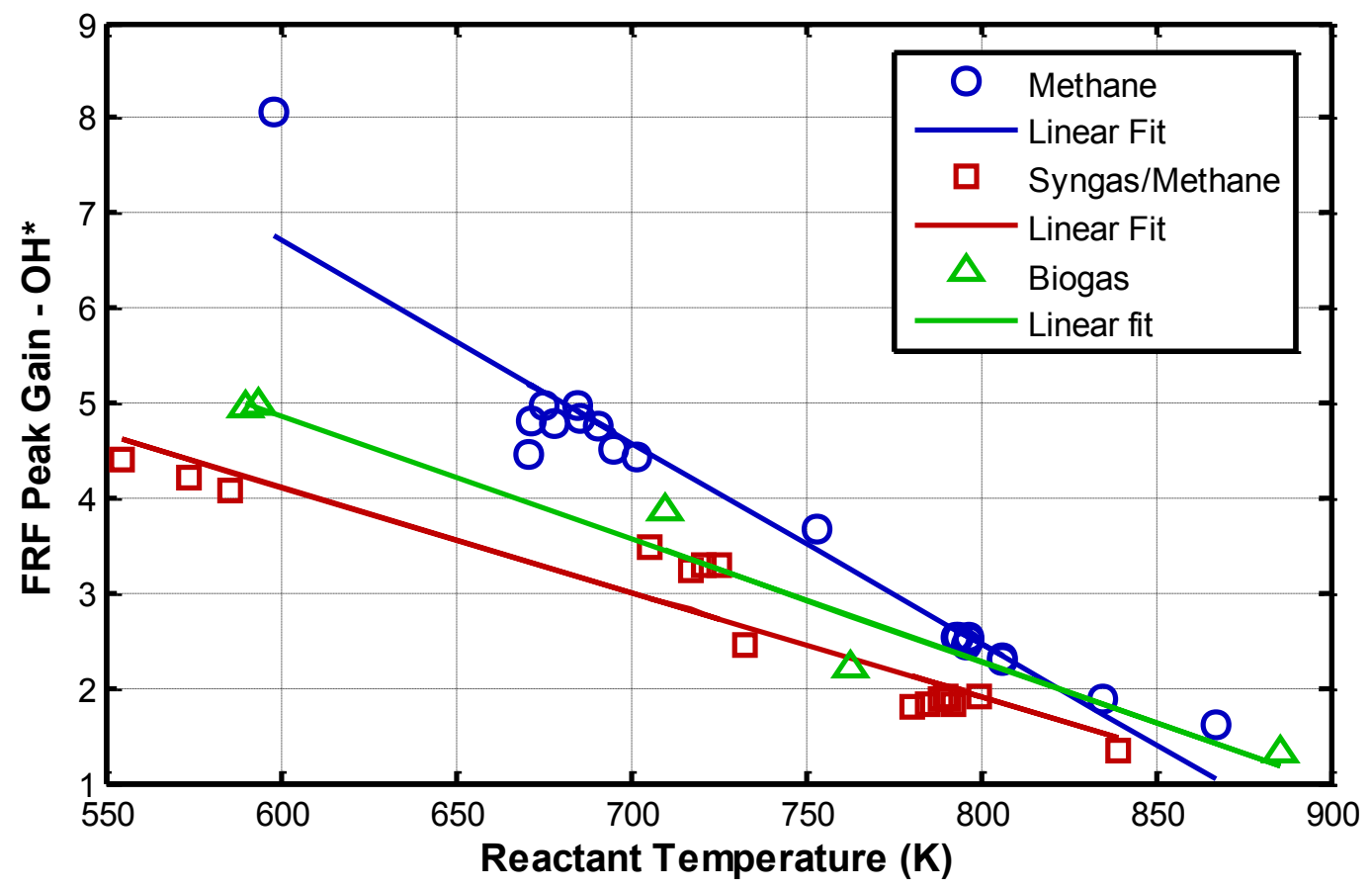

Figure 5.11: Trends in Peak FTF Magnitude $\left(\mathrm{OH}^{*}\right.$ based) vs. reactant gas temperature for 3 fuels 


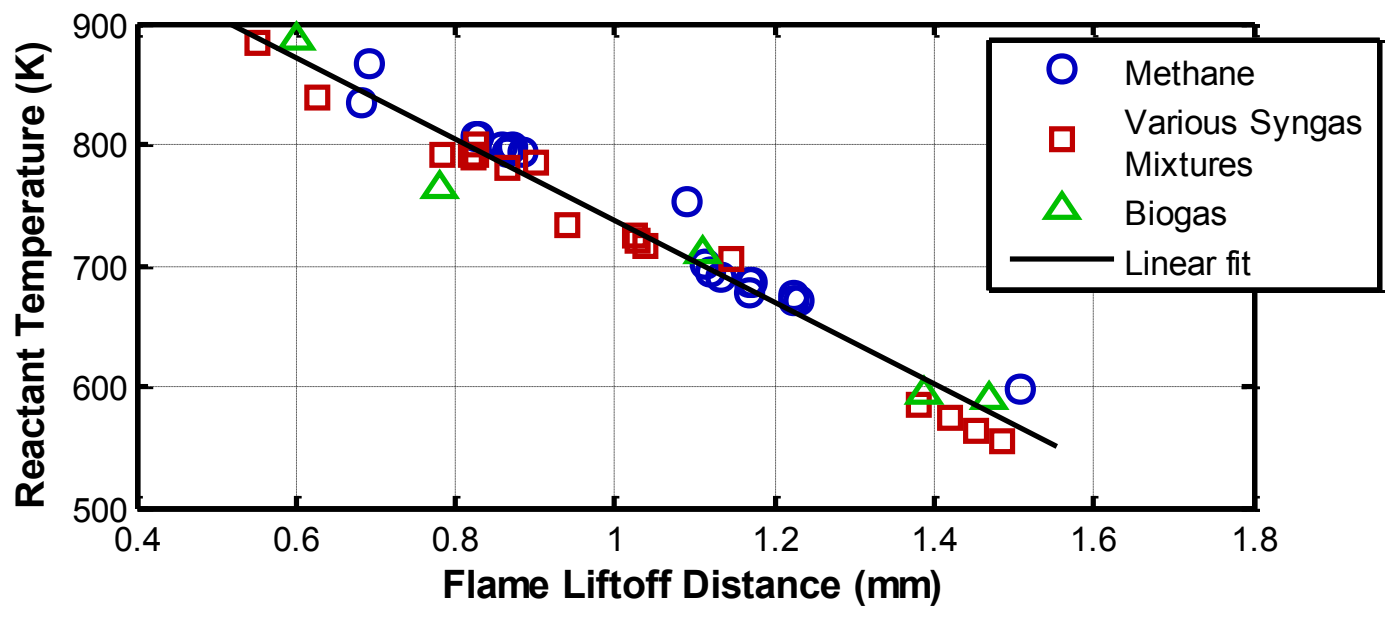

Figure 5.12: Reactant gas temperature vs. flame liftoff distance for all test conditions

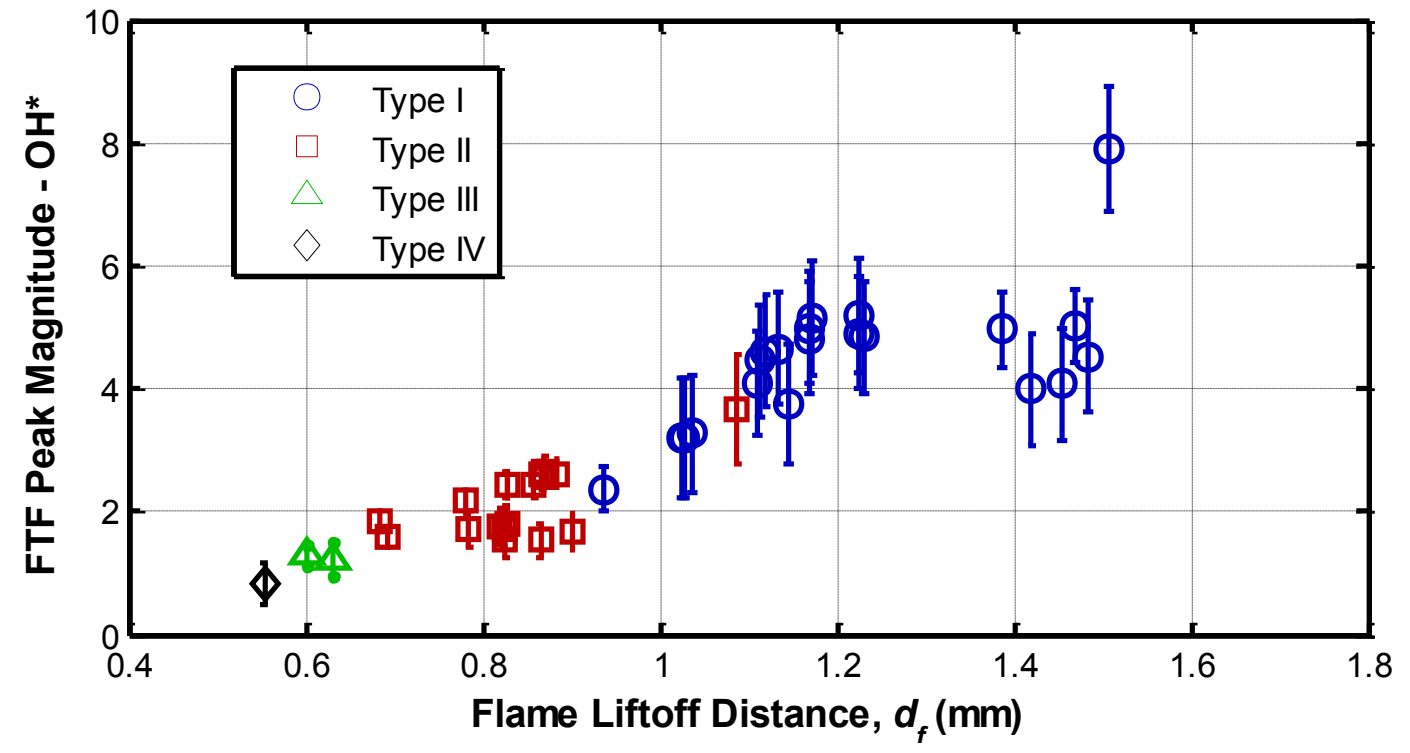

Figure 5.13: Trends in Peak FTF Magnitude $\left(\mathrm{OH}^{*}\right.$ based) vs. $d_{f}$ by type

Khanna (2001) conducted steady state modelling of the flat flame burner using a commercial code to investigate the effect of conductive heat transfer on flame response. The code, "Burner Stabilized Premix," was written by Sandia labs to model laminar premixed flames. By using experimentally determined honeycomb temperatures as inputs to the model, the spatial temperature gradient $d T / d x$ was calculated. Khanna (2001) also 
conducted transfer function modelling in Matlab to obtain the damping ratios and natural frequencies of the transfer function. He found that a fourth order model with a pure time delay shown in Equation (5.6) captured the flame response well.

$$
T F=\frac{K e^{-s \tau} N(s)}{\left(s^{2}+2 \zeta_{1} \omega_{n 1} s+\omega_{n 1}{ }^{2}\right)\left(s^{2}+2 \zeta_{2} \omega_{n 2} s+\omega_{n 2}{ }^{2}\right)}
$$

For the transfer function $T F, K$ is the gain, $\tau$ is the time delay, $N(s)$ is a polynomial of zeros, $\omega_{1}$ and $\omega_{2}$ are the natural resonant frequencies, and $\zeta_{1}$ and $\zeta_{2}$ are the damping ratios. From this, Khanna (2001) found that the damping ratios of the lower frequency peak of methane, propane, and ethane flames increased linearly with $d T / d x$ as shown in Figure 5.14. Khanna (2001) attributed this low frequency mechanism to conductive heat transfer oscillations.

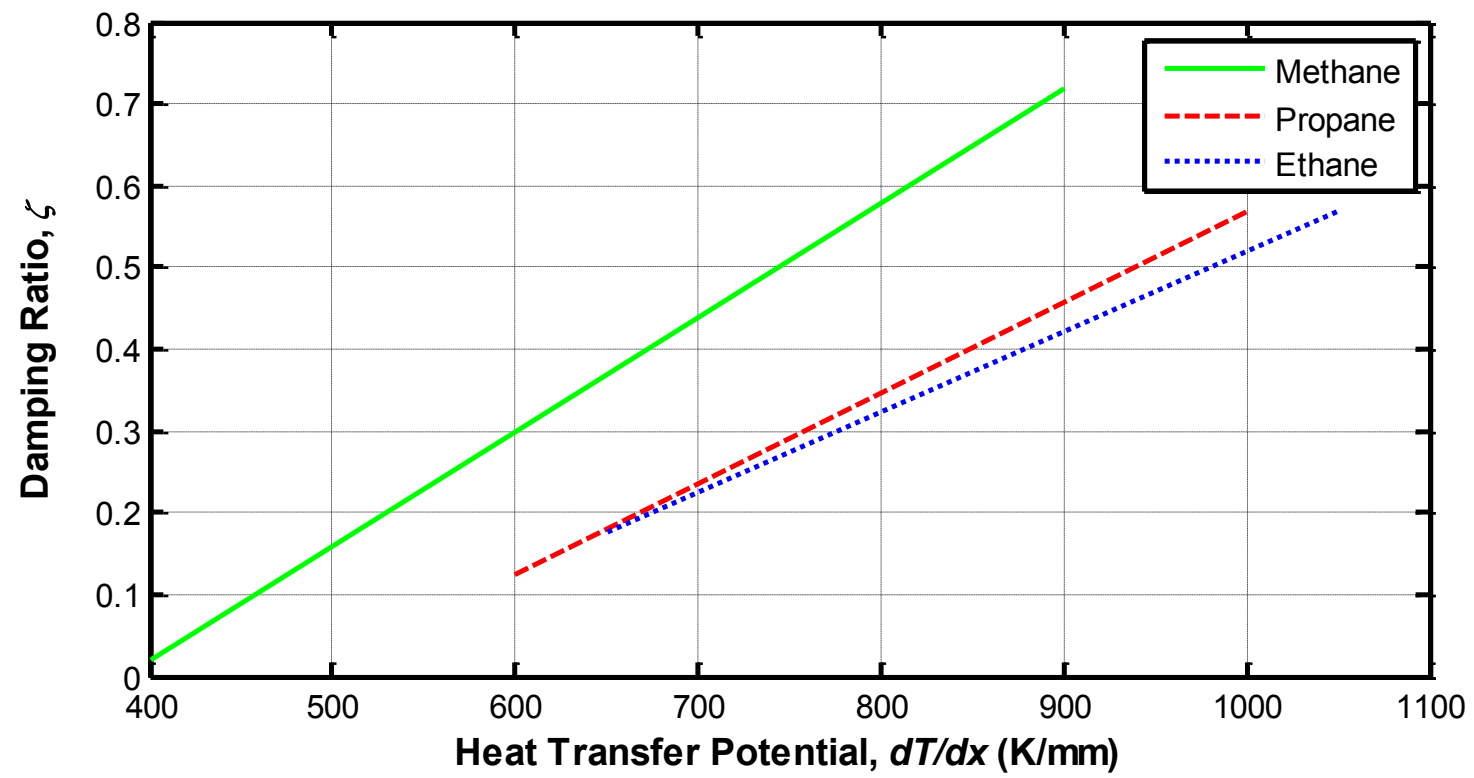

Figure 5.14: Dependence of damping factor on heat transfer potential for various fuel Khanna (2001) 
Although there is no flame temperature information for the current data, it can be argued that the trends in magnitude observed by Khanna (2001) are consistent with the trends observed here. The burner stabilized flat flame experiments conducted by Eng et al. (1995) represented in Figure 5.6 shows that as the flow rate was increased, the flame moved closer to the burner. Simultaneously, the heat loss increased before reaching a peak and beginning to decrease. Thus $d_{f}$ is inversely proportional to $d T / d x$. In addition, Figure 5.10 shows that the FTF magnitude decreases as the flame moves toward the burner. If we assume that the decrease in magnitude is due to higher damping, then the FTF magnitude is inversely proportional to the damping ratio. Therefore Khanna (2001)'s result of $d T / d x \propto$ damping is consistent with the results of Figure 5.10 which show that $d_{f} \propto$ FTF peak magnitude

A possible physical explanation for this comes from concepts related to flame stability discussed in Section 5.2. It was reasoned that for non-adiabatic flames, a change in flow velocity has a significant effect on the flame speed, causing the flame to move opposite of what is expected of flames where the flame temperature is close to the adiabatic limit. Thus, it can be said that the flame speed is more sensitive to changes in operating conditions as the flame temperature decreases away from the adiabatic flame temperature limit. The experiments conducted by Eng et al. (1995) represented in Figure 5.6 show that the flame temperature decreases away from the adiabatic limit as the flame moves away from the burner. Current data are consistent with this trend indirectly. Figure 5.15 shows that the flame speed increases as the flame moves closer to the burner independent of the fuel. It can be assumed that lower flame speeds correspond to lower flame temperatures for a given fuel. Therefore, as the flame moves away from the burner, 
the difference between the real flame temperature and the adiabatic flame temperature increases. This makes more energy available to be exchanged between heat losses and chemical energy. Both of which are influencing the flame speed, hence the increased sensitivity to changes in operating conditions.

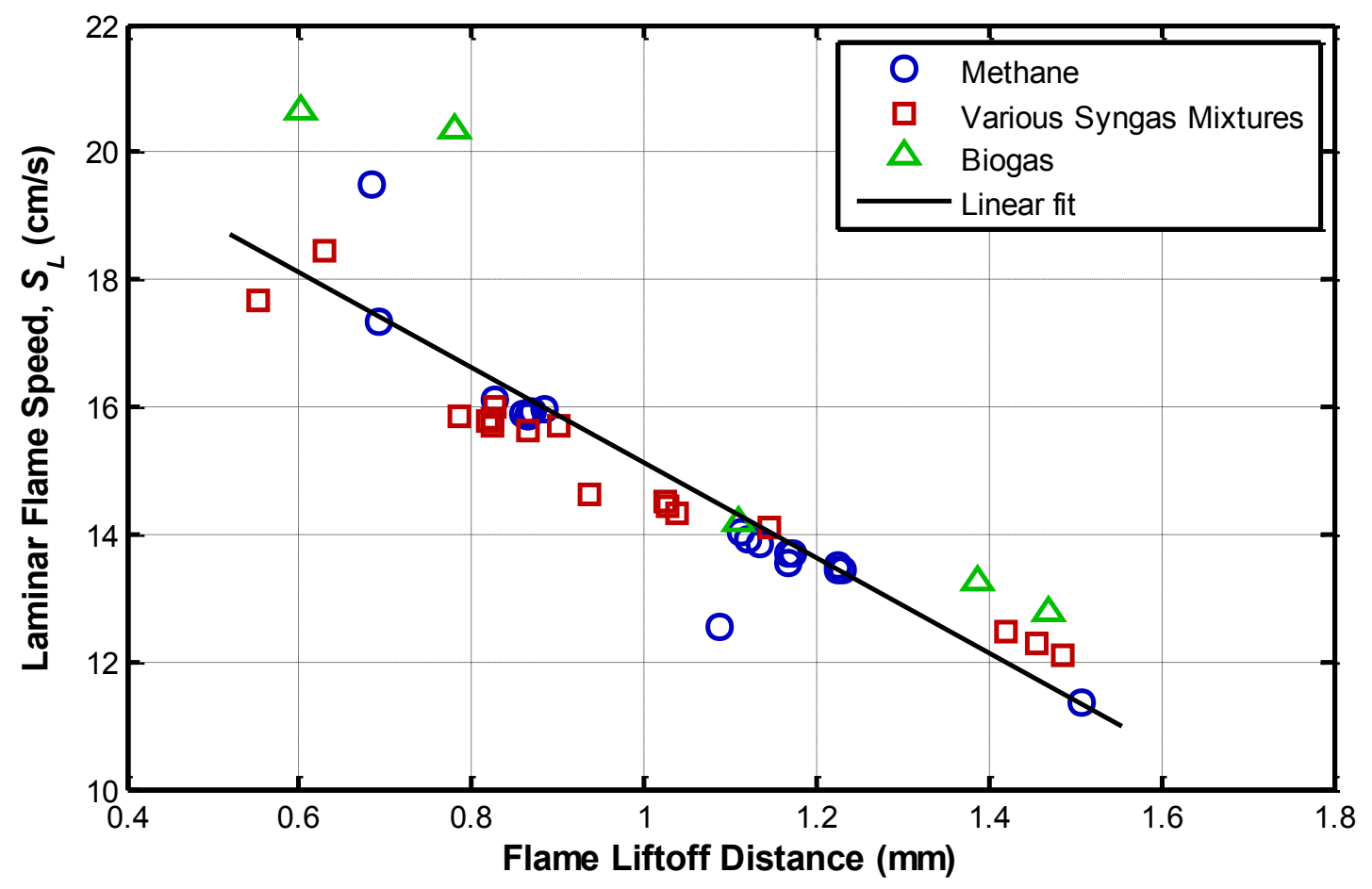

Figure 5.15: Variation of flame speed with flame liftoff distance for three fuels at various operating conditions

The hypothesis stated above can be related to the physical processes behind the instability mechanism as follows. A change in flow velocity resulting from acoustic forcing coupled with a change in reactant temperature due to heat transfer mechanisms will cause a larger change in flame speed (and therefore heat release rate) the farther the flame temperature is from the adiabatic limit. This corresponds to conditions where the flame is far from the burner and the heat transfer potential, $d T / d x$ is low. 
This does not explain why different fuels have different peak magnitudes at a constant flame liftoff distance. A possible explanation is thermal-diffusive effects on a pulsating flame as described in Law (2006). Any disturbance that causes the flame to move - acoustic forcing for example - will affect the thermal (due to heat conduction) and mass diffusion zones of the flame. As an example, if the flame moves forward toward the oncoming flow, the diffusion zones become thinner because they cannot instantaneously adjust. This causes the temperature and concentration gradients in the thermal and mass diffusion zones to steepen. The key parameter here is the Lewis number, $L e$, defined in Equation (5.6). For a flame with $L e>1$, the thermal diffusion zone is initially thicker than the mass diffusion zone. As a result, a thinning of the diffusion zones will cause the thermal gradient to steepen less dramatically than the concentration gradient. More reactants will now be brought into the reaction zone than the amount of heat lost, causing the flame to burn stronger and move forward even more. Flames with $L e>1$ will therefore have a destabilizing effect on pulsations, while flames with $L e<1$ will have a stabilizing effect.

$$
\text { Le }=\frac{\alpha}{\mathcal{D}}=\frac{\text { thermal diffusivity }}{\text { mass diffusivity }}
$$

To compare the trends in peak magnitude with theory described above, calculations were performed to estimate effective Lewis numbers. Thermal diffusivities for air were used, as tabulated in Incropera \& DeWitt (2002). As a first estimate, air was assumed to be the main constituent gas due to the dominant presence of nitrogen. The mass diffusivity of each fuel species in air was calculated using the Chapman and Enskog method outlined in Kuo (2005). Although the area close to the flame will have many 
intermediate species that are unaccounted for, this is an initial estimate of the mass diffusivity. Figure 5.16 shows the Lewis number as a function of temperature for relevant fuel species. Temperature does not seem to have a large impact on general trends. Propane has the highest Lewis number at around 1.8, ethane and carbon dioxide follow at about 1.5 , methane and carbon dioxide are both close to unity, while hydrogen has the lowest Lewis number at around 0.3. Thus propane and ethane are expected to have a destabilizing effect, methane and carbon monoxide should have a relatively neutral effect on flame stability, while the presence of hydrogen should have a stabilizing effect.

Results from Khanna (2001) in Figure 5.14 show that propane and ethane flames have higher transfer function peak magnitudes (lower damping) than methane flames. This is consistent with Lewis number data shown in Figure 5.16. Propane and ethane both have a higher Lewis number than methane, so thermal-diffusive effects will have a destabilizing effect on pulsating instabilities and the magnitude will be higher than methane.

For the present data, the syngas/methane flames studied had lower peak magnitudes than pure methane flames which is also consistent with a Lewis number based explanation. Hydrogen has a low Lewis number, and $\mathrm{H}_{2}$ containing syngas resulted in flames that were less prone to pulsating instabilities. The carbon monoxide in syngas has a similar Lewis number to methane and was not expected to change the response of the flame to pulsating instabilities.

Biogas FTF peak magnitudes were lower than methane but higher than those of methane-syngas mixtures for a fixed flame liftoff distance. The Lewis-number based 
explanation encounters problems for biogas, since carbon dioxide is not a fuel and is not a deficient species in the flame. Carbon dioxide is primarily a diluent, while also participating in the chemical kinetics and influencing the radiative heat transfer.

Consequently there must be other factors influencing the response of biogas flames.

In planar flames, the low Lewis number of hydrogen has a stabilizing effect, while in curved flame fronts hydrogen has a destabilizing effect (Law, 2006). This could increase the possibility of encountering combustion instabilities in non-planar flames found in gas turbine combustors.

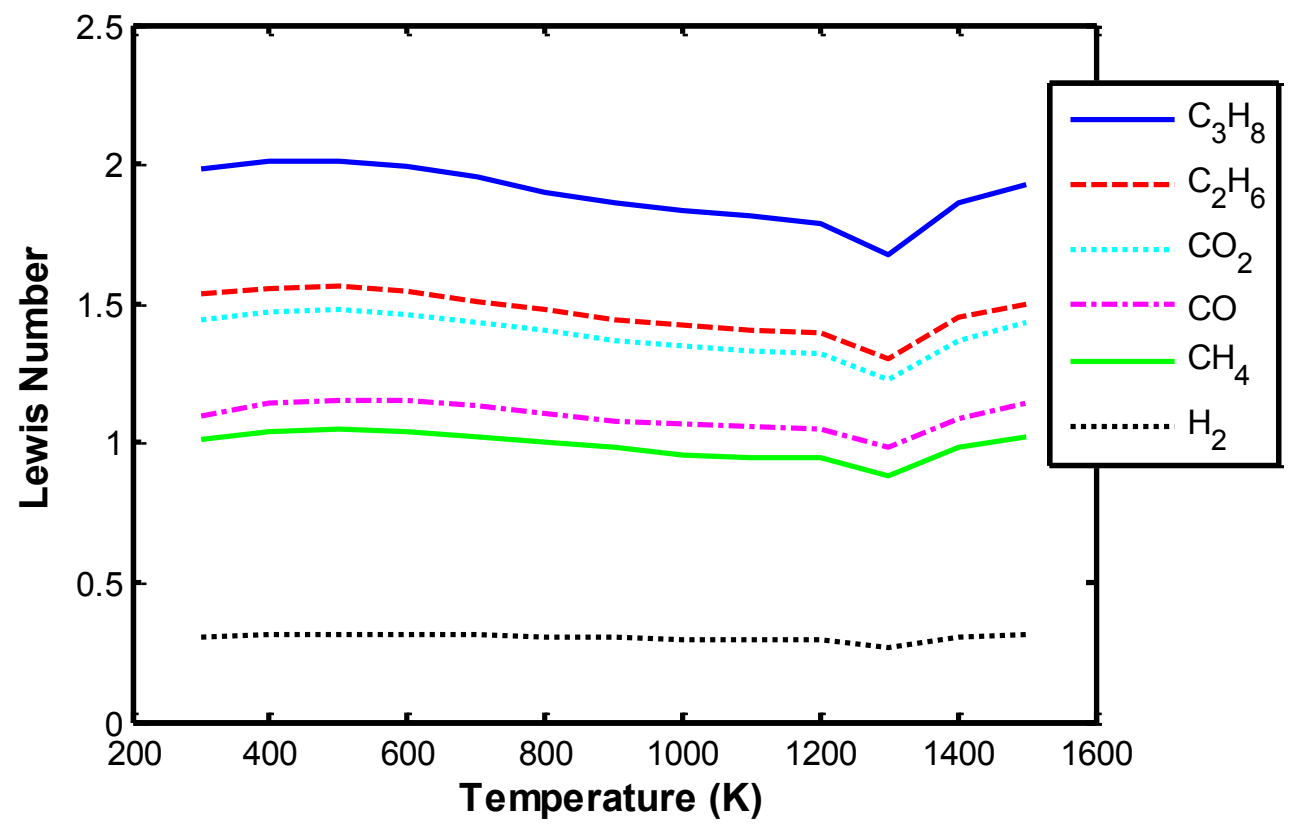

Figure 5.16: Mass diffusivities of various fuel species as a function of temperature 


\section{Chapter 6}

\section{Conclusions and Recommendations}

\subsection{Conclusions}

The primary objective of this thesis was to conduct a fundamental study of the effects of fuel composition on combustion dynamics. A simple flat flame burner was constructed to investigate the effects of fuel composition in isolation, while avoiding the complications inherent to more realistic combustion systems. The flame was acoustically forced and the flame transfer function (FTF) was calculated by measuring heat release rate and velocity fluctuations using $\mathrm{OH}^{*} / \mathrm{CH}^{*}$ chemiluminescence and LDV respectively. In addition, the flame liftoff distance and reactant temperature were measured as potential correlating parameters. Studies were performed using methane, syngas, and biogas fuels over a range of operating conditions.

For syngas-methane fuel mixtures, varying the methane concentration from $25 \%$ to $100 \%$ had a significant impact on the FTF. For a 50:50 mixture of methane and syngas, varying the ratio of hydrogen to carbon monoxide in the syngas from 0.5 to 2 did not have a significant impact on the FTF.

A Strouhal number correlation based on the flame liftoff distance and flow velocity was found to collapse the phase curves of the FTF for all operating conditions and fuel compositions studied. This implies that the feedback mechanism responsible for the primary peak in the magnitude of the FTF is advective in nature and supports the 
findings of Chatterjee (2004). Although the instability mechanisms particular to a thermally stabilized flat flame burner may not be directly applicable to gas turbines, nondimensional parameters such as Strouhal number have been shown to be important for predicting combustion dynamics in other flame configurations (Ducruix et al., 2000; Kim et al., 2010). The results presented in this thesis show that the Strouhal number is a useful tool for predicting combustion dynamics driven by advective mechanisms.

A unique trend in static stability previously observed by Eng et al. (1995) was confirmed in the present work whereby the flame moves towards the burner as the flow velocity is increased. A hypothesis is presented that this is due to the flame speed sensitivity to changes in mean velocity, $\partial S_{L} / \partial v$, that is present in flames with large heat losses and varies with standoff distance from the burner.

In addition, transfer function modelling was done in Matlab to allow extraction of the peak magnitudes of the FTF. For a given fuel, peak FTF magnitudes were found to increase as the flame moved away from the burner. One possible explanation, related to the flame speed sensitivity hypothesis for trends in static stability, is that an increase in the flame speed sensitivity to changes in velocity $\left(\partial S_{L} / \partial v\right)$ accompanies the reduction of the flame temperature that occurs when the flame moves away from the burner. This results in a higher oscillation in flame speed, and thus higher peak FTF magnitudes as the flame liftoff distance increases. The peak FTF magnitudes were also found to vary among the different fuels. This difference was attributed to thermal-diffusive effects on planar flame stability. 
For this simple, laminar flat flame, a hypothesis has been presented for the physical processes responsible for variations in the flame response due to changes in operating conditions and fuels. The results show that changing the fuel can have as big an impact on flame dynamics as changing the operating conditions. The effects of fuel composition have been attributed to changes in flame speed and thermal diffusive effects, and the Strouhal number was found to be a useful tool in predicting advective instability mechanisms. Thermal diffusive effects will be of importance for fuel switching in gas turbine combustion systems, although the effects may be different from those observed in laminar flat flames.

\subsection{Recommendations}

For future work, measurement of the flame temperature through laser diagnostics, thermocouples, or numerical simulation would be useful. This would allow comparison with the adiabatic flame temperature and calculation of the spatial temperature gradient between the flame and honeycomb, $d T / d x$. These are important correlating parameters that could help in testing the hypothesis presented explaining trends in the peak magnitude of the FTF.

A next step in investigating fuel composition effects using syngas would be to design a burner capable of burning pure syngas (hydrogen and carbon monoxide). This would require better flashback protection as well as more variability in flow rate. Burning at very lean conditions might allow pure syngas flames to be stabilized.

Combustion dynamics of conical flames with fuels such as syngas or biogas have not been studied. This would be a logical next step to bridge the gap in knowledge of 
syngas combustion dynamics between laminar flat flames and fully turbulent flames. The transition from flat to conical flames that comes with increasing the flow rate would be another interesting fundamental study. 


\section{References}

Abernathy, R., Benedict, R. \& Dowdell, R., 1985. ASME Measurement Uncertainty. ASME Journal of Fluids Engineering, 107(2).

Adrian, R.J. \& Westerweel, J., 2011. Particle Image Velocimetry, New York: Cambridge University Press.

Allison, P. \& Driscoll, J., 2012. Acoustic Behavior of a Partially-Premixed Gas Turbine Model Combustor. In 50th AIAA Aerospace Sciences Meeting including the New Horizons Forum and Aerospace Exposition. Nashville, Tennessee.

Altay, H.M. et al., 2009. Flame-vortex interaction driven combustion dynamics in a backward-facing step combustor. Combustion and Flame, 156(5), pp.1111-1125.

Balachandran, R. et al., 2005. Experimental investigation of the nonlinear response of turbulent premixed flames to imposed inlet velocity oscillations. Combustion and Flame, 143(1-2), pp.37-55.

Candel, S., 2002. Combustion Dynamics and Control: Progress and Challenges. Proceedings of the Combustion Institute, 29, pp.1-28.

Casleton, K.H., Breault, R.W. \& Richards, G.A., 2008. System Issues and Tradeoffs Associated with Syngas Production and Combustion. Combustion Science and Technology, 180(6), pp.1013-1052.

Chatterjee, P., 2004. A Computational Fluid Dynamics Investigation of Thermoacoustic Instabilities in Premixed Laminar and Turbulent Combustion Systems. Blacksburg, Virginia. Available at: http://scholar.lib.vt.edu/theses/available/etd-07142004165910/ [Accessed August 29, 2012].

Coleman, H.W. \& Steele, W.G., 2009. Experimentation, Validation, and Uncertainty Analysis for Engineers 3rd ed., Hoboken, New Jersey: John Wiley \& Sons, Inc.

Culick, F. \& Yang, V., 1995. Overview of combustion instabilities in liquid-propellant rocket engines. In V. Yang \& W. Anderson, eds. Liquid rocket engine combustion instability. American Institute of Aeronautics and Astronautics, pp. 3-37.

Dowling, A.P. \& Stow, S.R., 2005. Acoustic Analysis of Gas-Turbine Combustors. In T. Lieuwen \& V. Yang, eds. Combustion Instabilities in Gas Turbine Engines. AIAA, pp. $369-411$. 
Ducruix, S. et al., 2003. Combustion Dynamics and Instabilities: Elementary Coupling and Driving Mechanisms. Journal of Propulsion and Power, 19(5), pp.722-734.

Ducruix, S., Durox, D. \& Candel, S., 2000. Theoretical and experimental determinations of the transfer function of a laminar premixed flame. International Symposium on Combustion, 28(1), pp.765-773.

ET Enterprises, 2010. 9125WB series data sheet. Available at: http://my.etenterprises.com/pdf/9125B.pdf [Accessed October 20, 2012].

Elghobashi, S., 1994. On Predicting Particle-Laden Turbulent Flows. Applied Scientific Research, 52(4), pp.309-329.

Eng, J.A., Zhu, D.L. \& Law, C.K., 1995. On the structure, stabilization, and dual response of flat-burner flames. Combustion and flame, 100(4), pp.645-652.

Ferguson, D. et al., 2007. Impact of Fuel Variability on Dynamic Instabilities in Gas Turbine Combustion. In 5th US Combustion Meeting. San Diego.

Figura, L., Lee, J. \& Quay, B., 2007. The effects of fuel composition on flame structure and combustion dynamics in a lean premixed combustor. In Proceedings of GT2007 ASME Turbo Expo 2007: Power for Land, Sea and Air. Available at:

http://www.mne.psu.edu/tcl/TCL Website Pub-14.pdf [Accessed July 16, 2012].

Glassman, I., 1996. Combustion 3rd ed., San Diego: Academic Press.

Huang, Y. \& Ratner, A., 2009. Experimental Investigation of Thermoacoustic Coupling for Low-Swirl Lean Premixed Flames. Journal of Propulsion and Power, 25(2), pp.365-373.

Huang, Y; Yang, V., 2009. Dynamics and stability of lean-premixed swirl-stabilized combustion. Progress in energy and combustion science, 35(4), pp.293-364.

Hussain, T., Dowlut, A. \& Balachandran, R., 2011. Experimental Investigation of Response of Hydrogen Enriched Methane Flames to Acoustic Oscillations. In Proceedings of the European Combustion Meeting 2011. Wales, United Kingdom.

Incropera, F.P. \& DeWitt, D.P., 2002. Introduction to Heat Transfer 4th ed., New York: John Wiley \& Sons, Inc.

Janus, M., Richards, G. \& Yip, M., 1997. Effects of ambient conditions and fuel composition on combustion stability. In 1997 American Society of Mechanical Engineers (ASME)/International Gas Turbine Institute (IGTI) Turbo Expo Meeting. Orlando, Florida. 
Khanna, V.K., 2001. A Study of the Dynamics of Laminar and Turbulent Fully and Partially Premixed Flames. Virginia Polytechnic Institute and State University. Available at: http://scholar.lib.vt.edu/theses/available/etd-08052001-220918/.

Kido, H. et al., 2002. Influence of local flame displacement velocity on turbulent burning velocity. Proceedings of the Combustion Institute, 29(2), pp.1855-1861.

Kim, D. \& Park, S.W., 2010. Effects of hydrogen addition on flame structure and forced flame response to velocity modulation in a turbulent lean premixed combustor. Fuel, 89(11), pp.3475-3481.

Kim, K.T. et al., 2010. Characterization of Forced Flame Response of Swirl-Stabilized Turbulent Lean-Premixed Flames in a Gas Turbine Combustor. Journal of Engineering for Gas Turbines and Power, 132(4).

Kuo, K., 2005. Appendix A, Section 9: Gas Diffusivity. In Principles of Combustion. Hoboken, New Jersey: John Wiley and Sons, Inc., p. 678.

Lafay, Y. et al., 2007. Experimental study of biogas combustion using a gas turbine configuration. Experiments in Fluids, 43(2-3), pp.395-410.

Law, C.K., 2006. Combustion Physics, New York: Cambridge University Press.

Lee, J.G. \& Santavicca, D.A., 2003. Experimental Diagnostics for the Study of Combustion Instabilities in Lean Premixed Combustors. Journal of Propulsion and Power, 19(5), pp.735-750.

Lieuwen, T. et al., 2008. Fuel Flexibility Influences on Premixed Combustor Blowout, Flashback, Autoignition, and Stability. Journal of Engineering for Gas Turbines and Power, 130(1).

Lieuwen, T., 2006. Static and Dynamic Combustion stability. In R. Dennis, ed. The Gas Turbine Handbook. National Energy Technology Laboratory, pp. 197-203. Available at: http://www.netl.doe.gov/technologies/coalpower/turbines/refshelf/handbook/Tableof Contents.html.

McDonell, V.G., 2006. Key Combustion Issues Associated with Syngas and HighHydrogen Fuels. In R. Dennis, ed. The Gas Turbine Handbook. National Energy Technology Laboratory, pp. 195-197. Available at: http://www.netl.doe.gov/technologies/coalpower/turbines/refshelf/handbook/Tableof Contents.html.

Melling, A., 1997. Tracer particles and seeding for particle image velocimetry. Measurement Science and Technology, 8(12), pp.1406-1416. 
DOE National Energy Technology Laboratory, 2010. 2010 Worldwide Gasification Database, Available at: http://www.netl.doe.gov/technologies/coalpower/gasification/worlddatabase/index.ht $\mathrm{ml}$.

Rasi, S., Veijanen, A. \& Rintala, J., 2007. Trace compounds of biogas from different biogas production plants. Energy, 32(8), pp.1375-1380.

Rayleigh, Lord, 1896. The Theory of Sound Vol. 2., Dover, New York: Macmillan and co.

Richards, G.A. et al., 2001. Issues for low-emission, fuel-flexible power systems. Progress in Energy and Combustion Science, 27(2), pp.141-169.

Scarinci, T. \& Halpin, J., 2000. Industrial Trent combustor: Combustion noise characteristics. Journal of Engineering for Gas Turbines and Power - Transactions of the ASME, 122(2), pp.280-286.

Seybert, A.F. \& Ross, D.F., 1977. Experimental Determination of Acoustic Properties Using a 2-Microphone Random Excitation Technique. Journal of the Acoustical Society of America, 61(5), pp.1362-1370.

TSI Incorporated, 2003. Model 9306A Six-Jet Atomizer Instruction Manual B., Shoreview, MN: TSI Incorporated.

Tavoularis, S., 2005. Measurement in Fluid Mechanics, New York: Cambridge University Press.

Todd, D.M., 2000. Gas Turbine Improvements Enhance IGCC Viability. In Gasification Technologies Conference. San Francisco, CA.

Tuncer, O., Acharya, S. \& Uhm, J., 2009. Dynamics, NOx and flashback characteristics of confined premixed hydrogen-enriched methane flames. International Journal of Hydrogen Energy, 34(1), pp.496-506.

Turns, S., 2000. An Introduction to Combustion: Concepts and Applications 2nd ed., McGraw-Hill.

Waser, M. \& Crocker, M.J., 1984. Introduction to the Two-Microphone Cross-Spectral Method of Determining Sound Intensity. Noise Control Engineering Journal, 22(3), pp.76-85.

Wicksall, D.M. \& Agrawal, A.K., 2007. Acoustics measurements in a lean premixed combustor operated on hydrogen/hydrocarbon fuel mixtures. International Journal of Hydrogen Energy, 32, pp.1103-1112. 
Yilmaz, İ. et al., 2010. Experimental investigation of thermoacoustic coupling using blended hydrogen-methane fuels in a low swirl burner. International Journal of Hydrogen Energy, 35(1), pp.329-336.

Zhang, H., Zhang, X. \& Zhu, M., 2012. Experimental Investigation of Thermoacoustic Instabilities for a Model Combustor With Varying Fuel Components. Journal of Engineering for Gas Turbines and Power, 134(3).

Zinn, B. \& Lieuwen, T., 2005. Combustion Instabilities: Basic Concepts. In T. Lieuwen \& V. Yang, eds. Combustion Instabilities in Gas Turbine Engines. AIAA, pp. 3-28. 


\section{Appendix A}

\section{Uncertainty Analysis}

The measurement uncertainty of the flame transfer function magnitude and phase curves along with the uncertainty of flame liftoff distance measurements is required to evaluate the validity of trends observed in the data. Measurement uncertainty was calculated using methods outlined in the ASME Measurement Uncertainty Guide (Abernathy et al., 1985). The total uncertainty, $U$ consists of two parts, the bias error, $B$, and precision error, $S$. Precision error is the random error seen when measurements are repeated, and is caused by any number of sources. Bias error comes from known errors in all parts of the measurement process including instrument uncertainty, calibration errors, data acquisition errors, and data reduction errors.

True bias error is difficult to measure, so it is usually estimated. For simplicity, it is typically assumed that the bias is equally likely to be positive or negative. Bias error propagates through the measurement process, and so errors from all sources must be combined. This is typically done as the root of the sum of the squares assuming that for a large number of error sources there are as many positive as negative errors at any given time, and they are unlikely to be correlated.

$$
B=\sqrt{{B_{1}}^{2}+B_{2}{ }^{2}+\cdots{B_{N}}^{2}}
$$


When the number of sources of error is small, the probability of errors combining additively increases, and the root sum squares method of combining errors becomes less accurate. When calculating the error of a function, the sensitivity of each parameter must be taken into account. Each error is multiplied by its sensitivity, which is the partial derivative of that variable.

$$
B_{1}=B_{x 1} \frac{\partial f\left(x_{1}, x_{2}, \ldots x_{n}\right)}{\partial x_{1}}
$$

Precision error, $S$ is typically calculated from repeated measurements. Assuming the error is normally distributed, the precision is typically calculated based on a $95 \%$ confidence interval as:

$$
S=t \sigma
$$

where $t$ is the t-value, and depends on the degrees of freedom, and $\sigma$ is the standard deviation.

\section{A.1 Flame Transfer Function Magnitude}

The magnitude of the flame transfer function is defined as:

$$
H(f)=\frac{q^{\prime}(f) / \bar{q}}{v^{\prime}(f) / \bar{v}}
$$

The bias limit is calculated as:

$$
B_{H}=\sqrt{\left(B_{q^{\prime}} \frac{\partial H}{\partial q^{\prime}}\right)^{2}+\left(B_{\bar{q}} \frac{\partial H}{\partial \bar{q}}\right)^{2}+\left(B_{v}, \frac{\partial H}{\partial v^{\prime}}\right)^{2}+\left(B_{\bar{v}} \frac{\partial H}{\partial \bar{v}}\right)^{2}}
$$


where the sensitivities of the variables are:

$$
\begin{gathered}
\frac{\partial H}{\partial q^{\prime}}=\frac{\bar{v}}{v^{\prime} \bar{q}} \\
\frac{\partial H}{\partial \bar{q}}=\frac{q^{\prime} \bar{v}}{v^{\prime} \bar{q}^{2}} \\
\frac{\partial H}{\partial v^{\prime}}=\frac{q^{\prime} \bar{v}}{v^{\prime 2} \bar{q}} \\
\frac{\partial H}{\partial \bar{v}}=\frac{q^{\prime}}{v^{\prime} \bar{q}}
\end{gathered}
$$

Dividing the bias error by the transfer function, we get the fractional bias error in $H$ :

$$
\frac{B_{H}}{H}=\sqrt{\left(\frac{B_{q^{\prime}}}{q^{\prime}}\right)^{2}+\left(\frac{B_{\bar{q}}}{\bar{q}}\right)^{2}+\left(\frac{B_{v^{\prime}}}{v^{\prime}}\right)^{2}+\left(\frac{B_{\bar{v}}}{\bar{v}}\right)^{2}}
$$

Calculation of the individual bias errors is explained in the following sections.

\section{A.1.1 Bias Error of Mean Heat Release Rate}

There are four sources of bias error in the measurement of the mean heat release rate: the gain error of the data acquisition system (DAQ), the error due to the finite resolution of the DAQ, the variation in dark current (or DC offset), and the fluctuations in the output of the power supply which sets the gain of the photomultiplier tube.

The gain error of the NI 9215 analog voltage input module used for acquisition of the PMT signal is quoted as $0.6 \%$ of the reading for an uncalibrated module. The voltage 
range set for the measurement of the heat release rate was -10 to $10, \mathrm{~V}$ resulting in a range of $20 \mathrm{~V}$. The NI 9215 module has 16 bit resolution. This is equal to a theoretical resolution of $0.000305 \mathrm{~V}$ on the full $20 \mathrm{~V}$ range of the module. In practice, the resolution is not perfectly linear, and the actual resolution may be poorer at any given point. The resolution was measured by examining a typical signal from the PMT. The signal was sorted from lowest to highest as shown in Figure A.1. The resolution of the NI 9215 module was then calculated by subtracting the PMT output signal from the same signal shifted over by one point as shown. Figure A. 2 shows that the effective resolution of the NI 9215 module is $0.319 \mathrm{mV}$.

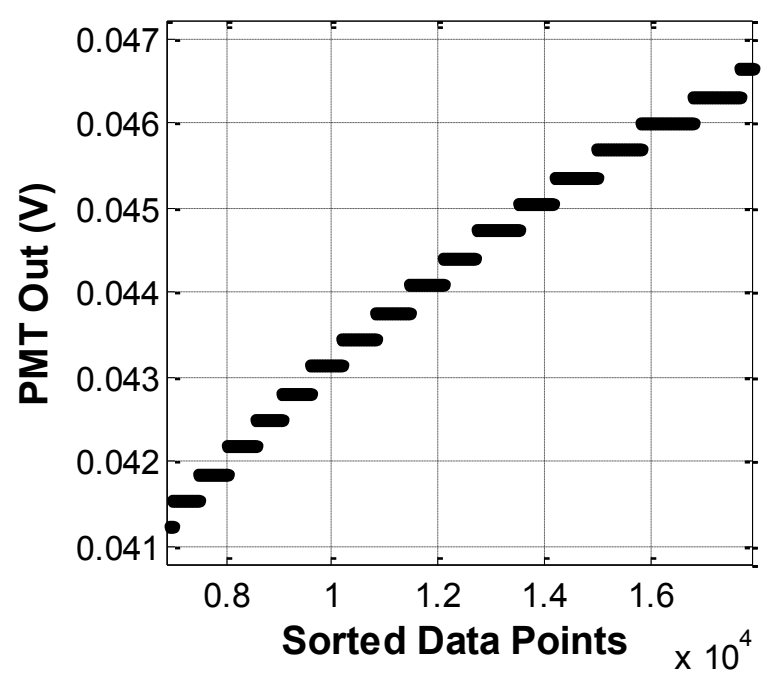

Figure A.1: PMT output, sorted

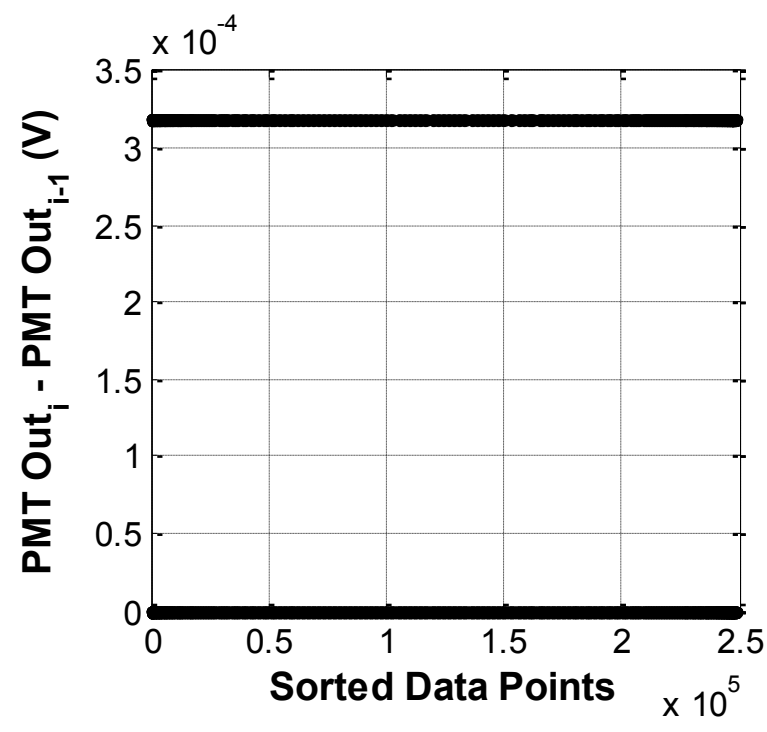

Figure A.2: Difference between adjacent points in PMT Output

Variation in the DC offset of the PMT signal due to dark current also contributes to bias error. The DC offset correction applied to the PMT signal also includes any offset inherent to the NI 9215 module. Although the dark current measured through the 
experiments varied between 0.0005 and $0.0025 \mathrm{~V}$, the maximum variation on any given day was closer to $0.0005 \mathrm{~V}$. This value was used as the bias error for the dark current.

As outlined in Chapter 3, the PMT power supply output was set to $1.4 \mathrm{~V}$. This sets the PMT high voltage to $1.4 \mathrm{kV}$, which determines the gain of the PMT. Inherent inaccuracies due to stability and thermal sensitivity of the power supply output will contribute to the bias error. Examining the measured values of power supply output for all test conditions, the mean setting was $1.4065 \mathrm{~V}$ with a standard deviation $0.074 \%$. This value was used as the bias error of the PMT power supply. The gain of the PMT increases exponentially with voltage applied, so the variation in the power supply output will not propagate linearly to the gain. The manufacturer supplied PMT gain curve is shown in Figure A.3 (ET Enterprises, 2010). Voltage is on the $\mathrm{x}$-axis in kV, with luminous sensitivity in amps/lumen on the left y-axis and gain on the right $y$-axis. By measuring the gain curve, it was determined that the gain varies linearly on a log scale between the voltages of $1.2 \mathrm{kV}$ and $1.6 \mathrm{kV}$. From this, the relationship between high voltage and gain was calculated to be:

$$
\text { gain }=10^{2.5 H V+3}
$$

Using this relationship, the error in the voltage from the power supply was propagated to PMT gain. Given the mean and standard deviation of the voltage setting, the mean and standard deviation of the gain were calculated to be $3.28 \times 10^{6}$ and $0.60 \%$ respectively. Multiplying the standard deviation by two results in an uncertainty of $1.2 \%$ at a $95 \%$ confidence interval. 


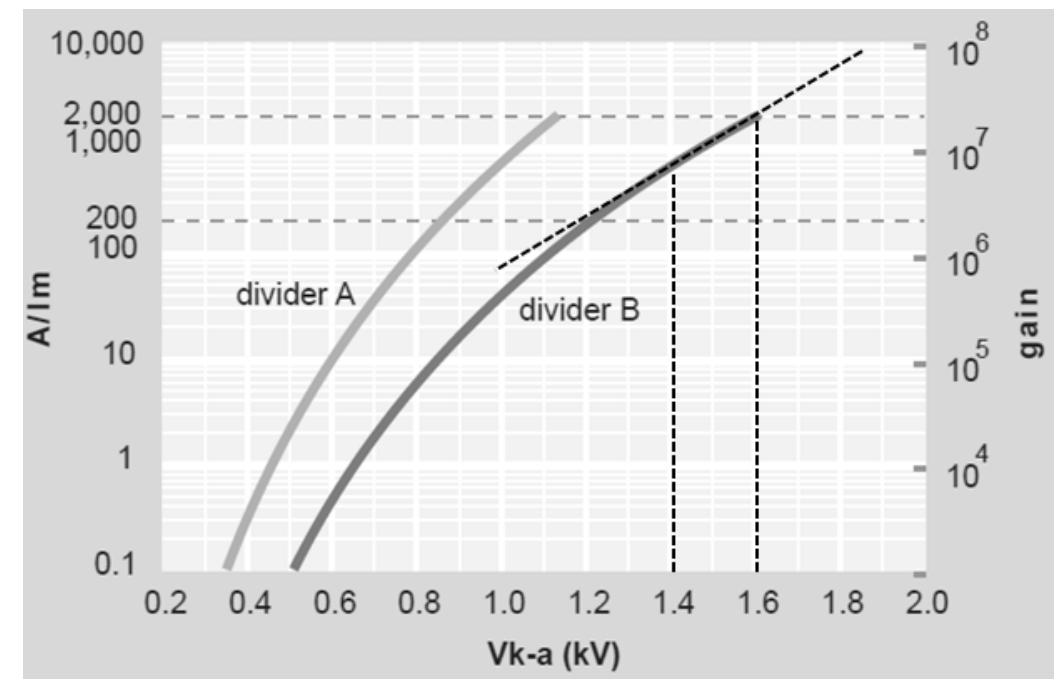

Figure A.3: Electron Tube PMT model 9125W gain curve (ET Enterprises, 2010)

Table A.1 summarizes the sources of error in the measurement of the mean heat release rate. The total bias error on the mean heat release rate is:

$$
\frac{B_{\bar{q}}}{\bar{q}}=\sqrt{0.6 \% \%^{2}+\left(\frac{0.000319}{\bar{q}}\right)^{2}+\left(\frac{0.0004}{\bar{q}}\right)^{2}+1.2 \%{ }^{2}}
$$

Table A.1: Sources of Error in Mean Heat Release Rate Measurement

\begin{tabular}{|l|l|}
\hline Source of Error & Error \\
\hline DAQ gain error & $0.6 \%$ \\
\hline DAQ resolution & $0.319 \mathrm{mV}$ \\
\hline DC current variation & $0.4 \mathrm{mV}$ \\
\hline Power supply stability & $1.20 \%$ \\
\hline
\end{tabular}

\section{A.1.2 Bias Error of Fluctuating Component of the Heat Release Rate}

The same bias errors determined for the measurement of the mean heat release

rate apply to the measurement of the fluctuating component, except for the DC current 
bias error. Since the fluctuating component of heat release rate is an AC signal, it is not affected by any offsets, assuming that the offsets do not change within the sampling time of $5 \mathrm{~s}$. Summing up the sources of error, we get the total bias error on the fluctuating component of the heat release rate:

$$
\frac{B_{q^{\prime}}}{q^{\prime}}=\sqrt{0.6 \%^{2}+\left(\frac{0.000319}{q^{\prime}}\right)^{2}+1.2 \%^{2}}
$$

The component of error due to a finite resolution was the largest contributor to the total uncertainty. However, the actual error from the finite resolution will be lower since FFT analysis involves fitting sine curves to the data, thus reducing the impact of the error at any given point.

\section{A.1.3 Bias Error of Velocity Fluctuation}

Bias error in the measurement of the velocity fluctuation stems from inaccuracies in the LDV equipment. The fringe spacing is accurate to within $0.07 \%$ while the signal processing unit has a reported accuracy of $0.1 \%$. To get a conservative estimate of error, these are summed directly, arriving at an overall bias error of $0.17 \%$.

\section{A.1.4 Bias Error of Mean Velocity}

The mean velocity is calculated from the total flow rate knowing the area:

$$
\bar{v}=\frac{Q_{t o t a l}}{A}=\frac{Q_{t o t a l}}{\pi \frac{d^{2}}{4}}
$$

The uncertainty of the total flow rate, $Q_{\text {total }}$, is based on the uncertainties of all the components: 


$$
B_{Q_{\text {total }}}=\sqrt{\sum B_{Q_{i}}^{2}}
$$

Each mass flow controller has a factory quoted error of $1 \%$ of the range or $0.2 \%$ of the full scale, whichever is larger. Propagating this error results in a calculated bias of $0.87 \%$ to $0.94 \%$ depending on the test condition. To simplify further calculations, the error on the total flow rate was assumed to be $1 \%$ for all fuel mixtures. To obtain the bias limit of the quartz tube diameter, it was measured ten times along different radial lines with a digital caliper and the difference between the maximum and minimum value $(0.06 \mathrm{~mm})$ used as the bias limit. The bias on the mean velocity can then be calculated:

$$
B_{\bar{v}}=\sqrt{\left(B_{Q_{\text {total }}} \frac{\partial \bar{v}}{\partial Q_{\text {total }}}\right)^{2}+\left(B_{d} \frac{\partial \bar{v}}{\partial d}\right)^{2}}
$$

where the sensitivities are calculated as:

$$
\begin{gathered}
\frac{\partial \bar{v}}{\partial Q_{\text {total }}}=\frac{1}{\pi \frac{d^{2}}{4}} \\
\frac{\partial \bar{v}}{\partial d}=\frac{Q_{\text {total }}}{\pi \frac{d^{4}}{4}}
\end{gathered}
$$

The overall bias error as a percentage of the mean velocity is $2.4 \%$ and is constant for all test points:

$$
\frac{B_{\bar{v}}}{\bar{v}}=\sqrt{\left(\frac{B_{Q_{\text {total }}}}{Q_{\text {total }}}\right)^{2}+\left(\frac{B_{d}}{d^{2}}\right)^{2}}=\sqrt{(1 \%)^{2}+\left(\frac{0.00006}{(0.05285)^{2}}\right)^{2}}=2.4 \%
$$




\section{A.1.5 Total Flame Transfer Function Bias Error}

Combining the individual sources of error, we get the total bias of the flame transfer function magnitude:

$$
\begin{gathered}
\frac{B_{H}}{H}=\sqrt{\left(\frac{B_{q^{\prime}}}{q^{\prime}}\right)^{2}+\left(\frac{B_{\bar{q}}}{\bar{q}}\right)^{2}+\left(\frac{B_{v^{\prime}}}{v^{\prime}}\right)^{2}+\left(\frac{B_{\bar{v}}}{\bar{v}}\right)^{2}} \\
\frac{B_{H}}{H}=\sqrt{\frac{\left(\frac{0.000319}{\bar{q}}\right)^{2}+\left(\frac{0.0004}{\bar{q}}\right)^{2}+1.2 \% \%^{2}+0.6 \%^{2}}{+\left(\frac{0.000319}{q^{\prime}}\right)^{2}+1.2 \%^{2}+0.6 \%^{2}+0.17 \%^{2}+2.4 \%^{2}}}
\end{gathered}
$$

\section{A.1.6 Precision Error}

The precision error, $S$ is typically calculated from the standard deviation of repeated measurements. For this experiment, the flame position changed slightly even when operating the burner with the same fuel mixtures and operating conditions at different times in the same day mainly due to slow burner stabilization. This resulted in small differences in the flame transfer function, which were not the result of random error, but instead due to the flame position changing. Consequently, the precision error was estimated from the data at a given test condition.

The flame transfer function was typically measured for 19 to 25 different forcing frequencies at each test condition. This value varied depending on the condition, and the selection of forcing frequencies was optimized for each test condition so that there were more points around the peak of the flame transfer function. At each frequency the mean heat release rate was measured by taking the mean of the heat release rate signal. The 
uncertainty on this value was low because it was based on 50,000 points. To estimate the uncertainty of the mean heat release rate, the standard deviation was calculated from the mean heat release rates at all the forcing frequencies. The precision was then calculated as the standard deviation multiplied by the t-value.

Similarly, for the mean velocity, the standard deviation was calculated from the mean velocities at all the forcing frequencies for a given test condition. The precision was then calculated as the standard deviation multiplied by the t-value.

Calculation of the precision error for the fluctuating components of heat release rate and velocity was done differently. The fluctuating components were calculated using FFT analysis on the time data at each frequency. To find the precision error at each frequency, the time domain data were split into ten equal parts, and FFT analysis was performed on these parts individually. The standard deviation was then calculated from the resulting ten data points. The mean values of the heat release rate and velocity fluctuations were checked to ensure they were close to the original means calculated from an FFT of the entire time domain. Performing FFT analysis based on signals a tenth of the size of the original time domain data gave a conservative estimate of the standard deviations for the fluctuating components of velocity and heat release rate. Again, the precision was calculated as the standard deviation multiplied by the t-value. 


\section{A.2 Flame Transfer Function Phase}

The transfer function phase, $\theta_{H}$ was calculated as the phase of the heat release rate, $\theta_{q}$ minus the phase of the velocity, $\theta_{v}$ :

$$
\theta_{H}=\theta_{q}-\theta_{v}
$$

Sources of bias error on the phase measurement would be the inaccuracies of the timing devices in the data acquisition system used to measure the heat release rate and in the Dantec LDV system used to measure the velocity fluctuation. These values can be assumed to be negligible compared to the precision error of the phase.

The precision error was quantified the same way as the precision error for the magnitude of the heat release rate and velocity fluctuations. The original time domain data were split into ten parts, and FFT analysis was performed on each of these parts. A standard deviation was then calculated from the ten values of phase and multiplied by the t-value to get the precision error.

\section{A.3 Flame Transfer Function Peak Magnitude}

To estimate the uncertainty of the peak transfer function magnitudes obtained from models created in Matlab, Monte Carlo analysis was conducted as outlined in Coleman \& Steele (2009). For the magnitude of the FTF, the bias and precision errors for each of the four variables $\left(v^{\prime}, \bar{v}, q^{\prime}\right.$, and $\left.\bar{q}\right)$ were combined and assumed to be normally distributed. Similarly, the phase of the fluctuating components of heat release rate and velocity were assumed to be normally distributed. Random data were then generated for these six variables. Two thousand iterations were found to be enough for the standard 
deviation of the transfer function magnitude to converge to within $1 \%$ of the calculated value. For each set of simulated data, a Matlab model was generated and the peak magnitude was found from the transfer function. The uncertainty of the peak magnitude was then calculated as twice the standard deviation.

This analysis was done for four test conditions - two each of type I and type II flame transfer functions. Figure A.4 and Figure A.5 show the peak uncertainty for two type I FTFs. The peak uncertainty calculated from Monte Carlo methods was less than the uncertainty on the original data points around the peak for the two type I FTFs studied. There was also less than a $1 \mathrm{~Hz}$ variation in the frequency of the peak. Figure A.6 and Figure A.7 show the peak uncertainty for two type II FTFs. For these two cases, the peak uncertainty was on the order of the uncertainty on the original data points around the peak. To get a conservative estimate on the uncertainty of the peak for type I and II FTFs, the uncertainty of the point nearest to the peak was taken.

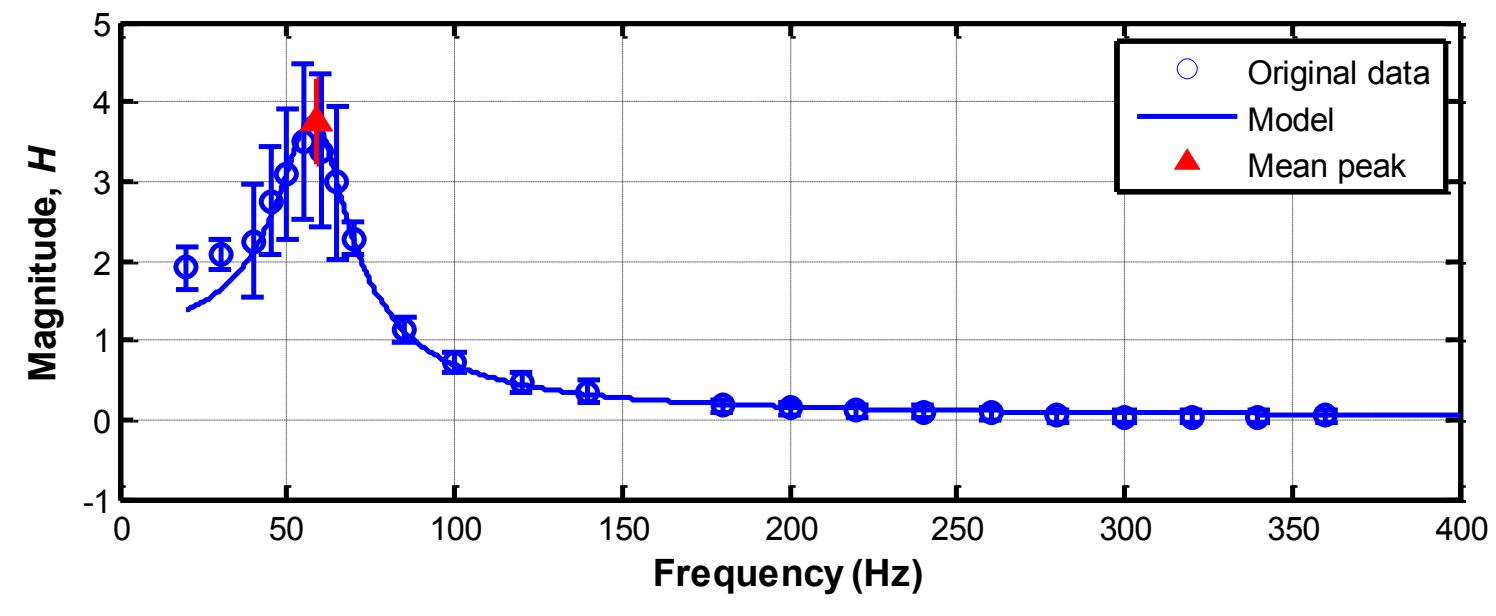

Figure A.4: Peak uncertainty for type I FTF $-\mathrm{M75H1C1}, \phi=0.65, \bar{v}=6 \mathrm{~cm} / \mathrm{s}, \mathrm{OH}^{*}$ 


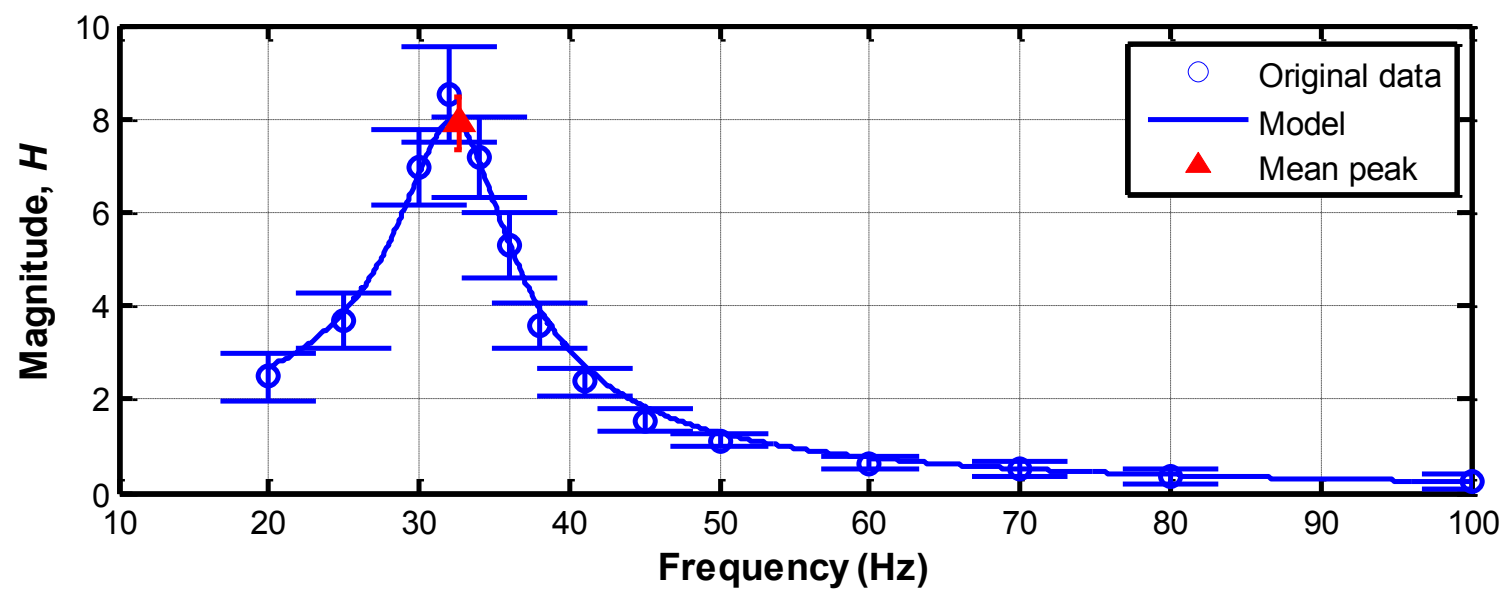

Figure A.5: Peak uncertainty for type I FTF $-\mathrm{CH}_{4}, \phi=0.62, \bar{v}=5.7 \mathrm{~cm} / \mathrm{s}, \mathrm{OH}^{*}$

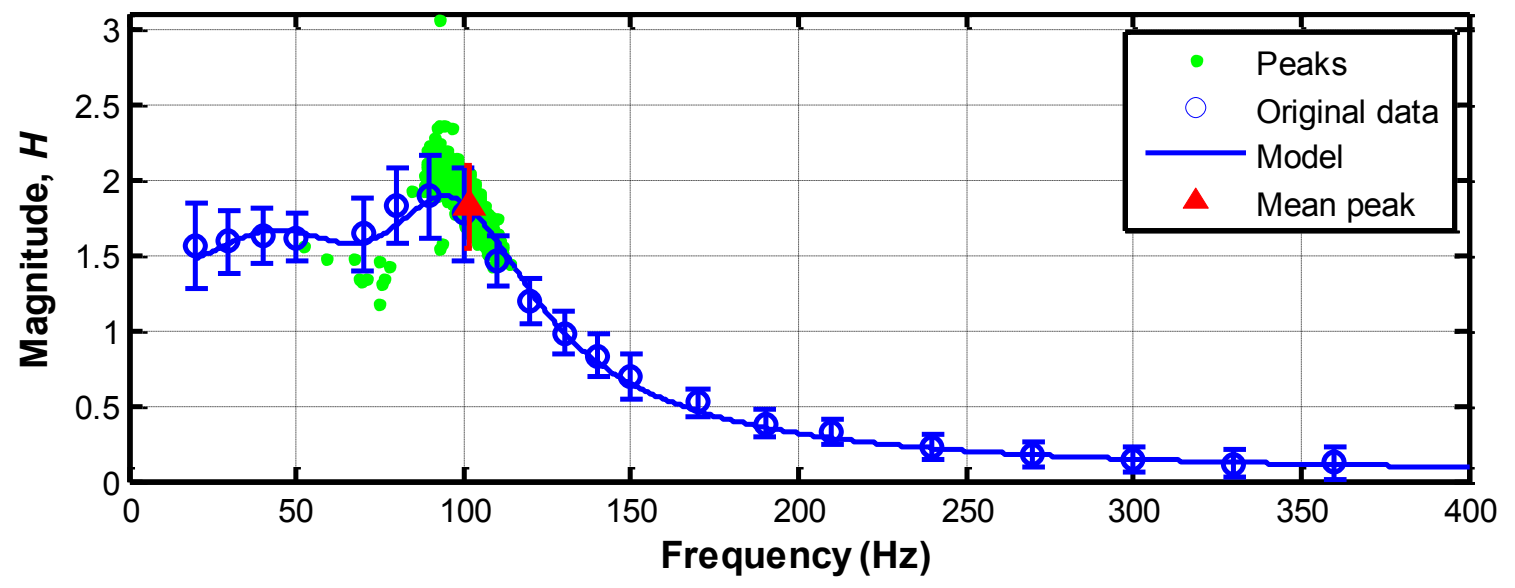

Figure A.6: Peak uncertainty for type II FTF - M50H1C2, $\phi=0.65, \bar{v}=6 \mathrm{~cm} / \mathrm{s}$, OH*

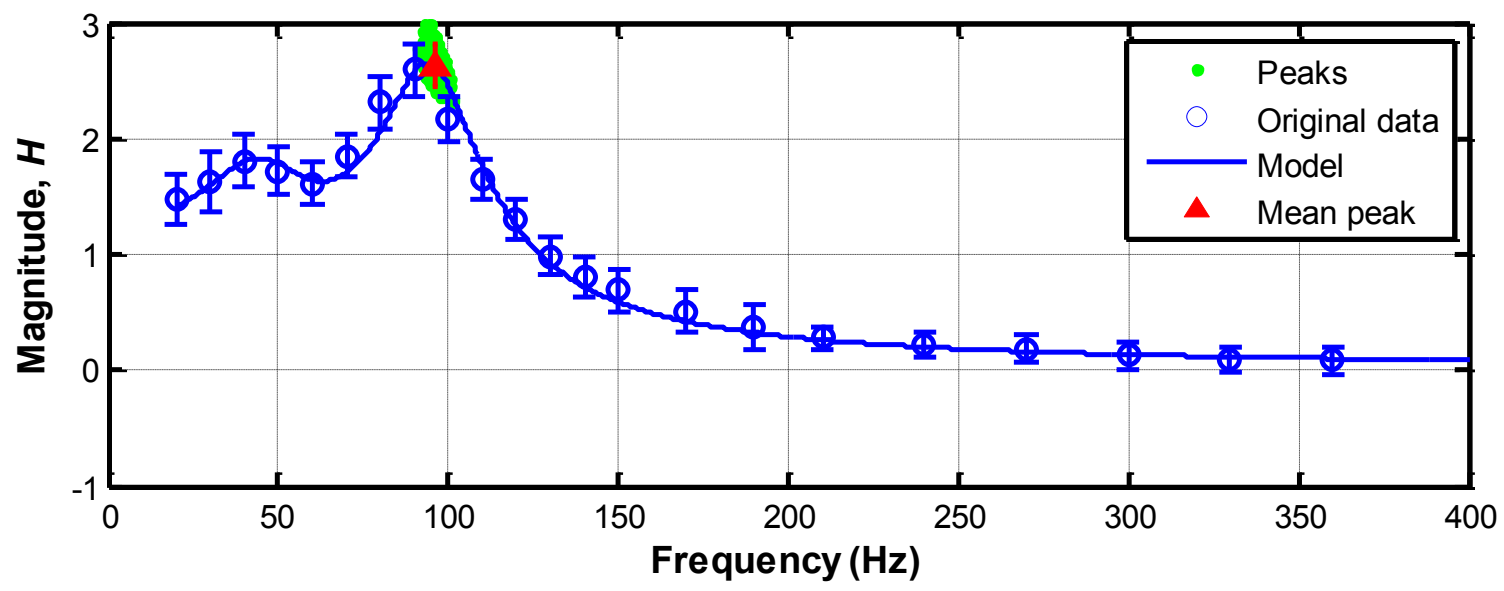

Figure A.7: Peak uncertainty for type II FTF $-\mathrm{CH}_{4}, \phi=0.7, \bar{v}=6 \mathrm{~cm} / \mathrm{s}, \mathrm{OH}^{*}$ 
This same analysis was attempted for type III FTFs. Due to the high order of the transfer function model, the Monte Carlo simulation yielded unstable results. However, since the peaks of the type III FTFs are generally small, it can be assumed that the uncertainty of the peak is equal to the uncertainty of the data points close to the peak.

\section{A.4 Flame Liftoff Distance}

The flame liftoff distance is calculated as follows:

$$
d_{f, m}=\frac{d_{f, p} w_{b, m}}{w_{b, p}}
$$

where $d_{f}$ is the flame liftoff distance and $w_{b}$ is the burner width. The subscripts, $p$ and $m$ denote units of pixels and millimetres respectively. The burner width was calculated knowing the locations of the edge of the burner on the image. Similarly, the flame liftoff distance was calculated knowing the location of the burner top edge and flame centre. It was assumed that each of these can be calculated accurately to within one pixel. Combining these additively to give a conservative estimate, the bias limit for both the flame distance and burner width was two pixels. The bias limit on the flame liftoff distance in metres was then calculated as:

$$
\frac{B_{d_{f, m}}}{d_{f, m}}=\sqrt{\left(B_{d_{f, p}} \frac{\partial d_{f, m}}{\partial d_{f, p}}\right)^{2}+\left(B_{w_{b, m}} \frac{\partial d_{f, m}}{\partial w_{b, m}}\right)^{2}+\left(B_{w_{b, p}} \frac{\partial d_{f, m}}{\partial w_{b, p}}\right)^{2}}
$$

Dividing by $d_{f}$, the bias limit as a percentage can then be calculated. 


$$
\frac{B_{d_{f, m}}}{d_{f, m}}=\sqrt{\left(\frac{B_{d_{f, p}}}{d_{f, p}}\right)^{2}+\left(\frac{B_{w_{b, m}}}{w_{b, m}}\right)^{2}+\left(\frac{B_{w_{b, p}}}{w_{b, p}}\right)^{2}}
$$

The burner width calculated from the images was about 2500 pixels for all conditions. The actual burner width was $71.63 \mathrm{~mm}$, measured with digital calipers that were accurate to at least $0.1 \mathrm{~mm}$. The largest flame liftoff distance in pixels was 47 for all test cases. For this case the flame liftoff distance contributed the least to the total bias, yet it was still much larger than the contributions of the other two sources. Thus the other sources could be ignored.

$$
\frac{B_{d_{f, m}}}{d_{f, m}}=\sqrt{\left(\frac{2}{47}\right)^{2}+\left(\frac{.1}{71.63}\right)^{2}+\left(\frac{2}{2500}\right)^{2}}=\sqrt{(4.3 \%)^{2}+(0.14 \%)^{2}+(0.08 \%)^{2}} \text { (A.26) }
$$

The bias limit on the flame liftoff distance is then:

$$
B_{d_{f, m}}=\frac{2 d_{f, m}}{d_{f, p}}=\frac{2 w_{b, m}}{w_{b, p}}=\frac{2 \times 71.63}{2500}=0.057 \mathrm{~mm}
$$

The precision error was estimated by examining the largest variation in the flame liftoff distance measured in a single day for a given test condition. This value was $0.04 \mathrm{~mm}$ and was comparable to the maximum variation seen during the flame stabilization tests after the flame had stabilized. Combining the bias and precision errors for the flame liftoff distance, the total error was:

$$
B_{d_{f, m}}=\sqrt{0.057^{2}+0.04^{2}}=0.07 \mathrm{~mm}
$$




\section{Appendix B}

\section{Flame Transfer Function Models}

Table B.1 shows the natural frequency, damping ratio, and peak magnitude for the primary FTF peak at all the test conditions. The flame transfer function magnitude and phase plots as well as the corresponding Matlab models for all the test conditions are shown in Sections B.1 to B.4 for data collected using $\mathrm{OH}^{*}$ chemiluminescence.

Table B.1: Model outputs for primary FTF peak

\begin{tabular}{|c|l|c|c|c|c|c|}
\hline Type & Fuel & $\boldsymbol{\Phi}$ & $\begin{array}{c}\overline{\mathbf{v}} \\
\mathbf{( c m} / \mathbf{s})\end{array}$ & $\begin{array}{c}\boldsymbol{\omega}_{\mathbf{n}} \\
\mathbf{( H z )}\end{array}$ & $\boldsymbol{\zeta}^{\mathbf{a}}$ & $\begin{array}{c}\text { FTF Peak } \\
\text { Magnitude }\end{array}$ \\
\hline \multirow{3}{*}{1} & M & 0.62 & 5.7 & 33 & 0.11 & 7.91 \\
& B & 0.65 & 6.5 & 34 & 0.16 & 5.03 \\
& M50H1C1 & 0.55 & 6.5 & 32 & 0.18 & 4.52 \\
& B & 0.65 & 6.7 & 38 & 0.17 & 4.96 \\
& M & 0.65 & 6 & 51 & 0.14 & 5.19 \\
& M75H1C1 & 0.65 & 6 & 59 & 0.17 & 3.74 \\
& B & 0.7 & 6 & 57 & 0.16 & 4.10 \\
& M50H1C1 & 0.6 & 6 & 67 & 0.31 & 2.36 \\
\hline & M & 0.7 & 5 & 60 & 0.17 & 3.66 \\
& M50H1C1 & 0.65 & 6 & 98 & 0.28 & 1.69 \\
& M & 0.7 & 6 & 96 & 0.16 & 2.63 \\
2 & M50H2C1 & 0.65 & 6 & 99 & 0.32 & 1.53 \\
& M50H1C2 & 0.65 & 6 & 102 & 0.23 & 1.82 \\
& B & 0.7 & 8 & 118 & 0.24 & 2.18 \\
& M & 0.75 & 6 & 136 & 0.23 & 1.59 \\
& M & 0.7 & 7 & 143 & 0.22 & 1.83 \\
\hline \multirow{2}{*}{3} & M50H1C1 & 0.65 & 7 & 156 & 0.33 & 1.21 \\
& B & 0.8 & 7 & 165 & 0.28 & 1.29 \\
\hline 4 & M25H1C1 & 0.65 & 6 & 143 & 0.87 & 0.82 \\
\hline amping factor of primary peak & &
\end{tabular}




\section{B.1 Type I}
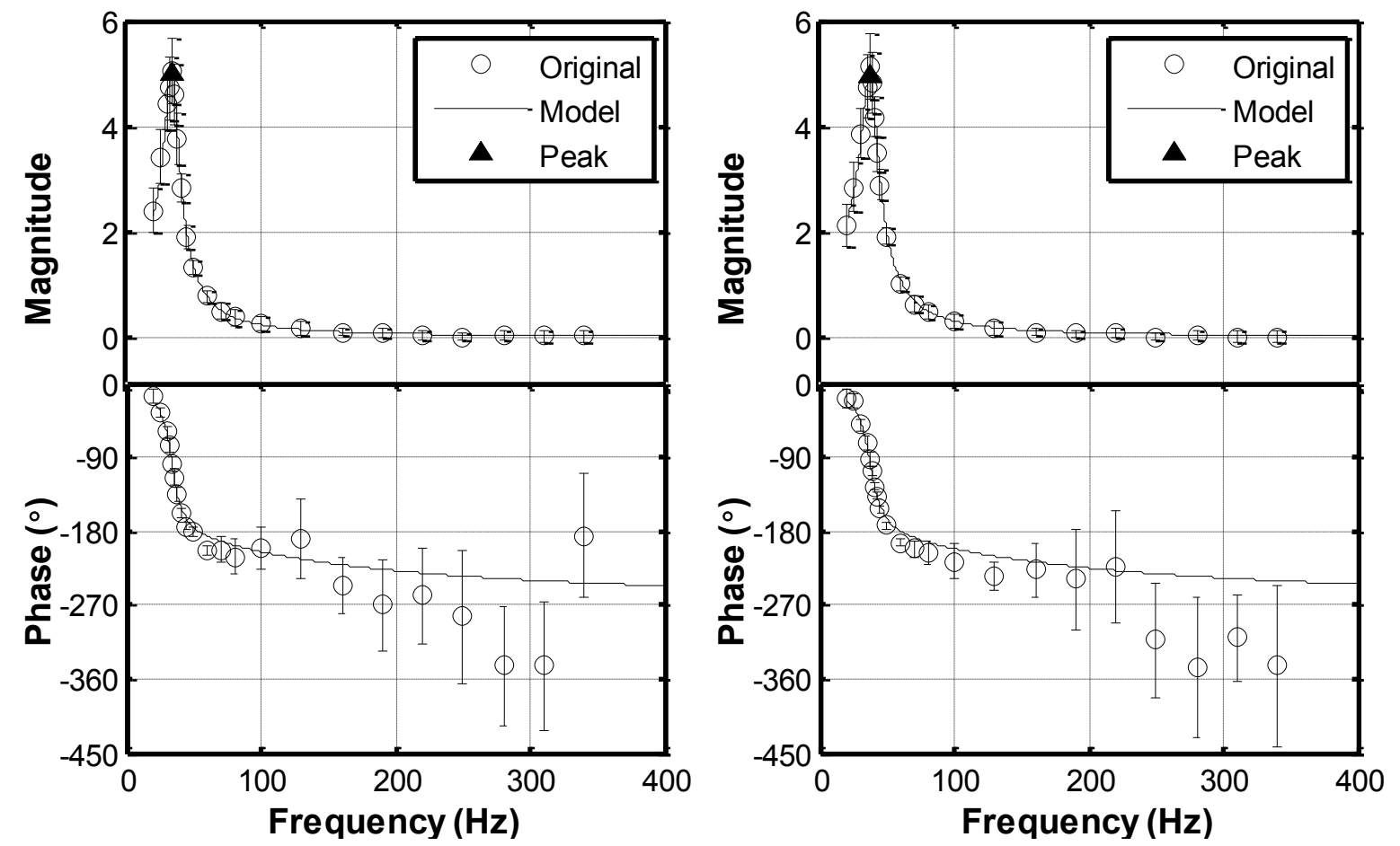

Figure B.1: $B I O, \Phi=0.65, \bar{v}=6.5 \mathrm{~cm} / \mathrm{s}$

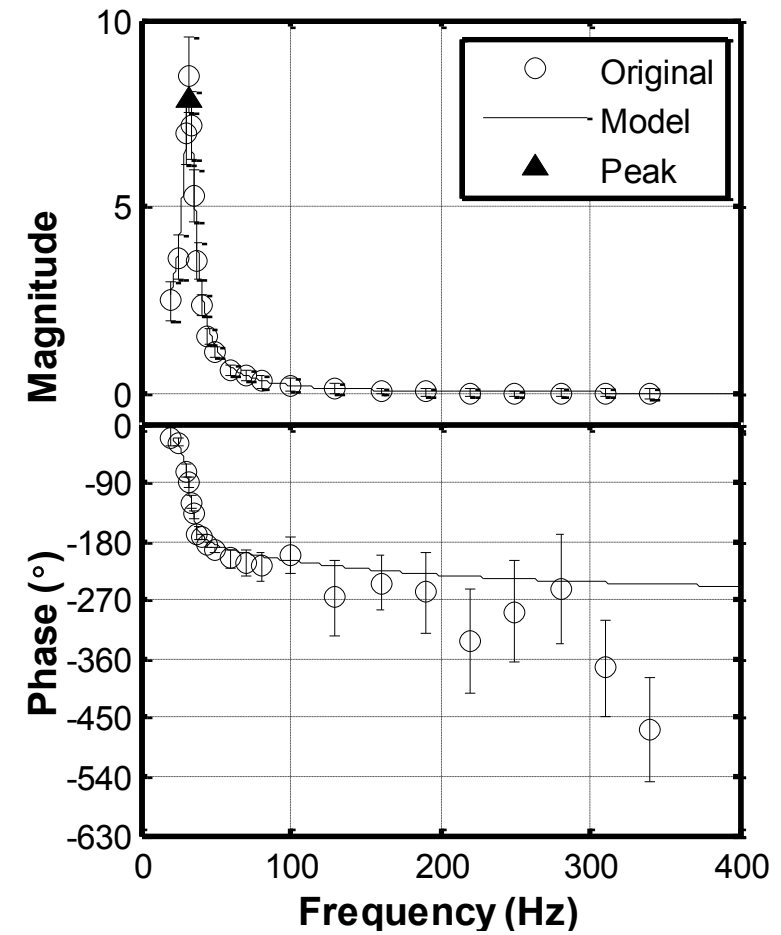

Figure B.2: $\mathrm{BIO}, \Phi=0.65, \bar{v}=6.7 \mathrm{~cm} / \mathrm{s}$

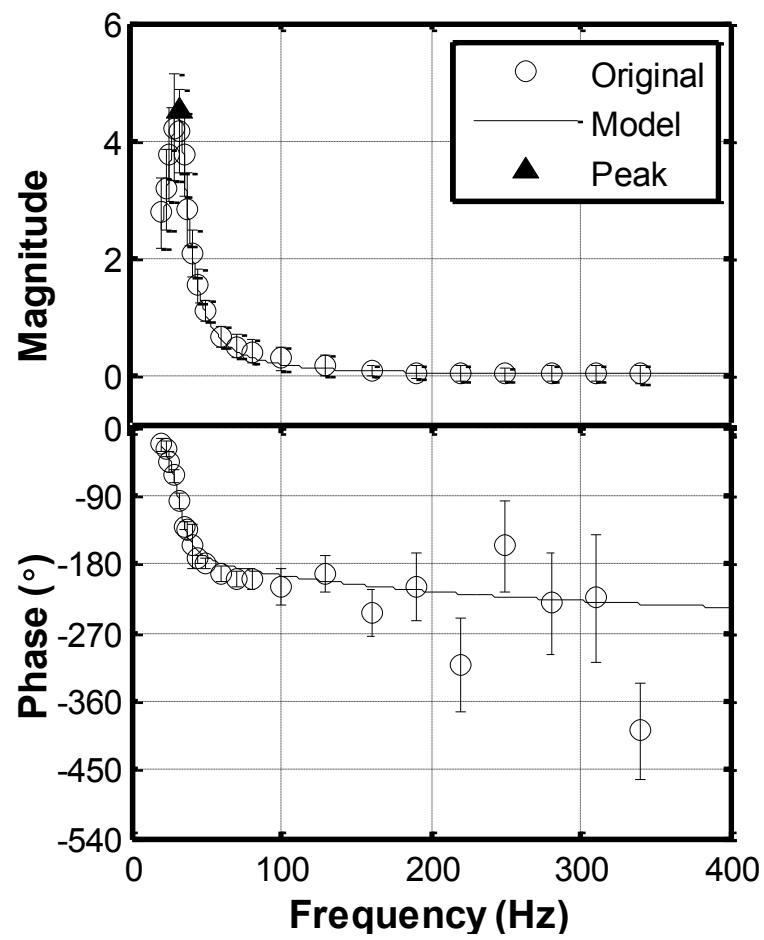

Figure B.3: $\mathrm{CH}_{4}, \Phi=0.62, \bar{v}=5.2 \mathrm{~cm} / \mathrm{s}$

Figure B.4: M50H1C1, $\Phi=0.55, \bar{v}=6.5$ 

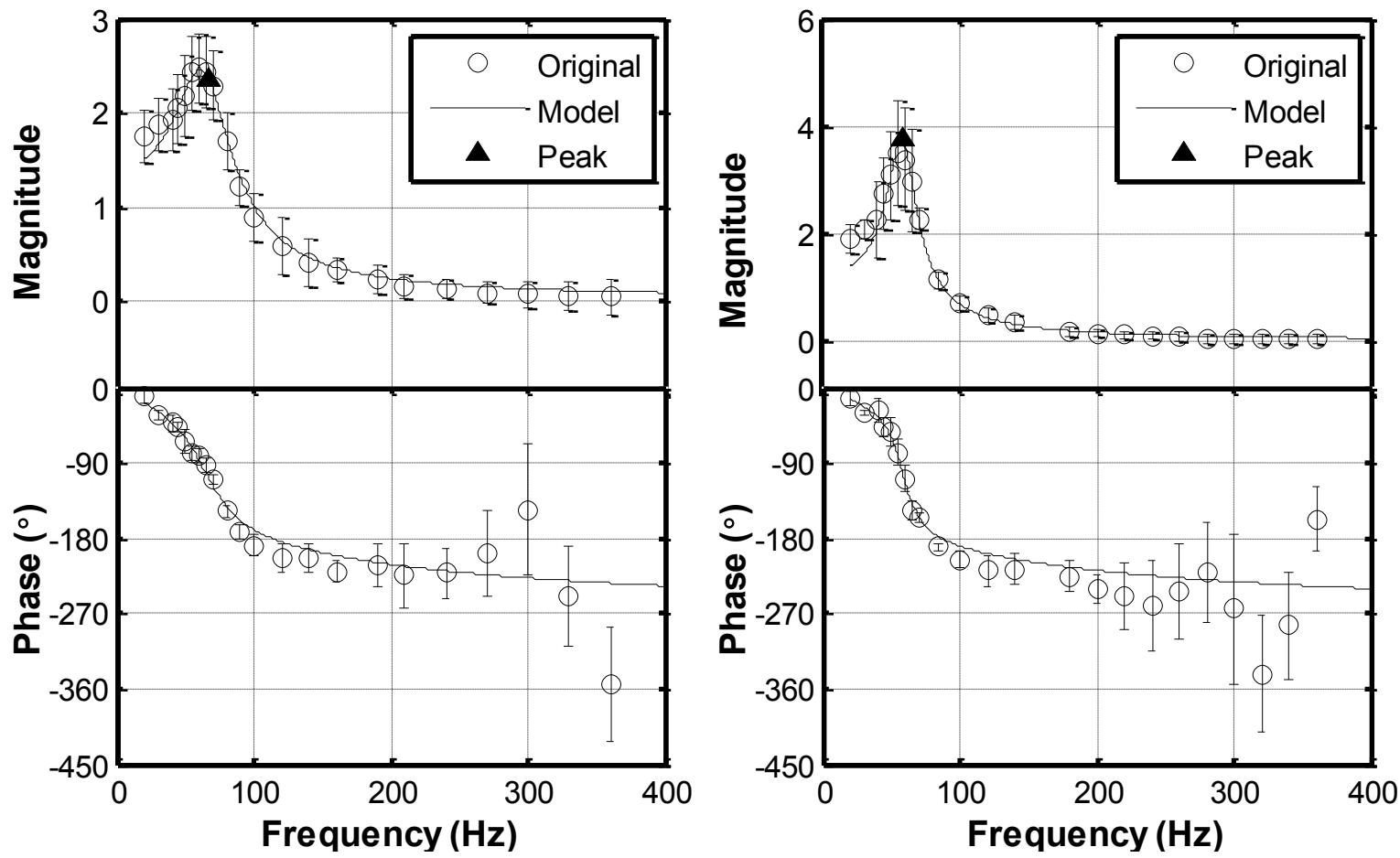

Figure B.5: M50H1C1, $\Phi=0.6, \bar{v}=6$ $\mathbf{c m} / \mathbf{s}$,

Figure B.6: M75H1C1, $\Phi=0.65$, $\bar{v}=6 \mathrm{~cm} / \mathrm{s}$

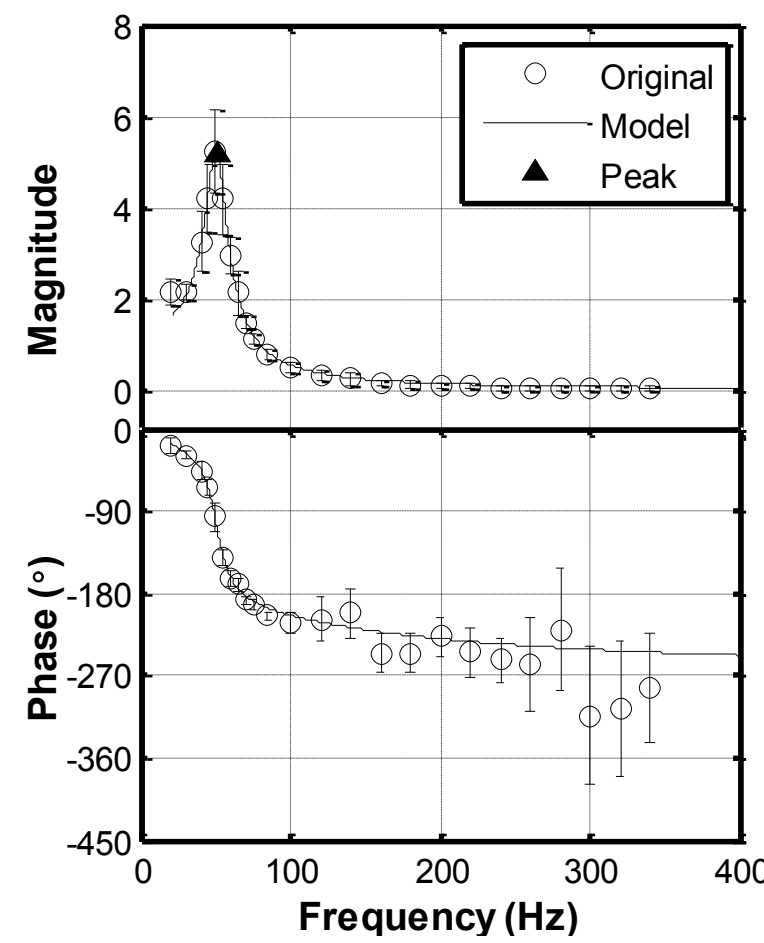

Figure B.7: $\mathrm{CH}_{4}, \Phi=0.65, \bar{v}=6 \mathrm{~cm} / \mathrm{s}$

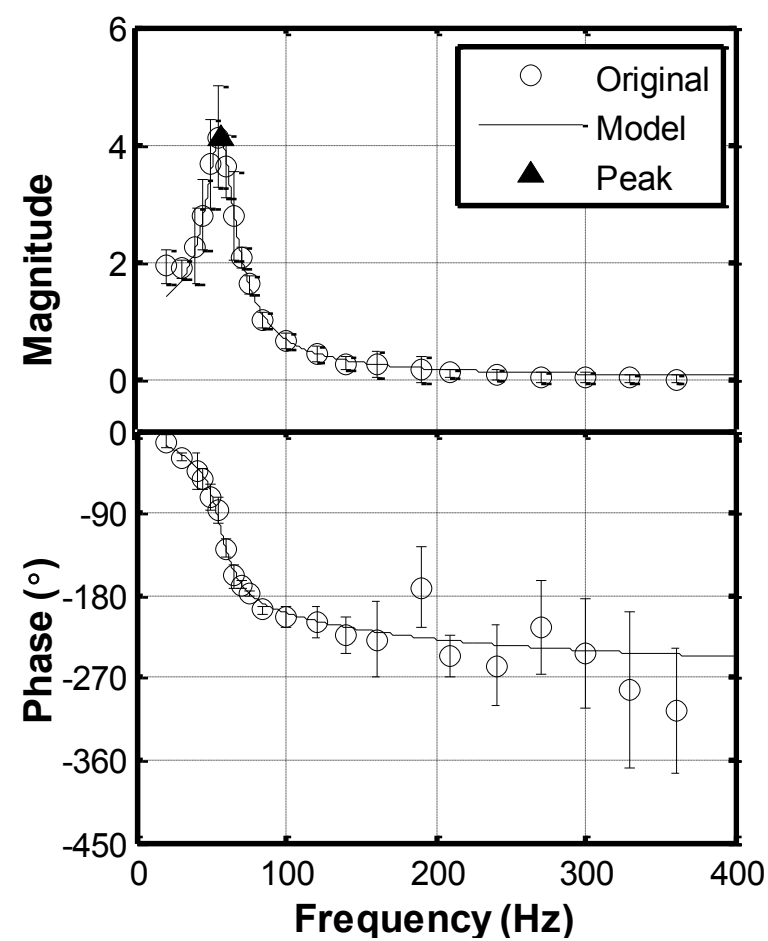

Figure B.8: $\mathrm{BIO}, \Phi=0.7, \bar{v}=6 \mathrm{~cm} / \mathrm{s}$ 


\section{B.2 Type II}

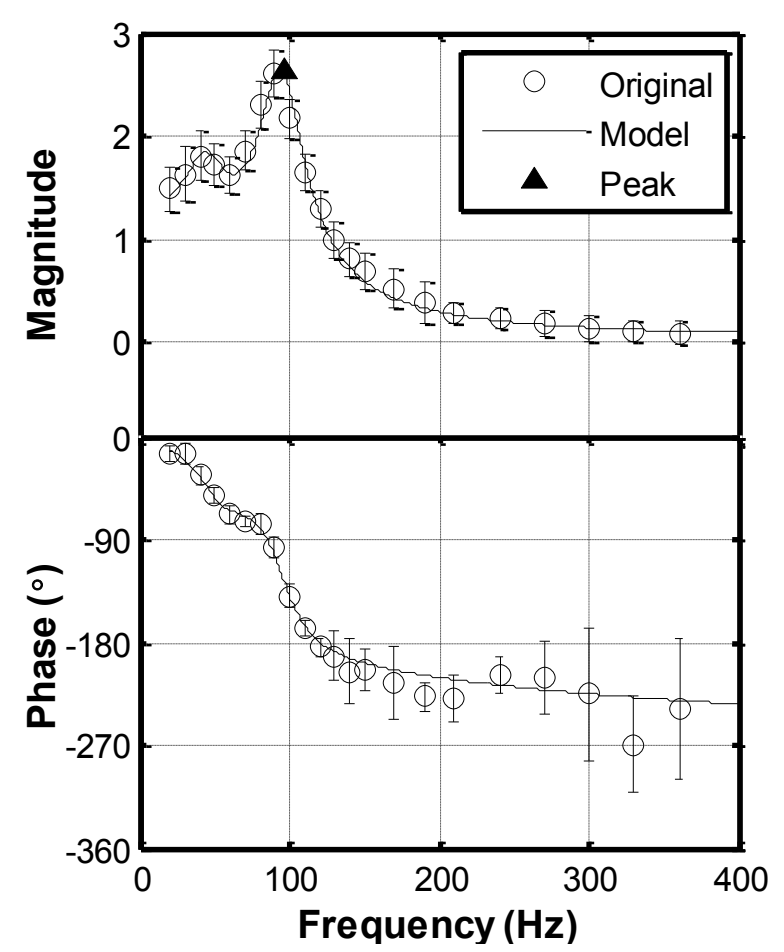

Figure B.9: $\mathrm{CH}_{4}, \Phi=0.7, \bar{v}=6 \mathrm{~cm} / \mathrm{s}$

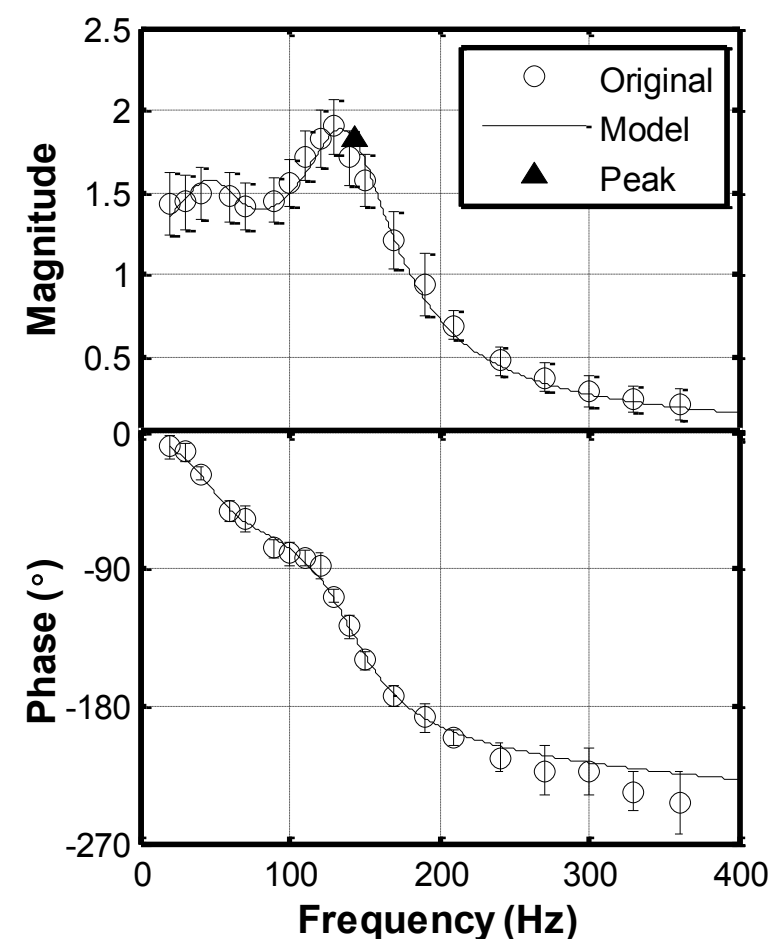

Figure B.11: $\mathrm{CH}_{4}, \Phi=0.7, \bar{v}=7 \mathrm{~cm} / \mathrm{s}$

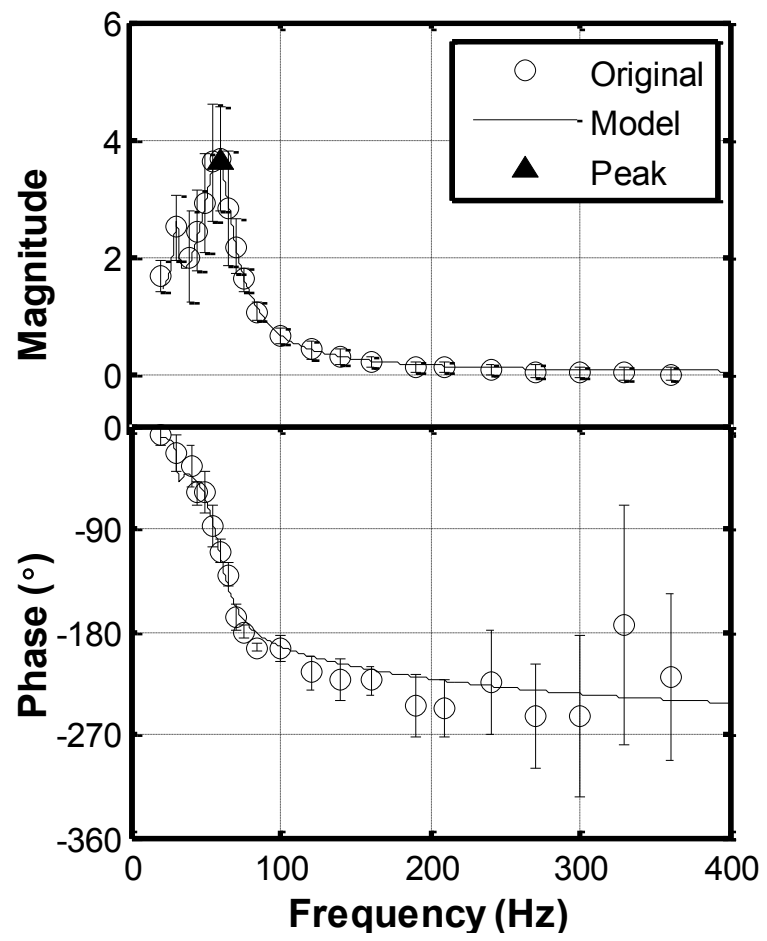

Figure B.10: $\mathrm{CH}_{4}, \Phi=0.7, \bar{v}=5 \mathrm{~cm} / \mathrm{s}$

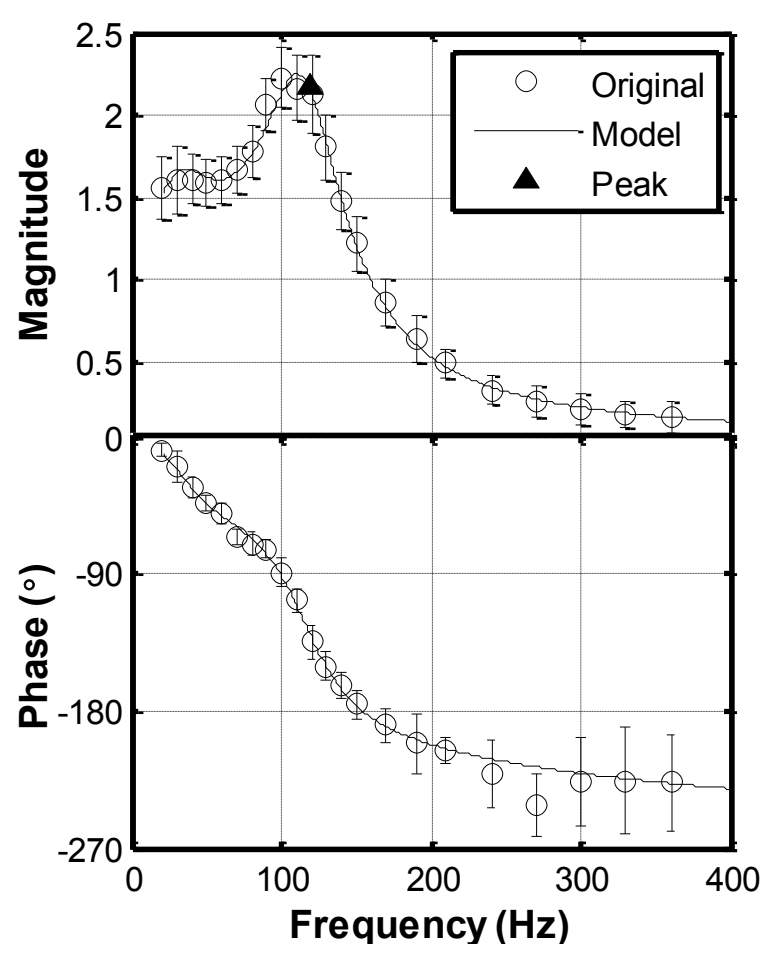

Figure B.12: $B I O, \Phi=0.7, \bar{v}=8 \mathrm{~cm} / \mathrm{s}$ 


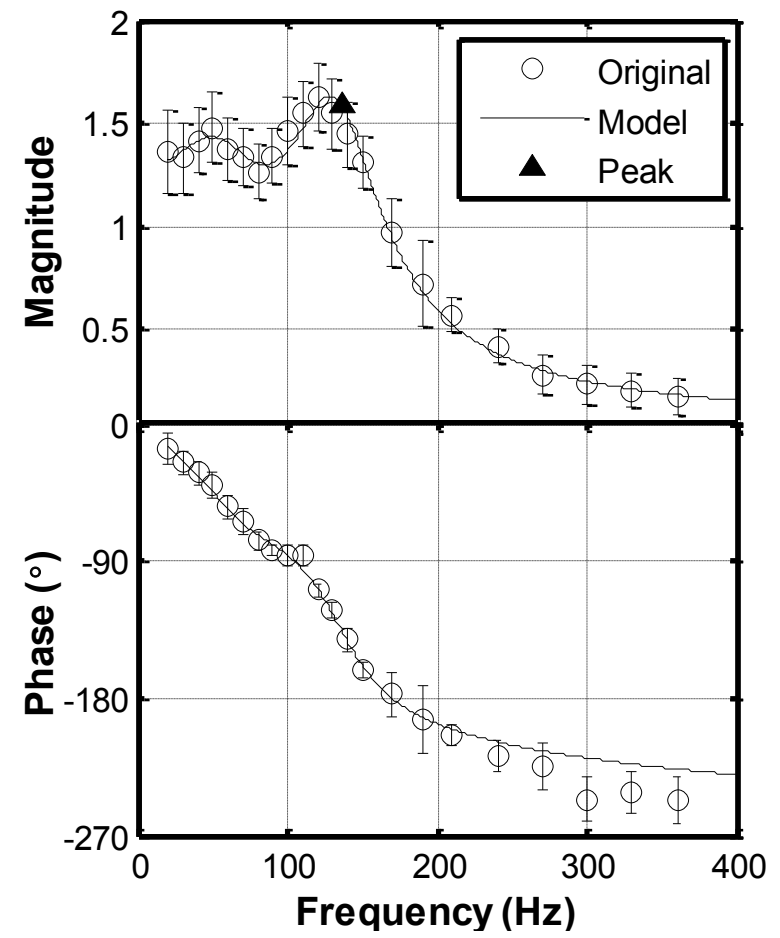

Figure B.13: $\mathrm{CH}_{4}, \Phi=0.75, \bar{v}=6 \mathrm{~cm} / \mathrm{s}$,

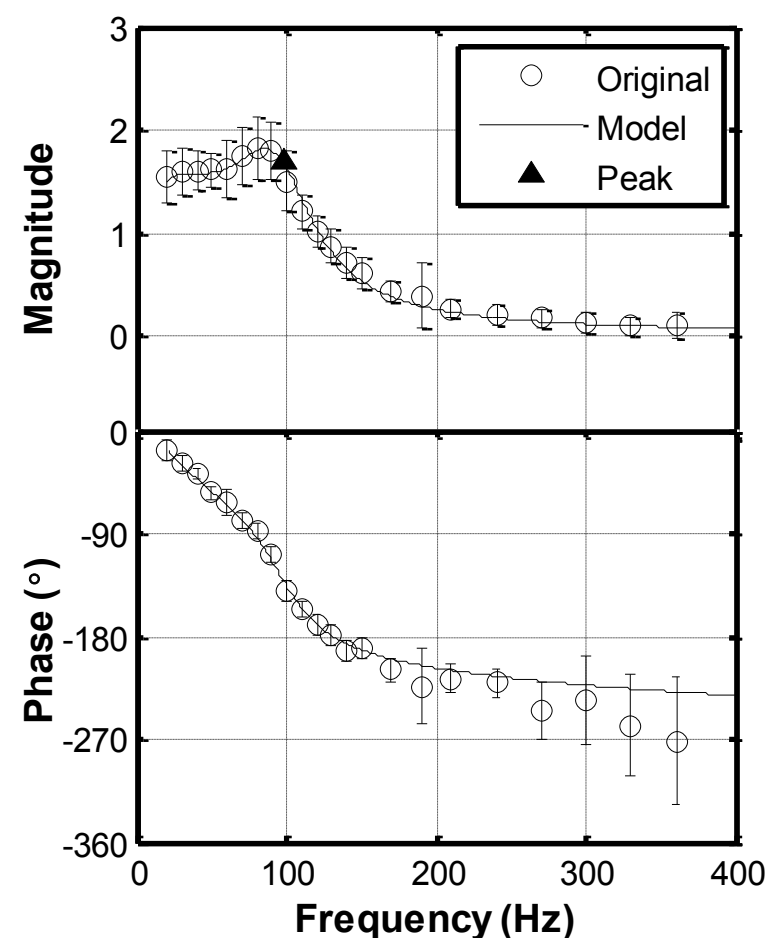

Figure B.15: M50H1C1 $\Phi=0.65$,

$$
\bar{v}=6 \mathrm{~cm} / \mathrm{s}
$$

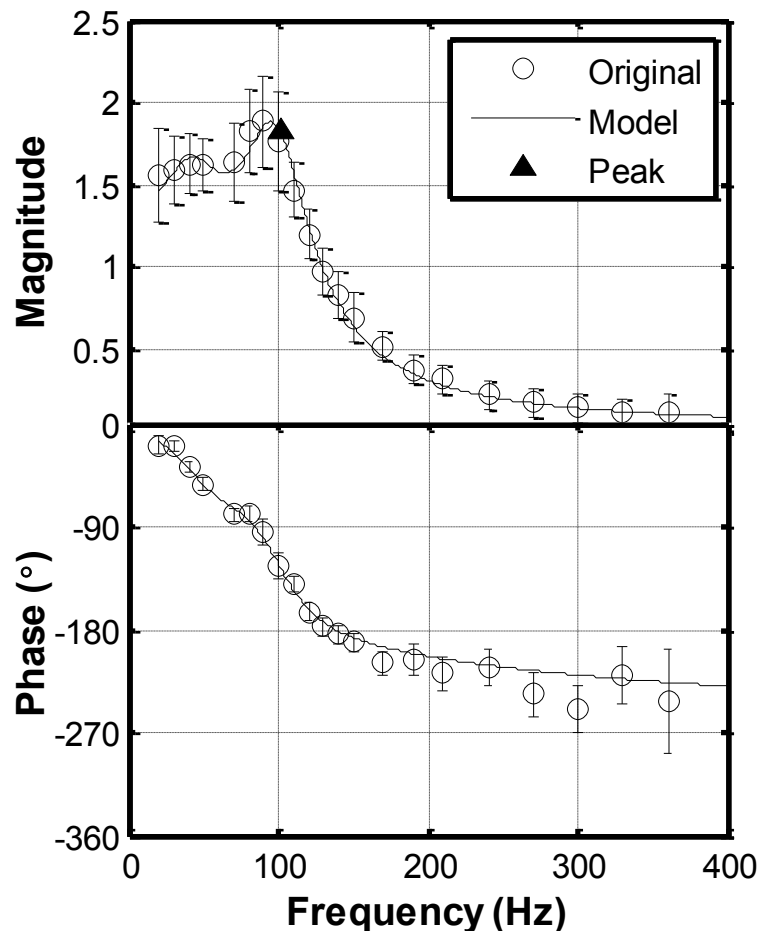

Figure B.14: $\mathrm{M50H1C2}, \Phi=0.65$, $\bar{v}=6 \mathrm{~cm} / \mathrm{s}$

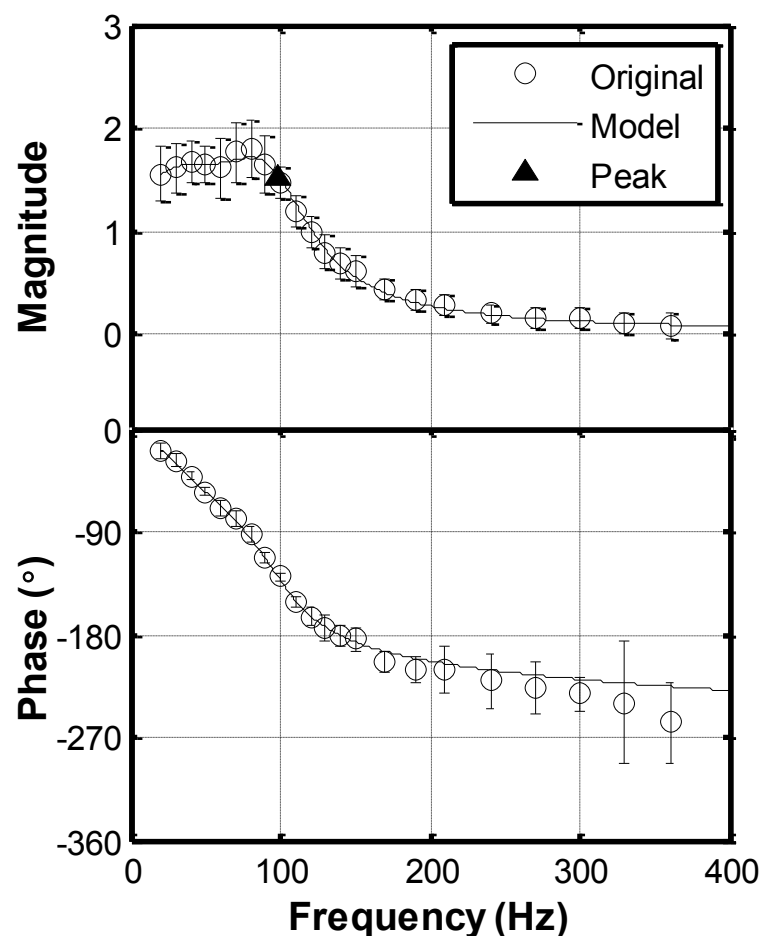

Figure B.16: $\mathrm{M50H2C} 1, \Phi=0.65, \bar{v}$

$$
=6 \mathrm{~cm} / \mathrm{s}
$$




\section{B.3 Type III}

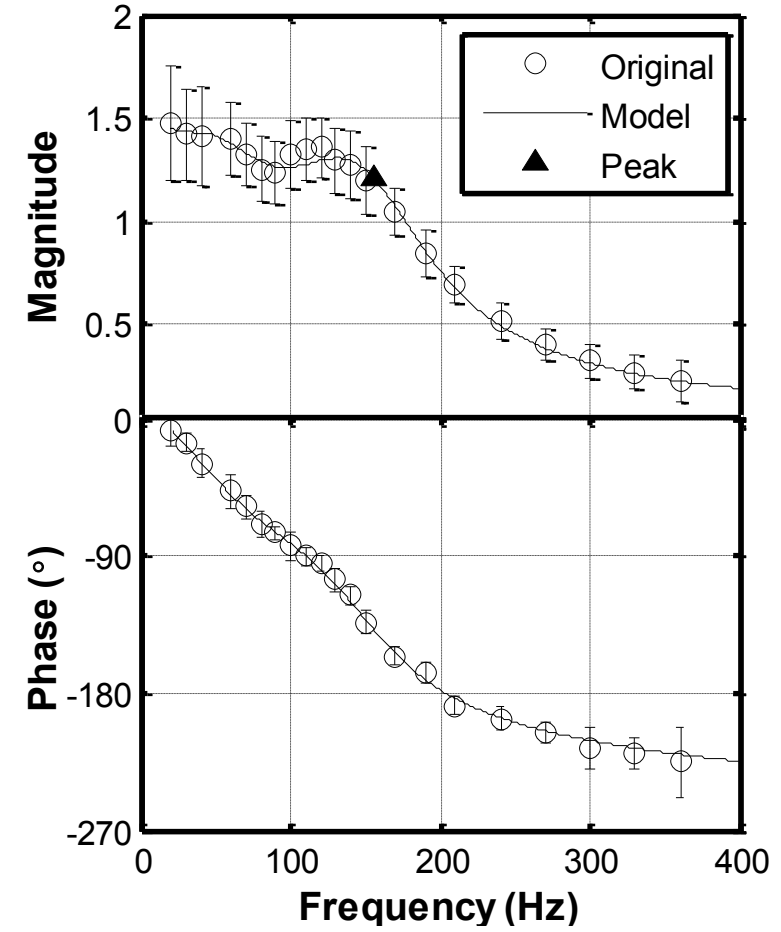

Figure B.17: M50H1C1, $\Phi=0.65, \bar{v}=7 \mathrm{~cm} / \mathrm{s}$

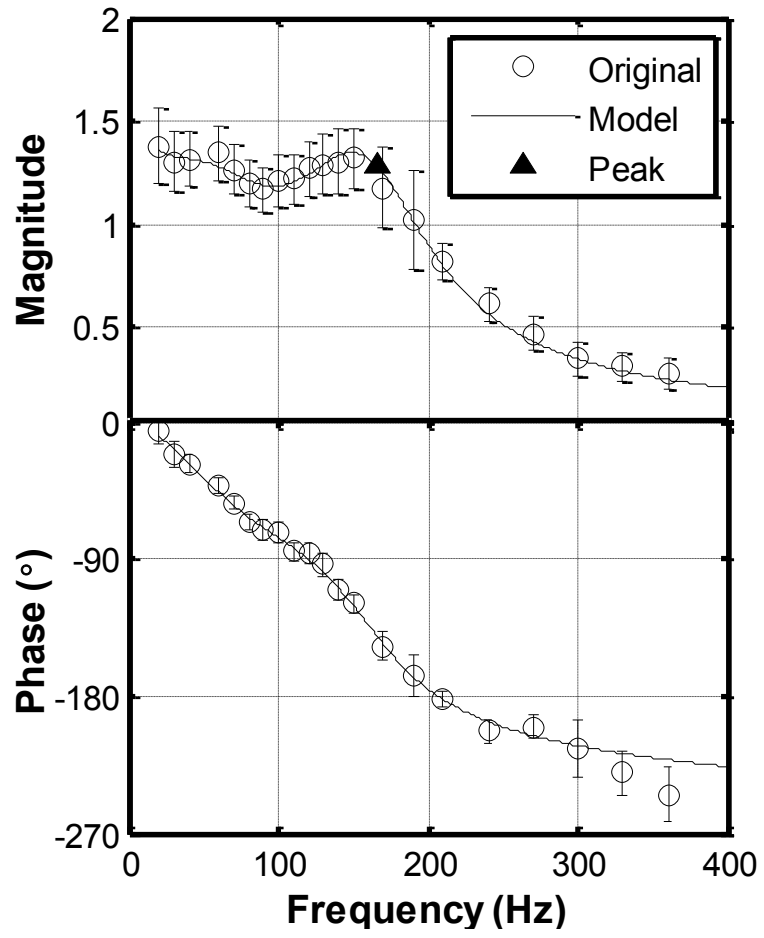

Figure B.18: BIO, $\Phi=0.8, \bar{v}=7 \mathrm{~cm} / \mathrm{s}$ 


\section{B.4 Type IV}

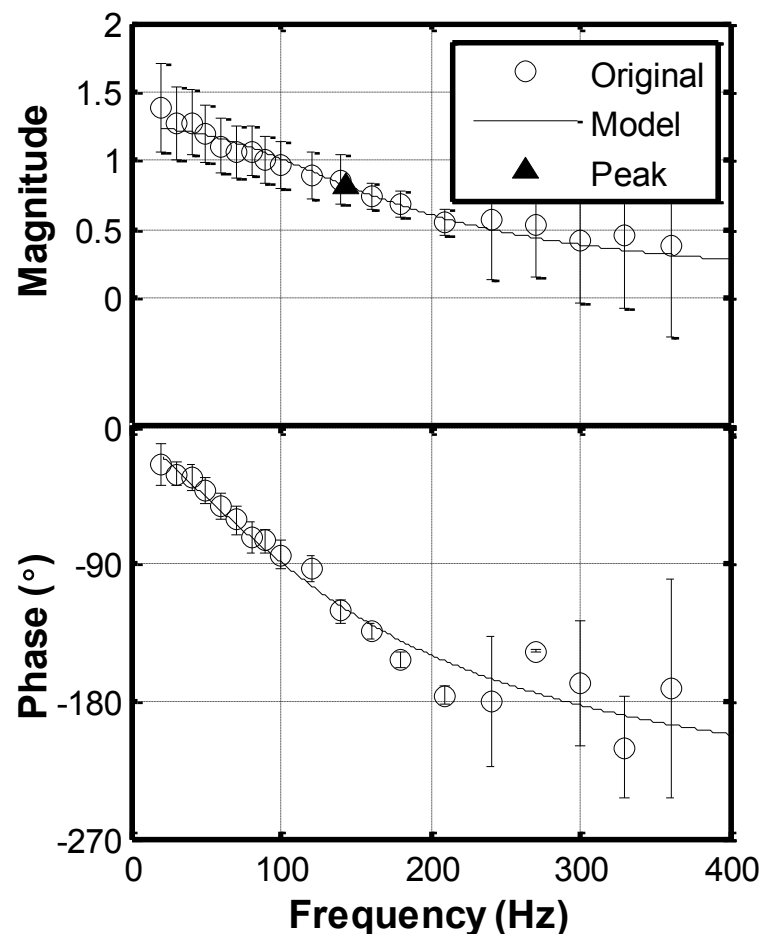

Figure B.19: M25H1C1, $\Phi=0.65, \bar{v}=6 \mathrm{~cm} / \mathrm{s}$ 


\section{Appendix C}

\section{Two Microphone Technique Theory and}

\section{Calibration}

The basis of the two microphone technique comes from Euler's equation, which can be simplified to the form shown below for low Mach number flows assuming 1-D, steady, incompressible flow (Khanna, 2001).

$$
v^{\prime}(t)=\frac{-1}{\rho} \int \frac{d P}{d x} d t
$$

The velocity fluctuation is equal to the integral of the spatial pressure gradient with respect to time divided by the density. The spatial pressure gradient can be approximated as a finite difference

$$
\frac{d P}{d x}=\frac{P_{2}-P_{1}}{\Delta x}
$$

where $P_{2}$ and $P_{1}$ are the pressure signals from the two microphones in time and $\Delta x$ is their separation distance. A large separation distance of $5.08 \mathrm{~cm}$ was chosen as per recommendations in Waser \& Crocker (1984) keeping in mind three common sources of error that stem from using the two microphone technique (Waser \& Crocker, 1984):

- Instrumentation phase mismatch,

- Finite difference error, and 
- Near field effects.

Phase mismatch becomes an issue when the phase error between the microphones approaches the actual phase difference between the pressure waves measured at the two microphones. As the frequency decreases, the wavelength gets larger and so the actual phase difference between the two signals may approach the phase mismatch error. This effectively sets the low frequency limit of the setup. A large spacing between the microphones was chosen to decrease the error at low frequencies. The phase mismatch between the microphones can also be measured and corrected for, decreasing the error. This is typically done using a long tube with a loudspeaker at one end and the microphones at the other (Waser \& Crocker, 1984). It is assumed that if the tube is long enough a planar wave will be formed and there will be no phase difference between the measurements from the two microphones. In case the tube used was not long or narrow enough to create a planar wave, the same measurement was done with the microphone positions switched and an average was taken. This corrects for any phase mismatch between the microphones that might be cause by a non-planar wave.

A schematic of the setup used to measure the microphone phase mismatch is shown in Figure C.1. A special fitting was designed to mount the tube onto the speaker, and to mount the microphones to the opposite end of the tube. Measurements were done using a custom LabVIEW program. The phase mismatch and amplitude ratio between the microphones was measured for $5 \mathrm{~s}$ at a sampling rate of $10 \mathrm{kHz}$ in for frequencies between 20 and $400 \mathrm{~Hz}$ in $10 \mathrm{~Hz}$ intervals. The microphone positions were then swapped, and the measurement was taken again. This was repeated three times so that 
three sets of data were collected for each microphone position. An average of the six sets was calculated and this was the phase mismatch used for correction.

The phase mismatch and amplitude ratio of the microphones are shown respectively in Figure C.2 and Figure C.3. Both are steady except at low frequencies where the low frequency operating limit of the microphones is approached. This implies that the microphone calibration may not be accurate at frequencies below $60 \mathrm{~Hz}$.

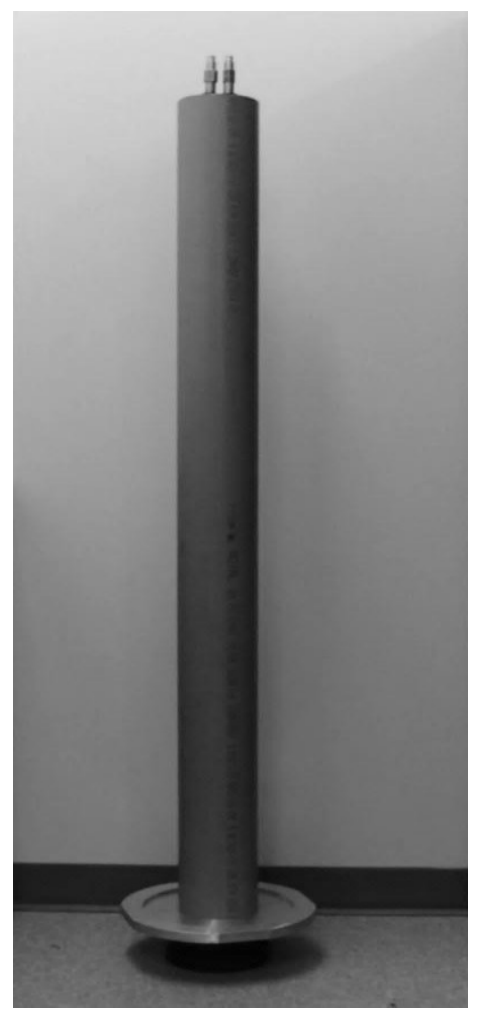

Figure C.1: Microphone phase mismatch measurement setup 


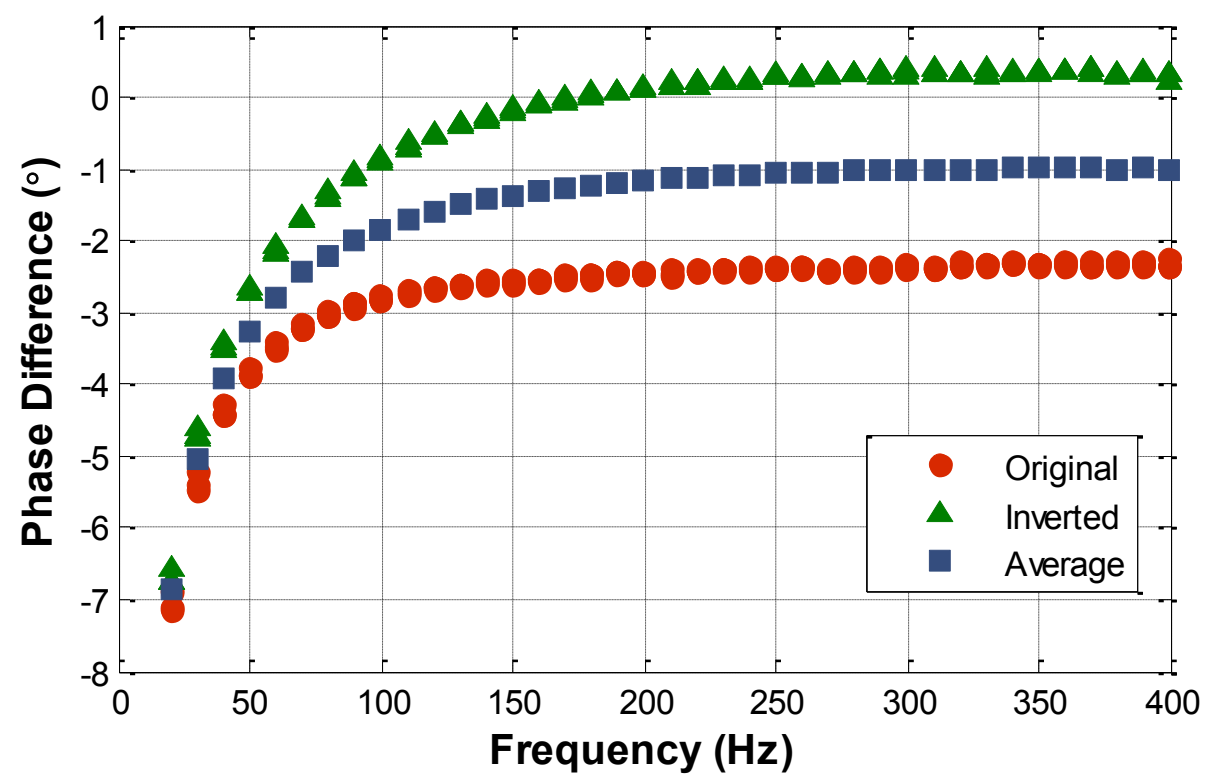

Figure C.2: Microphone phase mismatch

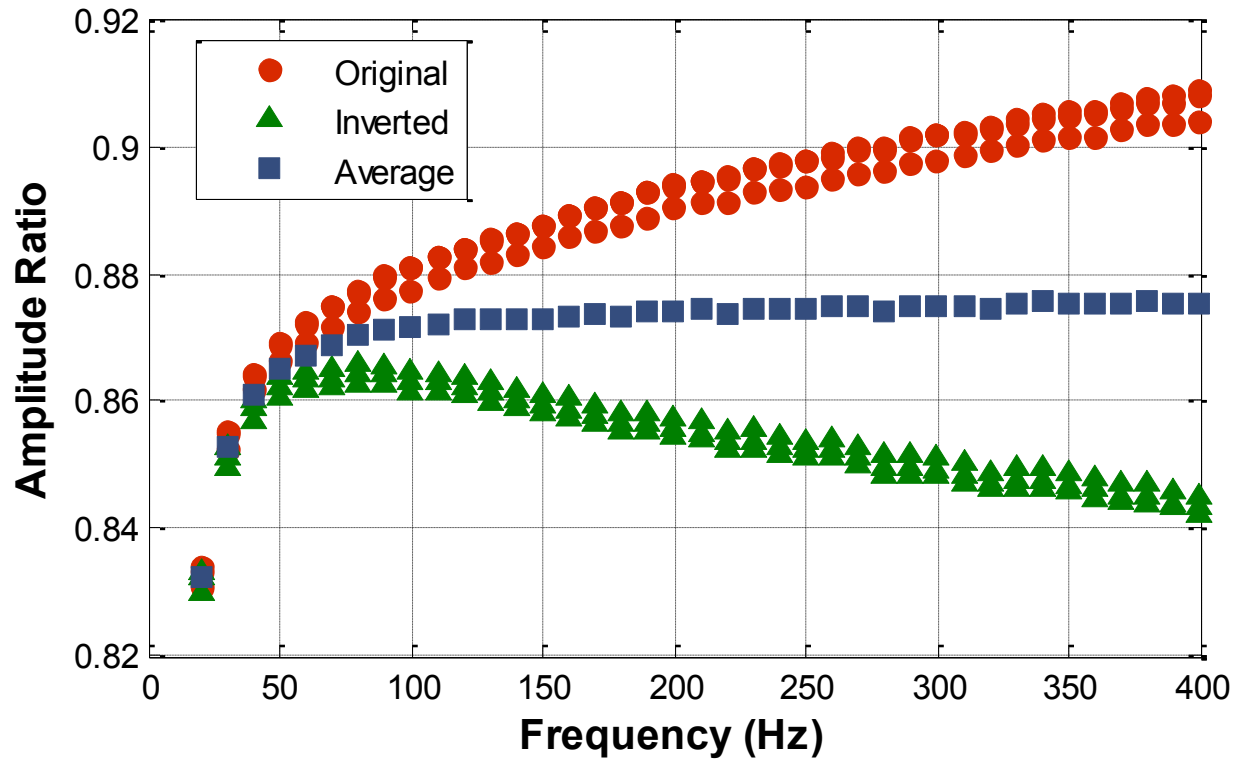

Figure C.3: Microphone amplitude ratio

The finite difference error is due to the approximation of the pressure gradient as a difference between two points. This effectively sets the high frequency limit of the technique. As the frequency increases, the wavelength decreases and so the error 
becomes large as the wavelength approaches the spacing between the two microphones (Waser \& Crocker, 1984). This was not an issue for the frequency range used in these studies, where the maximum frequency was $400 \mathrm{~Hz}$.

Another issue is that sound intensity changes with distance from the source. Thus if the microphones are too close to the source, there will be a difference in the signals not only due to the spacing between the microphones but due to the distance from the source as well. Waser \& Crocker (1984) stipulate that in order to avoid this error, the ratio of distance from source to separation distance should be at least 1.6 for a dipole source. This may be complicated by the fact that the measurements are made in an enclosed chamber.

Two Bruel and Kjaer Type 4188 A 021 condenser microphones in conjunction with a PCB Piezotronics Model 441A101 power supply and Model 442B104 signal conditioner were used in the two microphone technique. The microphones were calibrated using a G.R.A.S. Type 42AC pistonphone that emits a known sound level of $134 \mathrm{~dB}$ at $250 \mathrm{~Hz}$. After turning on the pistonphone and allowing it to warm up for about $30 \mathrm{~s}$, the microphone was tightly placed in the fitting. Data were taken for $60 \mathrm{~s}$ at $1 \mathrm{~Hz}$ using a custom made LabVIEW program. Using the measured voltage, and knowing that $134 \mathrm{~dB}$ corresponds to $100.23 \mathrm{~Pa}$, the microphone sensitivity was calculated. The same setup used for data acquisition during testing was also used during calibration. Due to the variation in microphone calibration with ambient pressure, calibration measurements were performed on ten different days. Each day, the microphone calibration was repeated three times. 
Figure C.4 shows the variation in microphone sensitivity with ambient pressure.

A linear fit was applied to each microphone and this was used to calculate the microphone sensitivity corresponding to the measured ambient pressures during testing. The ambient pressure was measured using the Omega pressure and temperature sensor. This sensor was also used to calculate the density, knowing the reactant gas composition and assuming that the reactant gas temperature at the microphones was equal to the ambient temperature.

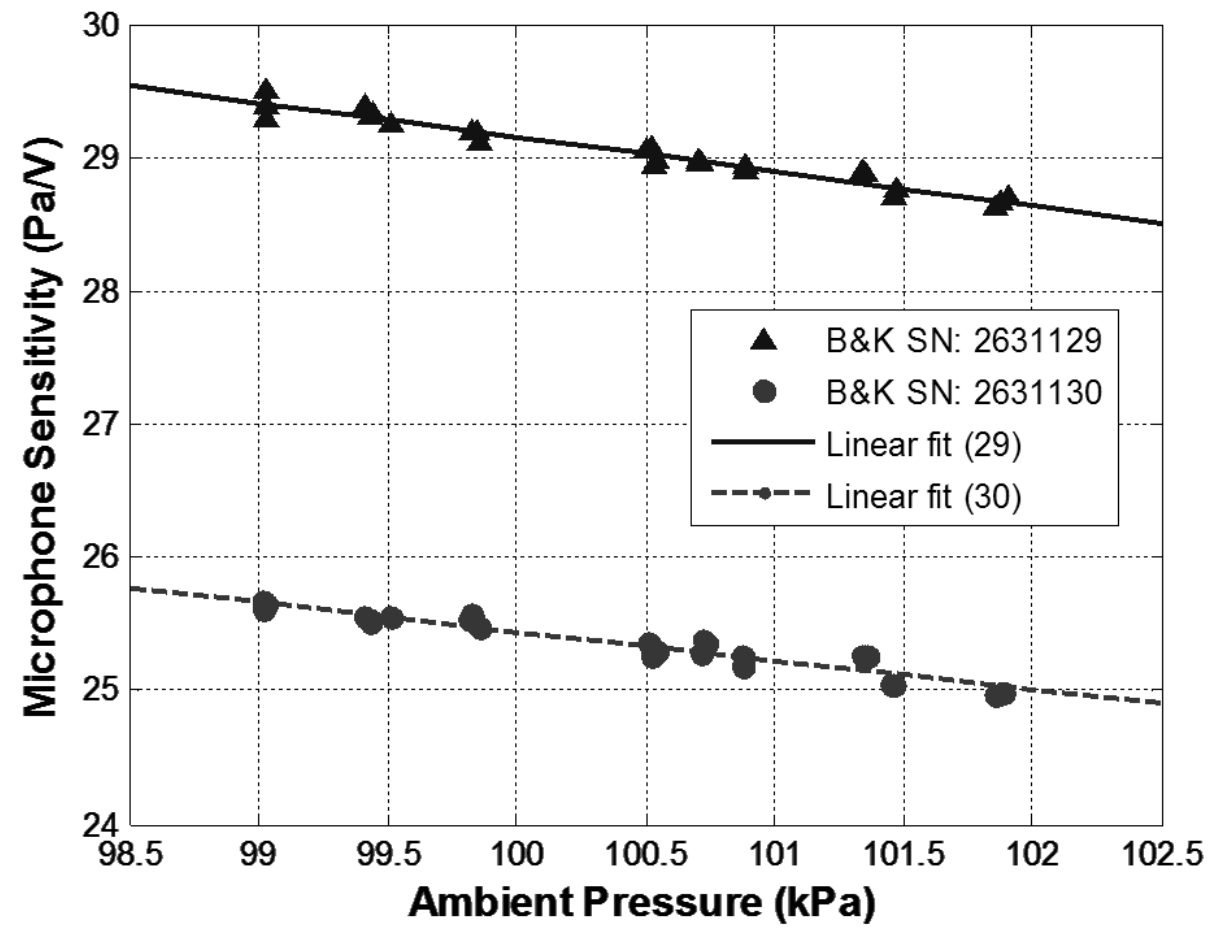

Figure C.4: Microphone sensitivity variation with ambient pressure

Equations C.1 and C.2 were implemented in LabVIEW using digitized forms of the calibrated microphone pressure signals. The integration was done using standard LabVIEW functions. Fast Fourier Transform analysis in LabVIEW was then used to 
extract tones in order to measure the amplitude and phase of velocity fluctuations. In addition to the fundamental frequency, the amplitude of the first harmonic was also measured so the linearity of the flame transfer function could be checked.

Calibration of the two microphone technique was first attempted using hot wire anemometry (HWA). The mean flow velocities used here $(5-7 \mathrm{~cm} / \mathrm{s})$ were found to be too low to obtain accurate measurements with HWA. Next, an attempt was made to calibrate with Laser Doppler Velocimetry (LDV). Results obtained at different flame operating conditions were inconsistent. The most likely source of error was postulated to be the heat from the burner heating the microphones. The difference in calibration curves at different operating conditions can be explained by the fact that the burner temperature changes with operating conditions and the difference in temperature at the two microphone locations also varies with operating conditions. The burner temperature was measured with the K type thermocouples. Due to the difficulty of cooling the microphones and the availability of a Laser Doppler Velocimetry (LDV) system, a decision was made to switch to LDV for measurement of the velocity fluctuation. 